APLICAÇÃO FOLIAR DE MOLIBDÊNIO E SEU EFETTO NAS

ATIVIDADES DA NITROGENASE E REDUTASE

DO NITRATO NO FEIJOEIRO EM CAMPO

ROSANA FARIA VIEIRA

Engenheira Agrônoma

Orientadora: Profa. Dra. ELKE J.B.N. CARDOSO

Tese apresentada à Escola Superior de Agricultura "Luiz de Queiroz" Universidade de São Paulo, para obtenção do título de Doutor em Agronomia, área de concentração: Solos e Nutrição de Plantas

PIRACICABA

Estado de São Paulo - Brasil

Julho - 1994 
Ficha catelogratics preparade pela sefad de Livroj da Divisad de Eibitateca E Documertaca - FCldugF

Vieira, Fiosane Faria

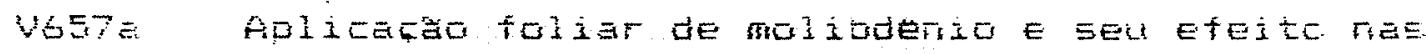
atividades da nitrogenase e redutase do nitrata re teijoeiro en campo. Friresicate, 1994. igep.

TESE - ESFLL

Fitidogratien.

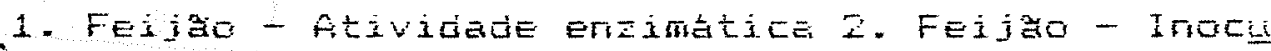

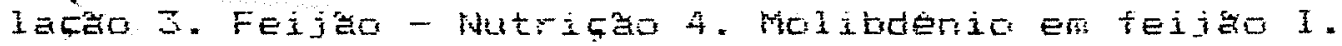

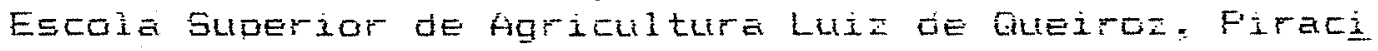
Laba 
APLICAÇÃO FOLIAR DE MOLIBDÊNIO E SEU EFETTO NAS

ATIVIDADES DA NITROGENASE E REDUTASE

DO NITRATO NO FEIJOEIRO EM CAMPO

ROSANA FARIA VIEIRA

Aprovada em: 30.08.1994

Comissão julgadora:

Prof. Dr. PEDRO JOSÉ VALARINI

CNPMA/EMBRAPA

Prof. Dr. SÉRVIO TÚLIO CASSINI

UFV/VIÇOSA

Prof. Dr. SUI MUI TSAI

CENA/USP

Prof. Dr. ANTONIO LUIZ FANCELLI

Prof. Dr. ELKE J.B.N. CARDOSO

ESALQ/USP

ESALQ/USP

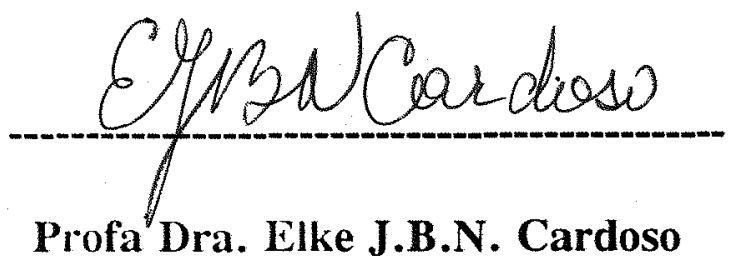

-Orientadora- 
A DEUS 
aos meus pais

Clibas e Jandira,

dedico. 


\section{AGRADECIMENTOS}

Agradeço a todos que, de alguma forma, colaboraram na execução deste trabalho. Entre eles:

- à Empresa Brasileira de Pesquisa Agropecuária (EMBRAPA) pela oportunidade oferecida de realização deste trabalho;

- à Prof ${ }^{a}$ Elke J.B.N. Cardoso pela orientação, pelas sugestões e pelo apoio constante na condução dos trabalhos;

- à Escola Superior de Agricultura "Luiz de Queiroz", (ESALQ), pela oportunidade de realização do curso de Doutorado.

- ao Prof. Clibas Vieira, meu pai, em especial, pelas sugestões e acompanhamento constante na parte da pesquisa realizada na Universidade Federal de Viçosa;

- aos Professores Paulo Roberto Mosquim e Servio Túlio Cassini, da Universidade Federal de Viçosa, pelas sugestões e pela utilização dos laboratórios de Fisiologia Vegetal e Microbiologia do Solo;

- ao Professor Paulo Roberto Pereira da Universidade Federal de Viçosa, pela autorização para utilização do laboratório de Nutrição de Plantas;

- à grande equipe de pessoas formada pelo Prof. Clibas Vieira, Prof. Geraldo Antonio de A. Araújo, Prof. Moacil Souza, Prof. Sérvio Túlio, Paulo Berger, Rogério F. Vieira, José Reinaldo Coelho, Polidoro, Navarro, Gerson Lima, Marco Antonio e Fábio Coelho, pela grande ajuda nas avaliações de campo. 
- à Prof. Maria Cristina S. Nogueira, da ESALQ-USP, pela orientação na realização e interpretação das análises estatísticas;

- aos técnicos do laboratório de Microbiologia do Solo, Denise de L.C. Mescolotti e Luis Fernando Baldesin, pela amizade e grande ajuda fornecida durante a realização dos experimentos em Piracicaba;

- ao Marcelo Corrêa Alves, pela realização das análises estatísticas;

- à minha mãe, Jandira Faria Vieira, pelo amor, força, compreensão, e ajuda na avaliação dos experimentos;

- à minha irmã, Milene Faria Vieira, pela amizade e apoio constante, durante o meu curso de Doutorado;

- aos colegas Ivanildo Evodio Marriel, Maria do Rosário Lobato Rodrigues, Julio Alves C. Filho, Silvia Vetorazzo e Lucimar Santiago de Abreu, pelo companherismo e amizade;

- um agradecimento especial à minha amiga Edwiges F. Carvalho, Professora da Universidade de Brasília, pelo estímulo, carinho, compreensão e amizade.

- aos professores do curso de Pós-graduação da ESALQ/USP, pela formação acadêmica. 


\section{INDICE}

Páginas

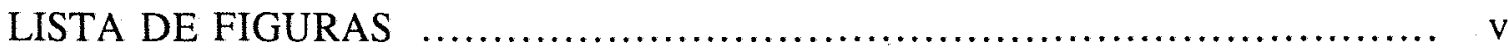

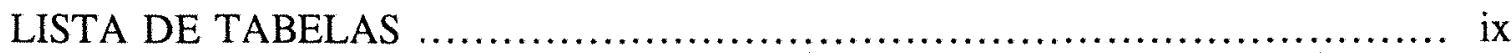

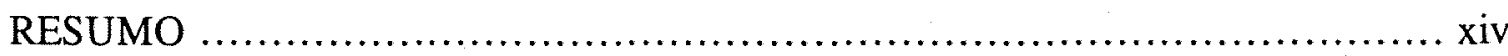

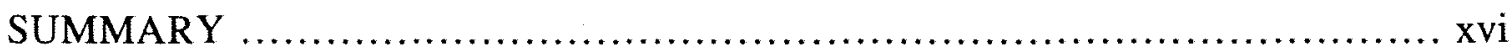

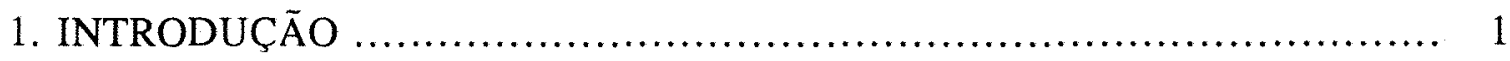

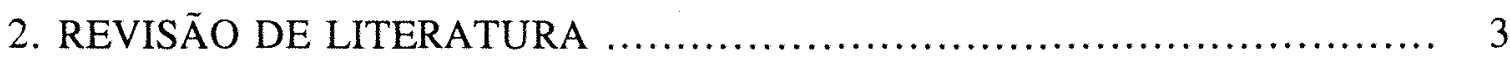

2.1. Adubação nitrogenada na cultura do feijão........................... 3

2.2. Fixação biológica do $\mathrm{N}_{2}$ atmosférico na cultura do feijão................. 11

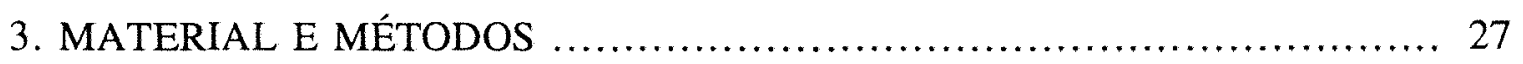

3.1. Determinação da atividade da nitrogenase............................. 29

3.2. Determinação da atividade da redutase do nitrato...................... 31

3.3. Determinação do $\mathrm{N}$-amoniacal e $\mathrm{N}$-nítrico na parte aérea................ 33

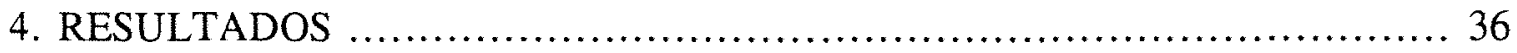

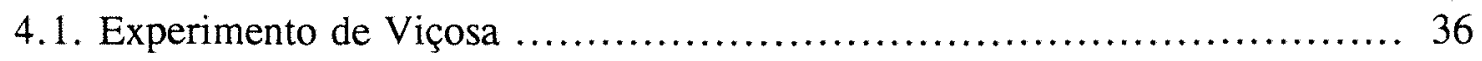

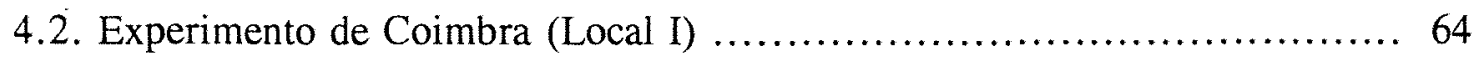

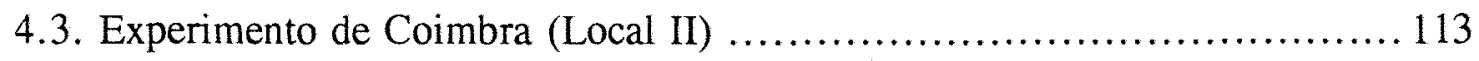

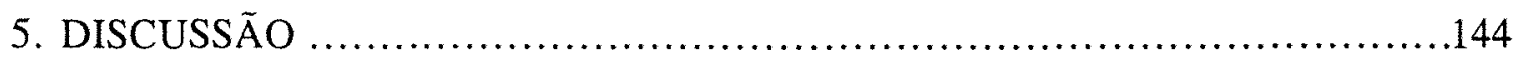

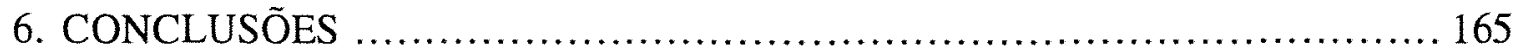

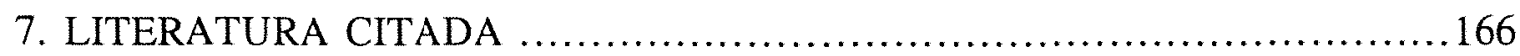




\section{LISTA DE FIGURAS}

Página

1. Efeito da interação Mo x épocas de avaliação na atividade da nitrogenase (umoles de $\mathrm{C}_{2} \mathrm{H}_{4} \cdot \mathrm{h}^{-1}$.planta-1), em Viçosa, MG.

2. Efeito da interação Mo x épocas de avaliação na atividade específica da nitrogenase (umoles de $\mathrm{C}_{2} \mathrm{H}_{4} \cdot \mathrm{h}^{-1}$. g.de nódulos ${ }^{-1}$ ), em Viçosa, MG

3. Efeito da interação Mo x épocas de avaliação no número de nódulos . plantas $^{-1}$, em Viçosa, MG

4. Efeito da interação $\mathrm{N}$ no plantio x épocas de avaliação no peso dos nódulos secos (mg/planta), em Viçosa, MG

5. Efeito da interação Mo x épocas de avaliação na atividade da redutase do nitrato (umoles de $\mathrm{NO}_{2} \cdot \mathrm{h}^{-1} \mathrm{~g}$. de matéria fresca-1), em Viçosa, $\mathrm{MG}$.

6. Efeito da interação Mo x épocas de avaliação na percentagem de N-amoniacal na parte aérea, em Viçosa, MG

7. Efeito da interação $\mathrm{N}$ no plantio x épocas de avaliação na percentagem de $\mathrm{N}$-amoniacal na parte aérea, em Viçosa, $\mathrm{MG}$

8. Efeito da interação $\mathrm{N}$ em cobertura $\mathrm{x}$ épocas de avaliação na percentagem de $\mathrm{N}$-amoniacal na parte aérea, em Viçosa, MG.

9. Efeito da interação Mo x épocas de avaliação na quantidade total de Namoniacal na parte aérea, em Viçosa, MG 
10. Efeito da interação $\mathrm{N}$ no plantio $\mathrm{x}$ épocas de avaliação na quantidade total de $\mathrm{N}$-amoniacal na parte aérea (mg/planta), em Viçosa, MG. 59

11. Efeito da interação Mo $x$ épocas de avaliação na atividade da nitrogenase (umoles de $\mathrm{C}_{2} \mathrm{H}_{4} \cdot \mathrm{h}^{-1}$. planta ${ }^{-1}$ ), em Coimbra, MG (Local I) 66

12. Efeito da interação $\mathrm{N}$ no plantio $\mathrm{x}$ épocas de avaliação na atividade da nitrogenase (umoles de $\mathrm{C}_{2} \mathrm{H}_{4} \cdot \mathrm{h}^{-1}$. planta $^{-1}$ ), em Coimbra, MG (Local I) 68

13. Efeito da interação Mo x épocas de avaliação na atividade específica da nitrogenase (umoles de $\mathrm{C}_{2} \mathrm{H}_{4} \cdot \mathrm{h}^{-1} \mathrm{~g}$. de nódulo ${ }^{-1}$ ), em Coimbra, $\mathrm{MG}$ (Local I)

14. Efeito da interação $\mathrm{N}$ no plantio $\mathrm{x}$ épocas de avaliação na atividade específica da nitrogenase (umoles de $\mathrm{C}_{2} \mathrm{H}_{4} \cdot \mathrm{h}^{-1} \mathrm{~g}$. de nódulo ${ }^{-1}$ ), em Coimbra, MG (Local I)

15. Efeito da interação Mo x épocas de avaliação no número de nódulos.planta $^{-1}$, em Coimbra, MG (Local I)

16. Efeito da interação $\mathrm{N}$ no plantio $\mathrm{x}$ épocas de avaliação no número de nódulos.planta ${ }^{-1}$, em Coimbra, MG (Local I) 78

17. Efeito da interação $\mathrm{N}$ em cobertura $\mathrm{x}$ épocas de avaliação no número de nódulos.planta ${ }^{-1}$, em Coimbra, MG (Local I).

18. Efeito da interação Mo x épocas de avaliação no peso dos nódulos secos (mg/planta), em Coimbra, MG (Local I) 82

19. Efeito da interação $\mathrm{N}$ no plantio x épocas de avaliação no peso dos nódulos secos (mg/planta), em Coimbra, MG (Local II) 
20. Efeito da interação Mo x épocas de avaliação na atividade da redutase do nitrato (umoles de $\mathrm{NO}_{2}^{-} \cdot h^{-1}$. g. de matéria fresca ${ }^{-1}$ ), em Coimbra, MG (Local I) 86

21. Efeito da interação Mo x épocas de avaliação na percentagem de N-amoniacal na parte aérea, em Coimbra, MG (Local I)

22. Efeito da interação $\mathrm{N}$ no plantio $\mathrm{x}$ épocas de avaliação na percentagem de $\mathrm{N}$-amoniacal na parte aérea, em Coimbra, MG (Local I) 90

23. Efeito da interação $\mathrm{N}$ em cobertura $\mathrm{x}$ épocas de avaliação na percentagem de $\mathrm{N}$-amoniacal na parte aérea, em Coimbra, MG (Local I)

24. Efeito da interação Mo x épocas de avaliação na quantidade total de Namoniacal na parte aérea (mg/planta), em Coimbra, MG (Local II) ........... 94

25. Efeito da interação $\mathrm{N}$ em cobertura $\mathrm{x}$ épocas de avaliação na quantidade total de $\mathrm{N}$-amoniacal na parte aérea (mg/planta), em Coimbra, MG (Local $\mathrm{I}) . .95$

26. Efeito da interação $\mathrm{N}$ no plantio $\mathrm{x}$ épocas de avaliação na percentagem de $\mathrm{N}-\mathrm{NO}_{3}^{-}$na parte aérea, em Coimbra, MG (Local I) 98

27. Efeito da interação $\mathrm{N}$ no plantio $x$ épocas de avaliação na quantidade total de $\mathrm{N}-\mathrm{NO}_{3}^{-}$na parte aérea (mg/planta), em Coimbra, MG (Local I) 101

28. Efeito da interação $\mathrm{N}$ em cobertura x épocas de avaliação na quantidade total de $\mathrm{N}-\mathrm{NO}_{3}^{-}$na parte aérea (mg/planta), em Coimbra, MG (Local I)...... 102

29. Efeito da interação $\mathrm{N}$ no plantio x épocas de avaliação sobre a atividade da nitrogenase (umoles de $\mathrm{C}_{2} \mathrm{H}_{4} \cdot \mathrm{h}^{-1}$. planta ${ }^{-1}$ ), em Coimbra, MG (Local II).. 115 
30. Efeito da interação Mo $\mathrm{x}$ épocas de avaliação na atividade específica da nitrogenase (umoles de $\mathrm{C}_{2} \mathrm{H}_{4} \cdot \mathrm{h}^{-1}$.g. de nódulo ${ }^{-1}$ ), em Coimbra, MG (Local II).. 118

31. Efeito da interação $\mathrm{N}$ no plantio $\mathrm{x}$ épocas de avaliação na atividade específica da nitrogenase (umoles de $\mathrm{C}_{2} \mathrm{H}_{4} \cdot \mathrm{h}^{-1} \cdot \mathrm{g}$. de nódulo ${ }^{-1}$ ), em Coimbra, MG (Local II)....

32. Efeito da interação $\mathrm{N}$ no plantio $\mathrm{x}$ épocas de avaliação no número de nódulos.planta ${ }^{-1}$, em Coimbra, MG (Local II).

33. Efeito da interação $\mathrm{N}$ no plantio $\mathrm{x}$ épocas de avaliação no peso dos nódulos secos (mg/planta), em Coimbra, MG (Local II)

34. Efeito da interação Mo $x$ épocas de avaliação na atividade de redutase do nitrato (umoles de $\mathrm{NO}_{2} \cdot \mathrm{h}^{-1}$. g. de matéria seca ${ }^{-1}$ ), em Coimbra, MG (Local II)

35. Efeito da interação $\mathrm{N}$ no plantio $\mathrm{x}$ épocas de avaliação na percentagem de $\mathrm{N}$-amoniacal na parte aérea, em Coimbra, MG (Local II)

36. Efeito da interação Mo x épocas de avaliação na percentagem de $\mathrm{N}$ $\mathrm{NO}_{3}^{-}$na parte aérea, em Coimbra, MG (Local II) 134

37. Efeito da interação $\mathrm{N}$ no plantio x épocas de avaliação na percentagem de $\mathrm{N}-\mathrm{NO}_{3}^{-}$na parte aérea, em Coimbra, MG (Local II) 135

38. Efeito da interação Mo x épocas de avaliação na quantidade total de $\mathrm{N}$ $\mathrm{NO}_{3}$ na parte aérea (mg/planta), em Coimbra, MG (Local II) 138

39. Distribuição de $\mathrm{N}$-amoniacal na parte aérea e nas vagens, aos 60 e 74 dias após a emergência das plantas. 


\section{LISTA DE TABELAS}

Páginas

1. Atividade da nitrogenase (umoles de $\mathrm{C}_{2} \mathrm{H}_{4} \cdot \mathrm{h}^{-1}$. planta ${ }^{-1}$ ), em Viçosa, MG..... 37

2. Efeito da interação $\mathrm{N}$ no plantio $\mathrm{x}$ Mo sobre a atividade da nitrogenase (umoles de $\mathrm{C}_{2} \mathrm{H}_{4} \cdot \mathrm{h}^{-1}$. planta-1), em Viçosa, $\mathrm{MG}$

3. Atividade específica da nitrogenase (umoles de $\mathrm{C}_{2} \mathrm{H}_{4} \cdot h^{-1} \cdot g$. de nódulos ${ }^{-1}$ ), em Viçosa, MG 40

4. Número de nódulos.planta ${ }^{-1}$, em Viçosa, MG 43

5. Peso dos nódulos secos (mg/planta), em Viçosa, MG 46

6. Atividade da redutase do nitrato (umoles de $\mathrm{NO}_{2}^{-} \cdot \mathrm{h}^{-1} \cdot \mathrm{g}$. de matéria fres$\mathrm{ca}^{-1}$ ), em Viçosa, $\mathrm{MG}$ 49

7. Percentagem de $\mathrm{N}$-amoniacal na parte aérea, em Viçosa, MG. 52

8. Quantidade total de N-amoniacal na parte aérea (mg/planta), em Viçosa, MG. 57

9. Percentagem de $\mathrm{N}$ nas sementes, quantidade de $\mathrm{N}$ exportado para os grãos (kg/ha) e produção (kg/ha), em Viçosa, MG.

10. Efeito da interação inoculação $x \mathrm{~N}$ no plantio sobre a percentagem de $\mathrm{N}$ nas sementes, em Viçosa, MG.

11. Efeito da interação inoculação $\times \mathrm{N}$ em cobertura sobre a percentagem de $\mathrm{N}$ nas sementes, em Viçosa, MG. 
12. Efeito da interação Mo x $\mathrm{N}$ em cobertura na produção $(\mathrm{kg} / \mathrm{ha})$, em Viçosa, MG.

13. Atividade da nitrogenase (umoles de $\mathrm{C}_{2} \mathrm{H}_{4} \cdot \mathrm{h}^{-1}$. planta ${ }^{-1}$ ), em Coimbra, MG (Local I). 65

14. Atividade específica da nitrogenase (umoles de $\mathrm{C}_{2} \mathrm{H}_{4} \cdot \mathrm{h}^{-1}$. g. de nodulo ${ }^{-1}$ ), em Coimbra, MG (Local I)

15. Efeito da interação $\mathrm{N}$ no plantio $\mathrm{x}$ Mo sobre a atividade específica da nitrogenase (umoles de $\mathrm{C}_{2} \mathrm{H}_{4} \cdot \mathrm{h}^{-1} \mathrm{~g}$. de nódulo ${ }^{-1}$ ), em Coimbra, MG (Local I)...... 70

16. Efeito da interação $\mathrm{N}$ no plantio $\mathrm{x} \mathrm{N}$ em cobertura sobre a atividade específica da nitrogenase (umoles de $\mathrm{C}_{2} \cdot \mathrm{H}_{4} \cdot \mathrm{h}^{-1} \mathrm{~g}$. de nodulo ${ }^{-1}$ ), em Coimbra, MG (Local I) 71

17. Número de nódulos.planta ${ }^{-1}$, em Coimbra, MG 75

18. Efeito da interação Mo $x \mathrm{~N}$ em cobertura sobre o número de nódulos. planta $^{-1}$, em Coimbra, MG (Local I) 76

19. Peso dos nódulos secos (mg/planta), em Coimbra, MG 81

20. Atividade da redutase do nitrato (umoles de $\mathrm{NO}_{2}^{-} \cdot h^{-1} . \mathrm{g}$. de matéria fres$\mathrm{ca}^{-1}$ ), em Viçosa, MG (Local I)

21. Percentagem de $\mathrm{N}$-amoniacal na parte aérea, em Coimbra, MG (Local I)

22. Quantidade total de $\mathrm{N}$-amoniacal na parte aérea (mg/planta), em Coimbra, MG (Local I) 
23. Efeito da interação inoculação $x$ Mo sobre a quantidade total de $\mathrm{N}$-amoniacal na parte aérea (mg/planta), em Coimbra, MG (Local I)............... 93

24. Percentagem de $\mathrm{N}-\mathrm{NO}_{3}{ }^{-}$na parte aérea, em Coimbra, $\mathrm{MG}$ (Local I).......... 97

25. Efeito da interação Mo x $\mathrm{N}$ no plantio sobre a percentagem de $\mathrm{N}-\mathrm{NO}_{3}^{-}$na parte aérea, em Coimbra, MG (Local I)

26. Quantidade total de $\mathrm{N}_{-} \mathrm{NO}_{3}^{-}$na parte aérea (mg/planta), em Coimbra, MG (Local I) 100

27. Efeito da interação inoculação $\mathrm{x} N$ no plantio sobre a quantidade total de $\mathrm{N}-\mathrm{NO}_{3}^{-}$na parte aérea (mg/planta), em Coimbra, MG (Local I). 104

28. Peso (g/planta), percentagem de $\mathrm{N}$ e quantidade total de $\mathrm{N}$-amoniacal nas vagens secas (mg/planta), em Coimbra, MG (Local I) 105

29. Efeito da interação inoculação $x \mathrm{~N}$ no plantio sobre o peso das vagens secas (g/planta), em Coimbra, MG (Local I) 106

30. Efeito da interação Mo x épocas de avaliação no peso das vagens secas (g/ planta), em Coimbra, MG (Local I) 106

31. Efeito da interação Mo x $\mathrm{N}$ em cobertura sobre a percentagem de $\mathrm{N}$ nas vagens secas, em Coimbra, MG (Local I).

32. Efeito da interação $\mathrm{N}$ no plantio $\mathrm{x} N$ em cobertura sobre a percentagem de $\mathrm{N}$ nas vagens secas, em Coimbra, MG (Local I) 108 
33. Efeito da interação $\mathrm{N}$ em cobertura $\mathrm{x}$ épocas de avaliação na percentagem de $\mathrm{N}$ nas vagens secas, em Coimbra, MG (Local I)

34. Efeito da interação inoculação x Mo sobre a quantidade total de N-amoniacal nas vagens secas (mg/planta), em Coimbra, MG (Local I)....

35. Efeito da interação Mo x épocas de avaliação na quantidade total de Namoniacal nas vagens secas (mg/planta), em Coimbra, MG (Local I)

36. Percentagem de $\mathrm{N}$ nas sementes, quantidade de $\mathrm{N}$ exportado para os grãos (kg/ha) e produção (kg/ha), em Coimbra, MG (Local I)

37. Atividade da nitrogenase (umoles de $\mathrm{C}_{2} \mathrm{H}_{4} \cdot \mathrm{h}^{-1}$ planta ${ }^{-1}$ ), em Coimbra, MG (Local II)

38. Atividade específica da nitrogenase (umoles de $\mathrm{C}_{2} \mathrm{H}_{4} \cdot \mathrm{h}^{-1} \mathrm{~g}$. de nodulo ${ }^{-1}$ ), em Coimbra, MG (Local II) 116

39. Número de nódulos.planta ${ }^{-1}$, em Coimbra, MG (Local II) 120

40. Peso dos nódulos secos (mg/planta), em Coimbra, MG (Local II) 123

41. Atividade da redutase do nitrato (umoles de $\mathrm{NO}_{2}^{-} \cdot \mathrm{h}^{-1} \cdot \mathrm{g}$. de matéria fres$\left.\mathrm{ca}^{-1}\right)$, em Coimbra, MG (Local II)

42. Efeito da interação Mo $\times \mathrm{N}$ no plantio sobre atividade da redutase do nitrato (umoles de $\mathrm{NO}_{2}^{-} \cdot h^{-1} \cdot$ g. de matéria fresca ${ }^{-1}$ ), em Coimbra, MG (Local II).

43. Percentagem de $\mathrm{N}$-amoniacal na parte aérea, em Coimbra, MG (Local II) 129 
44. Quantidade total de $\mathrm{N}$-amoniacal na parte aérea, (mg/planta), em Coimbra, MG (Local II)

45. Percentagem de $\mathrm{N}^{-\mathrm{NO}^{-}}{ }_{3}$ na parte aérea, em Coimbra, MG (Local II)

46. Quantidade total de $\mathrm{N}-\mathrm{NO}_{3}^{-}$na parte aérea (mg/planta), em Coimbra, $\mathrm{MG}$ (Local II)

47. Efeito da interação Mo x $\mathrm{N}$ no plantio sobre a quantidade total de $\mathrm{N}^{-\mathrm{NO}_{3}^{-}}$ na parte aérea (mg/planta), em Coimbra, MG (Local II)

48. Efeito da interação $\mathrm{N}$ no plantio $\mathrm{x} N \mathrm{~N}$ em cobertura sobre a quantidade total de $\mathrm{N}-\mathrm{NO}_{3}^{-}$na parte aérea (mg/planta), em Coimbra, MG (Local II)

49. Peso (g/planta), percentagem de $\mathrm{N}$ e quantidade total de $\mathrm{N}$-amoniacal nas vagens secas (mg/planta), em Coimbra, MG (Local II)

50. Efeito da interação $\mathrm{N}$ no plantio $\times \mathrm{N}$ em cobertura sobre o peso das vagens secas (g/planta), em Coimbra, MG (Local II)

51. Percentagem de $\mathrm{N}$ nas sementes, quantidade de $\mathrm{N}$ exportado para os grãos (kg/ha) e produção (kg/ha), em Coimbra, MG (Local II) 


\title{
APLICAÇÃO FOLIAR DE MOLIBDÊNIO E SEU EFEITO NAS \\ ATIVIDADES DA NITROGENASE E REDUTASE \\ DO NITRATO NO FEIJOEIRO EM CAMPO
}

\author{
Autora: ROSANA FARIA VIEIRA \\ Orientadora: ELKE J.B.N. CARDOSO
}

\section{RESUMO}

O objetivo desse trabalho foi verificar o efeito da aplicação foliar de Mo na atividade das enzimas nitrogenase e redutase do nitrato na variedade de feijão Ouro Negro 1992. Os experimentos foram conduzidos no campo, nos municípios de Viçosa e Coimbra, localizados na Zona da Mata de Minas Gerais. Foi usado um fatorial de $2^{4}$ com quatro repetições e os tratamentos constituíram-se de: inoculação com Rhizobium (realizada e não-realizada), aplicação de Mo (0 e 40g/ha), nitrogênio no sulco de plantio ( 0 e $20 \mathrm{~kg} / \mathrm{ha})$ e nitrogênio em cobertura $(0$ e $30 \mathrm{~kg} / \mathrm{ha})$, totalizando 16 tratamentos, distribuídos em um delineamento de blocos ao acaso, com 4 repetições. Tanto no experimento de Viçosa como no de Coimbra, a aplicação foliar com Mo, aos 25 dias, aumentou a atividade da nitrogenase e da redutase do nitrato, com conseqüente maior 
acúmulo total de $\mathrm{N}$-amoniacal na parte aérea, em relação às plantas não-sujeitas a essa adubação. A produção final do feijoeiro foi a mesma tanto com a aplicação de Mo ou de $\mathrm{N}$ em cobertura; em termos de nutrição nitrogenada portanto, o Mo substituiu o efeito de $30 \mathrm{~kg} /$ ha de $\mathrm{N}$, aplicados aos 25 dias. A pulverização com Mo aumentou a atividade da nitrogenase independentemente da estirpe, se inoculada ou não, o que demonstra que a população nativa de rizóbio pode ser eficiente, desde que adequadamente manejada. A aplicação de $\mathrm{N}$ no plantio, em qualquer das combinações fatoriais, além de ter prejudicado o processo simbiótico, não trouxe benefícios para o feijoeiro em termos de produção. A adubação nitrogenada de plantio ou de cobertura não afetaram a atividade da redutase do nitrato, o que demonstra haver no solo uma quantidade de $\mathrm{N}$ suficiente para induzí-la, embora o teor de Mo seja limitante. 


\section{FOLIAR APPLICATION OF MOLYBDENUM AND ITS EFFECT ON THE NITROGENASE AND NITRATE REDUCTASE ACTIVITY \\ IN COMMON BEAN UNDER FIELD CONDITION}

Author: ROSANA FARIA VIEIRA Adviser: Prof ${ }^{\mathfrak{a}}$ ELKE J.B.N. CARDOSO

\section{SUMMARY}

The aim of this work was to verify the effect of the foliar application of Mo on the nitrogenase and nitrate reductase activity in common beans cv. Ouro Negro 1992. Experiments were carried out under field conditions at the municipalities of Viçosa and Coimbra, Zona da Mata area, state of Minas Gerais. A $2 \times 2 \times 2 \times 2$ factorial with four replications was used, in which the factors were the following: inoculation with Rhizobium (done and not done), Mo application ( 0 and $40 \mathrm{~g} / \mathrm{ha}$ ), furrow application of $\mathrm{N}$ ( 0 and $20 \mathrm{~kg} / \mathrm{ha})$, and $\mathrm{N}$ as side dressing ( 0 and $30 \mathrm{~kg} / \mathrm{ha})$. Both in Viçosa and Coimbra the foliar application of Mo, 25 days after plant emergence, brought about an increase of the nitrogenase and nitrate reductase activity, resulting in greater 
accumulation of ammoniacal $\mathrm{N}$ in bean aerial parts. Bean yield was the same when either Mo or $\mathrm{N}$ as side dressing were applied, showing that the micronutrient was able to substitute the effect of $30 \mathrm{~kg} / \mathrm{ha}$ of $\mathrm{N}$ applied as side dressing Molybdenum increased nitrogenase activity, even when inoculation was not done; this shows that native population of Rhizobium can be effective when well handled. Furrow application of $\mathrm{N}$ was prejudicial to the symbiotic process and, furthermore, brought no yield increase. Nitrate reductase activity was not affect by nitrogen fertilization, showing that the soil had sufficient quantity of nitrogen to induce that activity, despite its limited content of Mo. 


\section{INTRODUÇÃO}

O feijoeiro, a exemplo de outras leguminosas, é capaz de fixar o nitrogênio atmosférico quando em simbiose com bactéria do gênero Rhizobium. A utilização da prática de inoculação nessa cultura é bastante limitada, uma vez que têm sido obtidas respostas contraditórias no campo. Em decorrência desse fato, a adubação nitrogenada é freqüentemente utilizada para obtenção de grandes produções. A resposta do feijoeiro ao nitrogênio ocorre geralmente em todo o Brasil, variando de amplitude de acordo com a região.

O alto custo dos adubos nitrogenados associado às perdas de nitrato no solo por lixiviação e às perdas de $\mathrm{N}_{2} \mathrm{O}$ e outros óxidos de nitrogênio, causando poluição ambiental, desperta o interesse para a procura de técnicas que possam maximizar o uso eficiente desse elemento pela planta, sem a necessidade de adições elevadas de adubos nitrogenados ou, em alguns casos, até com a eliminação dessa prática.

A absorção do $\mathrm{N}$ pelo feijoeiro é feita através do $\mathrm{NO}_{3}$ proveniente do solo ou através da fixação simbiótica do $\mathrm{N}_{2}$ atmosférico. A assimilação pela planta desse $\mathrm{N}$ é controlada principalmente por duas enzimas: a nitrogenase, que reduz o $\mathrm{N}_{2}$ atmosférico a $\mathrm{NH}_{3}$ nos nódulos, e a redutase do nitrato, que reduz $\mathrm{NO}_{3}^{-}$a $\mathrm{NO}_{2}^{-}$na parte 
aérea e raízes. $\mathrm{O} \mathrm{NO}_{2}^{-}$produzido será, posteriormente, nos cloroplastos, reduzido a amônia, através da redutase do nitrato.

A nitrogenase é uma enzima complexa, que pode ser separada em dois componentes; uma proteína ligada ao Fe e uma proteína ligada ao Fe e ao molibdênio. $\mathrm{Na}$ redução do $\mathrm{N}_{2}$ ao $\mathrm{NH}_{3}$ a nitrogenase recebe elétrons de substâncias redutoras; estes elétrons são transferidos para a proteína ligada ao Fe que, tornando-se agora um agente redutor, transfere estes elétrons à proteína ligada ao Fe e Mo que, por sua vez, reduz o $\mathrm{N}_{2}$ a duas moléculas de amônia.

A redutase do nitrato, por outro lado, catalisa a redução do $\mathrm{NO}_{3}^{-}$a $\mathrm{NO}_{2}^{-}$no citossol da células. Esta enzima contém Mo como grupo prostético e é considerada a principal proteína contendo aquele elemento nos tecidos vegetativos. Sob condições de deficiência de Mo, a atividade da redutase do nitrato nas células é muito reduzida.

Assim, este trabalho foi conduzido no sentido de verificar o efeito da aplicação foliar de Mo na atividade das enzimas nitrogenase e redutase do nitrato na cultura do feijão, em campo. 


\section{REVISÃO DE LITERATURA}

\subsection{Adubação nitrogenada na cultura do feijão}

O nitrogênio é o nutriente absorvido em maior quantidade pelo feijoeiro juntamente com o K, seguidos pelo Ca (FANCELLI, 1994). COBRA NETO (1967) mostrou que para a produção de $1.100 \mathrm{~kg}$ de grãos, uma população de 250.000 plantas retira aproximadamente $101 \mathrm{~kg} / \mathrm{ha}$ de $\mathrm{N}$, e CABALLERO et alii (1985) determinaram que, para a produção de $4000 \mathrm{~kg} / \mathrm{ha}$ de matéria seca total, o feijoeiro absorve $138 \mathrm{~kg} / \mathrm{ha}$ de nitrogênio. Conforme será discutido adiante, nem sempre é possível a obtenção de altas produções na cultura $d$ feijão, apenas através da fixação simbiótica do $N_{2}$ atmosférico; a adubação nitrogenada tem, em conseqüência, proporcionado acréscimos consideráveis no rendimento dessa cultura.

Com o crescimento das plantas, a concentração de $\mathrm{N}$ diminui e em condições normais situa-se entre $2 \%$ e $3 \%, 40$ a 50 dias após a emergência. No grão, a concentração de $\mathrm{N}$ é comumente pouco maior que $3 \%$, ou cerca de $50 \mathrm{~kg} / \mathrm{ha}$ de $\mathrm{N}$ para a produção de $1500 \mathrm{~kg} / \mathrm{ha}$ (MORAES, 1988). 
MALAVOLTA (1972) em revisão sobre adubação do feijoeiro constatou que, depois do $\mathrm{P}$, as respostas positivas mais comuns nos experimentos de adubação foram proporcionadas pelo nitrogênio. Do mesmo modo, FRANÇA et alii (1985) verificaram que, em Minas Gerais, num total de 76 experimentos com feijão, $56 \%$ responderam positivamente à adubação nitrogenada.

A quantidade de $\mathrm{N}$ recomendada para o cultivo do feijoeiro varia de acordo com a região (MORAES, 1988) e é baseada nas curvas de resposta a doses crescentes de $\mathrm{N}$, pois não existe critério adequado que permita relacionar a resposta do feijoeiro ao teor de matéria orgânica ou a alguma forma de nitrogênio no solo.

Todas as tabelas recomendam que parte do nitrogênio seja aplicado no sulco de plantio e parte em cobertura, antes do início do florescimento. A adubação de cobertura, nesta época, baseia-se nos resultados obtidos por uma série de autores (HAAG et alii, 1967; MAFRA et alii, 1974; NEPTUNE \& MURAOKA, 1978; MEIRELLES et alii, 1980) de que a absorção de $\mathrm{N}$ pelo feijoeiro é mais intensa no intervalo de 20-30 dias após a emergência. Apesar desses resultados, porém, o fracionamento de $\mathrm{N}$ no feijoeiro ainda tem sido assunto de muitas pesquisas e muitos resultados contraditórios ainda têm sido obtidos.

GALLO \& MIYASAKA (1961) estudaram a absorção de elementos nutritivos pelo feijoeiro (cv. Chumbinho Opaco), cultivado em terra roxa misturada em Campinas, do florescimento à maturação, e constataram que o período de máxima taxa de absorção variou de acordo com o nutriente; no caso do nitrogênio, esse período ficou 
entre 53 e 65 dias após a emergência, durante o crescimento das sementes nas vagens. Os autores sugeriram que a aplicação mais tardia de $\mathrm{N}$ no feijoeiro seria desejável, sempre que as necessidades da planta não fossem satisfeitas pelo $\mathrm{N}$ do solo.

Em outro trabalho, conduzido por MIYASAKA et alii (1963), foi estudado o modo e a época de aplicação de nitrogênio na cultura do feijão (cv. Creme), na Estação Experimental de Ribeirão Preto, numa área de terra roxa estruturada. A dose de $50 \mathrm{~kg} /$ ha de $\mathrm{N}$ foi aplicada de uma só vez após completada a germinação ou aos 22, 42 e 62 dias após a emergência. O N aplicado logo após a emergência resultou em aumento de $81 \%$ na produção em relação à testemunha sem $\mathrm{N}$, mas baixou para $57 \%$ quando empregado 22 dias depois e mais ainda nas duas aplicações posteriores.

MASCARENHAS et alii (1966) mostraram que a adubação nitrogenada (30 kg/ha de $\mathrm{N}$ ) provocou aumentos médios na produção do feijoeiro (cv. Creme) de $94 \%$ e $29 \%$, respectivamente, nos experimentos conduzidos em Monte Alegre do Sul (podzólico vermelho-amarelo - orto) e Tietê (latossolo vermelho-escuro - orto), SP. A análise estatística não mostrou, porém, diferenças significativas entre as produções obtidas, em decorrência da aplicação do adubo nitrogenado aos 7,14 e 21 dias após a emergência das plantas.

Segundo HAAG et alii (1967), a absorção de $\mathrm{N}$ nos primeiros 20 dias do ciclo do feijoeiro (cv. Chumbinho Opaco) é muito pequena. A partir dessa época, ela tende a aumentar consideravelmente atingindo um máximo aos 50 dias de idade. Diante desses resultados, os autores levantaram a hipótese de que a adubação nitrogenada de 
sulco poderia ser suprimida, transferindo-a para 30 dias após a emergência. MAFRA et alii (1974) também observaram que a quantidade de $\mathrm{N}$ na matéria seca do feijoeiro (cv. Rico 23) atingiu o ponto de máximo entre os 30 e 50 dias após a emergência das plantas.

REIS et alii (1972), em um solo de fertilidade média, em Viçosa, MG, por outro lado, comprovaram que a falta de aplicação do adubo nitrogenado no sulco de plantio mostrou-se prejudicial à cultura do feijão (cv. Rico 23), mesmo com o aumento da dose de $\mathrm{N}$ aplicada em cobertura. KORNELIUS et alii (1975) usaram níveis de 0,30 e $60 \mathrm{~kg} / \mathrm{ha}$ de $\mathrm{N}$, aplicados no plantio, aos 15 e 20 dias após a emergência. Não houve significância estatística dos tratamentos sobre a produção de grãos de feijão. Observaram, porém, uma tendência para a produção mais alta, quando o $\mathrm{N}$ foi aplicado em cobertura. Também SILVA et alii (1977), em experimento instalado na Universidade Federal de Santa Maria, não obtiveram diferenças significativas na produção do feijoeiro (cvs. Rico 23 e Rio Tibagi), com a aplicação de $\mathrm{N}$ em diferentes épocas, ou seja: tudo na semeadura, $1 / 3$ na semeadura mais $2 / 3$ aos 20 dias e $1 / 3$ na semeadura mais $2 / 3$ aos 40 dias, embora houvesse também uma tendência de maior produtividade do feijoeiro quando a aplicação do nitrogênio foi feita $1 / 3$ na semadura e $2 / 3$ aos 20 dias após a emergência. Houve porém, um incremento de produção de grãos com o aumento dos níveis de $\mathrm{N}$ de 0 para $120 \mathrm{~kg} / \mathrm{ha}$. Os últimos resultados concordam com os obtidos por CARDOSO et alii (1978) que, em experimentos montados em Tocantins e Viçosa, na Zona da Mata de Minas Gerais, obtiveram uma resposta linear positiva do feijoeiro (cv. 
Rico 23) aos níveis de $\mathrm{N}$ utilizados $(0,30,60$ e $90 \mathrm{~kg} / \mathrm{ha}$ em Tocantins e $0,30,60,90$, 120 e $150 \mathrm{~kg} / \mathrm{ha}$ em Viçosa), não havendo, porém, efeito significativo do parcelamento da adubação nitrogenada (1/3 no plantio $+1 / 310$ dias após a emergência, $1 / 3$ no plantio $+1 / 320$ dias após a emergência).

Do mesmo modo, URBEN FILHO et alii (1980), estudando doses (0, $40,80,130$ e $160 \mathrm{~kg} /$ ha de N) e modo de aplicação do adubo nitrogenado na cultura do feijão (cv. Ricobaio 1014), em Viçosa, verificaram que no período das águas a produção aumentou com o incremento de $\mathrm{N}$, apesar do alto teor de matéria orgânica e $\mathrm{N}$ total do solo utilizado; no período da seca, somente teve efeito sobre a produção o nível de 40 $\mathrm{kg} /$ ha de nitrogênio. Em ambos os casos, não houve efeito do parcelamento do $\mathrm{N}$ sobre a produção. ARAYA et alii (1981) estudaram, também em Viçosa, MG, o efeito do fracionamento de $80 \mathrm{~kg} / \mathrm{ha}$ de $\mathrm{N}$ sobre a produção do feijoeiro (cv Preto 897), no período das "águas" e no período da "seca"; os fracionamentos estudados foram: todo o adubo nitrogenado no sulco de plantio, $1 / 2$ do adubo nitrogenado no sulco de plantio e a outra metade aplicada em cobertura aos $15,22,29,36,43$ ou 50 dias após a emergência das plântulas. No período das águas, as maiores produções foram obtidas com a aplicação do adubo nitrogenado aos 15, 22 ou 29 dias após a emergência das plantas, enquanto que, no período da seca, o fracionamento da adubação nitrogenada não trouxe vantagem. Estes mesmos autores também verificaram o efeito de doses crescentes de $\mathrm{N}(0,30,60,90$ e $120 \mathrm{~kg} / \mathrm{ha}$ de $\mathrm{N})$ sobre a produtividade do feijoeiro, em 6 experimentos conduzidos em diferentes localidades da Zona da Mata de Minas Gerais. 
O fracionamento da adubação nitrogenada, neste caso, foi feito de acordo com o nível de $\mathrm{N}$ utilizado, ou seja: $30 \mathrm{~kg} / \mathrm{ha}$ de $\mathrm{N}$ : todo adubo aplicado no plantio; $60 \mathrm{~kg} / \mathrm{ha}$ de $\mathrm{N}$ : $1 / 2$ do adubo no plantio e $1 / 2$ aos 15 dias; $80 \mathrm{~kg} / \mathrm{ha}$ de $\mathrm{N}: 1 / 3$ no sulco de plantio, $1 / 3$ aos 15 dias e $1 / 3$ aos 25 dias; $120 \mathrm{~kg} / \mathrm{ha}$ de $\mathrm{N}: 1 / 4$ no sulco de plantio, $1 / 4$ aos 15 dias e 2/4 aos 25 dias. Houve efeito altamente significativo das doses de $\mathrm{N}$ em Viçosa, Ponte Nova, Leopoldina (efeito linear) e em Coimbra (efeito quadrático) o que não aconteceu em Rio Pomba e Raul Soares. Não houve porém, efeito do fracionamento do adubo nitrogenado.

NEPTUNE \& MURAOKA (1978) estudaram o efeito da uréia ${ }^{15} \mathrm{~N}$ no feijoeiro (cultivar Carioca), em terra-roxa-estruturada, e não verificaram aumento de produção de grãos com a aplicação de 15 a $120 \mathrm{~kg} / \mathrm{ha}$ de nitrogênio, distribuídos parceladamente de diferentes formas. Diante de tais resultados, os autores inferiram que a quantidade de $\mathrm{N}$ no solo mais a proveniente da possível fixação biológica do $\mathrm{N}_{2}$ atmosférico foram suficientes para suprir as necessidades da cultura nesse elemento e que o feijoeiro absorve e utiliza o $\mathrm{N}$ até um certo teto para a produção de grãos. Os autores verificaram ainda que, apesar disso, o feijoeiro absorveu o nitrogênio do fertilizante e que esta utilização foi maior quando o adubo foi aplicado antes ou durante o florescimento do que quando aplicado na semeadura. Resultados diferentes foram obtidos por MEIRELLES et alii (1980) em experimento também conduzido em Piracicaba, em terra-roxa-estruturada, com o cultivar Rosinha; a aplicação de $100 \mathrm{~kg} / \mathrm{ha}$ de $\mathrm{N}$ no plantio resultou em uma produção de $2025 \mathrm{~kg} / \mathrm{ha}$ de grãos, enquanto que na 
ausência da adubação nitrogenada a produção foi de apenas $575 \mathrm{~kg} / \mathrm{ha}$ de grãos. Conforme resultados obtidos por NEPTUNE \& MURAOKA (1978), os autores também verificaram maior eficiência de utilização do fertilizante nitrogenado no período de 30 a 45 dias após a emergência. Baseados nesses resultados, MEIRELLES et alii (1980) recomendam que, para o feijoeiro, a fertilização nitrogenada deva ser parcelada: $1 / 3 \mathrm{da}$ dose total no plantio e os $2 / 3$ restantes dos 30 aos 45 dias após a germinação. Após os 45 dias, não se deve fazer adubação nitrogenada porque a contribuição do $\mathrm{N}$ do fertilizante cai sensivelmente, havendo maior absorção do nitrogênio do solo.

BERGER et alii (1983) constataram, em experimento conduzido em Coimbra, na Zona da Mata de Minas Gerais, que a resposta do feijoeiro (cv. Negrito 897) à adubação nitrogenada está relacionada à quantidade de adubo fosfático utilizado. Assim, no período das águas, o $\mathrm{N}$ não teve efeito na ausência da adubação com $\mathrm{P}$; com a aplicação de 60 e $120 \mathrm{~kg} /$ ha de $\mathrm{P}_{2} \mathrm{O}_{5}$, as maiores produções foram obtidas com 60 $90 \mathrm{~kg} / \mathrm{ha}$ de $\mathrm{N}$; com 180 e $240 \mathrm{~kg} / \mathrm{ha}$ de $\mathrm{P}_{2} \mathrm{O}_{5}$ atingiram-se as maiores produções e não houve efeito significativo do nitrogênio.

De maneira geral, o que se pode concluir desses experimentos de adubação nitrogenada é que não existe uma unanimidade, em termos de resposta da cultura, quanto à necessidade de parcelamento desse adubo. De certa forma, uma comparação entre os vários experimentos torna-se difícil, uma vez que as condições edafoclimáticas e mesmo as cultivares não foram os mesmos. SANTA CECílIA (1972) já havia demonstrado que as cultivares de feijão respondem diferencialmente à adubação nitrogenada e, mais recentemente, SILVA (1988) observou que, enquanto a cultivar 
Carioca apresentou um máximo de produção com $50 \mathrm{~kg} / \mathrm{ha}$ de N, a cultivar Rio Tibagi mostrou uma resposta linear a até $100 \mathrm{~kg} / \mathrm{ha}$ de nitrogênio.

O efeito benéfico do Mo na produção do feijoeiro já havia sido demonstrado em uma série de trabalhos realizados nesta Zona (BRAGA, 1972; ROBITAILLE, 1975; JUNQUEIRA NETTO, 1977; SANTOS et alii, 1979; MACHADO et alii, 1979) não obtiveram acréscimos significativos na produção de grãos com a aplicação de molibdênio, na Zona Sul de Minas Gerais.

Recentemente, na Zona da Mata de Minas Gerais, tem sido demonstrado que a aplicação foliar de $20 \mathrm{~g}$ /ha de Mo, na cultura do feijão, aos 25 dias, permite uma substituição ou complementação da adubação nitrogenada em cobertura (VIEIRA et alii, 1992; AMANE, 1994).

ARAÚJO et alii (1987), num experimento conduzido em Viçosa,MG, em que foi estudada a influência do Mo e do $\mathrm{N}$ sobre duas variedades de feijão, verificaram que o Mo teve efeito sobre o peso de 100 grãos e, sobre o teor de $\mathrm{N}$ nas folhas. O nível de $20 \mathrm{~g} /$ ha de Mo propiciou o maior peso de 100 grãos e apesar de causar uma queda na percentagem de $\mathrm{N}$ nas folhas, não diminuiu a produção, fato que o autor atribuiu a uma economia de nitrogênio.

O efeito benéfico do Mo na produção do feijoeiro está possivelmente relacionado a uma maior atividade das enzimas nitrogenase e/ou redutase do nitrato, que apresentam aquele micronutriente como constituinte estrutural (SALISBURY \& ROSS, 1992). 
Os nitratos constituem a principal fonte de $\mathrm{N}$ inorgânico disponível no solo. Este íon provém da atmosfera trazidos por descargas elétricas, de fertilizantes ou oxidação do amônio do solo. Para que possa ser utilizado pela planta, o $\mathrm{NO}_{3}^{-}$deve ser reduzido a amônia. A importância da redutase do nitrato reside no fato de que o primeiro passo dessa transformação é catalizado por ela.

\subsection{Fixação biológica do $\mathbf{N}_{2}$ atmosférico na cultura do feijoeiro}

Os trabalhos sobre fixação biológica do nitrogênio atmosférico no feijoeiro, no Brasil, receberam maior atenção na década de 60 e 70, e os resultados promissores em relação à resposta dessa cultura à inoculação constituíram forte incentivo à pesquisa dessa associação simbiótica. O trabalho de RUSCHEL \& SAITO (1977), por exemplo, conduzido em casa de vegetação, mostrou que o peso das vagens por vaso, no tratamento inoculado com Rhizobium, foi equivalente ao obtido com a adição de $100 \mathrm{~kg}$ de uréia/ha, aplicados aos 10 e 23 dias após o plantio. Resultados obtidos sob condições controladas devem, entretanto, ser interpretados com cuidado, uma vez que trabalhos posteriores, conduzidos no campo, passaram a dar respostas contraditórias com relação à necessidade de inoculação do feijão. Em alguns trabalhos, não se encontraram respostas à inoculação (SAITO, 1982; DUQUE et alii, 1985; RAMOS \& BODDEY, 1987; WEISER et alii 1985), enquanto em outros, rendimentos de até $3000 \mathrm{~kg} / \mathrm{ha}$ de feijão foram obtidos em decorrência da introdução de estirpes eficientes de Rhizobium 
leguminosarum biovar phaseoli (TAYLOR et alii, 1983). Estas diferenças em relação à eficiência da fixação simbiótica, obtidas sob condições controladas e no campo, pressupõem a ocorrência de fatores ainda não determinados, que afetam sobremaneira a eficiência da inoculação desta leguminosa sob condições naturais. Segundo GRAHAM (1981), a maioria dos solos em que se cultiva feijão contém uma população nativa de Rhizobium leguminosarum biovar phaseoli (hoje R.etli e R.tropici, MARTINEZROMERO et alii, 1991), que compete pelos sítios de nodulação com o rizóbio proveniente da inoculação. Em locais em que não existe essa população nativa, como nos solos do oeste do Canadá, estirpes selecionadas de rizóbio podem fixar quantidades que vão além dos $100 \mathrm{~kg} / \mathrm{ha}$ de nitrogênio (RENNIE \& KEMP, 1983a e 1983b). Segundo KUCEY (1989), respostas do feijão à inoculação devem ocorrer em solos com população nativa de rizóbio e nível de nitrogênio mineral menores que $8.10^{3}$ e 25 ug - $\mathrm{g}^{-1}$ de solo, respectivamente. Por causa desses problemas, menos que $0,5 \%$ do feijão plantando no Brasil é inoculado, em contraste com $65-70 \%$ da soja.

Vários fatores interferem na simbiose entre leguminosas e estirpes do gênero Rhizobium, como variedade de planta, estirpe e espécie da bactéria, clima e solo, este atuando através do nível de $\mathrm{pH}$, disponibilidade de elementos minerais e de água, temperatura, aeração etc.

A acidez do solo, juntamente com todos os fatores associados a ela, como, por exemplo, alta saturação de alumínio, baixo teor de $\mathrm{P}$ e $\mathrm{Ca}$, tem sido citada como um dos principais fatores edáficos responsáveis por possíveis decréscimos na eficiência simbiótica da população nativa ou exótica de $R$. leguminosarum biovar 
phaseoli (LOVATO et alii, 1985a, 1985b; KEYSER \& MUNNS, 1979). Segundo FRANCO \& MUNNS (1982), no Brasil a resposta do feijoeiro à calagem e aos fertilizantes nitrogenados pode ser relacionada à alta sensibilidade tanto da planta como da iniciação de formação do nódulo ao alumínio livre em solos com baixo $\mathrm{pH}$. FRANCO \& DOBEREINER (1968), estudando a interferência do cálcio e do nitrogênio na fixação simbiótica do nitrogênio em duas variedades de Phaseolus vulgaris L., verificaram que, para uma mesma dosagem de nitrogênio, a nodulação variou com a variedade de feijão e com os níveis de cálcio empregados. Assim, tanto a variedade Venezuela como a Rico 23 aumentaram a nodulação com a adubação de $20 \mathrm{~kg} / \mathrm{ha}$ de $\mathrm{N}$, diminuindo à medida que se aumentava o teor de Ca no solo. A adubação com $80 \mathrm{~kg} / \mathrm{ha}$ de $\mathrm{N}$, por outro lado, embora tenha reduzido a nodulação da variedade Venezuela, independentemente do nível de cálcio, não afetou a nodulação da variedade Rico 23, nos dois níveis menores de cálcio. Segundo verificaram ANDREW \& NORRIS (1961), a eficiência da nodulação de leguminosas tropicais em solos com deficiência de cálcio pode ser atribuída à grande habilidade dessas plantas em extrair esse elemento do solo e não à uma baixa necessidade de cálcio para a nodulação, uma vez que ele é necessário para o desenvolvimento dos pontos meristemáticos das raízes bem como dos nódulos.

O nitrogênio é elemento cujo efeito na simbiose rizóbio-feijão tem sido bastante controversa. Alguns autores têm constatado um efeito sinérgico entre a absorção de nitrogênio mineral, fornecido em doses baixas, e a fixação do $\mathrm{N}_{2}$ (RUSCHEL et alii, 1979; WESTERMANN et alii, 1981; HUNGRIA \& RUSCHEL, 1982; SSALI \& 
KEYA, 1982), enquanto outros não têm demonstrado tal benefício (FRANCO et alii, 1979). Em trabalho realizado por HUNGRIA et alii (1985a), a adição de $2,5 \mathrm{mg}$ $\mathrm{N} \cdot \mathrm{pl}^{-1} \cdot \mathrm{dia}^{-1}$ aos sistemas simbióticos estudados de rizóbio e feijão aumentou a produção e o $\mathrm{N}$ total das sementes e das plantas. De acordo com os autores, porém, essa dose de nitrogênio, que equivale a $40 \mathrm{~kg} / \mathrm{ha}$ de $\mathrm{N}$ numa população de 250.000 plantas . ha ${ }^{-1}$, aumentou a produção de grãos, no sistema simbiótico eficiente Negro Argel - CO5, em apenas $18 \%$, o que poderia não ser econômico, dependendo do preço do adubo nitrogenado; ademais, o $\mathrm{N}$ assimilável já está próximo de $40 \mathrm{~kg} / \mathrm{ha}$ de $\mathrm{N}$ em muitos solos. Neste mesmo experimento, o fornecimento de $10 \mathrm{mg} \mathrm{N} \cdot \mathrm{pl}^{-1} \cdot \mathrm{dia}^{-1}(160 \mathrm{~kg} / \mathrm{ha}$ de $\mathrm{N})$ às plantas que não receberam inóculo não aumentou o $\mathrm{N}$ total da parte aérea em relação à simbiose eficiente, como Negro Argel - CO5, recebendo a menor dose de nitrogênio. FRANCO \& DOBEREINER (1967) verificaram que a aplicação de $84 \mathrm{~kg} / \mathrm{ha}$ de $N(1 / 2$ no plantio e $1 / 2$ em cobertura) agiu diferentemente na simbiose das variedades estudadas, inibindo a nodulação da Rico 23 e não das variedades Preto 120 , Venezuela e Chumbinho Opaco. TAYLOR et alii (1983) em experimento conduzido no campo, verificaram que o fertilizante nitrogenado suprimiu a nodulação, particularmente de plantas jovens, nas quais o peso dos nódulos produzidos foi inversamente relacionado com o nível de fertilizante nitrogenado adicionado.

Em feijão, não há uma sincronização entre o período de depleção de nitrogênio nos cotilédones e o começo da fixação de $\mathrm{N}_{2}$, o que causa um período de estresse de $\mathrm{N}$, usualmente entre 15 e 20 dias após a emergência (BARRADAS \& HUNGRIA, 1989). Segundo HUNGRIA et alii (1991), tal fato poderia estar ligado à 
atividade das enzimas glutamina sintetase e glutamato sintase (dependente do NADH) no citossol dos nódulos de determinadas estirpes de Rhizobium leguminosarum biovar phaseoli. As estirpes denominadas "precoces" apresentariam alta atividade dessas enzimas no período inicial do ciclo do feijoeiro, enquanto que, nas estirpes tradicionais, a atividade enzimática seria baixa, com o decorrente acúmulo de $\mathrm{N}$ nos nódulos $\mathrm{e}$ conseqüente amarelecimento da parte aérea. Considerando-se que o feijão é cultura de ciclo curto, o estresse inicial de $\mathrm{N}$ poderá refletir-se diretamente no rendimento final da cultura; associado a isso ainda existe o fato de que diversos autores têm verificado uma queda abrupta da fixação após o florescimento (WESTERMAN \& KOLAR, 1978; FRANCO et alii, 1979), embora tal fenômeno não seja generalizado. Uma das principais limitações do feijoeiro na fixação biológica do $\mathrm{N}_{2}$ estaria, portanto, ligada ao ciclo curto da cultura. BARRADAS et alii (1989), em experimento conduzido em casa de vegetação, selecionaram cultivares de feijão e estirpes de rizóbio para nodulação precoce e senescência tardia dos nódulos. Embora as estirpes diferissem entre si quanto à capacidade de fixação no início do ciclo vegetativo, as plantas que receberam $\mathrm{N}$ mineral acumularam cerca de $50 \%$ mais $\mathrm{N}$ total na planta, mostrando ainda haver limitações de $\mathrm{N}$ na fase inicial, mesmo na combinação simbiótica cujas taxas de redução do acetileno foram elevadas nos primeiros 20 dias após a emergência; o mesmo foi verificado para a senescência tardia dos nódulos. Nesse trabalho, porém, ficou evidenciada a possibilidade de seleção de estirpes de rizóbio para fixação precoce de $\mathrm{N}$ e senescência tardia dos nódulos, que poderão no futuro fornecer melhores resultados. 
O fósforo é outro elemento cuja deficiência pode afetar sobremaneira a simbiose rizóbio-feijoeiro. SAITO \& RUSCHEL (1978), estudando o efeito da adubação fosfática na nodulação natural do feijoeiro, verificaram que esse elemento afeta tanto o peso como o número de nódulos; o efeito do fósforo sobre o número de nódulos foi acentuado nos solos mediterrâneo arraial de São Bento (SP) e no podzolizado var. laras, na Estação Experimental de Tietê (SP) e inexistente em terras-roxas-estruturadas de Piracicaba (SP). Resultados semelhantes quanto ao efeito do fósforo no número e peso de nódulos foram também obtidos por BONETTI et alii (1984). Segundo GRAHAM \& ROSAS (1979), os nódulos representam um forte dreno para o fósforo. Em estudo que realizaram com 30 variedades de feijão e níveis crescentes do macronutriente, constataram que o aumento no conteúdo de $\mathrm{P}$, em decorrência da maior fertilização, foi mais acentuado nos nódulos do que no resto da planta. Nesse trabalho, não foi encontrado nenhum cultivar de feijão capaz de razoável fixxação de $\mathrm{N}_{2}$, quando o nível de fósforo foi baixo, embora PEREIRA \& BLISS (1987) tenham verificado que algumas variedades requerem quantidades menores de P para uma eficiente fixação de $\mathrm{N}_{2}$. Estes autores confirmaram as observações de GRAHAM \& ROSAS (1975) de que os nódulos são um forte dreno para o $\mathrm{P}$, além de também observarem uma relação nódulos verdes/nódulos vermelhos maior em plantas cultivadas com baixos níveis desse elemento. Os nódulos verdes seriam considerados não-eficientes quanto à capacidade de fixar $\mathrm{N}_{2}$, em virtude da ausência da leghemoglobina.

A influência de micronutrientes é outro fator marcante do solo, não só no desenvolvimento da planta e da bactéria, como também na simbiose. 
O molibdênio, micronutriente essencial para o crescimento das plantas, é elemento estrutural da enzima nitrogenase, e seu efeito benéfico na fixação simbiótica do $\mathrm{N}_{2}$ é amplamente conhecido (HEWITT, 1958; MULDER, 1984; SHAH et alii, 1984). FRANCO \& DOBEREINER (1967) verificaram que, embora o molibdênio seja essencial para o processo simbiótico, seu excesso pode prejudicar mais a fixação biológica do nitrogênio do que o desenvolvimento das plantas. FRANCO \& DAY (1980) estudaram o efeito do molibdênio juntamente com o da calagem, na nodulação e fixação do nitrogênio em feijoeiro, em solos ácidos do Brasil. Os autores verificaram, em experimentos conduzidos em casa de vegetação com solo podzólico vermelho-amarelo, que, entre $\mathrm{pH}$ 5,3 e 6,0, houve efeito significativo da aplicação de molibdênio na fixação do nitrogênio e crescimento das plantas. Acima de $\mathrm{pH}$ 6,0, as plantas cresceram bem com abundante fixação e não houve resposta à aplicação do micronutriente.

Segundo BRODRICK \& GILLER (1991a), determinadas variedades de feijão mantêm constante a concentração de molibdênio nos nódulos, independentemente do fornecimento externo desse elemento, enquanto em outras variedades o seu conteúdo aumenta em resposta à aplicação foliar em doses crescentes do micronutriente. Esses autores levantaram a hipótese de haver, no primeiro caso, uma possível regulação específica do conteúdo de molibdênio nos nódulos, devido a algum limite interno na quantidade de nitrogenase sintetizada; em seu experimento não foram conduzidas avaliações das atividades das enzimas ligadas à fïxação do $\mathrm{N}_{2}$ atmosférico. Nos dois grupos de variedades, aplicações foliares crescentes de molibdênio aumentaram as concentrações desse elemento nas raízes e parte aérea, indicando também que, 
possivelmente, nas variedades em que o conteúdo de molibdênio nos nódulos permanece constante, possa não haver translocação adequada do elemento para os nódulos, por via do floema. Num segundo trabalho, BRODRICK \& GILLER (199lb) levantaram a hipótese de que variedades de feijão mais eficientes na translocação de molibdênio para os nódulos seriam mais eficientes simbioticamente. JACOB-NETO et alii (1988) estudaram as variações sazonais da concentração de molibdênio nos nódulos e na parte aérea do feijoeiro Carioca, em solução nutritiva e observaram que as concentrações de molibdênio nos tecidos da planta variavam com o seu estádio de crescimento, sendo encontrados maiores teores nos nódulos que na parte aérea ou raiz, quando as plantas eram cultivadas com baixa disponibilidade de molibdênio. BRODRICK \& GILLER (1991a) também verificaram que os nódulos são capazes de competir eficientemente com outras partes da planta pela aquisição de molibdênio, quando o seu suprimento é pequeno.

Dentre os fatores do solo que afetam a fixação simbiótica do nitrogênio, a umidade tem sido intensivamente estudada (MASEFIELD, 1961). Segundo KORNELIUS \& FREIRE (1974), quando o teor de água na planta está abaixo de 80\% de sua turgidez máxima, a atividade da nitrogenase dos nódulos é irreversivelmente afetada. BONETTI et alii (1984) verificaram que, sob condições de seca, os nódulos não se desenvolvem, mesmo na presença de altas taxas de fósforo, mas, uma vez fornecida a água, a resposta dependerá do conteúdo do fósforo no solo. AMARA \& MILLER (1986), em trabalho conduzido em casa-de-vegetação, demonstraram que a inundação 
do solo, após a inoculação com diferentes estirpes de Rhizobium, por quatro semanas consecutivas antes da semeadura do feijão não teve efeito sobre a sobrevivência $\mathrm{e}$ capacidade de fixação de $\mathrm{N}_{2}$ e que, por razões ainda não conhecidas, este pré-alagamento do solo antes da semeadura do feijão pareceu estimular a atividade das estirpes de rizóbio, contrariamente ao observado por DEPOLLI et alii (1973), em centrosema, e por CARROL \& DUNIGAN (1977), na soja. AMARA \& MILLER (1986) também observaram diferenças entre estirpes de rizóbio na habilidade para sobreviver à dessecação; um declínio na população de todas as estirpes ocorreu quando as tensões de umidade foram maiores que 15 bars. Segundo verificaram SMITH \& HUME (1985), em experimento conduzido no campo com soja e feijão, a fixação do $\mathrm{N}_{2}$ no feijoeiro é extremamente sensível ao estresse de água. A irrigação aumentou a fixação do $\mathrm{N}_{2}$ no feijão de 4 a 150 vezes e, na soja, de 2 a 4 vezes. $\mathrm{O}$ tamanho, peso e atividade específica dos nódulos no feijoeiro foram geralmente maiores nos tratamentos irrigados. De acordo com esses autores, a maior sensibilidade ao estresse de água na fixação simbiótica do $\mathrm{N}_{2}$, na cultura do feijão, em relação à soja, pode estar relacionada às diferentes respostas ao estresse de umidade nas duas espécies; o fechamento dos estôma-tos no feijoeiro ocorreu com tensões de umidade no solo bem superiores às da soja.

A umidade juntamente com a temperatura tornam-se fatores extremamente importantes no estudo da fixação simbiótica do $\mathrm{N}_{2}$ no feijoeiro, quando se considera que $80 \%$ dos cultivos de feijão, na América Latina, são realizados em 
associação com outras culturas. Trabalhos conduzidos no Centro Internacional de Agricultura Tropical (CIAT) (1976) mostraram maiores níveis de fixação de $\mathrm{N}_{2}$ em culturas de feijão associadas com o milho do que em monocultura, atribuíram tal fato às menores oscilações de temperatura e umidade do solo no consórcio. Por outro lado, PEREIRA et alii (1984a) não observaram efeito sobre a fixação do $\mathrm{N}_{2}$ no feijoeiro cultivado em associação com o milho, embora as parcelas inoculadas e não-inoculadas no cultivo consorciado apresentassem peso de nódulos secos bem superior ao observado no cultivo "solteiro". FERRAZ \& CARDOSO (1993) também verificaram que independentemente da inoculação, a nodulação dos cultivares Carioca e Rio Tibagi foi sempre significativamente maior no feijão consorciado.

A fixação do $\mathrm{N}_{2}$ é processo termo-sensível, em que todos os estádios, desde a formação até o funcionamento dos nódulos, podem ser afetados pela temperatura. Além desses efeitos diretos, a temperatura pode afetar indiretamente o processo simbiótico, reduzindo a formação de pêlos absorventes nas raízes e, conseqüentemente, os sítios de nodulação (Frings, $1976^{1}$, citado por HUNGRIA \& FRANCO, 1990a). GRAHAM (1979) cita que a temperatura máxima em que ocorreria a fixação de $\mathrm{N}_{2}$ no feijoeiro seria de $30^{\circ} \mathrm{C}$. No experimento de PEREIRA et alii (1984a), citado anteriormente, considerando que as temperaturas máximas não ultrapassaram $30^{\circ} \mathrm{C}$, tanto no plantio associado como no "solteiro", conforme descrito no trabalho, era de se esperar que o sombreamento causado pelo milho tivesse afetado

' FRINGS, J.F.J. The rhizobium-pea symbiosis as effected by temperatures. Meded. Landbouwhogeschool Wageningen, 76:1-76, 1976. 
negativamente a taxa de fixação do nitrogênio. Tal suposição encontra suporte no experimento conduzido por HUNGRIA et alii (1985b), em que foram testados os efeito da luminosidade total e sombreamento de $25 \%$ e de $40 \%$. O abaixamento da temperatura no nível de $25 \%$ de sombreamento aumentou a fixação do $\mathrm{N}_{2}$; já no de $40 \%$ a luz passou a ser um fator limitante para a fixação do nitrogênio.

Altas temperaturas parecem, de acordo com PIHA \& MUNNS (1987), causar pouca ou nenhuma supressão no número de nódulos, mas podem torná-los pequenos e com baixa atividade específica. Esses autores, trabalhando em casa de vegetação, observaram que temperaturas continuamente altas foram mais detrimentais à simbiose do que temperaturas altas de dia alternadas com temperaturas baixas à noite, o que é mais provável de ocorrer no campo. Assim, muitos trabalhos conduzidos em casa de vegetação, com regime constante de temperatura, podem demonstrar uma sensibilidade ao calor muito maior da simbiose feijão-rizóbio do que realmente ocorre.

HUNGRIA \& FRANCO (1990) verificaram que diversas estirpes de $R$. legumisosarum biovar phaseoli, apesar de serem capazes de nodular em temperaturas mais elevadas $\left(35-38^{\circ} \mathrm{C} / 8 \mathrm{~h} / \mathrm{dia}\right)$, não acumularam $\mathrm{N}$ na parte aérea, enquanto que as plantas que receberam nitrogênio mineral não foram afetadas pelo choque térmico. Esses autores também observaram, conforme já descrito em outros trabalhos (OLIVEIRA et alii, 1983; LA FAVRE \& EAGLESHAM, 1986), que a capacidade de estirpes de rizóbio crescerem em meio de cultura em temperaturas elevadas não parece estar relacionada com a habilidade para nodular nessas condições. HUNGRIA \& FRANCO (1990) verificaram também que algumas estirpes capazes de nodular leguminosas 
arbóreas, tão bem quanto o feijoeiro, fixaram $\mathrm{N}_{2}$ atmosférico em altas temperaturas; estes resultados são de grande importância no processo de seleção de estirpes para utilização em escala comercial, quando se considera que nos solos tropicais as temperaturas são normalmente elevadas.

Diversos trabalhos indicaram a importância de se considerar tanto a cultivar de feijão como a estirpe de Rhizobium nos programas que visam incrementar a fixação biológica do nitrogênio nessa cultura. FRANCO \& DOBEREINER (1967) verificaram existir de fato um comportamento diferenciado na fixação de $\mathrm{N}_{2}$ de diferentes estirpes, quando em simbiose com distintas variedades. Variação intraespecífica na capacidade de fixação de $\mathrm{N}_{2}$ entre genótipos de $P$. vulgaris $\mathrm{L}$. foi também verificada por WESTERMANN \& KOLAR (1978), GRAHAM \& ROSAS (1977) e por GRAHAM (1981). PEREIRA et alii (1984a) estudaram a capacidade de 339 genótipos de Phaseolus vulgaris $\mathrm{L}$. de fixar $\mathrm{N}_{2}$ atmosférico. O experimento foi instalado no campo em um latossolo vermelho-escuro. Os autores verificaram uma ampla variabilidade no peso da matéria seca dos nódulos e na atividade da nitrogenase entre os genótipos estudados; alguns mostraram produções similares às obtidas com o uso de adubo nitrogenado, na dose de $20 \mathrm{~kg} / \mathrm{ha}$ de $\mathrm{N}$ no plantio e $80 \mathrm{~kg} / \mathrm{ha}$ de $\mathrm{N}$ em cobertura, aos 25 dias após a emergência das plantas. Em outro trabalho, SAITO (1982) verificou a capacidade de fixação simbiótica de diferentes estirpes de $R$. leguminosarum biovar phaseoli na variedade Carioca, no campo, em dois solos de terra roxa estruturada. No primeiro experimento, conduzido na Estação Experimental Areão, em 
Piracicaba-SP, não foram observadas diferenças significativas no desenvolvimento e produção das plantas por causa da inoculação, o que a autora atribuiu ao provável teor de $\mathrm{N}$ já existente no solo, demonstrado pela pequena diferença de produção entre as testemunhas sem e com nitrogênio (100 kg/ha de $\mathrm{N})$. Aqui deve-se chamar a atenção para o fato de que todo o nitrogênio foi adicionado no plantio e que grande parte deve ter sido perdido antes de ser adequadamente utilizado pela planta. No segundo solo, situado na Estação Experimental de Piracicaba-SP, as respostas de produção somente foram significativas com a adição de $\mathrm{N}$, não havendo resposta à inoculação. A autora salienta a necessidade de se conhecer melhor a simbiose do feijoeiro no campo, no sentido de determinar quais fatores podem atuar para maximizar a expressão do rizóbio na planta. É bom salientar que as estirpes utilizadas nesses experimentos foram previamente testadas quanto à capacidade de fixar $\mathrm{N}_{2}$ atmosférico no feijoeiro. Mais recentemente, HUNGRIA \& RUSCHEL (1987), estudando a fixação simbiótica do nitrogênio em duas variedades de feijão, Carioca e Venezuela-350, inoculadas isoladamente com três estirpes de Rhizobium (CO5, C-88 e C-29), encontraram efeito do cultivar de feijão, da estirpe de Rhizobium e da interação entre ambos na atividade e eficiência relativa da nitrogenase e no $\mathrm{N}$ total acumulado pelas plantas. Segundo as autoras, a melhor combinação simbiótica (cultivar Carioca x estirpes C-88) relacionou-se com a melhor alocação dos elétrons para a nitrogenase, devido o menor desprendimento de $\mathrm{H}_{2}$ pelos nódulos. PACOVSKY et alii (1984), estudando as interações simbióticas entre estirpes de Rhizobium e diferentes cultivares de feijão, também constataram 
influência do desprendimento de $\mathrm{H}_{2}$ na eficiência das estirpes utilizadas, observando grandes perdas energéticas que poderiam estar limitando a eficiência da simbiose. Segundo SCHUBERT \& EVANS (1976), o desprendimento de $\mathrm{H}_{2}$ pelos nódulos de leguminosas pode provocar o desvio de 40 a $60 \%$ dos elétrons destinados à nitrogenase; parte dessa energia, porém, poderá ser recuperada quando houver a ação da enzima hidrogenase. Diferentemente do que se pensava anteriormente (CARTER et alii, 1978), não somente a bactéria contém as informações genéticas para a síntese da hidrogenase, como também a planta hospedeira pode influenciar o metabolismo do hidrogênio (GIBSON et alii, 1981; HUNGRIA \& RUSCHEL, 1982). Tal fato foi também observado por HUNGRIA \& NEVES (1986b).

Os sistemas simbióticos não diferem somente na quantidade de nitrogênio fixado, mas também na distribuição desse nutriente pela planta. Segundo HUNGRIA \& RUSCHEL (1982), o efeito da interação entre cultivares e estirpes foi observado não só no nitrogênio total da parte vegetativa e das sementes, mas também no índice de colheita do nitrogênio ( $\mathrm{N}$ semente/ $\mathrm{N}$ planta). No trabalho conduzido por essas autoras, o sistema simbiótico mais eficiente (cultivar Negro Argel-estirpe CO5) apresentou, além de maior $\mathrm{N}$ total e peso de sementes, maior índice de colheita, levando à sugestão da necessidade de verificação das diferenças no metabolismo assimilatório do nitrogênio nos sistemas simbióticos, além da medição do $\mathrm{N}$ total da planta. Estas diferenças na distribuição do $\mathrm{N}$ assimilado já haviam também sido constatadas anteriormente por RUSCHEL \& SAITO (1977) e por RUSCHEL et alii (1979). 
PEREIRA et alii (1989), embora demonstrassem que o conteúdo de $\mathrm{N}$ total da parte aérea apresentou um padrão de acumulação similar ao do $\mathrm{N}_{2}$ fixado, verificaram, como HUNGRIA \& RUSCHEL (1982), que determinadas linhagens de feijão, boas fixadoras de $\mathrm{N}_{2}$, não translocavam grandes quantidades de nitrogênio para os grãos.

O parâmetro adequado para se medir a fixação biológica do nitrogênio é pré-requisito extremamente importante, quando se pretende o melhoramento genético do hospedeiro, visando aumentar-lhe a capacidade de fixação de $\mathrm{N}_{2}$. Embora muitos trabalhos citem a redução do acetileno e o peso de nódulos secos como aceitáveis indicadores de fixação de $\mathrm{N}_{2}$, outros não obtiveram tal relação ou a obtiveram somente durante um estádio determinado de crescimento da planta (RENNIE \& KEMP, 1981b). Conforme enfatizam PEREIRA et alii (1989), caraterísticas associadas com o peso de nódulos são extremamente difíceis de serem obtidas sob condições de campo, uma vez que os altos coeficientes de variação raramente tornam significativas diferenças entre as linhagens. Segundo WOLYN et alii (1989), avaliações das caraterísticas associadas com a fixação biológica do $\mathrm{N}_{2}$ nas raízes laterais foram mais correlacionadas com o $\mathrm{N}$ total da parte aérea das plantas do que os resultados obtidos das raízes próximas ao coleto ou de todo o sistema radicular; do mesmo modo, o rendimento de sementes correlacionou-se mais com a massa de nódulos das raízes laterais. Attewell \& Bliss $(1985)^{2}$, citados por WOLYN et alii (1989), já haviam sugerido que as raízes laterais 
noduladas, freqüentemente não amostradas em experimentos de campo, podem ter importante papel na fixação do $\mathrm{N}_{2}$ no feijoeiro durante a fase de crescimento reprodutivo.

Outro fator que pode afetar sobremaneira o sucesso da inoculação é a aplicação de pesticidas. Muitos fungicidas são tóxicos para o rizóbio e alguns reduzem a quantidade de $\mathrm{N}_{2}$ fixado, o que torna o tratamento de sementes muitas vezes incompatível com o processo de inoculação. LENNOX \& ALEXANDER (1981) verificaram um efeito positivo na nodulação do feijoeiro, quando as sementes foram, antes da semeadura, tratadas com thiram e inoculadas com estirpes de rizóbio tolerantes a esse fungicida. Segundo os autores, o efeito benéfico da utilização das bactérias resistentes ao thiram, no número de nódulos e estabelecimento do inóculo, foi evidente somente nos estádios iniciais de crescimento da planta. Tal fato é extremamente importante, visto ser o feijão uma leguminosa cuja fixação simbiótica somente se inicia três semanas após o plantio. O thiram apresentou um efeito pronunciado sobre a população de protozoários, o que teria favorecido a colonização do rizóbio na rizosfera do feijão. Diversos trabalhos têm demonstrado o efeito antagonista de protozoários sobre a população de rizóbio (DANSO \& ALEXANDER, 1975; HABTE \& ALEXANDER, 1977). KEYA (1977) verificou que, além de protozoários, bactérias do gênero Bdellovibrio são grandemente responsáveis pelo declínio da população de rizóbio no solo; de acordo com observações do autor, a população de rizóbio não é totalmente dizimada pelos seus predadores, devido à inabilidade destes em se alimentarem do hospedeiro, quando a sua população é baixa. 


\section{MATERIAL E MÉTODOS}

Foram montados dois experimentos no campo, em Viçosa e Coimbra, na Zona da Mata de Minas Gerais.

Em Viçosa, o experimento foi instalado em 9 de março de 1993, em solo classificado como podzólico vermelho-amarelo câmbico, fase terraço, apresentando as seguintes caraterísticas químicas: $\mathrm{pH}\left(\mathrm{H}_{2} \mathrm{O}\right)=5,8,28,4$ ppm de $\mathrm{P}, 80$ ppm de $\mathrm{Ke}$ 0,$1 ; 3,4 ; 0,5$ e $4,5 \mathrm{meq} / 100 \mathrm{~cm}^{3}$ de solo de $\mathrm{Al}, \mathrm{Ca}, \mathrm{Mg}$ e $\mathrm{H}+\mathrm{Al}$, respectivamente. Esse solo, de textura argilosa (52\%), apresentou ainda 3,9 ppm de $\mathrm{Zn}, 76,8 \mathrm{ppm}$ de Fe 49,4 ppm de Mn e 3,02\% de matéria orgânica.

Em Coimbra, o experimento foi instalado em 12 de abril de 1993; neste local o solo, também classificado como podzólico vermelho-amarelo câmbico, fase terraço, apresentou as seguintes caraterísticas físicas e químicas: $\mathrm{pH}(\mathrm{H} 2 \mathrm{O})=5,5 ; 5,1$ ppm de $\mathrm{P}, 22 \mathrm{ppm}$ de $\mathrm{K}$ e 0,$1 ; 1,7 ; 0,5$ e $2,5 \mathrm{meq} / 100 \mathrm{~cm}^{3}$ de solo de $\mathrm{Al}, \mathrm{Ca}, \mathrm{Mg}$ e $\mathrm{H}+\mathrm{Al}$, respectivamente. Apresentou ainda 2,2 ppm de $\mathrm{Zn}, 60,4 \mathrm{ppm}$ de $\mathrm{Fe}, 43,2 \mathrm{ppm}$ de $\mathrm{Mn}, 71 \%$ de argila e $2,34 \%$ de matéria orgânica.

Os solos de ambos os ensaios são reconhecidamente deficientes em $\mathrm{N}$, conforme experimentos e plantios anteriores comprovaram. Também são povoados por 
estirpes nativas de rizóbio e respondem à aplicação de Mo, conforme comprovaram os experimentos levados a efeito por VIEIRA et alii (1992), VIEIRA et alii (1993), BERGER et alii (1993a, 1993b) e AMANE (1994).

Em ambas as localidades, utilizou-se um fatorial de 4 , em blocos ao acaso com quatro repetições, em que os fatores foram: inoculação com Rhizobium (realizada e não realizada), molibdênio em aplicação foliar ( 0 e $40 \mathrm{~g} / \mathrm{ha})$, nitrogênio no sulco de plantio ( 0 e $20 \mathrm{~kg} / \mathrm{ha})$ e nitrogênio em cobertura ( 0 e $30 \mathrm{~kg} / \mathrm{ha})$. A adubação em cobertura e a adubação molíbdica foram feitas aos 25 dias após a emergência das plantas. As fontes de $\mathrm{N}$ e Mo foram, respectivamente, sulfato de amônio e molibdato de amônio. O inoculante utilizado era turfoso e constituído pelas estirpes CIAT 899 e 1135, gentilmente fornecido pelo CPAC-EMBRAPA. Todos os tratamentos receberam uma adubação de $80 \mathrm{~kg} /$ ha de $\mathrm{P}_{2} \mathrm{O}_{5}$, na forma de superfosfato simples.

Cada parcela experimental foi constituída de seis fileiras de $5 \mathrm{~m}$ de comprimento com espaçamento de $50 \mathrm{~cm}$ entre fileiras, sendo as extremas consideradas como bordadura e as duas centrais, como úteis. As demais fileiras foram usadas para colheitas periódicas de plantas necessárias para as várias avaliações realizadas. A densidade de semeadura foi de, aproximadamente, 15 sementes por metro linear do feijão Ouro Negro 1992.

Os tratos culturais foram os normais da cultura. Quando necessário, fizeram-se irrigações por aspersão. 
Foram avaliados os seguintes parâmetros: atividade da nitrogenase e da redutase do nitrato, número e peso dos nódulos secos e percentagens de $\mathrm{N}$-amoniacal e de $\mathrm{N}^{-\mathrm{NO}_{3}}$ na parte aérea. As avaliações iniciaram-se aos 18 dias após a emergência das plantas e foram repetidas repetidas a partir dessa época, a cada 14 dias até o $60^{\circ}$ dias após a emergência, no experimento de Viçosa, e até o $74^{\circ}$ dia após a emergência, no experimento de Coimbra. Em cada avaliação, em cada data, foram retiradas quatro plantas por parcela, nas fileiras próprias. Após a colheita das plantas, foi feita a análise de $\mathrm{N}$-amoniacal nas sementes.

Não houve decréscimo na produção em decorrência do aparecimento de pragas e doenças.

\subsection{Determinação da atividade de nitrogenase}

As amostragens de plantas no campo iniciaram-se às 9:00 horas da manhã, terminando ao redor das 11:00 horas. As raízes, após serem destituídas do excesso de solo, foram colocadas aos pares em frascos de $600 \mathrm{ml}$, que foram hermeticamente fechados. O acetileno foi aplicado à base de $10 \%$ do volume do frasco, tendo-se o cuidado de retirar previamente este mesmo volume de ar, para que a pressão não fosse alterada. Os vidros foram incubados em lugar sombreado, com temperatura média de $25^{\circ} \mathrm{C}$, por uma hora. Terminado este tempo, $0,5 \mathrm{ml}$ da atmosfera dos frascos foi retirado com seringas de insulina e injetado no cromatógrafo a gás. 
As análises de redução do acetileno foram feitas em cromotógrafo de gás Modelo CG 37-D, usando um detector de chama de nitrogênio a $100^{\circ} \mathrm{C}$ e coluna de vidro de $1 / 8$ polegada $x$ 0,5 metro, contendo Poropak N, 100 a 120 mesh, a $50^{\circ} \mathrm{C}$, com $\mathrm{N}_{2}$ como gás de arraste a um fluxo de 40 mililitros. minuto ${ }^{-1}$.

O padrão de etileno foi determinado injetando-se no cromotógrafo $0,5 \mathrm{ml} \mathrm{de}$ etileno puro, na concentração de $490 \mathrm{vpm}$. Foram feitas quatro injeções de etileno e o valor médio de altura dos vários picos obtidos foi utilizado nos cálculos posteriores.

Possível contaminação do gás acetileno utilizado, com gás etileno, foi verificado por meio da injeção de $0,5 \mathrm{ml}$ de acetileno puro no cromatógrafo; para esta verificação, utilizou-se a menor atenuação possível, de modo que a presença de pequenos vestígios do gás etileno pudesse ser constatada.

O cálculo da atividade da nitrogenase foi feito pela seguinte equação:

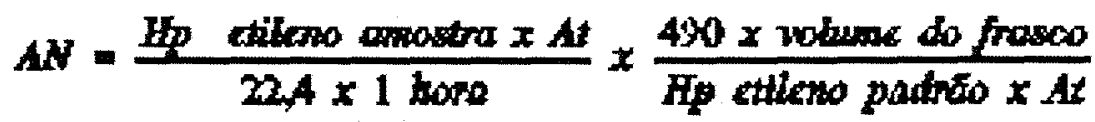

em que:

$\mathrm{AN}=$ atividade da nitrogenase $\left(\mu\right.$ moles $\left.\mathrm{C}_{2} \mathrm{H}_{4} \cdot \mathrm{h}^{-1}\right)$

$\mathrm{Hp}=$ altura do pico

At $=$ atenuação.

Foram também determinados os valores de atividade específica da nitrogenase, dividindo-se os valores de atividade da nitrogenase pelos correspondentes pesos de nódulos secos. 


\title{
3.2. Determinação da atividade da redutase do nitrato
}

\author{
A determinação da atividade da redutase do nitrato foi feita segundo \\ o método descrito por HAGEMAN \& REED (1980).
}

As amostragens para avaliação da redutase do nitrato foram feitas no período da tarde, entre 13:30 e 14:30 horas. Testes preliminares conduzidos no laboratório não indicaram, para o caso do feijão, variações acentuadas na atividade da redutase do nitrato no decorrer do dia.

Conforme já descrito, quatro plantas foram amostradas por parcela; em cada planta foi coletada a folha trifoliolada mais jovem, porém totalmente expandida, por possuir a mais alta atividade da redutase do nitrato.

As folhas assim coletadas no campo foram acondicionadas em sacos plásticos e armazenadas no escuro, em caixa de isopor com gelo, para que houvesse inibição e paralisação da atividade da enzima.

No laboratório foram retirados oito discos de $0,5 \mathrm{~mm}$ de diâmetro de cada folha sem atingir as nervuras principais e reunidos em uma amostra composta, de modo a fornecer cerca de $70 \mathrm{mg}$ de material fresco por parcela.

Os discos foliares foram colocados em frascos Erlenmeyer de $25 \mathrm{ml}$ contendo $10 \mathrm{ml}$ do meio de incubação: tampão fosfato $0,1 \mathrm{M}(\mathrm{pH}=7,5), 0,1 \mathrm{M}$ de $\mathrm{KNO}_{3}, 1 \%(\mathrm{v} / \mathrm{v})$ de propanol e $0,1 \%$ de triton. Para melhor penetração do nitrato nas células, os frascos Erlenmeyer foram submetidos a três vácuos de dois minutos. 
Posteriormente, os frascos foram incubados durante 30 minutos no escuro em banho-maria a $30^{\circ} \mathrm{C}$. Para medir a atividade da enzima por hora, amostras de $2 \mathrm{ml}$ do meio de incubação foram retiradas aos 10 e 30 minutos de incubação e colocadas em tubos contendo $1 \mathrm{ml}$ da solução $1 \%$ de sulfanilamida em $\mathrm{HCL} 3 \mathrm{~N}$; a função desta substância é paralisar a atividade da enzima.

Para a quantificação da atividade da redutase do nitrato, foram adicionados em cada tubo mais $1 \mathrm{ml}$ da solução $0,01 \%$ de naftilamida. Este reagente produz uma reação de cor rosa, cuja intensidade é proporcional à atividade enzimática da redutase do nitrato. A medição da coloração foi feita decorridos 20 minutos da adição da naftilamida, em espectrofotômetro Coleman Jr, na faixa de $540 \mathrm{~nm}$. As absorbâncias obtidas foram correlacionadas com uma curva padrão, feita com quantidades conhecidas de $\mathrm{NO}_{2}$, através de uma equação de regressão. A atividade da redutase do nitrato foi calculada segundo a seguinte equação:

$$
A=\operatorname{athdiade}(30)-\operatorname{athldad}(10) \times \frac{1}{P F P} \times \frac{60}{20^{\prime}} \times \frac{1}{1000}
$$

em que:
$\mathrm{A}=$ atividade da redutase do nitrato $\left(\mu\right.$ moles $\mathrm{NO}_{2}^{-} \cdot \mathrm{h}^{-1} \cdot \mathrm{g}$. de matéria fresca $\left.{ }^{-1}\right)$ PFP $=$ peso da planta fresca 


\subsection{Determinação do $\mathbf{N}$-amoniacal e $\mathbf{N}$-nítrico na parte aérea}

A determinação do $\mathrm{N}$-amoniacal foi feita pelo método de Nessler (JACKSON, 1944). Cem miligramas da parte aérea seca e moída foram colocadas em tubos de digestão, onde foi adicionado $1 \mathrm{ml} \mathrm{de} \mathrm{ácido} \mathrm{sulfúrico} \mathrm{p.a.} 96 \%$. Os tubos assim preparados foram mantidos à temperatura ambiente por 12 horas para que ocorresse uma pré-digestão. Após este período, os tubos foram colocados no bloco digestor a uma temperatura de $300^{\circ} \mathrm{C}$ por aproximadamente 35 minutos. Posteriormente, foi adicionado $1 \mathrm{ml}$ de $\mathrm{H}_{2} \mathrm{O}_{2}$ a $30 \%$ para completar a digestão do material. Após a adição deste reagente, os tubos foram levados novamente ao bloco digestor à $200^{\circ} \mathrm{C}$ por 15 minutos e tampados com pequenos funis de vidro, de modo a evitar um rápida evaporação da água oxigenada adicionada. Decorridos os quinze minutos, se o material ainda mantivesse a coloração amarelada, mais $1 \mathrm{ml} \mathrm{de} \mathrm{H}_{2} \mathrm{O}_{2}$ era adicionado; tal processo foi repetido até que se obtivesse uma coloração bem clara do extrato. No final desta etapa, os tubos foram mantidos no bloco digestor por mais 15 minutos sem os funis, para que houvesse uma completa evaporação da água oxigenada adicionada. Terminado o processo de digestão, o volume dos tubos foi completado para $25 \mathrm{ml}$ com água destilada e agitados. Um mililitro destes extratos foi transferido para outros tubos e o seu volume completado para $20 \mathrm{ml}$ com água destilada. A seguir, foram adicionadas $2,5 \mathrm{ml}$ de tartarato de $\mathrm{Na}$ a $10 \%$ e $2,5 \mathrm{ml}$ do reagente de Nessler. Este último reagente desenvolve no extrato uma coloração amarela proporcional ao conteúdo de $\mathrm{N}$-orgânico contido no mate- 
rial vegetal. Na sua preparação, foram dissolvidos em $100 \mathrm{ml}$ de água destilada, contidos em um Becker de $1000 \mathrm{ml}, 45,6 \mathrm{~g}$ de iodeto de mercúrio e $35 \mathrm{~g}$ de iodeto de potássio. A seguir, foram adicionados $112 \mathrm{~g}$ de $\mathrm{KOH}$ e $800 \mathrm{ml}$ de água destilada. Depois de agitada por dois minutos, a solução foi transferida para um balão de $1000 \mathrm{ml}$, deixada em repouso para esfriar e completado o volume. A solução foi posteriormente transferida para um copo de $2000 \mathrm{ml}$, onde permaneceu em repouso por três dias no escuro. Decorrido este período, o sobrenadante foi transferido para um frasco escuro para posterior utilização. Os extratos com o reagente de Nessler foram avaliados no espectrofotômetro Coleman Jr a $480 \mathrm{~nm}$, para a quantificação da intensidade da cor desenvolvida.

A determinação do $\mathrm{N}$-nítrico foi feita pelo método de CATALDO $e t$ alii (1975), com algumas modificações. Cem miligramas do tecido vegetal foram adicionados em tubos de ensaio contendo $250 \mathrm{ml}$ de carvão vegetal ativado e misturados. Após a adição de $10 \mathrm{ml}$ de água destilada, os tubos foram colocados em banho-maria à temperatura de $45^{\circ} \mathrm{C}$ durante 60 minutos. Decorrido este tempo, o material foi agitado e filtrado em papel de filtragem lenta. Dois mililitros do filtrado assim obtido foram colocados em outros tubos, que foram imersos em uma bandeja contendo água gelada. Lentamente, foi adicionado a cada tubo $0,8 \mathrm{ml}$ de ácido salicílico $5 \%$ em $\mathrm{H}_{2} \mathrm{SO}_{4}$, agitados e mantidos em repouso por 15 minutos. Posteriormente, mais $19 \mathrm{ml}$ de $\mathrm{NaOH}$ $2 \mathrm{~N}$ foram adicionados aos tubos que, após permanecerem em repouso por mais 30 minutos, tiveram o desenvolvimento da cor avaliada no espectrofotômetro em um comprimento de onda de $410 \mathrm{~nm}$. 
Os cálculos das concentrações de $\mathrm{N}$-orgânico e de $\mathrm{N}$-nítrico nas plantas foram feitos com a ajuda de equações de regressão obtidas de curvas padrões, relacionando concentrações crescentes e conhecidas destas duas formas de nitrogênio, com as leituras em absorbância obtidas no espectrofotômetro.

No experimento de Coimbra, as vagens foram avaliadas separadamente da parte aérea quanto ao teor de nitrogênio, também utilizando o método de Nessler.

Os dados foram avaliados estatisticamente pelo GLM, procedimento ANOVA do sistema SAS (Statistical Analysis System), versão 6.04 . 


\section{4 - RESULTADOS}

\section{1 - Experimento de Viçosa}

Os dados médios relativos à atividade da nitrogenase encontram-se na Tabela 1. Sua análise de variância revelou que foram significativos os efeitos de Mo (P $<0,01)$, $\mathrm{N}$ no plantio $(\mathrm{P}<0,01)$, épocas de avaliação $(\mathrm{P}<0,01)$ e as interações Mo $x$ N no plantio $(P<0,05)$ e Mo $x$ épocas de avaliação $(P<0,01)$. Não houve efeito significativo da inoculação nem da aplicação em cobertura do adubo nitrogenado.

A aplicação de $\mathrm{N}$ no plantio não afetou significativamente a atividade da nitrogenase, quando não houve aplicação foliar de molibdênio (Tabela 2). Com a aplicação desse micronutriente, porém, houve um aumento da atividade desta enzima, cuja magnitude foi afetada pela realização ou não da adubação nitrogenada no plantio. Com a associação de $0 \mathrm{~kg} / \mathrm{ha}$ de $\mathrm{N}$ no plantio e de $40 \mathrm{~g} / \mathrm{ha}$ de Mo houve um aumento de $181 \%$ na atividade da nitrogenase, enquanto a associação de $20 \mathrm{~kg} / \mathrm{ha}$ de $\mathrm{N}$ mais 40 g/ha de Mo trouxe um aumento de apenas $87 \%$ na sua atividade. 
Tabela 1 - Atividade da nitrogenase ( $\mu$ moles de $C_{2} \cdot H_{4} \cdot h^{-1} \cdot$ planta $\left.^{-1}\right)$, em Viçosa, MG.

\begin{tabular}{|c|c|c|c|c|c|c|c|}
\hline \multicolumn{4}{|c|}{ Tratamentos* } & \multicolumn{4}{|c|}{ Dias após a emergência } \\
\hline In & Mo & $\mathrm{Np}$ & $\mathrm{Nc}$ & 18 & 36 & 46 & 60 \\
\hline 0 & 0 & 0 & 0 & 3,59 & 2,34 & 4,59 & 0,79 \\
\hline 0 & 1 & 0 & 0 & 3,71 & 9,04 & 26,15 & 2,06 \\
\hline 0 & 0 & 1 & 0 & 0,62 & 0,45 & 1,53 & 0,20 \\
\hline 0 & 1 & 1 & 0 & 0,85 & 2,21 & 4,72 & 0,67 \\
\hline 0 & 0 & 0 & 1 & 4,97 & 3,92 & 5,12 & 0,14 \\
\hline 0 & 1 & 0 & 1 & 4,15 & 3,25 & 7,67 & 1,82 \\
\hline 0 & 0 & 1 & 1 & 1,76 & 2,08 & 3,81 & 0,32 \\
\hline 0 & 1 & 1 & 1 & 1,17 & 1,01 & 4,68 & 1,61 \\
\hline 1 & 0 & 0 & 0 & 5,41 & 2,07 & 4,52 & 0,31 \\
\hline 1 & 1 & 0 & 0 & 7,00 & 11,87 & 19,01 & 1,16 \\
\hline 1 & 0 & 1 & 0 & 1,93 & 3,00 & 4,75 & 0,75 \\
\hline 1 & 1 & 1 & 0 & 1,38 & 3,78 & 12,04 & 2,39 \\
\hline 1 & 0 & 0 & 1 & 5,26 & 1,34 & 2,37 & 0,33 \\
\hline 1 & 1 & 0 & 1 & 5,18 & 5,06 & 22,93 & 2,36 \\
\hline 1 & 0 & 1 & 1 & 3,30 & 2,54 & 2,97 & 0,51 \\
\hline 1 & 1 & 1 & 1 & 1,33 & 4,39 & 13,86 & 1,02 \\
\hline
\end{tabular}

(") 0 = ausência;

In = inoculação

Mo $=$ molibdênio
$1=$ presença

$\mathrm{Np}=$ nitrogênio no plantio

$\mathrm{Nc}=$ nitrogênio em cobertura 
O desdobramento da interação doses de Mo x épocas de avaliação revelou que, na presença daquele micronutriente, a atividade de nitrogenase apresentou uma resposta quadrática, com um máximo de atividade aos 40 dias (Figura 1). O período de máxima atividade da nitrogenase esteve, portanto, associado à aplicação de Mo, uma vez que na sua ausência ela manteve-se baixa (em média $2,42 \mu$ moles de $\mathrm{C}_{2} \mathrm{H}_{4} \cdot \mathrm{h}^{-1}$. planta ${ }^{-1}$ ) e praticamente constante durante todo o ciclo do feijoeiro.

A análise de variância dos dados de atividade específica da nitrogenase (Tabela 3) mostrou que foram significativos somente os efeitos de Mo $(\mathrm{P}<0,01)$, épocas de avaliação $(\mathrm{P}<0,01)$ e a interação Mo x épocas de avaliação $(\mathrm{P}<0,01)$.

Tabela 2 - Efeito da interação $\mathrm{N}$ no plantio $\mathrm{x}$ Mo sobre a atividade da nitrogenase ( $\mu$ moles de $\mathrm{C}_{2} \mathrm{H}_{4} \cdot \mathrm{h}^{-1}$. planta ${ }^{-1}$ ), em Viçosa, MG.*

\begin{tabular}{ccc}
\hline \hline Nitrogênio & \multicolumn{2}{c}{ Molibdênio } \\
\cline { 2 - 3 } no plantio & $0 \mathrm{~g} / \mathrm{ha}$ & $40 \mathrm{~g} / \mathrm{ha}$ \\
\hline $0 \mathrm{~kg} / \mathrm{ha}$ & $2,94 \mathrm{aB}$ & $8,28 \mathrm{aA}$ \\
$20 \mathrm{~kg} / \mathrm{ha}$ & $1,91 \mathrm{aB}$ & $3,57 \mathrm{bA}$ \\
\hline \hline
\end{tabular}

(*) Médias seguidas pela mesma letra minúscula, na vertical, e maiúscula, na horizontal, não diferem significativamente, pelo teste de Duncan, ao nível de $5 \%$. 
Atvidade da nitrogenase (umoles $\mathrm{C}_{2} \mathrm{H}_{4} \mathrm{~h}^{-1}$.planta ${ }^{-1}$ )

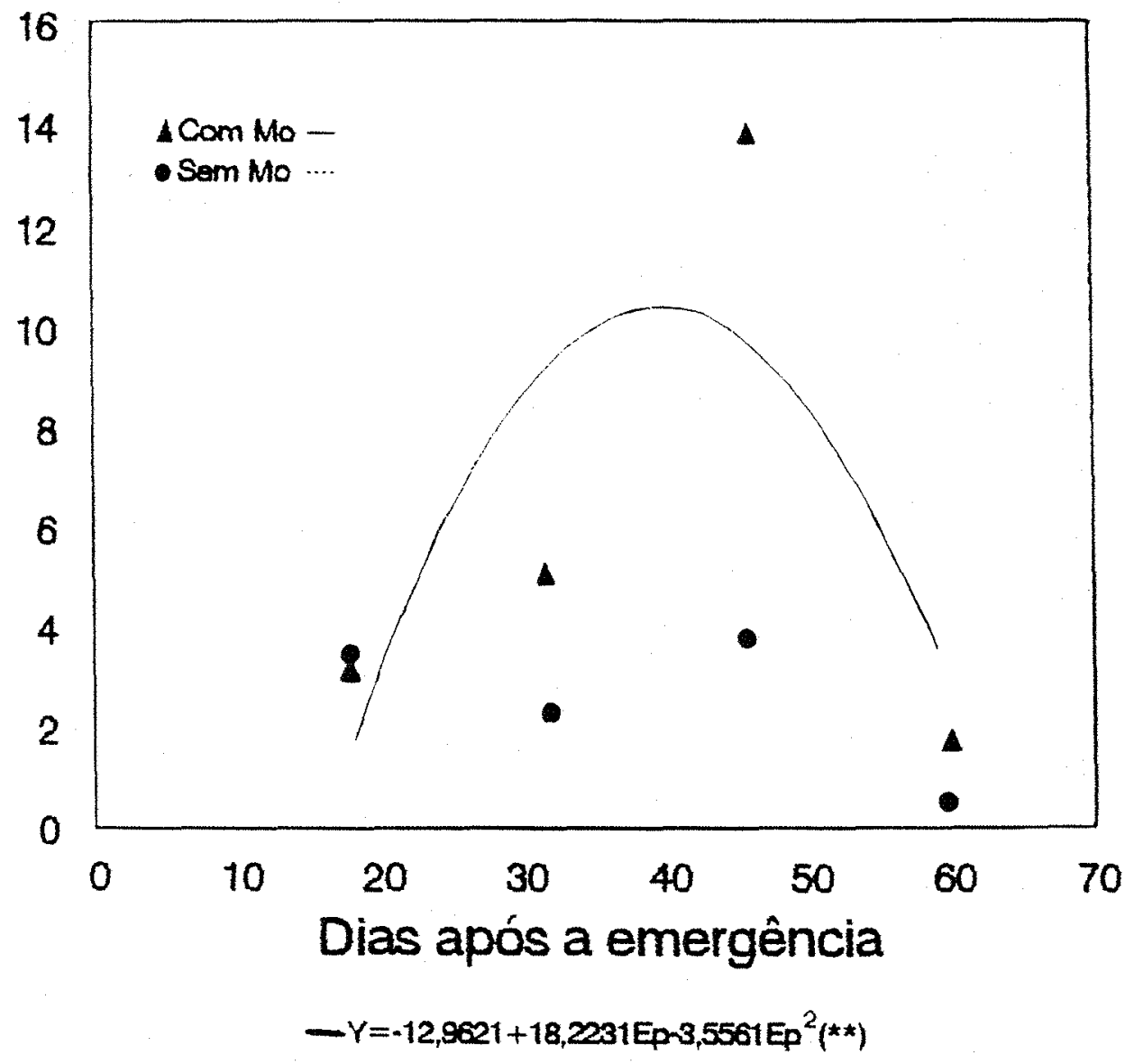

Figura 1 - Efeito de interação Mo x épocas de avaliação na atividade da nitrogenase ( $\mu$ moles de $\mathrm{C}_{2} \mathrm{H}_{4} \cdot \mathrm{h}^{-1}$. planta- ${ }^{-1}$ ), em Viçosa, MG.

$\left.{ }^{*}\right)$ No experimento de Viçosa, as equações de regressão foram obtidas dando-se às épocas os valores de 1, 2, 3, 4 e não 18, 32, 46 e 60 dias. 
Tabela 3 - Atividade específica da nitrogenase $\left(\mu\right.$ moles de $\mathrm{C}_{2} \mathrm{H}_{4} \cdot \mathrm{h}^{-1}$. g. de nódulo $\left.{ }^{-1}\right)$, em Viçosa, MG.

\begin{tabular}{ccccccccc}
\hline \hline & \multicolumn{3}{c}{ Tratamentos* } & & \multicolumn{4}{c}{ Dias após a emergência } \\
\cline { 1 - 2 } \cline { 7 - 9 } In & Mo & Np & Nc & & 18 & 32 & 46 & 60 \\
\hline 0 & 0 & 0 & 0 & & 59,04 & 29,34 & 36,82 & 11,26 \\
0 & 1 & 0 & 0 & & 60,00 & 111,54 & 130,11 & 27,67 \\
0 & 0 & 1 & 0 & & 57,24 & 29,80 & 19,50 & 15,91 \\
0 & 1 & 1 & 0 & & 39,59 & 67,27 & 79,05 & 24,19 \\
0 & 0 & 0 & 1 & & 62,11 & 30,83 & 34,14 & 6,01 \\
0 & 1 & 0 & 1 & & 62,85 & 64,91 & 88,96 & 55,08 \\
0 & 0 & 1 & 1 & & 54,43 & 30,04 & 28,15 & 8,91 \\
0 & 1 & 1 & 1 & & 96,57 & 52,63 & 84,12 & 33,38 \\
1 & 0 & 0 & 0 & & 64,46 & 27,14 & 27,81 & 19,26 \\
1 & 1 & 0 & 0 & & 64,99 & 77,35 & 117,12 & 35,45 \\
1 & 0 & 1 & 0 & & 51,46 & 44,33 & 27,60 & 3,91 \\
1 & 1 & 1 & 0 & & 51,52 & 75,00 & 98,29 & 30,02 \\
1 & 0 & 0 & 1 & & 60,47 & 23,85 & 33,99 & 10,40 \\
1 & 1 & 0 & 1 & & 63,62 & 61,01 & 94,71 & 31,40 \\
1 & 0 & 1 & 1 & & 93,49 & 43,15 & 22,95 & 22,87 \\
1 & 1 & 1 & 1 & & 40,69 & 68,46 & 92,37 & 30,90 \\
\hline \hline
\end{tabular}

$\left.{ }^{*}\right) 0$ = ausência;

In $=$ inoculação

Mo $=$ molibdênio
$1=$ presença

$\mathrm{Np}=$ nitrogênio no plantio

$\mathrm{Nc}=$ nitrogênio em cobertura 
$\mathrm{Na}$ ausência de Mo, a atividade especifica da nitrogenase apresentou uma resposta linear decrescente em relação às épocas de avaliação; com a aplicação foliar de Mo, a resposta passou a ser quadrática, atingindo a máxima atividade aos 38 dias (Figura 2). Nesta época, esta atividade foi $149,46 \%$ maior que a obtida no tratamento sem aplicação de molibdênio. Aos 60 dias, embora um declínio de $53 \%$ ocorresse em relação à média feita na época anterior, o resultado obtido $\left(38,69 \mu\right.$ moles de $\mathrm{C}_{2} \mathrm{H}_{4} \cdot \mathrm{g}$. de nódulo ${ }^{-1}$ ) correspondeu praticamente aos conseguidos entre os 32 e 46 dias de idade no tratamento sem aplicação foliar de molibdênio.

Em relação ao número de nódulos por planta (Tabela 4), houve efeito significativo de Mo $(\mathrm{P}<0,01)$, do $\mathrm{N}$ no plantio $(\mathrm{P}<0,05)$, das épocas de avaliação $(\mathrm{P}<0,01)$ e da interação Mo x épocas de avaliação $(\mathrm{P}<0,01)$.

A aplicação de $20 \mathrm{~kg} /$ ha de $\mathrm{N}$ no plantio causou um decréscimo de $23 \%$ no número de nódulos, em comparação aos tratamentos que não receberam esta adubação nitrogenada. Todas as plantas inoculadas ou não apresentaram formação de nódulos, demonstrando a presença no terreno utilizado de bactérias fixadoras de $\mathrm{N}_{2}$ nativas.

Tanto na ausência como na presença de Mo, houve uma resposta quadrática do número de nódulos em relação às épocas de avaliação (Figura 3). Na ausência do micronutriente, o número de nódulos foi similar ao dos tratamentos com Mo somente até aos 18 dias; a partir desta época, observou-se um aumento de $23 \%, 35 \%$ e $57 \%$, aos 32, 46 e 60 dias, respectivamente, nos tratamentos que não receberam Mo em relação aos adubados foliarmente com este micronutriente. Na ausência de Mo, apesar 


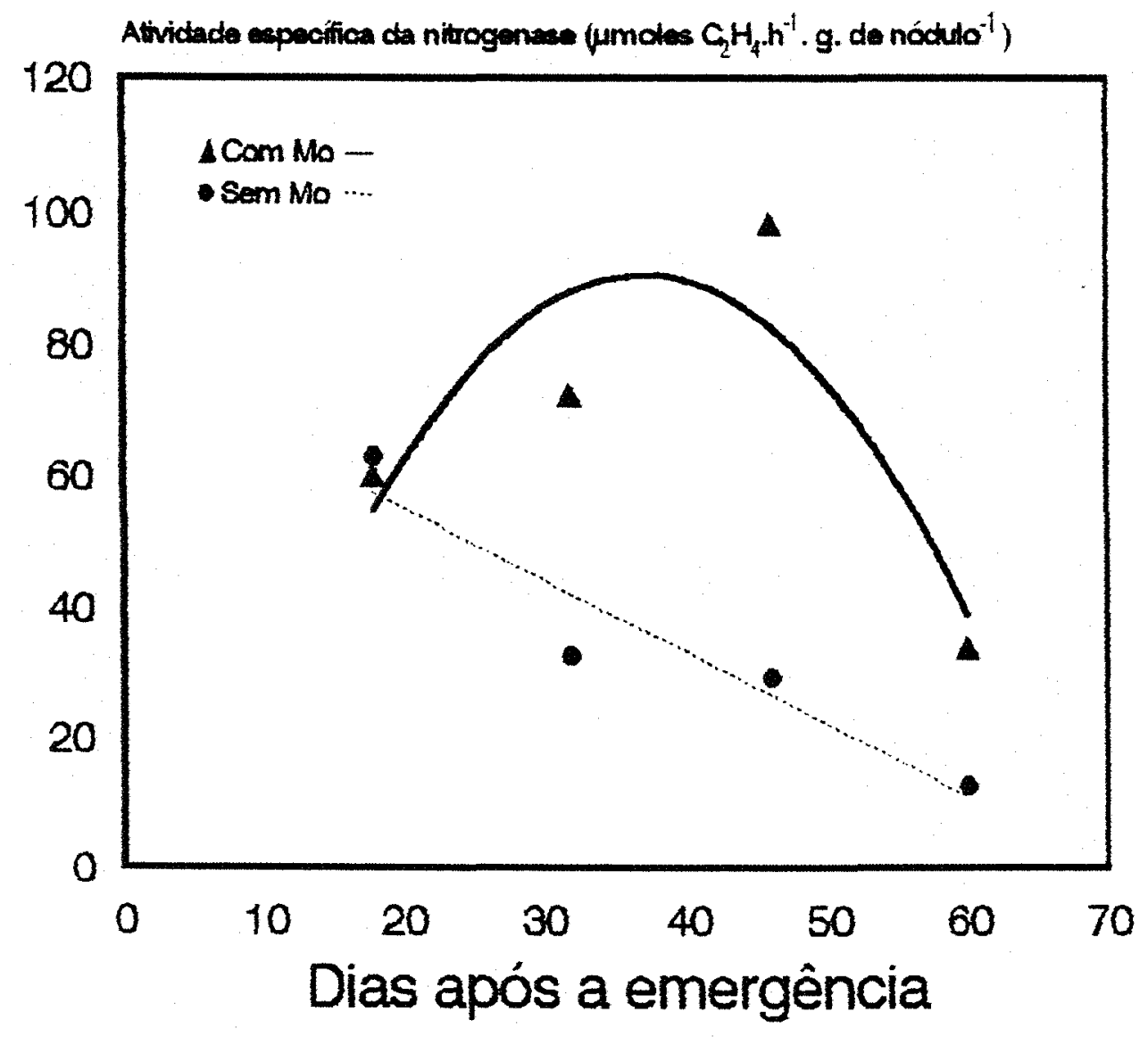

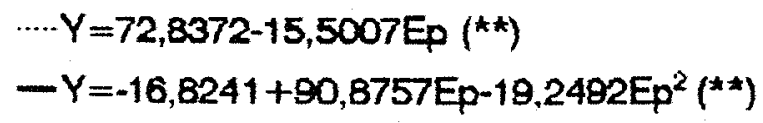

Figura 2 - Efeito da interação Mo x épocas de avaliação na atividade específica da nitrogenase ( $\mu$ moles $\mathrm{C}_{2} \mathrm{H}_{4} \cdot \mathrm{h}^{-1}$. g. de nódulo ${ }^{-1}$ ), em Viçosa, MG. 
Tabela 4 - Número de nódulos.planta ${ }^{-1}$, em Viçosa, MG.

\begin{tabular}{|c|c|c|c|c|c|c|c|}
\hline \multicolumn{4}{|c|}{ Tratamentos* } & \multicolumn{4}{|c|}{ Dias após a emergência } \\
\hline In & Mo & $\mathrm{Np}$ & $\mathrm{Nc}$ & 18 & 32 & 46 & 60 \\
\hline 0 & 0 & 0 & 0 & 46,25 & 75,87 & 105,69 & 96,00 \\
\hline 0 & 1 & 0 & 0 & 48,99 & 95,88 & 92,81 & 43,44 \\
\hline 0 & 0 & 1 & 0 & 14,50 & 33,31 & 69,25 & 47,75 \\
\hline 0 & 1 & 1 & 0 & 22,67 & 38,12 & 34,62 & 22,37 \\
\hline 0 & 0 & 0 & 1 & 46,67 & 89,31 & 112,62 & 36,69 \\
\hline 0 & 1 & 0 & 1 & 45,58 & 63,06 & 66,75 & 33,44 \\
\hline 0 & 0 & 1 & 1 & 34,67 & 72,06 & 117,69 & 45,31 \\
\hline 0 & 1 & 1 & 1 & 21,92 & 31,52 & 41,50 & 22,25 \\
\hline 1 & 0 & 0 & 0 & 50,92 & 65,19 & 181,50 & 72,87 \\
\hline 1 & 1 & 0 & 0 & 60,25 & 106,81 & 91,06 & 29,00 \\
\hline 1 & 0 & 1 & 0 & 28,33 & 78,87 & 155,94 & 135,12 \\
\hline 1 & 1 & 1 & 0 & 25,25 & 56,31 & 70,19 & 44,62 \\
\hline 1 . & 0 & 0 & 1 & 54,92 & 66,69 & 85,12 & 51,12 \\
\hline 1 & 1 & 0 & 1 & 51,50 & 79,37 & 82,30 & 34,62 \\
\hline 1 & 0 & 1 & 1 & 40,33 & 95,31 & 105,56 & 63,94 \\
\hline 1 & 1 & 1 & 1 & 30,83 & 54,12 & 67,50 & 21,12 \\
\hline
\end{tabular}

$\left.{ }^{*}\right) 0$ = ausência

In = inoculação

Mo = molibdênio
$1=$ presença

$\mathrm{Np}=$ nitrogênio no plantio

$\mathrm{Nc}=$ nitrogênio em cobertura 


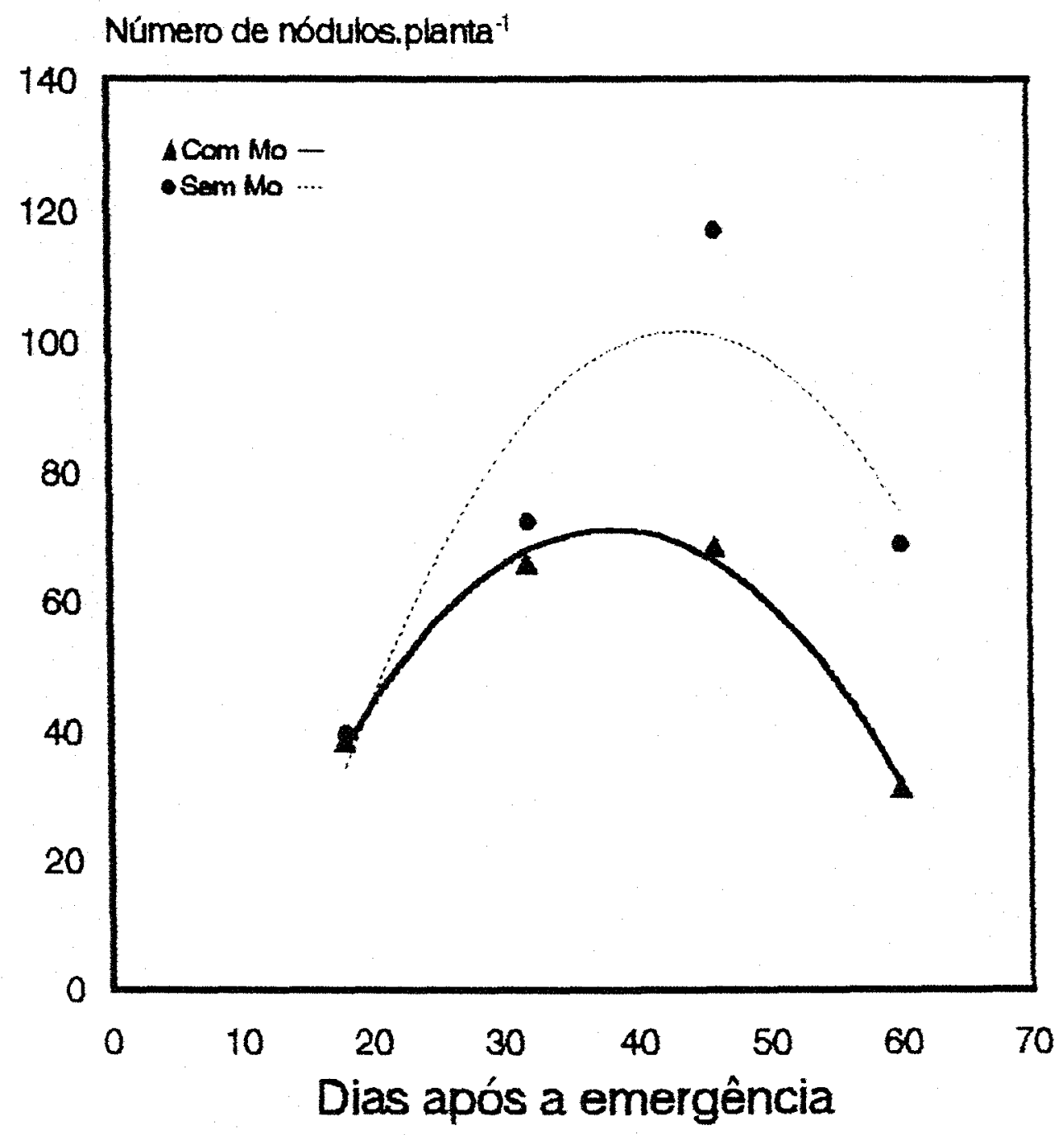

$\cdots Y=-59,4063+113,8861 \mathrm{Ep}-20,1437 \mathrm{Ep}^{2}($ tk)

$-Y=-24,8962+78,6073 E p-16,0962 E p^{2}(k *)$

Figura 3 - Efeito de interação Mo x épocas de avaliação no número de nódulos.planta ${ }^{-1}$, em Viçosa, MG. 
do número máximo de nódulos ter sido obtido aos 45 dias, mesmo aos 60 dias ele foi alto, comparativamente ao tratamento que recebeu o micronutriente (Figura 3). A aplicação foliar de $40 \mathrm{~g} / \mathrm{ha}$ de $\mathrm{Mo}$ fez com que o número máximo de nódulos ocorresse já aos 39 dias, mantendo-se até os 46 dias e sofendo então um forte declínio. Conforme exposto anteriormente, os maiores valores de atividade da nitrogenase foram obtidos com a aplicação foliar de Mo, não estando, portanto, o número de nódulos relacionado diretamente com a atividade dessa enzima.

A análise de variância dos pesos de nódulos secos revelou que foram significativos os efeitos de inoculação $(P<0,05), N$ no plantio $(P<0,01)$, épocas de avaliação $(\mathrm{P}<0,01)$ e $\mathrm{N}$ no plantio $\mathrm{x}$ épocas de avaliação $(\mathrm{P}<0,01)$. Não houve portanto, efeito do Mo sobre os pesos dos nódulos secos. Os dados médios relativos a este parâmetro encontram-se na Tabela 5 .

Contrariamente aos resultados obtidos com o número de nódulos, a inoculação afetou os pesos dos nódulos secos. As plantas inoculadas com estirpes selecionadas de Rhizobium apresentaram peso médio de nódulos secos $30 \%$ maior que o obtido com as plantas noduladas com estirpes nativas.

O peso de nódulos, ao longo do ciclo do feijoeiro, foi também afetado pela aplicação de $\mathrm{N}$ no plantio; tanto na presença como na ausência desta adubação houve uma resposta quadrática desse parâmetro em relação às épocas de avaliação (Figura 4). A aplicação de $20 \mathrm{~kg} /$ ha de $\mathrm{N}$ diminuiu o peso dos nódulos em $72,43,32$ e $0 \%$, respectivamente, aos $18,32,46$ e 60 dias, em relação aos tratamentos sem aplicação de 
Tabela 5 - Peso dos nódulos secos (mg/planta), em Viçosa, MG.

\begin{tabular}{|c|c|c|c|c|c|c|c|}
\hline \multicolumn{4}{|c|}{ Tratamentos* } & \multicolumn{4}{|c|}{ Dias após a emergência } \\
\hline In & Mo & $\mathrm{Np}$ & $\mathrm{Nc}$ & 18 & 32 & 46 & 60 \\
\hline 0 & 0 & 0 & 0 & 18,70 & 30,71 & 50,23 & 50,85 \\
\hline 0 & 1 & 0 & 0 & 17,93 & 52,85 & 78,28 & 42,86 \\
\hline 0 & 0 & 1 & 0 & 3,55 & 7,83 & 29,19 & 16,42 \\
\hline 0 & 1 & 1 & 0 & 5,22 & 12,63 & 23,31 & 24,61 \\
\hline 0 & 0 & 0 & 1 & 24,81 & 53,85 & 43,59 & 14,56 \\
\hline 0 & 1 & 0 & 1 & 27,13 & 27,85 & 37,46 & 22,69 \\
\hline 0 & 0 & 1 & 1 & 10,02 & 25,27 & 50,14 & 20,91 \\
\hline 0 & 1 & 1 & 1 & 4,00 & 8,85 & 19,16 & 21,57 \\
\hline 1 & 0 & 0 & 0 & 27,24 & 44,28 & 72,09 & 32,17 \\
\hline 1 & 1 & 0 & 0 & 37,48 & 78,88 & 80,30 & 25,24 \\
\hline 1 & 0 & 1 & 0 & 11,42 & 35,94 & 72,13 & 74,81 \\
\hline 1 & 1 & 1 & 0 & 7,90 & 24,33 & 53,77 & 43,73 \\
\hline 1 & 0 & 0 & 1 & 28,89 & 27,93 & 32,44 & 22,48 \\
\hline 1 & 1 & 0 & 1 & 24,79 & 41,25 & 81,27 & 31,30 \\
\hline 1 & 0 & 1 & 1 & 14,62 & 41,41 & 43,07 & 29,58 \\
\hline 1 & 1 & 1 & 1 & 13,19 & 27,65 & 59,17 & 20,17 \\
\hline
\end{tabular}

$\left.{ }^{*}\right) 0$ = ausência;

In = inoculação

Mo $=$ molibdênio
$1=$ presença

$\mathrm{Np}=$ nitrogênio no plantio

$\mathrm{Nc}=$ nitrogênio em cobertura 
Peso dos nódulos secos (mg/planta)

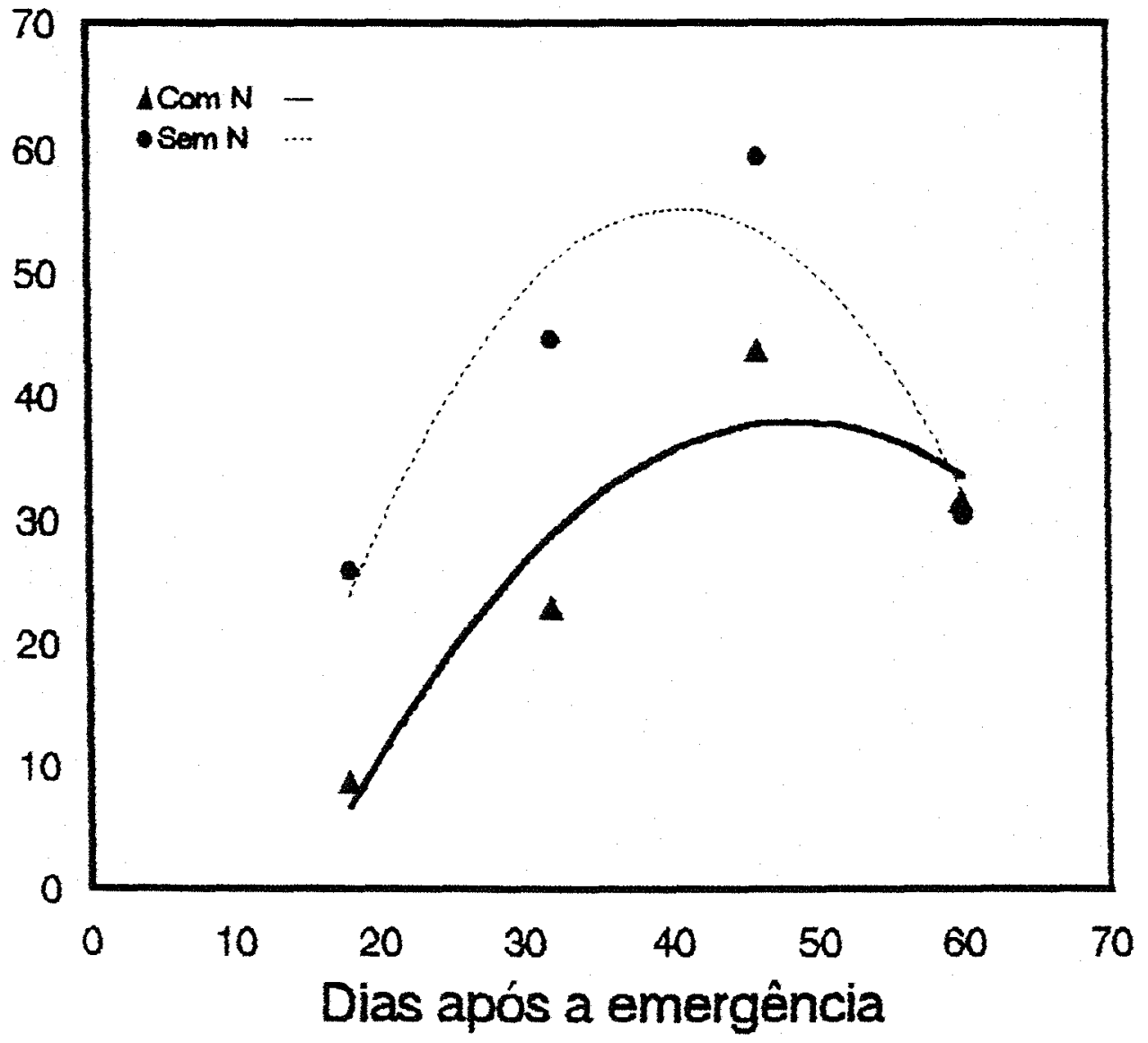

‥ $Y=-26,0382+62,8213 E p-12,0051 E p^{2}\left({ }^{* t}\right)$

$-Y=-28,6434+42,00835 p-6,6286 p^{2}(k *)$

Figura 4 - Efeito da interação $\mathrm{N}$ no plantio $\mathrm{x}$ épocas de avaliação no peso dos nódulos secos (mg/planta), em Viçosa, MG. 
$\mathrm{N}$ no plantio. $\mathrm{Na}$ ausência de $\mathrm{N}$ no plantio, o peso máximo dos nódulos foi obtido aos 42 dias de idade, enquanto que na sua presença o peso máximo foi obtido aos 51 dias de idade (Figura 4).

A Tabela 6 apresenta os dados médios relativos à atividade da redutase do nitrato nos vários tratamentos utilizados. A análise de variância desses dados mostrou que foram significativos os efeitos de Mo $(\mathrm{P}<0,01)$, épocas de avaliação $(\mathrm{P}<0,01)$ e a interação Mo $\mathrm{x}$ épocas de avaliação $(\mathrm{P}<0,01)$. $\mathrm{O}$ efeito benéfico da aplicação foliar de Mo sobre a atividade da redutase do nitrato foi, portanto, independente da aplicação de $\mathrm{N}$ ao solo, no plantio, em cobertura ou associados.

Houve resposta quadrática da atividade da redutase do nitrato, em relação às épocas de avaliação, tanto na ausência como na presença de molibdênio (Figura 5). Conforme verificado na análise de atividade da nitrogenase, o período de alta atividade da redutase do nitrato, durante o ciclo do feijoeiro, dependeu da aplicação foliar de molibdênio. Nos tratamentos que não receberam o micronutriente, a máxima atividade da redutase foi obtida aos 18 dias após a emergência da planta, reduzindo-se em cerca de $46 \%$, aos 32 e 46 dias. Aos 60 dias, houve um novo aumento da sua atividade, atingindo cerca de $74 \%$ da atividade obtida aos 18 dias. Com a aplicação foliar de Mo, a atividade mais elevada foi atingida aos 60 dias de idade. Nas duas épocas intermediárias a atividade manteve-se praticamente constante e $13 \%$ menor que a obtida aos 18 dias. 
Tabela 6 - Atividade da redutase do nitrato $\left(\mu\right.$ moles de $\mathrm{NO}_{2} \cdot \mathrm{h}^{-1}$. g. de matéria fresca $^{-1}$ ), em Viçosa, MG.

\begin{tabular}{|c|c|c|c|c|c|c|c|}
\hline \multicolumn{4}{|c|}{ Tratamentos* } & \multicolumn{4}{|c|}{ Dias após a emergência } \\
\hline In & Mo & $\mathrm{Np}$ & $\mathrm{Nc}$ & 18 & 32 & 46 & 60 \\
\hline 0 & 0 & 0 & 0 & 8,51 & 3,80 & 4,24 & 5,63 \\
\hline 0 & 1 & 0 & 0 & 5,36 & 3,27 & 5,17 & 5,74 \\
\hline 0 & 0 & 1 & 0 & 4,85 & 6,12 & 4,08 & 6,91 \\
\hline 0 & 1 & 1 & 0 & 5,01 & 4,65 & 4,06 & 7,69 \\
\hline 0 & 0 & 0 & 1 & 4,55 & 2,86 & 3,69 & 5,21 \\
\hline 0 & 1 & 0 & 1 & 3,95 & 5,20 & 6,47 & 6,02 \\
\hline 0 & 0 & 1 & 1 & 7,32 & 3,07 & 3,90 & 4,10 \\
\hline 0 & 1 & 1 & 1 & 6,70 & 5,54 & 5,73 & 5,41 \\
\hline 1 & 0 & 0 & 0 & 4,98 & 2,36 & 2,64 & 3,75 \\
\hline 1 & 1 & 0 & 0 & 6,75 & 3,86 & 3,66 & 7,17 \\
\hline 1 & 0 & 1 & 0 & 8,88 & 1,68 & 2,75 & 3,51 \\
\hline 1 & 1 & 1 & 0 & 6,00 & 4,22 & 5,31 & 6,54 \\
\hline 1 & 0 & 0 & 1 & 6,16 & 4,34 & 2,54 & 4,85 \\
\hline 1 & 1 & 0 & 1 & 4,19 & 5,84 & 5,17 & 7,52 \\
\hline 1 & 0 & 1 & 1 & 6,88 & 5,13 & 3,19 & 3,94 \\
\hline 1 & 1 & 1 & 1 & 6,00 & 3,16 & 4,95 & 5,26 \\
\hline
\end{tabular}

$\left(^{*}\right) 0 \quad=$ ausência;

In $=$ inoculação

Mo $=$ molibdênio
$1=$ presença

$\mathrm{Np}=$ nitrogênio no plantio

$\mathrm{Nc}=$ nitrogênio em cobertura 

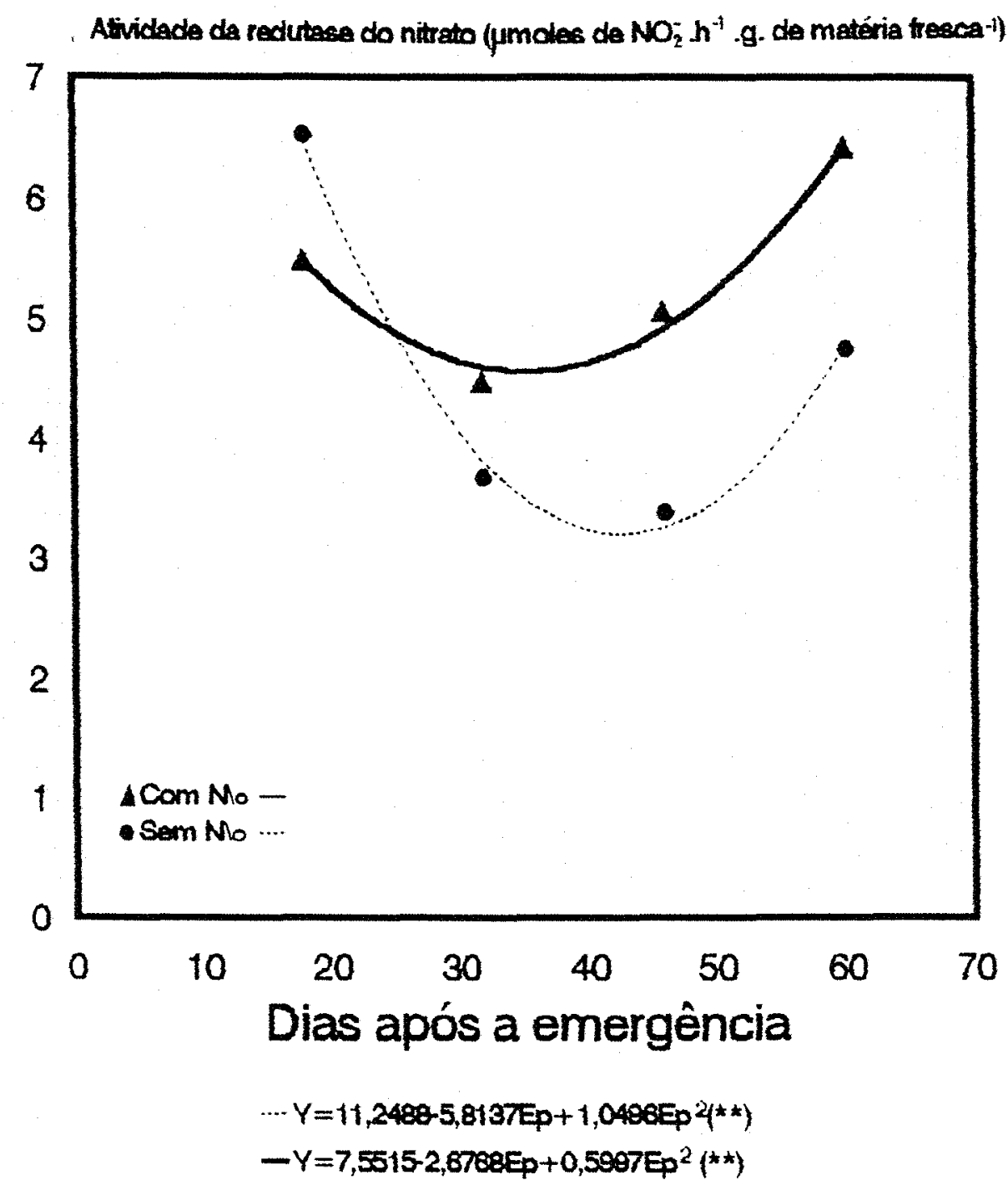

Figura 5 - Efeito da interação Mo x épocas de avaliação na atividade da redutase do nitrato $\left(\mu\right.$ moles de $\mathrm{NO}_{2}{ }^{*} \cdot h^{-1}$. g. de matéria fresca $\left.{ }^{-1}\right)$, em Viçosa, MG. 
A maior diferença na atividade da redutase do nitrato, entre os tratamentos que receberam ou não adubação foliar de Mo, foi aos 46 e 60 dias. Neste período a pulverização do micronutriente nas plantas fez com que a atividade aumentasse em 51 e 34\%, respectivamente, em relação ao tratamento sem Mo. A aplicação foliar de Mo fez, portanto, com que fosse ampliado o período de alta atividade desta enzima, durante o ciclo do feijoeiro.

O ponto de mínima atividade da redutase do nitrato foi obtido aos 44 dias nas plantas que não receberam $\mathrm{Mo}$, e aos 36 dias nas plantas pulverizadas com o micronutriente (Figura 5).

A análise de variância dos dados de percentagem de $\mathrm{N}$-amoniacal na parte aérea (Tabela 7) revelou que foram significativos os efeitos de Mo $(\mathrm{P}<0,01)$, épocas de avaliação $(\mathrm{P}<0,01)$ e as interaçōes Mo $\mathrm{x}$ épocas de avaliação $(\mathrm{P}<0,01)$, $\mathrm{N}$ no plantio $\mathrm{x}$ épocas de avaliação $(\mathrm{P}<0,01)$ e do $\mathrm{N}$ em cobertura $\mathrm{x}$ épocas de avaliação $(\mathrm{P}<0,01)$.

Na ausência da aplicação foliar de Mo, houve uma resposta linear decrescente da percentagem de $\mathrm{N}$-amoniacal na parte aérea enquanto na sua presença a resposta foi quadrática (Figura 6). No início do ciclo do feijoeiro, ou seja, até aos 32 dias de idade, praticamente não houve efeito do Mo sobre a percentagem de $\mathrm{N}$ na parte aérea. Esta percentagem foi, porém, aumentada em $10 \%$ e $18 \%$, respectivamente, aos 46 e 60 dias de idade nos tratamentos com Mo, em relação aos que não o receberam. 
Tabela 7 - Percentagem de $\mathrm{N}$-amoniacal na parte aérea, em Viçosa, MG.

\begin{tabular}{|c|c|c|c|c|c|c|c|}
\hline \multicolumn{4}{|c|}{ Tratamentos* } & \multicolumn{4}{|c|}{ Dias após a emergência } \\
\hline In & Mo & $\mathrm{Np}$ & $\mathrm{Nc}$ & 18 & 32 & 46 & 60 \\
\hline 0 & 0 & 0 & 0 & 4,13 & 3,54 & 2,62 & 2,05 \\
\hline 0 & 1 & 0 & 0 & 4,25 & 3,43 & 3,24 & 2,09 \\
\hline 0 & 0 & 1 & 0 & 4,47 & 3,54 & 2,93 & 2,11 \\
\hline 0 & 1 & 1 & 0 & 4,52 & 3,73 & 3,01 & 2,27 \\
\hline 0 & 0 & 0 & 1 & 4,24 & 3,43 & 2,78 & 2,24 \\
\hline 0 & 1 & 0 & 1 & 4,07 & 3,78 & 3,06 & 2,17 \\
\hline 0 & 0 & 1 & 1 & 4,34 & 3,78 & 2,83 & 2,01 \\
\hline 0 & 1 & 1 & 1 & 4,33 & 4,06 & 3,11 & 2,52 \\
\hline 1 & 0 & 0 & 0 & 4,21 & 3,05 & 2,65 & 2,04 \\
\hline 1 & 1 & 0 & 0 & 4,13 & 3,46 & 3,02 & 2,23 \\
\hline 1 & 0 & 1 & 0 & 4,26 & 3,49 & 2,43 & 1,70 \\
\hline 1 & 1 & 1 & 0 & 4,42 & 3,47 & 3,04 & 2,24 \\
\hline 1 & 0 & 0 & 1 & 3,98 & 3,75 & 2,93 & 2,03 \\
\hline 1 & 1 & 0 & 1 & 4,02 & 3,48 & 3,20 & 2,19 \\
\hline 1 & 0 & 1 & 1 & 3,98 & 3,51 & 2,68 & 2,11 \\
\hline 1 & 1 & 1 & 1 & 4,41 & 3,78 & 3,05 & 2,34 \\
\hline
\end{tabular}

(*) 0 = ausência;

In = inoculação

Mo = molibdênio
$1=$ presença

$\mathrm{Np}=$ nitrogênio no plantio

$\mathrm{Nc}=$ nitrogênio em cobertura 


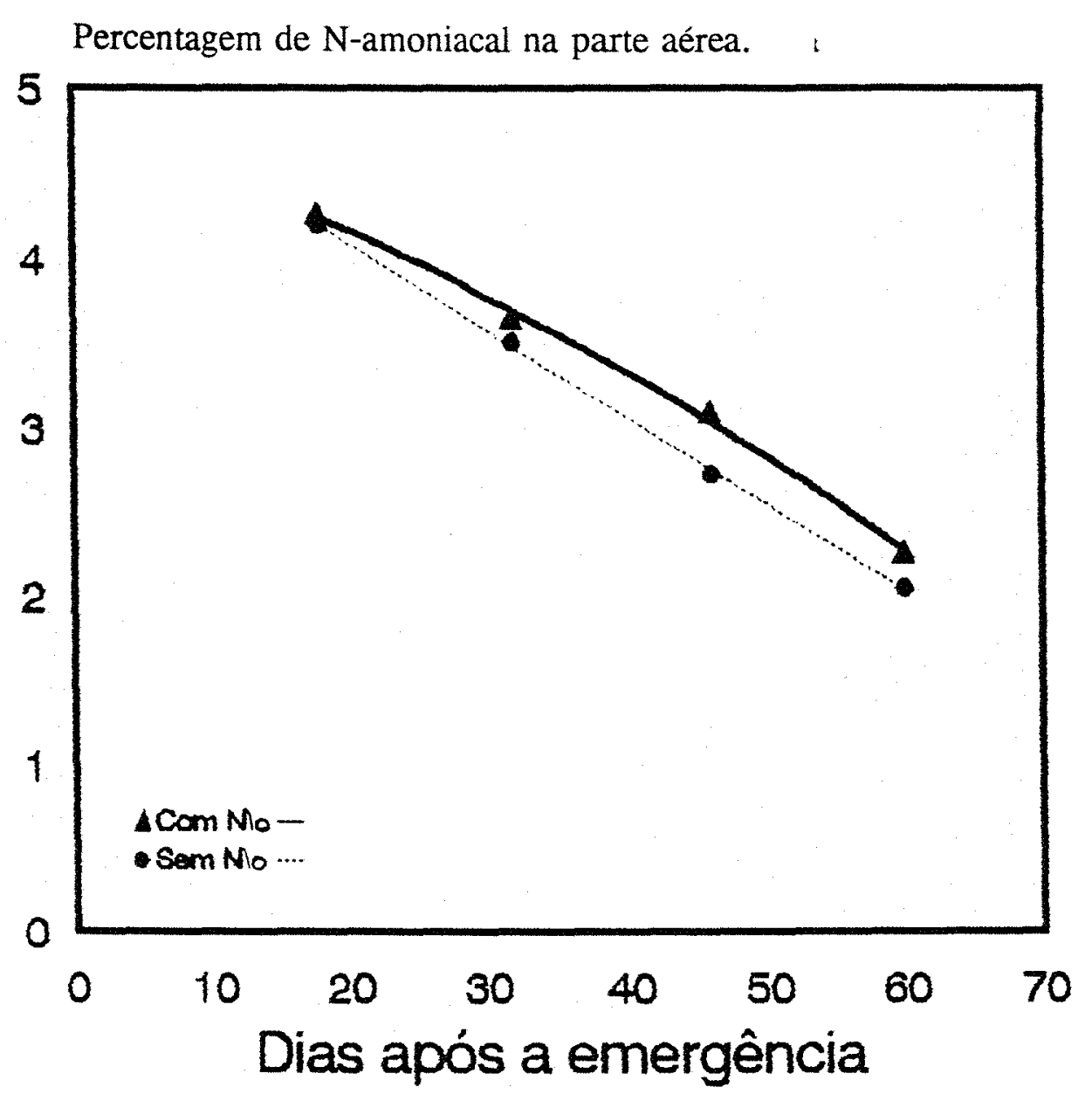

$Y=4,9367-0,7265 \mathrm{Ep}\left(^{\star \star}\right)$
$-Y=4,6994-0,3931 \mathrm{Ep}-0,0533 \mathrm{Ep}{ }^{2}\left({ }^{\star}\right)$

Figura 6 - Efeito da interação Mo $\mathrm{x}$ épocas de avaliação na percentagem de $\mathrm{N}$ amoniacal na parte aérea, em Viçosa, MG. 
Houve também uma resposta linear decrescente da percentagem de $\mathrm{N}$ amoniacal na parte aérea, em relação à presença ou não de $\mathrm{N}$ no plantio (Figura 7). Quanto à aplicação de $\mathrm{N}$ em cobertura a resposta foi linear na sua ausência e quadrática na sua presença (Figura 8). Conforme se verifica nas Figuras 7 e 8 , a adição de $20 \mathrm{~kg}$ de $\mathrm{N}$ no plantio, ou de $30 \mathrm{~kg}$ de $\mathrm{N}$ em cobertura, fez com que fosse maior a percentagem de $\mathrm{N}$-amoniacal na parte aérea ao longo do ciclo do feijoeiro.

Quanto à quantidade total de $\mathrm{N}$-amoniacal na parte aérea (Tabela 8), a análise de variância mostrou efeito significativo de $\mathrm{Mo}(\mathrm{P}<0,01)$, do $\mathrm{N}$ no plantio $(\mathrm{P}<0,01)$, das épocas de avaliação $(\mathrm{P}<0,01)$ e das interações Mo $\mathrm{x}$ épocas de avaliação $(\mathrm{P}<0,01)$ e $\mathrm{N}$ no plantio $\mathrm{x}$ épocas de avaliação $(\mathrm{P}<0,05)$.

Houve resposta quadrática na quantidade de $\mathrm{N}$-amoniacal da parte aérea, tanto na presença como na ausência da aplicação foliar de molibdênio. Aos 46 e 60 dias a quantidade total de $\mathrm{N}$-amoniacal na parte aérea foi, em média, $26 \%$ maior nas plantas que receberam pulverização com o micronutriente (Figura 9).

A máxima quantidade de $\mathrm{N}$-amoniacal na parte aérea das plantas que não receberam Mo foi atingida aos 62 dias de idade, enquanto que, naquelas sujeitas à aplicação foliar do nutriente, a Figura 9 sugere um ponto de máximo bem mais tardio.

A aplicação de $\mathrm{N}$ no plantio causou um aumento na quantidade total de $\mathrm{N}$ amoniacal na parte aérea, que se acentuou com o decorrer do ciclo do feijoeiro, em relação ao tratamento isento desta adubação, independentemente da aplicação ou não do molibdênio (Figura 10). 
Percentagem de $\mathrm{N}$-amoniacal na parte aérea.

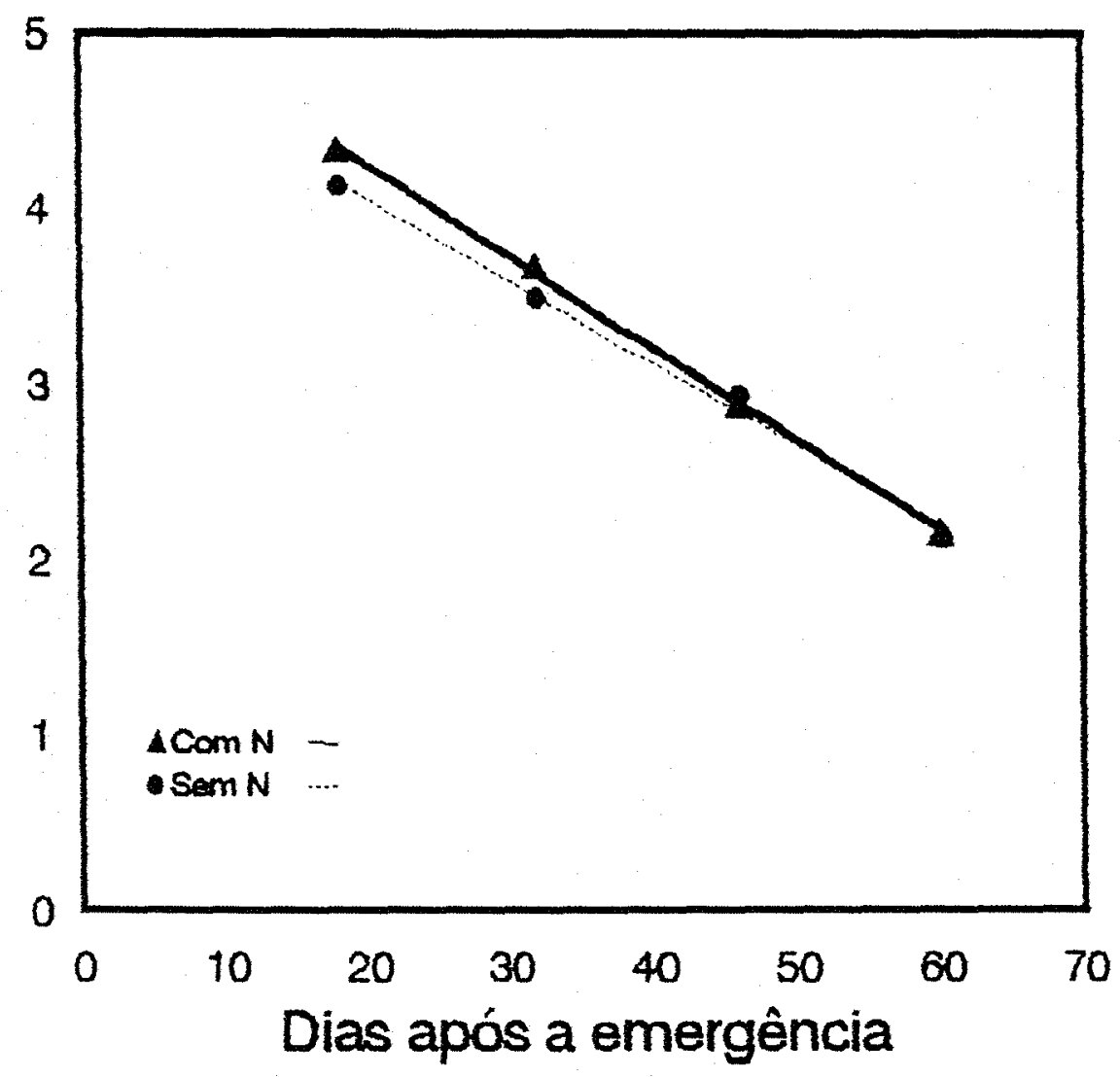

$$
\begin{aligned}
& \cdots \cdot Y=4,8000-0,6548 \mathrm{Ep}\left(^{\star \star}\right) \\
& -Y=5,00000,7316 \mathrm{Ep}\left(^{\star \star}\right)
\end{aligned}
$$

Figura 7 - Efeito da interação $\mathrm{N}$ no plantio $\mathrm{x}$ épocas de avaliação na percentagem de $\mathrm{N}$-amoniacal na parte aérea, em Viçosa, $\mathrm{MG}$. 
Percentagem de $\mathrm{N}$-amoniacal na parte aérea.

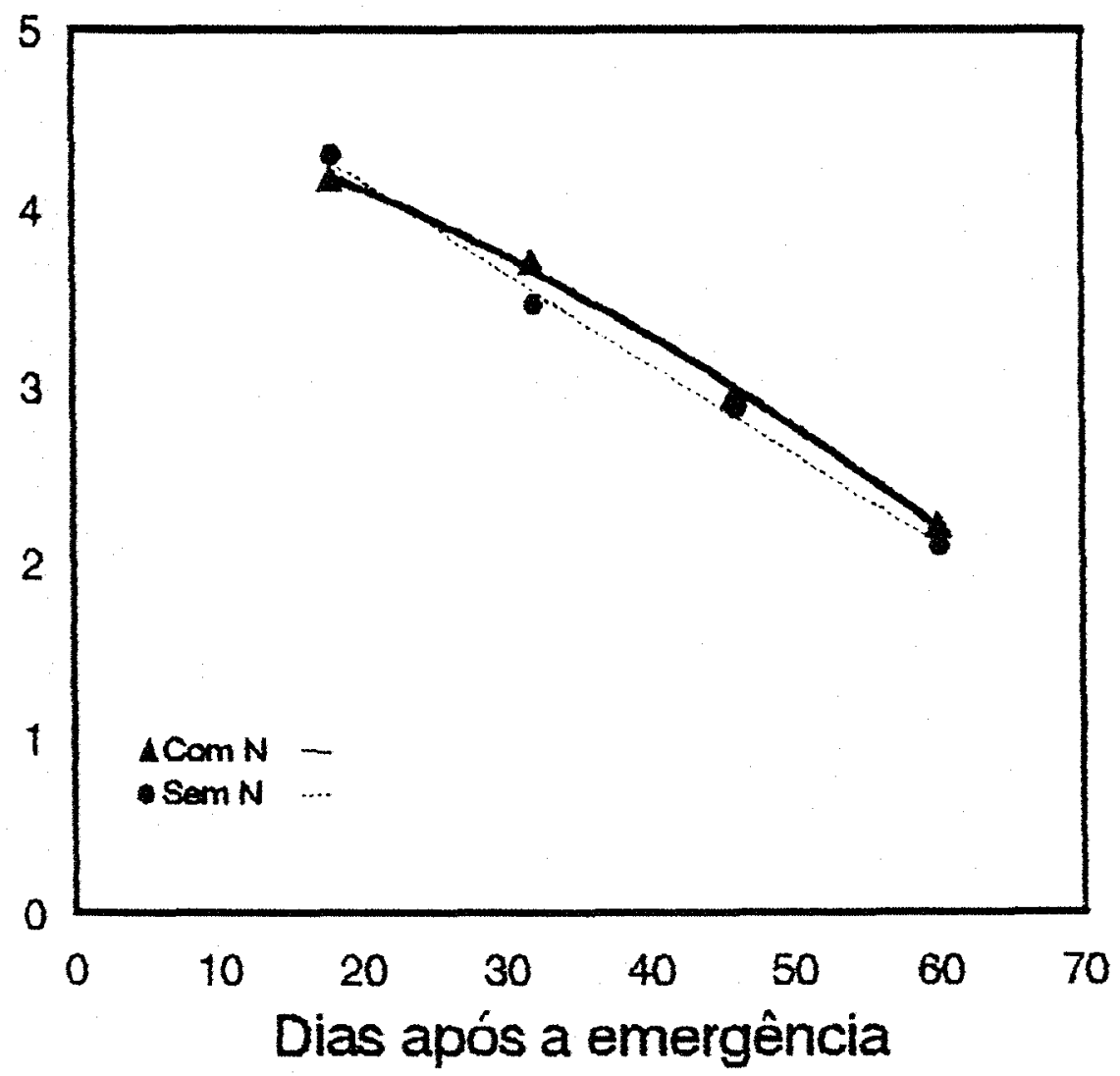

$$
\begin{aligned}
& \cdots Y=4,9864-0,7221 E p\left({ }^{\star \star}\right) \\
& -Y=4,5771-0,3248 E \mathrm{p}-0,0679 \mathrm{Ep}^{2}{ }^{2}(\star)
\end{aligned}
$$

Figura 8 - Efeito da interação $\mathrm{N}$ em cobertura $\mathrm{x}$ épocas de avaliação na percentagem de $\mathrm{N}$-amoniacal na parte aérea, em Viçosa, MG. 
Tabela 8 - Quantidade total de $\mathrm{N}$-amoniacal na parte aérea (mg/planta), em Viçosa, MG.

\begin{tabular}{|c|c|c|c|c|c|c|c|}
\hline \multicolumn{4}{|c|}{ Tratamentos } & \multicolumn{4}{|c|}{ Dias após a emergência } \\
\hline In & Mo & $\mathrm{Np}$ & $\mathrm{Nc}$ & 18 & 32 & 46 & 60 \\
\hline 0 & 0 & 0 & 0 & 62,35 & 210,33 & 364,58 & 404,56 \\
\hline 0 & 1 & 0 & 0 & 76,19 & 299,52 & 508,29 & 548,27 \\
\hline 0 & 0 & 1 & 0 & 79,34 & 289,60 & 457,21 & 616,95 \\
\hline 0 & 1 & 1 & 0 & 79,96 & 316,33 & 508,00 & 532,37 \\
\hline 0 & 0 & 0 & 1 & 65,97 & 266,06 & 335,51 & 318,66 \\
\hline 0 & 1 & 0 & 1 & 69,50 & 258,00 & 448,59 & 457,77 \\
\hline 0 & 0 & 1 & 1 & 105,45 & 309,82 & 528,74 & 573,33 \\
\hline 0 & 1 & 1 & 1 & 74,82 & 313,10 & 506,90 & 746,53 \\
\hline 1 & 0 & 0 & 0 & 76,71 & 247,05 & 364,91 & 465,24 \\
\hline 1 & 1 & 0 & 0 & 69,03 & 246,59 & 438,20 & 431,98 \\
\hline 1 & 0 & 1 & 0 & 88,60 & 298,40 & 327,83 & 357,25 \\
\hline 1 & 1 & 1 & 0 & 84,07 & 272,82 & 520,74 & 695,95 \\
\hline 1 & 0 & 0 & 1 & 64,99 & 344,94 & 371,55 & 404,62 \\
\hline 1 & 1 & 0 & 1 & 64,88 & 208,06 & 414,00 & 575,24 \\
\hline 1 & 0 & 1 & 1 & 76,69 & 264,66 & 379,30 & 393,15 \\
\hline 1 & 1 & 1 & 1 & 90,94 & 374,32 & 524,62 & 665,47 \\
\hline
\end{tabular}

(*) 0 = ausência

$1=$ presença

In $=$ inoculação

$\mathrm{Np}=$ nitrogênio no plantio

Mo $=$ molibdênio

$\mathrm{Nc}=$ nitrogênio em cobertura 
Quantidade total de $\mathrm{N}$-amoniacal na parte aérea (mg/planta)

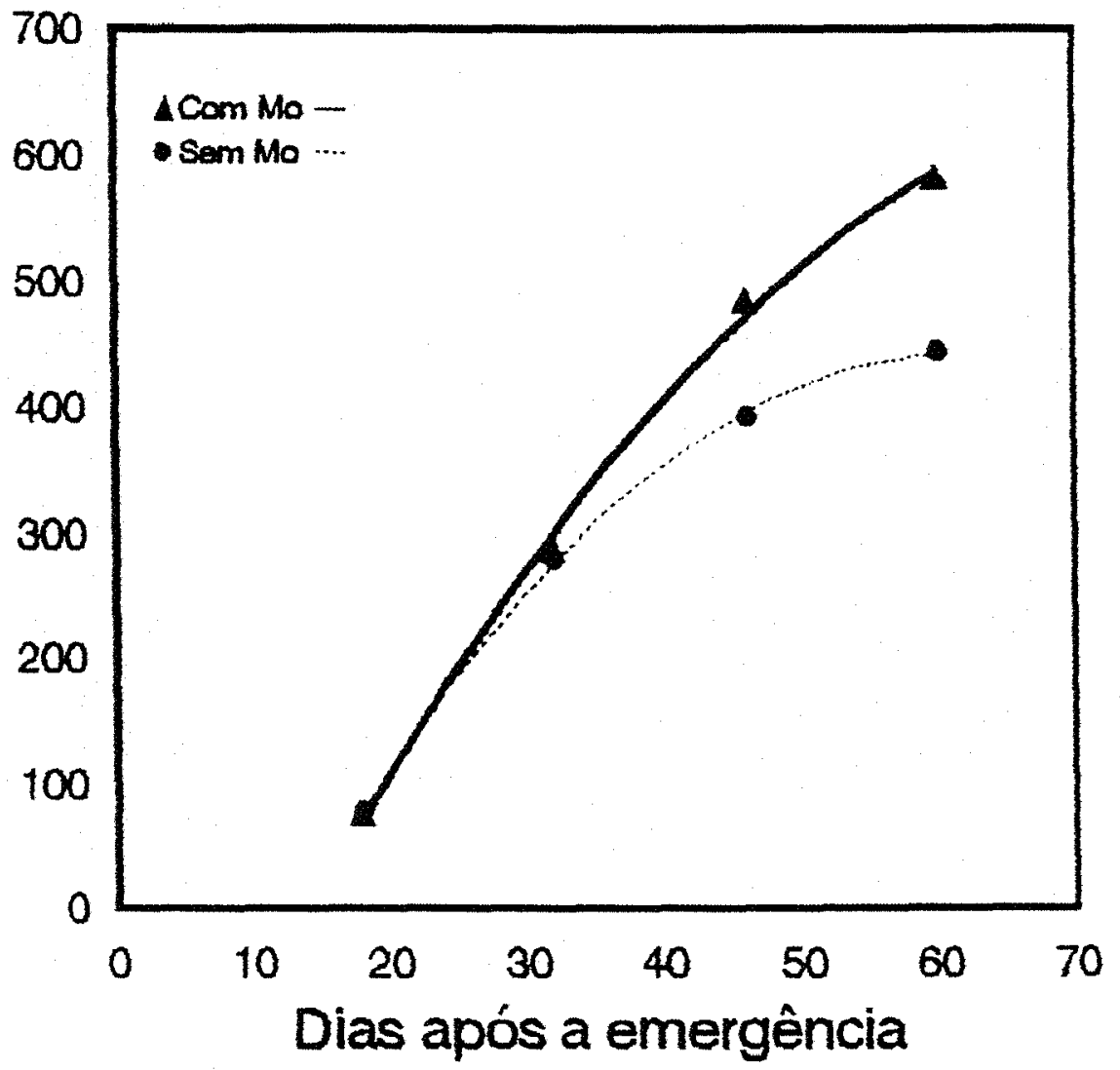

$$
\begin{aligned}
& \cdots Y=-191,4192+307,4862 \text { Ep-37,3628Ep }{ }^{2}\left(^{(*)}\right) \\
& -Y=-211,4843+311,2723 E p-27,9716 \mathrm{Ep}^{2}\left(^{\star \star}\right)
\end{aligned}
$$

Figura 9 - Efeito de interação Mo x épocas de avaliação na quantidade total de Namoniacal na parte aérea (mg/planta), em Viçosa, MG. 
Quantidade total de N-amoniacal na parte aérea (mg/planta)

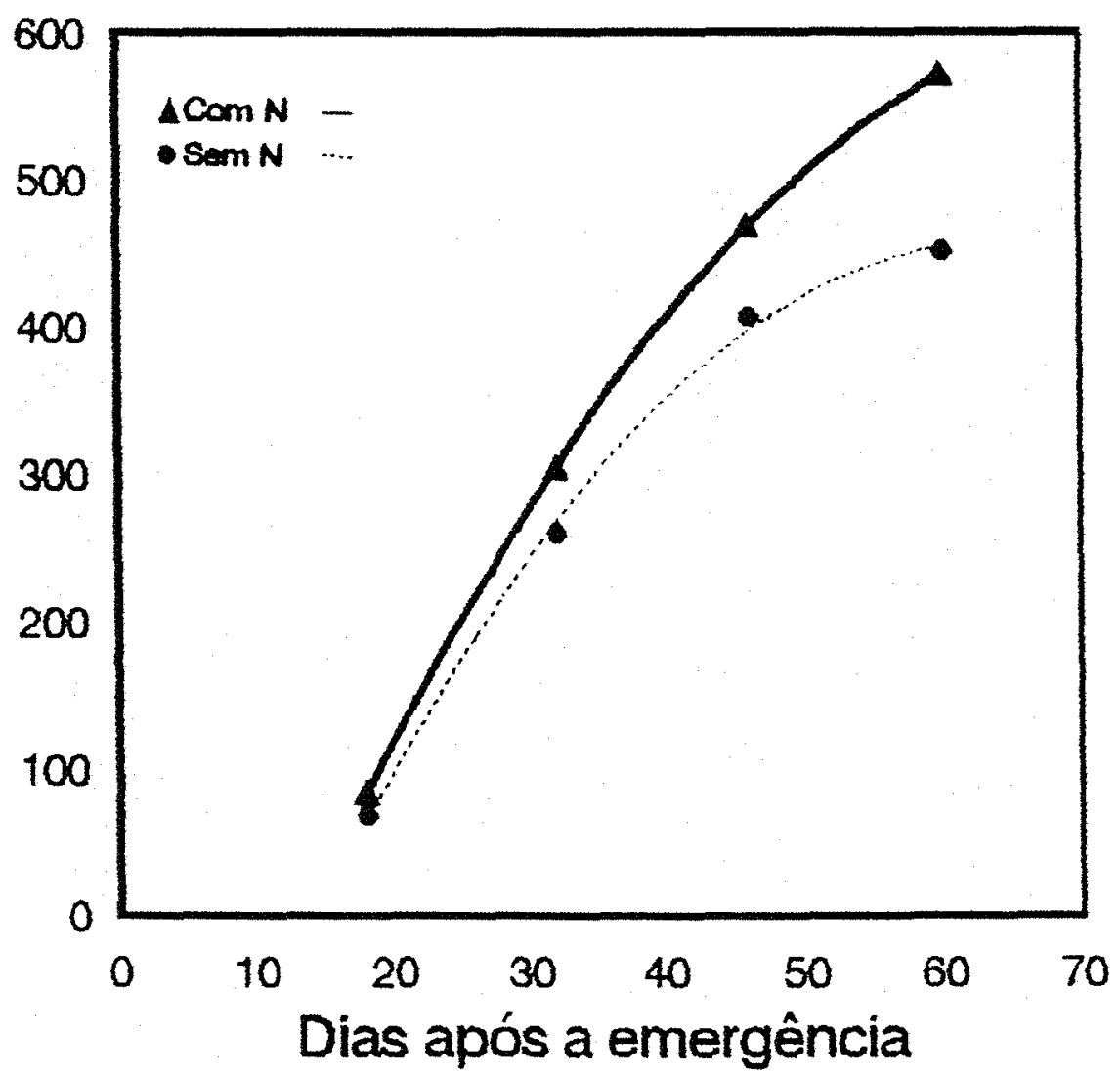

-... $\left.Y=-208,4721+310,5039 E p-36,2252 E p 2^{2 \star \star}\right)$

$-Y=-194,4314+308,2665 \mathrm{Ep}-29,1002 \mathrm{Ep}{ }^{2(\star \star)}$

Figura 10 - Efeito da interação $\mathrm{N}$ no plantio $\mathrm{x}$ épocas de avaliação na quantidade total de $\mathrm{N}$-amoniacal na parte aérea (mg/planta), em Viçosa, MG. 
$\mathrm{O}$ ponto de máxima quantidade total de $\mathrm{N}$-amoniacal na parte aérea foi obtido, aos 64 dias, nas plantas que não receberam $\mathrm{N}$ no plantio, e bem mais tardiamente nas plantas adubadas com $20 \mathrm{~kg} \mathrm{~N} / \mathrm{ha}$, no início do ciclo de feijoeiro.

$O$ efeito do Mo na percentagem de $N$ nas sementes (Tabela 9) foi significativo, ao nível de $1 \%$. Foram também significativos os efeitos das interações inoculação $x \mathrm{~N}$ no plantio $(\mathrm{P}<0,05)$ e inoculação $\mathrm{x}$ em cobertura $(\mathrm{P}<0,05)$.

A aplicação foliar de Mo, independentemente de qualquer outro tratamento, fez com que a percentagem de $\mathrm{N}$ nas sementes aumentasse, em média, 7,2\%. (Tabela 9). Com a inoculação, a percentagem de $\mathrm{N}$ nas sementes não foi afetada pela presença ou não de $\mathrm{N}$ no plantio; já as plantas que não foram inoculadas se beneficiaram da aplicação de $20 \mathrm{~kg}$ de $\mathrm{N}$ no plantio (Tabela 10). Resultados contrários foram obtidos com a aplicação de $\mathrm{N}$ em cobertura (Tabela 11), ou seja, quando não se inoculou, a aplicação de $\mathrm{N}$ em cobertura não afetou a percentagem de $\mathrm{N}$ nas sementes, ao passo que, com a inoculação, a aplicação de $30 \mathrm{~kg}$ de $\mathrm{N} \mathrm{em}$ cobertura aumentou a percentagem de $\mathrm{N}$ nas sementes.

O efeito de doses de Mo $(\mathrm{P}<0,01)$ e do $\mathrm{N}$ em cobertura $(\mathrm{P}<0,05)$ se fez sentir também na quantidade de $\mathrm{N}$ exportado para os grãos (Tabela 9). A aplicação foliar de Mo e a aplicação de $\mathrm{N}$ aos 25 dias após a emergência dos fejoeiros causaram um aumento de $13,4 \%$ e $10 \%$, respectivamente, na quantidade total de $\mathrm{N}$ exportado para os grãos. 
Tabela 9 - Percentagem de $\mathrm{N}$ nas sementes, quantidade de $\mathrm{N}$ exportado para os grãos (kg/ha) e produção (kg/ha), em Viçosa, MG.

\begin{tabular}{|c|c|c|c|c|c|c|}
\hline \multicolumn{4}{|c|}{ Tratamentos $^{*}$} & \multirow{2}{*}{$\begin{array}{c}\mathrm{N} \text { nas } \\
\text { sementes }\end{array}$} & \multirow{2}{*}{$\begin{array}{l}\mathrm{N} \text { exportado } \\
\text { para os grãos }\end{array}$} & \multirow[t]{2}{*}{ Produção } \\
\hline In & Mo & $\mathrm{Np}$ & $\mathrm{Nc}$ & & & \\
\hline 0 & 0 & 0 & 0 & 3,38 & 64,99 & 1927 \\
\hline 0 & 1 & 0 & 0 & 3,67 & 69,92 & 1877 \\
\hline 0 & 0 & 1 & 0 & 3,89 & 77,50 & 1998 \\
\hline 0 & 1 & 1 & 0 & 3,71 & 83,56 & 2248 \\
\hline 0 & 0 & 0 & 1 & 3,29 & 67,08 & 2001 \\
\hline 0 & 1 & 0 & 1 & 3,64 & 74,23 & 2037 \\
\hline 0 & 0 & 1 & 1 & 3,38 & 80,94 & 2362 \\
\hline 0 & 1 & 1 & 1 & 3,89 & 84,02 & 2152 \\
\hline 1 & 0 & 0 & 0 & 3,60 & 64,79 & 1781 \\
\hline 1 & 1 & 0 & 0 & 3,67 & 73,66 & 1997 \\
\hline 1 & 0 & 1 & 0 & 3,25 & 46,96 & 1442 \\
\hline 1 & 1 & 1 & 0 & 3,64 & 82,28 & 2266 \\
\hline 1 & 0 & 0 & 1 & 3,60 & 73,95 & 2031 \\
\hline 1 & 1 & 0 & 1 & 3,86 & 83,34 & 2147 \\
\hline 1 & 0 & 1 & 1 & 3,52 & 76,06 & 2131 \\
\hline 1 & 1 & 1 & 1 & 3,99 & 86,79 & 2169 \\
\hline
\end{tabular}

$\left.{ }^{*}\right) 0$ = ausência

$1=$ presença

In = inoculação

$\mathrm{Np}=$ nitrogênio no plantio

Mo = molibdênio

$\mathrm{Nc}=$ nitrogênio em cobertura 
Tabela 10 - Efeito da interação inoculação $\mathrm{x} N$ no plantio sobre as percentagens de $\mathrm{N}$ nas sementes, em Viçosa, $\mathrm{MG}^{*}$.

\begin{tabular}{ccc}
\hline \hline \multirow{2}{*}{ Inoculação } & \multicolumn{2}{c}{ Nitrogênio no plantio } \\
\cline { 2 - 3 } & $0 \mathrm{~kg} / \mathrm{ha}$ & $20 \mathrm{~kg} / \mathrm{ha}$ \\
\hline Sem inoculação & $3,50 \mathrm{bB}$ & $3,72 \mathrm{aA}$ \\
Com inoculação & $3,68 \mathrm{aA}$ & $3,60 \mathrm{aA}$ \\
\hline \hline
\end{tabular}

$\left.{ }^{*}\right)$ Médias seguidas pela mesma letra minúscula, na vertical, e maiúscula, na horizontal, não diferem significativamente, pelo teste de Duncan, ao nível de $5 \%$.

Tabela 11 - Efeito da interação inoculação x $\mathrm{N}$ em cobertura sobre a percentagem de $\mathrm{N}$ nas sementes, em Viçosa, $\mathrm{MG}^{*}$.

\begin{tabular}{ccc}
\hline & \multicolumn{2}{c}{ Nitrogênio em cobertura } \\
\cline { 2 - 3 } Inoculação & $0 \mathrm{~kg} / \mathrm{ha}$ & $30 \mathrm{~kg} / \mathrm{ha}$ \\
\hline Sem inoculação & $3,66 \mathrm{aA}$ & $3,55 \mathrm{bA}$ \\
Com inoculação & $3,54 \mathrm{aB}$ & $3,74 \mathrm{aA}$ \\
\hline \hline
\end{tabular}

(*) Médias seguidas pela mesma letra minúscula, na vertical, e maiúscula, na horizontal, não diferem significativamente, pelo teste de Duncan, ao nível de $5 \%$. 
Em relação às produções, a análise de variância revelou que houve efeito significativo da aplicação foliar de Mo $(\mathrm{P}<0,01)$, da aplicação de $\mathrm{N}$ em cobertura $(\mathrm{P}$ $<0,05)$ e da interação entre eles $(P<0,05)$.

Na ausência do Mo, a aplicação de $30 \mathrm{~kg} / \mathrm{ha}$ de $\mathrm{N}$ em cobertura resultou em aumento de $19 \%$ na produção, ou seja, $344 \mathrm{~kg} / \mathrm{ha}$; na presença de Mo, não houve efeito significativo da aplicação do $\mathrm{N}$ em cobertura sobre a produção (Tabela 12). A utilização de $40 \mathrm{~g} /$ ha de Mo sem a adubação nitrogenada de cobertura causou um aumento de $17 \%$ na produção, isto é, $310 \mathrm{~kg}$ de feijão por hectare. Na presença da adubação nitrogenada de cobertura a mesma produção foi obtida $(x=2128 \mathrm{~kg} / \mathrm{ha})$, com ou sem molibdênio (Tabela 9). Constata-se, portanto, que a aplicação foliar de Mo apresentou, sobre o feijoeiro, efeito semelhante ao de $30 \mathrm{~kg} / \mathrm{ha}$ de $\mathrm{N}$, em cobertura.

Tabela 12 - Efeito da interação Mo x $\mathrm{N}$ em cobertura na produção $(\mathrm{kg} / \mathrm{ha})$, em Viçosa, MG*.

\begin{tabular}{ccc}
\hline \hline Doses de & \multicolumn{2}{c}{ Nitrogênio em cobertura } \\
\cline { 2 - 3 } molibdênio & $0 \mathrm{~kg} / \mathrm{ha}$ & $40 \mathrm{~kg} / \mathrm{ha}$ \\
\hline $0 \mathrm{~g} / \mathrm{ha}$ & $1787 \mathrm{bB}$ & $2131 \mathrm{aA}$ \\
$40 \mathrm{~g} / \mathrm{ha}$ & $2097 \mathrm{aA}$ & $2126 \mathrm{aA}$ \\
\hline
\end{tabular}

(*) Médias seguidas pela mesma letra minúscula, na vertical, e maiúscula, na horizontal, não diferem significativamente, pelo teste de Duncan, ao nível de $5 \%$. 


\subsection{Experimento de Coimbra (Local I)}

O experimento de Coimbra foi montado em quatro blocos, conforme feito no experimento de Viçosa. Com o desenvolvimento do feijoeiro, verificou-se uma enorme diferença entre as plantas crescendo nos blocos 1 e 2 e nos blocos 3 e 4 .

Os blocos 1 e 2 foram montados sob terreno em pousio, enquanto que, os blocos 3 e 4, foram montados em uma área adjacente onde havia sido plantado milho. A análise química do solo, feita separadamente, para os blocos 1-2 e 3-4, mostraram uma diferença acentuada em termos de micronutrientes $\left(\mathrm{pH} \mathrm{H}_{2} \mathrm{O}=5,3 ; 4,8 \mathrm{ppm}\right.$ de $\mathrm{P}$; 17 ppm de $\mathrm{K} ; 0,1 ; 1,6 ; 0,5$ e $2,7 \mathrm{meq} / 100 \mathrm{~cm}^{3}$ de solo de $\mathrm{Al}, \mathrm{Ca}, \mathrm{Mg} \mathrm{e} \mathrm{H}+\mathrm{Al}$, respectivamente, 0,9 ppm de $\mathrm{Zn} ; 50 \mathrm{ppm}$ de Fe e 24,5 ppm de $\mathrm{Mn}$ ). Diante disto, optou-se por analisar os experimentos separadamente, de modo a obter mais informações sobre as possíveis respostas positivas ou negativas, decorrentes da aplicação foliar de molibdênio.

Os dados médios relativos à atividade da nitrogenase encontram-se na Tabela 13. A análise de variância desses dados mostrou que foram significativos os efeitos de Mo $(\mathrm{P}<0,01), \mathrm{N}$ no plantio $(\mathrm{P}<0,01)$, épocas de avaliação $(\mathrm{P}<0,01)$ e as interações Mo $\mathrm{x}$ épocas de avaliação $(\mathrm{P}<0,01)$ e $\mathrm{N}$ no plantio $\mathrm{x}$ épocas de avaliação $(P<0,01)$. Não houve, portanto, efeito significativo da inoculação.

O desdobramento da interação Mo $\mathrm{x}$ épocas de avaliação mostrou que, na ausência do micronutriente, a atividade da nitrogenase apresentou uma resposta linear 
Tabela 13 - Atividade da nitrogenase ( $\mu$ moles de $\mathrm{C}_{2} \mathrm{H}_{4} \cdot \mathrm{h}^{-1} \cdot$ planta ${ }^{-1}$ ), em Coimbra, MG. (Local I)*

\begin{tabular}{|c|c|c|c|c|c|c|c|c|}
\hline \multicolumn{4}{|c|}{ Tratamentos } & \multicolumn{5}{|c|}{ Dias após a emergência } \\
\hline In & Mo & $\mathrm{Np}$ & $\mathrm{Nc}$ & 18 & 32 & 46 & 60 & 74 \\
\hline 0 & 0 & 0 & 0 & 6,13 & 0,90 & 2,31 & 1,17 & 0,79 \\
\hline 0 & 1 & 0 & 0 & 5,29 & 3,67 & 12,22 & 6,00 & 1,88 \\
\hline 0 & 0 & 1 & 0 & 4,13 & 0,46 & 1,77 & 0,89 & 0,33 \\
\hline 0 & 1 & 1 & 0 & 1,45 & 0,77 & 5,93 & 2,48 & 1,69 \\
\hline 0 & 0 & 0 & 1 & 7,17 & 1,20 & 1,03 & 0,13 & 0,17 \\
\hline 0 & 1 & 0 & 1 & 6,11 & 4,16 & 5,26 & 3,67 & 1,64 \\
\hline 0 & 0 & 1 & 1 & 1,53 & 0,78 & 1,02 & 0,52 & 0,22 \\
\hline 0 & 1 & 1 & 1 & 0,69 & 2,04 & 16,21 & 7,80 & 2,32 \\
\hline 1 & 0 & 0 & 0 & 5,77 & 2,30 & 5,38 & 1,42 & 0,70 \\
\hline 1 & 1 & 0 & 0 & 4,84 & 5,86 & 13,24 & 6,51 & 2,21 \\
\hline 1 & 0 & 1 & 0 & 1,89 & 0,73 & 1,57 & 0,67 & 0,45 \\
\hline 1 & 1 & 1 & 0 & 1,58 & 2,92 & 8,61 & 9,65 & 3,01 \\
\hline 1 & 0 & 0 & 1 & 7,78 & 3,16 & 2,49 & 0,43 & 0,55 \\
\hline 1 & 1 & 0 & 1 & 6,63 & 2,71 & 12,67 & 5,79 & 1,43 \\
\hline 1 & 0 & 1 & 1 & 1,04 & 0,28 & 2,98 & 1,11 & 0,59 \\
\hline 1 & 1 & 1 & 1 & 1,68 & 1,84 & 12,18 & 11,51 & 3,57 \\
\hline
\end{tabular}

* 0 = ausência

In = inoculação

Mo $=$ molibdênio
$1=$ presença

$\mathrm{Np}=$ nitrogênio no plantio

$\mathrm{Nc}=$ nitrogênio em cobertura 


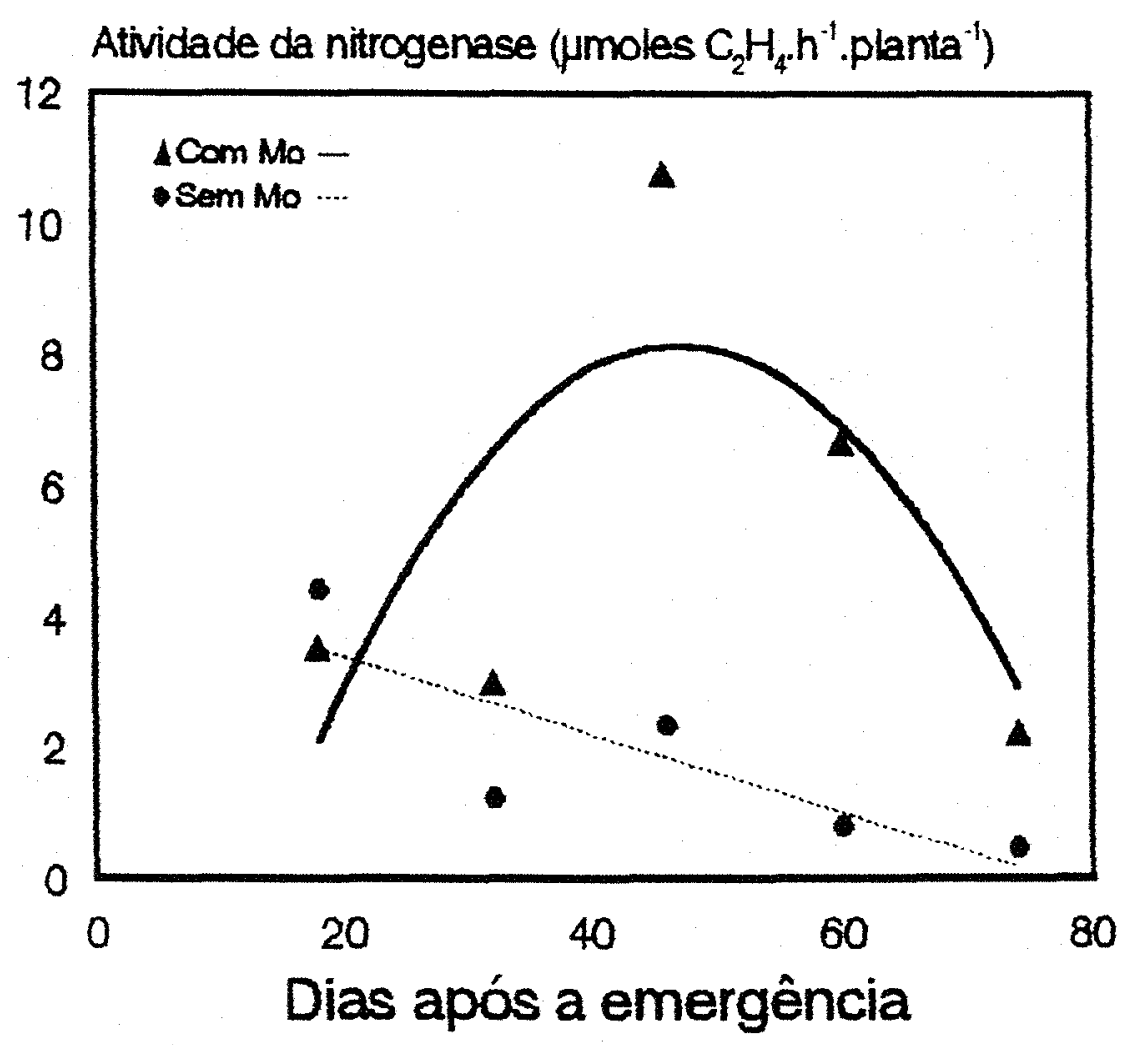

$\cdots Y=4,5935-0,0506 \mathrm{Ep}\left(^{* k}\right)$
$-Y=-7,7297+0,6768 \mathrm{Ep}-0,0072 \mathrm{Ep}{ }^{2}(k)$

Figura 11 - Efeito da interação Mo x épocas de avaliação na atividade da nitrogenase ( $\mu$ moles de $\mathrm{C}_{2} \mathrm{H}_{4} \cdot \mathrm{h}^{-1}$. planta ${ }^{-1}$ ), em Coimbra, MG (Local I). 
decrescente, enquanto que, na sua presença, a resposta foi quadrática (Figura 11). A máxima atividade da nitrogenase ocorreu aos 47 dias após a emergência das plantas, nos tratamentos que receberam molibdênio. Nesta época e aos 32 e 60 dias, a atividade dessa enzima foi aproximadamente 4,2 e 7 vezes maior que nos tratamentos com ausência de molibdênio. O efeito benéfico do Mo persistiu até a última medição aos 74 dias.

Nas plantas não submetidas à aplicação foliar de Mo, a atividade máxima da nitrogenase ocorreu aos 18 dias; após este período, ela clecresceu até o fim do ciclo do feijoeiro.

A atividade da nitrogenase apresentou resposta quadrática na ausência e presença de $\mathrm{N}$ no plantio, em relação às épocas de avaliação (Figura 12). O efeito prejudicial da aplicação de $20 \mathrm{~kg}$ de $\mathrm{N}$ no plantio sobre a atividade da nitrogenase ocorreu somente no início do ciclo do fejoeiro. Aos 18 e 32 dias, houve um decréscimo de $85 \%$ e $29 \%$, respectivamente, na atividade da enzima, com aplicação de $\mathrm{N}$ no plantio, em relação aos tratamentos não submetidos a essá adubação.

A máxima atividade da nitrogenase foi obtida aos 29 dias, nas plantas que não receberam $\mathrm{N}$ no plantio, e aos 48 dias, nas plantas submetidas a essa adubação.

A análise de variância dos dados de atividade específica da nitrogenase revelou que foram significativos os efeitos de Mo $(\mathrm{P}<0,01)$, épocas de avaliação $(\mathrm{P}<0,01)$ e as interações Mo $x \mathrm{~N}$ no plantio $(\mathrm{P}<0,05), \mathrm{N}$ no plantio $\times \mathrm{N}$ em cobertura $(\mathrm{P}<0,05)$, Mo $x$ épocas de avaliação $(\mathrm{P}<0,01)$ e $\mathrm{N}$ no plantio $\mathrm{x}$ épocas de avaliação $(\mathrm{P}<0,05)$. Os dados médios da atividade específica da nitrogenase encontram-se na Tabela 14 . 


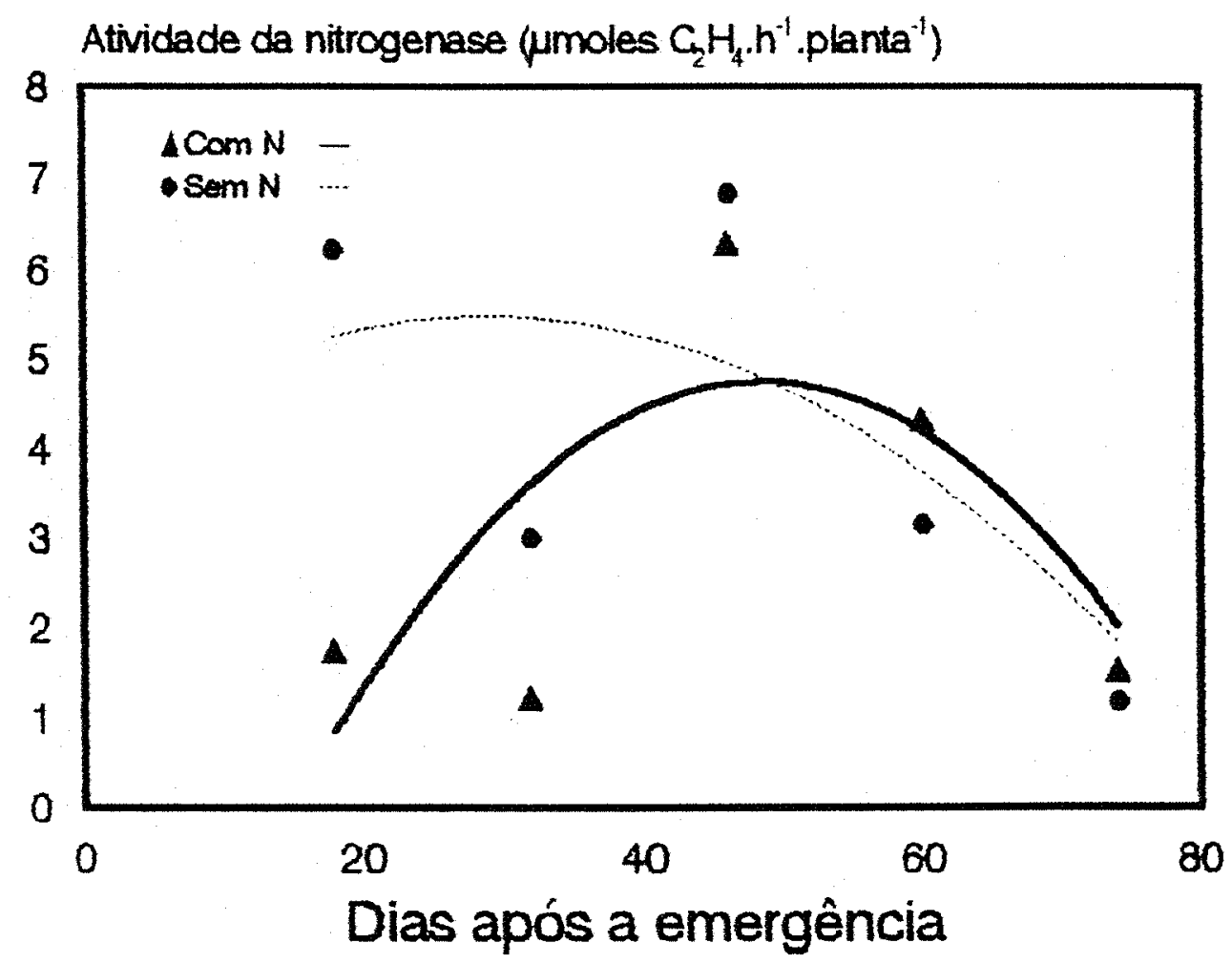

$Y=3,8660+0,1042 E \mathrm{E}-0,0018 \mathrm{Ep}^{2(\star \star)}$
$-Y=-5,1239+0,4073 \mathrm{Ep}-0,0042 \mathrm{Ep}{ }^{2(\star \star)}$

Figura 12 - Efeito da interação $\mathrm{N}$ no plantio $\mathrm{x}$ épocas de avaliação na atividade da nitrogenase ( $\mu$ moles de $\mathrm{C}_{2} \mathrm{H}_{4} \cdot \mathrm{h}^{-1}$. planta ${ }^{-1}$ ), em Coimbra, MG (Local l). 
Tabela 14 - Atividade específica da nitrogenase $\left(\mu\right.$ moles de $\mathrm{C}_{2} \mathrm{H}_{4} \cdot \mathrm{h}^{-1} \cdot \mathrm{g}$. de nódulo $^{-1}$ ), em Coimbra, MG (Local I).

\begin{tabular}{|c|c|c|c|c|c|c|c|c|}
\hline \multicolumn{4}{|c|}{ Tratamentos* } & \multicolumn{5}{|c|}{ Dias após a emergência } \\
\hline In & Mo & $\mathrm{Np}$ & $\mathrm{Nc}$ & 18 & 32 & 46 & 60 & 74 \\
\hline 0 & 0 & 0 & 0 & 91,74 & 10,72 & 28,47 & 28,76 & 14,44 \\
\hline 0 & 1 & 0 & 0 & 134,09 & 33,02 & 82,67 & 56,85 & 85,34 \\
\hline 0 & 0 & 1 & 0 & 210,04 & 6,26 & 18,78 & 10,82 & 14,72 \\
\hline 0 & 1 & 1 & 0 & 103,62 & 38,10 & 94,70 & 81,90 & 130,20 \\
\hline 0 & 0 & 0 & 1 & 143,60 & 13,47 & 13,36 & 3,24 & 13,49 \\
\hline 0 & 1 & 0 & 1 & 79,78 & 24,61 & 48,59 & 76,55 & 48,95 \\
\hline 0 & 0 & 1 & 1 & 77,63 & 27,91 & 85,34 & 32,27 & 73,95 \\
\hline 0 & 1 & 1 & 1 & 65,12 & 65,16 & 147,67 & 202,83 & 200,87 \\
\hline 1 & 0 & 0 & 0 & 397,73 & 27,09 & 49,61 & 18,07 & 10,42 \\
\hline 1 & 1 & 0 & 0 & 78,90 & 40,08 & 103,13 & 80,76 & 253,48 \\
\hline 1 & 0 & 1 & 0 & 138,01 & 43,56 & 36,90 & 12,08 & 19,94 \\
\hline 1 & 1 & 1 & 0 & 115,74 & 68,27 & 155,67 & 119,73 & 86,65 \\
\hline 1 & 0 & 0 & 1 & 293,12 & 26,12 & 20,87 & 4,96 & 14,49 \\
\hline 1 & 1 & 0 & 1 & 108,60 & 28,03 & 64,57 & 65,15 & 65,26 \\
\hline 1 & 0 & 1 & 1 & 112,33 & 29,41 & 73,39 & 63,24 & 32,10 \\
\hline 1 & 1 & 1 & 1 & 78,73 & 65,08 & 101,01 & 111,58 & 213,37 \\
\hline
\end{tabular}

$\left(^{*}\right)$ = ausência

In = inoculação

Mo = molibdênio
$1=$ presença

$\mathrm{Np}=$ nitrogênio no plantio

$\mathrm{Nc}=$ nitrogênio em cobertura 
O efeito do Mo sobre a atividade específica da nitrogenase esteve associado à presença ou ausência da aplicação de $\mathrm{N}$ no plantio. Com $0 \mathrm{~kg} / \mathrm{ha}$ de $\mathrm{N}$ no plantio, a aplicação de $40 \mathrm{~g} / \mathrm{ha}$ de Mo não afetou significativamente a atividade específica da nitrogenase, enquanto que, na presença de $20 \mathrm{~kg} / \mathrm{ha}$ de $\mathrm{N}$ no plantio, o Mo causou um aumento de $101 \%$. Na ausência da adubação com Mo, a adubação nitrogenada de plantio não afetou significativamente a atividade específica da nitrogenase, enquanto que, na presença de $40 \mathrm{~g} / \mathrm{ha}$ de $\mathrm{Mo}$, trouxe um aumento de $44 \%$ (Tabela 15).

Tabela 15 - Efeito da interação $\mathrm{N}$ no plantio $\mathrm{x}$ Mo sobre a atividade específica da nitrogenase ( $\mu$ moles de $\mathrm{C}_{2} \mathrm{H}_{4} \cdot \mathrm{h}^{-1} \cdot \mathrm{g}$. de nódulo $\left.{ }^{-1}\right)$, em Coimbra, $\mathrm{MG}$ (Local I).

\begin{tabular}{ccc}
\hline \hline Nitrogênio & \multicolumn{2}{c}{ Molibdênio } \\
\cline { 2 - 3 } no plantio & $0 \mathrm{~g} / \mathrm{ha}$ & $40 \mathrm{~g} / \mathrm{ha}$ \\
\hline $0 \mathrm{~kg} / \mathrm{ha}$ & $61,19 \mathrm{aA}$ & $77,92 \mathrm{bA}$ \\
$20 \mathrm{~kg} / \mathrm{ha}$ & $55,93 \mathrm{aB}$ & $112,30 \mathrm{aA}$ \\
\hline \hline
\end{tabular}

(*) Médias seguidas pela mesma letra minúscula, na vertical, e maiúscula, na horizontal, não diferem significativamente, pelo teste de Duncan, ao nível de $5 \%$. 
$\mathrm{O}$ efeito da aplicação de $\mathrm{N}$ no plantio sobre a atividade específica da nitrogenase esteve, também, relacionada com a adubação nitrogenada de cobertura (Tabela 16). Com a aplicação de $20 \mathrm{~kg} /$ ha de $\mathrm{N}$ no plantio, a aplicação, aos 25 dias, de $30 \mathrm{~kg} / \mathrm{ha}$ de $\mathrm{N}$ provocou um aumento de $61 \%$ na atividade específica da nitrogenase, enquanto que na ausência da adubação nitrogenada de cobertura não houve efeito do $\mathrm{N}$ aplicado no plantio (Tabela 16).

A atividade específica da nitrogenase apresentou resposta quadrática na presença de Mo, em relação às épocas de avaliação. A aplicação foliar de Mo provocou um grande efeito sobre essa atividade, chegando a um aumento de até $289 \%$, como pode ser observado no $74^{\circ}$ dia de avaliação (Figura 13).

Tabela 16 - Efeito da interação $\mathrm{N}$ no plantio $\mathrm{x} \mathrm{N}$ em cobertura sobre a atividade específica da nitrogenase ( $\mu$ moles de $\mathrm{C}_{2} \mathrm{H}_{4} \cdot \mathrm{h}^{-1} \cdot \mathrm{g}$. de nódulo ${ }^{-1}$ ), em Coimbra, MG (Local I).

\begin{tabular}{ccc}
\hline \hline Nitrogênio & \multicolumn{2}{c}{ Nitrogênio em cobertura } \\
\cline { 2 - 3 } no plantio & $0 \mathrm{~kg} / \mathrm{ha}$ & $30 \mathrm{~kg} / \mathrm{ha}$ \\
\hline $0 \mathrm{~kg} / \mathrm{ha}$ & $80,82 \mathrm{aA}$ & $57,84 \mathrm{bA}$ \\
$20 \mathrm{~kg} / \mathrm{ha}$ & $75,28 \mathrm{aA}$ & $92,95 \mathrm{aA}$ \\
\hline
\end{tabular}

(*) Médias seguidas pela mesma letra minúscula, na vertical, e maiúscula, na horizontal, não diferem siginificativamente, pelo teste de Duncan, ao nível de $5 \%$. 


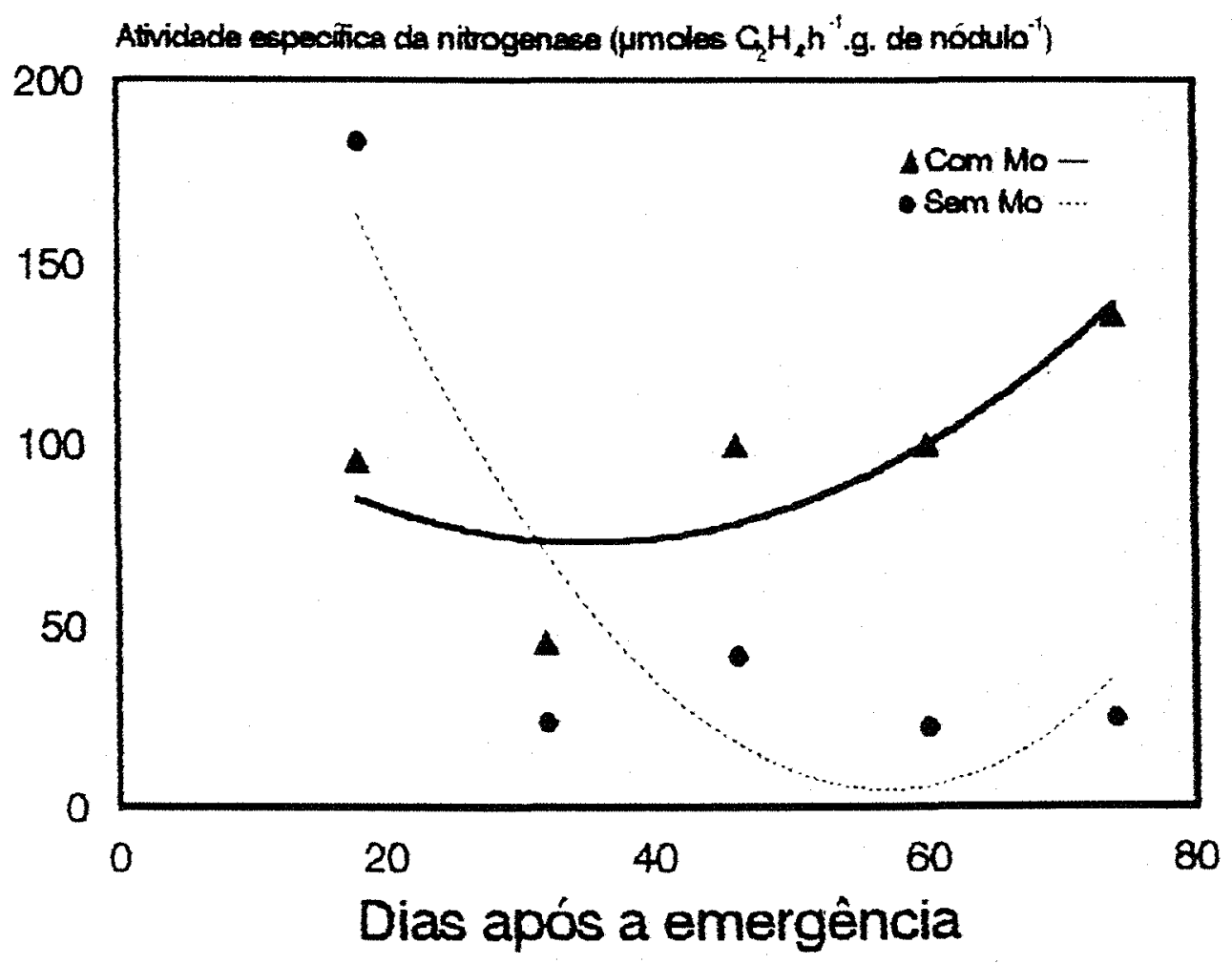

… $\left.Y=344,2829-11,8028 E p+0,1040 E p^{\prime \prime \star \star}\right)$

$-Y=125,1925-2,9978 E p+0,0430 E p^{2}(*)$

Figura 13 - Efeito da interação Mo x épocas de avaliação na atividade específica da nitrogenase ( $\mu$ moles de $\mathrm{C}_{2} \mathrm{H}_{4} \cdot \mathrm{h}^{-1} \cdot \mathrm{g}$. de nódulo $\left.{ }^{-1}\right)$, em Coimbra, MG (Local I). 
Os pontos de mínima atividade específica da nitrogenase foram obtidos aos 35 e 57 dias, respectivamente, para as plantas adubadas e não adubadas com molibdênio.

A atividade específica da nitrogenase foi também afetada pela presença ou ausência da adubação nitrogenada no plantio. Em ambos os casos, respostas quadráticas foram obtidas (Figura 14). A aplicação de $20 \mathrm{~kg} / \mathrm{ha}$ de $\mathrm{N}$ no plantio provocou um aumento médio de $144 \%$ na atividade específica da nitrogenase, do 46 ao $60^{\circ}$ dia, e de 39 no $74^{\circ}$ dia. Tal efeito não foi observado no início do ciclo do feijoeiro. Os pontos de de mínima atividade específica da nitrogenase foram obtidos aos 46 e 52 dias, respectivamente, para as plantas adubadas e não adubadas com $\mathrm{N}$ no plantio.

Quanto ao número de nódulos/planta, a análise de variância revelou que foram significativos os efeitos de $\mathrm{N}$ no plantio $(\mathrm{P}<0,01)$, épocas de avalição $(\mathrm{P}<$ $0,01)$ e as interações Mo x $N$ em cobertura $(P<0,05)$, Mo x épocas de avaliação ( $P$ $<0,01)$, $\mathrm{N}$ no plantio x épocas de avaliação $(\mathrm{P}<0,01)$ e $\mathrm{N}$ em cobertura $\mathrm{x}$ épocas de avaliação $(\mathrm{P}<0,05)$. Os dados médios relativos ao número de nódulos encontram-se na Tabela 17.

Apesar de a interação Mo x $\mathrm{N}$ em cobertura ter sido significativa, quando se compararam as médias obtidas pelo teste de Duncan, não se encontraram diferenças significativas (Tabela 18). Nota-se, entretanto, que as maiores médias (aproximadamente 30 nódulos) foram obtidas nos tratamentos sem $\mathrm{Mo}+0 \mathrm{~kg} / \mathrm{ha}$ de $\mathrm{N}$ em cobertura e com $40 \mathrm{~g} / \mathrm{ha}$ de $\mathrm{Mo}+30 \mathrm{~kg} / \mathrm{ha}$ de $\mathrm{N}$ em cobertura.

A aplicação de Mo mostrou uma tendência à diminuição do número de nódulos (Figura 15). O maior efeito do Mo ocorreu no fim do ciclo do feijoeiro: aos 74 


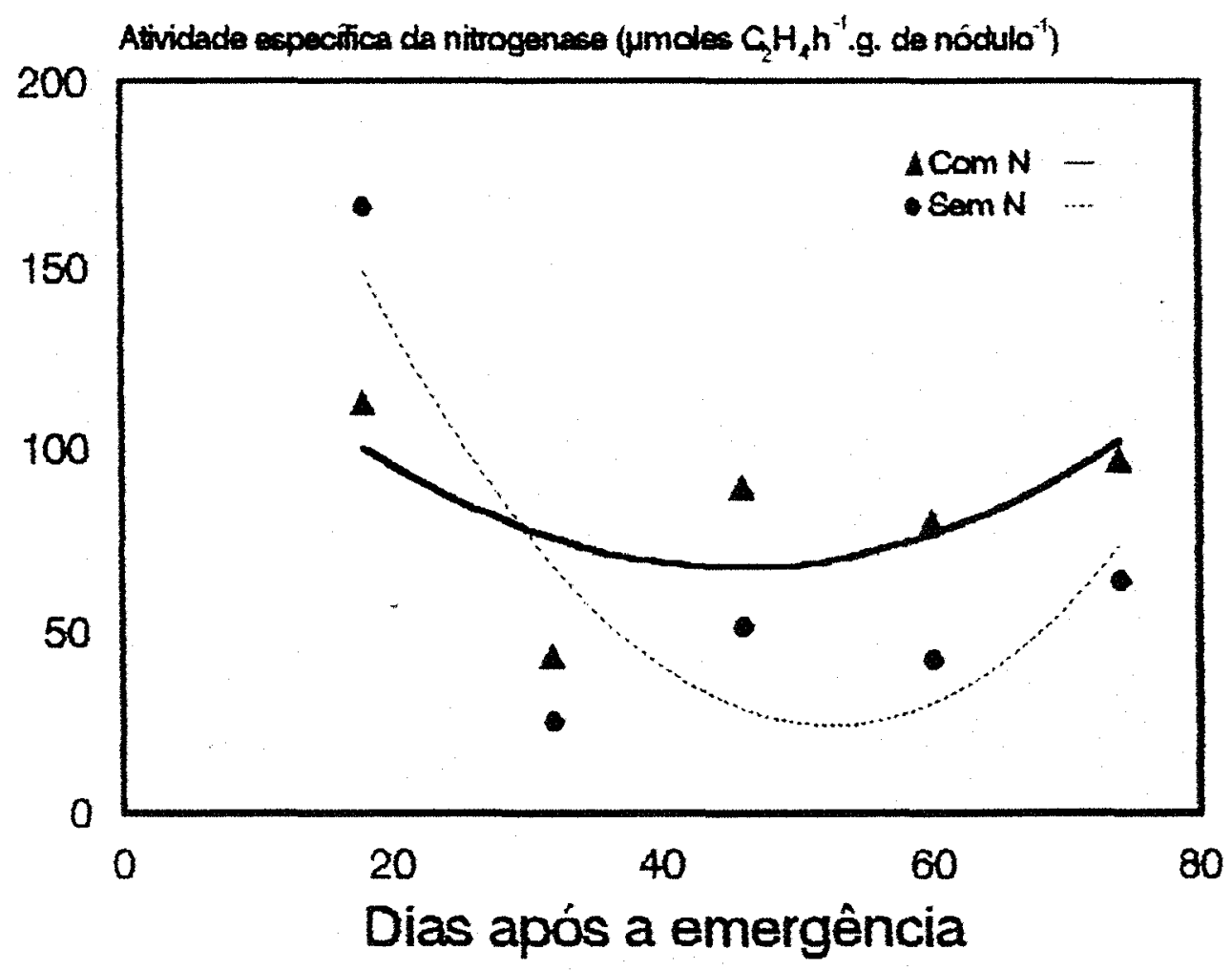

$\cdots . Y=312,7682-11,0155 \mathrm{Ep}+0,1051 \mathrm{Ep} 2(k \star)$
$-Y=156,7072-3,9150 \mathrm{Ep}+0,0409 \mathrm{p}^{2}(\star)$

Figura 14 - Efeito da interação $\mathrm{N}$ no plantio $\mathrm{x}$ épocas de avaliação na atividade específicada nitrogenase ( $\mu$ moles de $\mathrm{C}_{2} \mathrm{H}_{4} \cdot \mathrm{h}^{-1}$. g. de nódulo ${ }^{-1}$ ), em Coimbra, MG (Local I). 
Tabela 17 - Número de nódulos.planta-1 ${ }^{-1}$ em Coimbra, MG (Local I).

\begin{tabular}{|c|c|c|c|c|c|c|c|c|}
\hline \multicolumn{4}{|c|}{ Tratamentos ${ }^{*}$} & \multicolumn{5}{|c|}{ Dias após a emergência } \\
\hline In & Mo & $\mathrm{Np}$ & $\mathrm{Nc}$ & 18 & 32 & 46 & 60 & 74 \\
\hline 0 & 0 & 0 & 0 & 47,12 & 34,25 & 37,25 & 26,12 & 40,25 \\
\hline 0 & 1 & 0 & 0 & 34,25 & 35,62 & 34,00 & 23,62 & 7,75 \\
\hline 0 & 0 & 1 & 0 & 19,87 & 35,12 & 28,12 & 44,12 & 28,12 \\
\hline 0 & 1 & 1 & 0 & 12,00 & 9,87 & 12,37 & 30,37 & 7,50 \\
\hline 0 & 0 & 0 & 1 & 39,87 & 36,25 & 31,62 & 19,50 & 10,87 \\
\hline 0 & 1 & 0 & 1 & 61,75 & 62,00 & 46,37 & 19,00 & 15,62 \\
\hline 0 & 0 & 1 & 1 & 11,75 & 15,62 & 13,75 & 7,12 & 4,87 \\
\hline 0 & 1 & 1 & 1 & 21,25 & 20,37 & 20,75 & 12,87 & 11,37 \\
\hline 1 & 0 & 0 & 0 & 28,25 & 37,12 & 42,50 & 39,75 & 27,62 \\
\hline 1 & 1 & 0 & 0 & 49,75 & 51,25 & 44,37 & 25,87 & 6,00 \\
\hline 1 & 0 & 1 & 0 & 14,25 & 17,00 & 23,87 & 23,87 & 10,12 \\
\hline 1 & 1 & 1 & 0 & 17,75 & 21,62 & 18,62 & 19,62 & 10,75 \\
\hline 1 & 0 & 0 & 1 & 39,75 & 33,75 & 34,25 & 33,25 & 23,50 \\
\hline 1 & 1 & 0 & 1 & 46,37 & 38,62 & 62,87 & 24,25 & 7,25 \\
\hline 1 & 0 & 1 & 1 & 16,37 & 12,37 & 16,25 & 15,37 & 15,25 \\
\hline 1 & 1 & 1 & 1 & 26,25 & 23,75 & 27,62 & 27,37 & 10,37 \\
\hline
\end{tabular}

(*) 0 = ausência;

In $=$ inoculação

Mo = molibdênio
$1=$ presença

$\mathrm{Np}=$ nitrogênio no plantio

$\mathrm{Nc}=$ nitrogênio em cobertura 
Tabela 18 - Efeito da interação Mo $\times$ N em cobertura sobre o número de nódulos. planta $^{-1}$ em Coimbra, MG (Local I).

\begin{tabular}{ccc}
\hline \multirow{2}{*}{ Molibdênio } & \multicolumn{2}{c}{ Nitrogênio em cobertura } \\
\cline { 2 - 3 } & $0 \mathrm{~kg} / \mathrm{ha}$ & $30 \mathrm{~kg} / \mathrm{ha}$ \\
\hline $0 \mathrm{~g} / \mathrm{ha}$ & $30,24 \mathrm{aA}$ & $21,92 \mathrm{aA}$ \\
$40 \mathrm{~g} / \mathrm{ha}$ & $22,40 \mathrm{aA}$ & $29,31 \mathrm{aA}$ \\
\hline
\end{tabular}

(*) Médias seguidas pela mesma letra minúscula, na vertical, e maiúscula, na horizontal, não diferem significativamente, pelo teste de Duncan, ao nível de $5 \%$.

dias as plantas pulverizadas com este micronutriente apresentaram $58 \%$ menos nódulos que as plantas não pulverizadas.

Na presença e ausência de Mo o número máximo de nódulos.planta ${ }^{-1}$ foi obtido aos 29 e 38 dias, respectivamente.

O efeito das épocas de avaliação sobre o número de nódulos foi quadrático, tanto na presença como na ausência da adubação nitrogenada de plantio e de cobertura (Figuras 16 e 17). A adição de $20 \mathrm{~kg} / \mathrm{ha}$ de $\mathrm{N}$ na semeadura do feijoeiro causou um decréscimo médio no número de nódulos de $57 \%$, dos 18 aos 46 dias, e de $27 \%$, dos 60 aos 74 dias.

A aplicação de $30 \mathrm{~kg} / \mathrm{ha}$ de $\mathrm{N}$ em cobertura apresentou também uma tendência a diminuir o número de nódulos, principalmente no final do ciclo do feijoeiro. Aos 74 dias, havia $33 \%$ menos nódulos nas plantas que haviam recebido adubação nitrogenada de cobertura (Figura 17). 


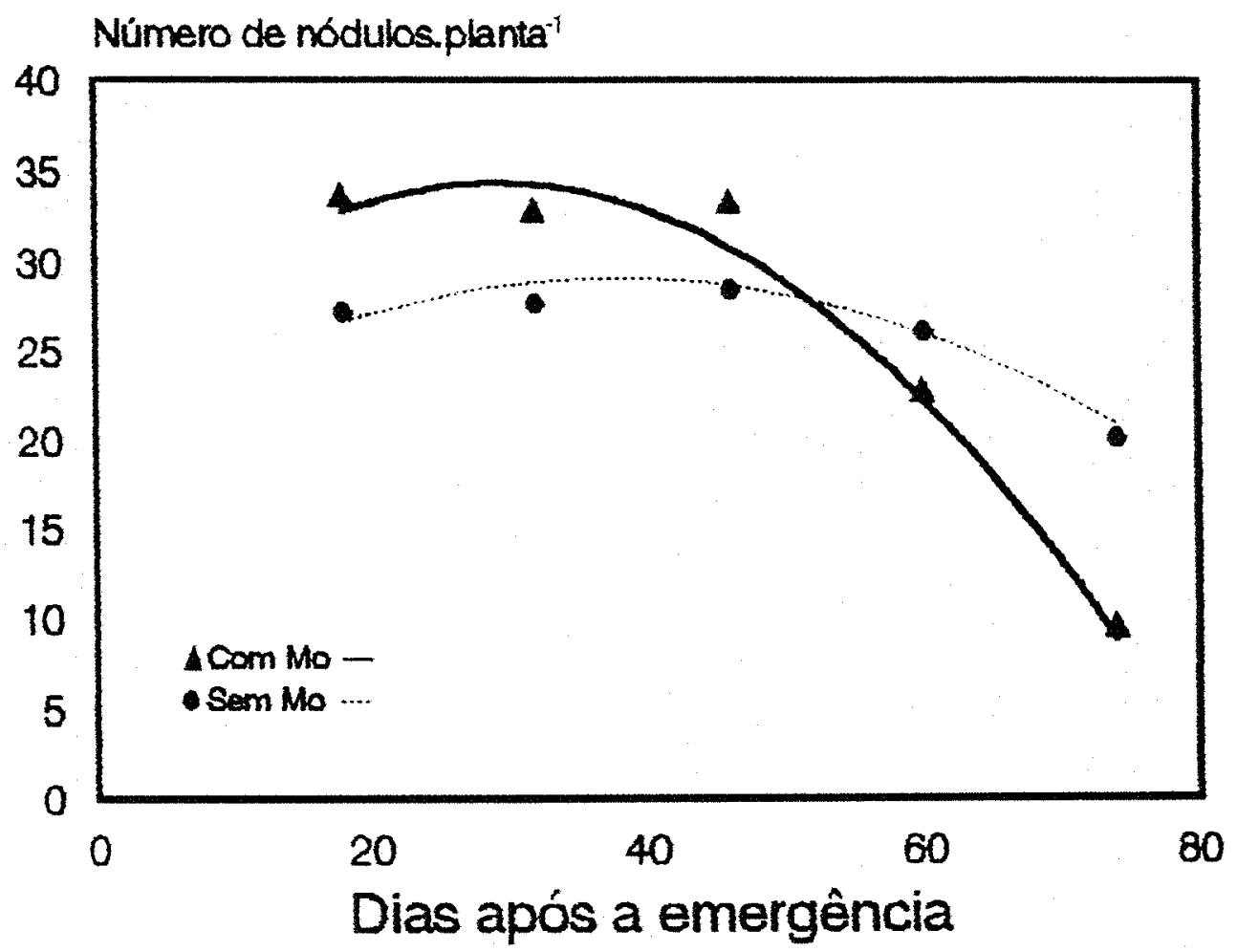

… $Y=20,1083+0,4604 \mathrm{Ep}-0,0002 \mathrm{Ep}^{2}$ (*)

$-Y=23,5452+0,7400 \mathrm{Ep}-0,0127 \mathrm{Ep} 2(\star \star))$

Figura 15 - Efeito da interação Mo x épocas de avaliação no número de nódulos . planta $^{-1}$, em Coimbra, MG (Local I). 


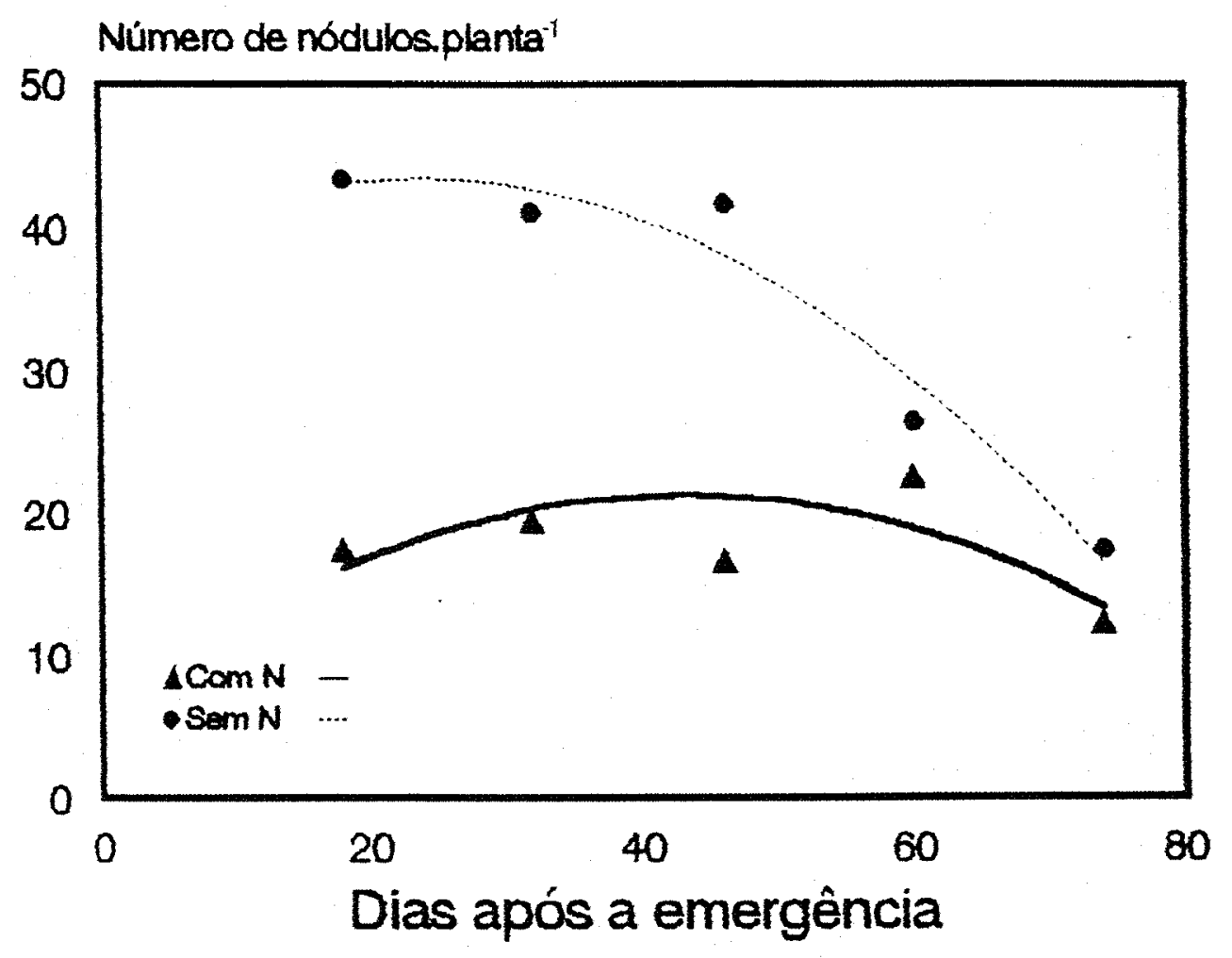

-... $Y=37,4835+0,5070 \mathrm{Ep}-0,0107 \mathrm{Ep}^{2}(\star \star)$

$-Y=6,2300+0,7033$ Ep-0,0002EP $4(k)$

Figura 16 - Efeito da interação $\mathrm{N}$ no plantio $\mathrm{x}$ épocas de avaliação no número de nódulos . planta ${ }^{-1}$, em Coimbra, MG (Local I). 


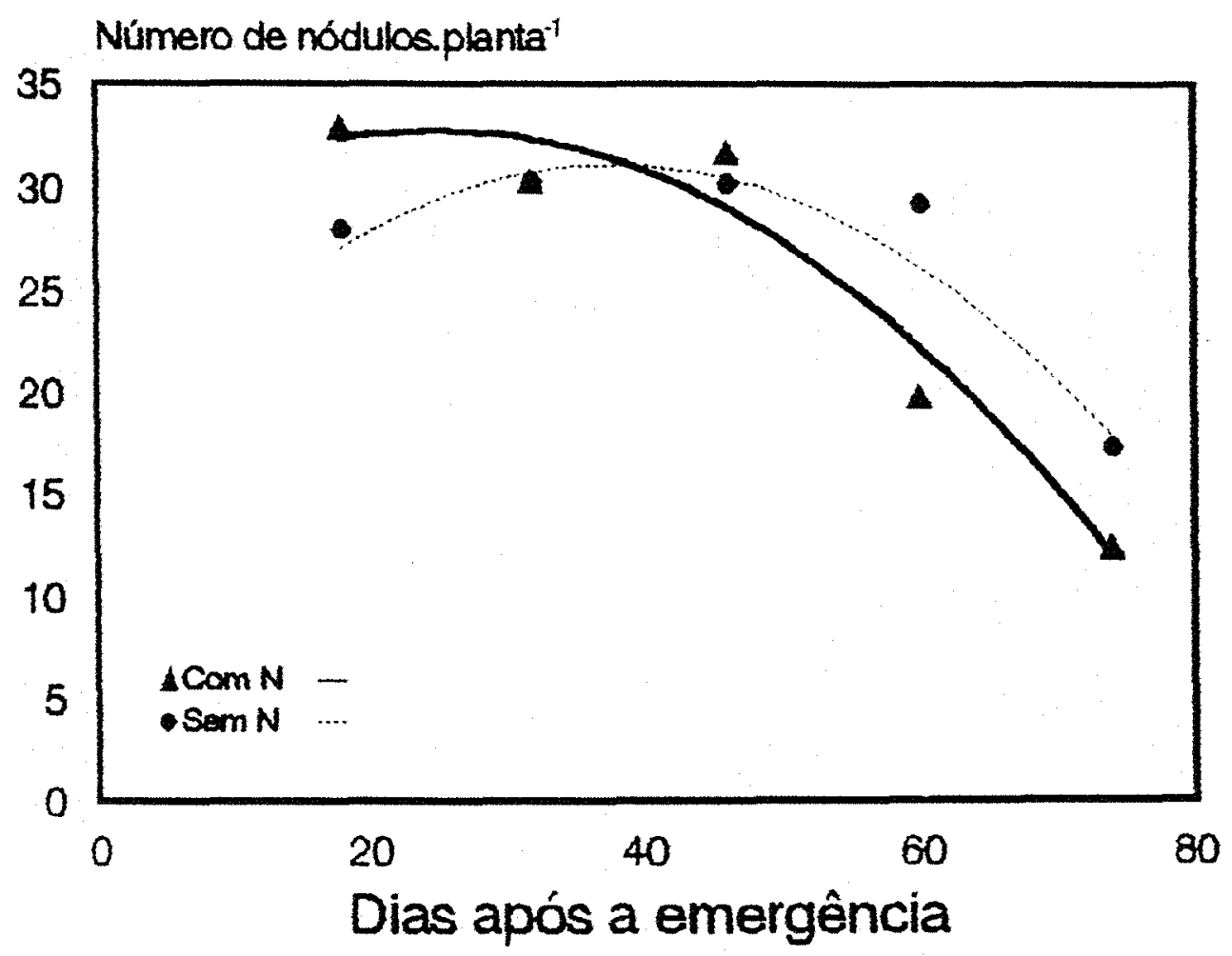

$\left.\cdots . Y=16,4202+0,7734 E p-0,0102 E_{p}^{2} 4^{\star \star}\right)$
$-Y=27,2942+0,4370 E-0,0087 \mathrm{Fp}^{2}(\star \star)$

Figura 17 - Efeito da interação $\mathrm{N}$ em cobertura $\mathrm{x}$ épocas de avaliação no número de nódulos . planta ${ }^{-1}$, em Coimbra, MG (Local I). 
Na presença de $\mathrm{N}$ no plantio, o número máximo de nódulos foi obtido somente aos 43 dias e, na sua ausência, aos 24 dias. Já no caso da adubação de cobertura, o número máximo de nódulos foi obtido primeiramente a presença de $30 \mathrm{~kg} / \mathrm{ha}$ de $\mathrm{N}$, ou seja aos 26 dias, enquanto que, na sua ausência, o número máximo de nódulos foi somente obtido aos 38 dias.

A análise de variância dos pesos de nódulos secos mostrou que foram significativos os seguintes fatores: $\mathrm{N}$ no plantio $(\mathrm{P}<0,01)$, épocas de avaliação $(\mathrm{P}<0,01)$ e as interações Mo x épocas de avaliação $(\mathrm{P}<0,01)$ e $\mathrm{N}$ no plantio $\mathrm{x}$ épocas de avaliação $(\mathrm{P}<0,01)$. Os dados médios relativos a este parâmetro encontram-se na Tabela 19. A aplicação de Mo provocou aumento no peso dos nódulos em relação às plantas que não o receberam; este aumento foi, em média, de $40 \%$, até o $60^{\circ}$ dia. No $74^{\circ}$ dia, os pesos dos nódulos no tratamento com Mo cairam em relação às plantas não sujeitas a essa adubação. Em ambos os casos, aos 46 dias foi a época em que se obteve o máximo peso de nódulos secos (Figura 18).

A aplicação de $\mathrm{N}$ no plantio, por outro lado, causou um grande decréscimo no peso dos nódulos secos (Figura 19). Os efeitos mais prejudiciais da aplicação de $20 \mathrm{~kg}$ de $\mathrm{N}$ no plantio ocorreram nos primeiros 46 dias, com decréscimo médio de $62 \%$; aos 60 dias, este percentual caiu para $35 \%$ e, aos 74 dias, para $9 \%$. Na presença ou na ausência de $\mathrm{N}$ no plantio o peso máximo dos nódulos secos foi obtido ao redor de 46 dias. 
Tabela 19 - Peso de nódulos secos (mg/planta), em Coimbra, MG (Local I).

\begin{tabular}{|c|c|c|c|c|c|c|c|c|}
\hline \multicolumn{4}{|c|}{ Tratamentos ${ }^{*}$} & \multicolumn{5}{|c|}{ Dias após a emergência } \\
\hline In & Mo & $\mathrm{Np}$ & $\mathrm{Nc}$ & 18 & 32 & 46 & 60 & 74 \\
\hline 0 & 0 & 0 & 0 & 31,34 & 35,50 & 51,63 & 32,31 & 33,70 \\
\hline 0 & 1 & 0 & 0 & 21,48 & 64,58 & 73,50 & 48,79 & 16,08 \\
\hline 0 & 0 & 1 & 0 & 12,03 & 24,55 & 47,77 & 54,83 & 19,88 \\
\hline 0 & 1 & 1 & 0 & 5,67 & 8,95 & 29,93 & 15,49 & 8,53 \\
\hline 0 & 0 & 0 & 1 & 12,92 & 45,87 & 16,35 & 27,13 & 8,93 \\
\hline 0 & 1 & 0 & 1 & 39,88 & 89,56 & 86,71 & 31,28 & 19,22 \\
\hline 0 & 0 & 1 & 1 & 7,96 & 16,13 & 14,32 & 12,27 & 2,81 \\
\hline 0 & 1 & 1 & 1 & 4,94 & 16,58 & 53,88 & 22,18 & 10,18 \\
\hline 1 & 0 & 0 & 0 & 21,22 & 43,40 & 62,86 & 47,67 & 33,47 \\
\hline 1 & 1 & 0 & 0 & 30,86 & 74,31 & 68,87 & 28,07 & 7,36 \\
\hline 1 & 0 & 1 & 0 & 6,27 & 13,98 & 20,49 & 36,44 & 12,41 \\
\hline 1 & 1 & 1 & 0 & 10,18 & 24,43 & 34,38 & 39,82 & 19,67 \\
\hline 1 & 0 & 0 & 1 & 27,90 & 58,27 & 57,68 & 40,96 & 18,84 \\
\hline 1 & 1 & 0 & 1 & 29,57 & 50,03 & 103,62 & 48,28 & 11,42 \\
\hline 1 & 0 & 1 & 1 & 4,23 & 5,98 & 10,97 & 12,16 & 10,36 \\
\hline 1 & 1 & 1 & 1 & 14,08 & 14,03 & 63,16 & 55,60 & 11,53 \\
\hline
\end{tabular}

(*) 0 = ausência

In = inoculação

Mo = molibdênio
$1=$ presença

$\mathrm{Np}=$ nitrogênio no plantio

$\mathrm{Nc}=$ nitrogênio em cobertura 


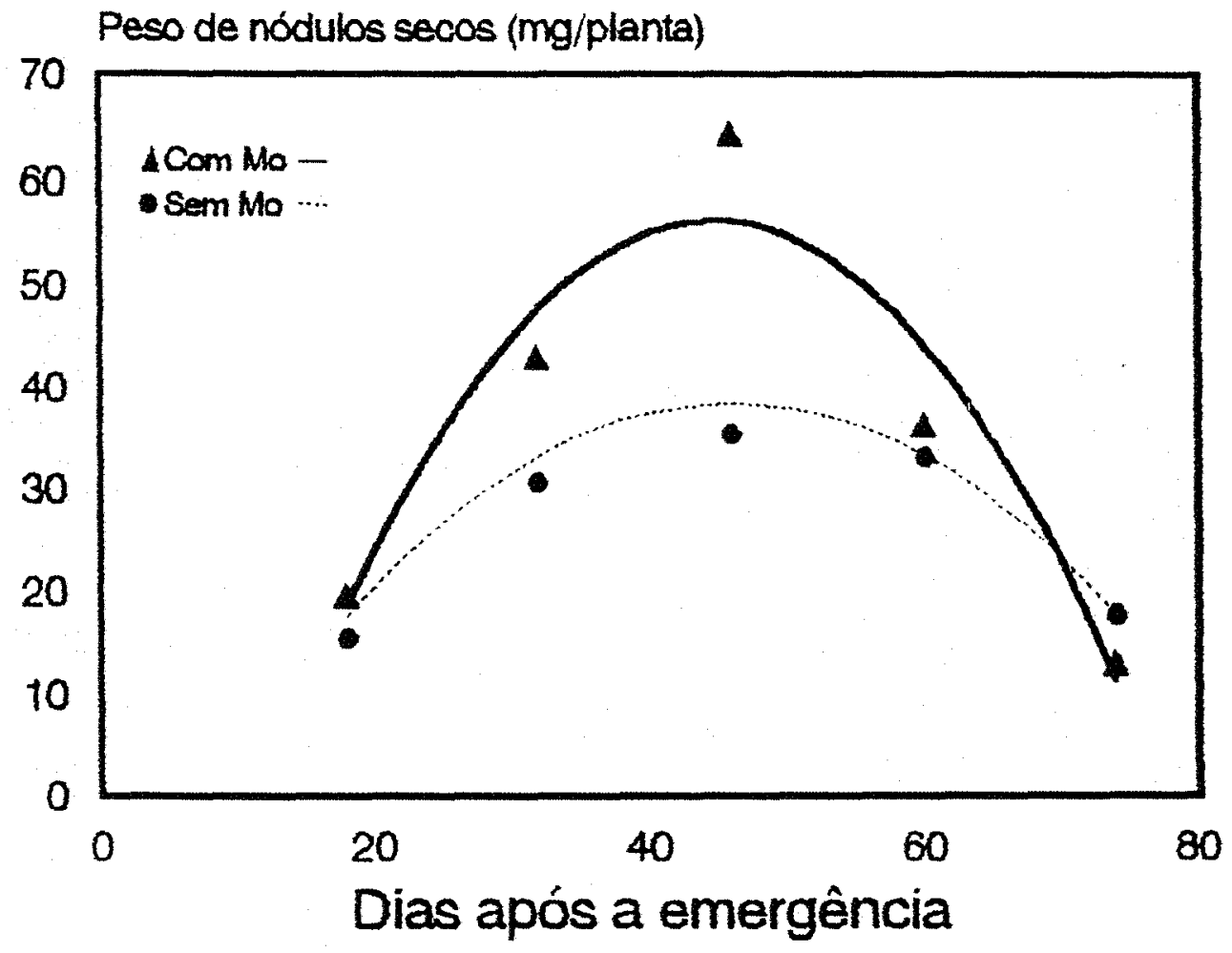

$\cdots Y=-17,6003+2,4293 \mathrm{Ep}-0,0264 \mathrm{Ep}^{2}\left(^{(\star)}\right)$
$-Y=-48,6819+4,6811 \mathrm{Ep}-0,0523 \mathrm{Ep}^{2}\left(^{\star \star}\right)$

Figura 18 - Efeito da interação Mo x épocas de avaliação no peso dos nódulos secos (mg/planta), em Coimbra, MG (Local I). 


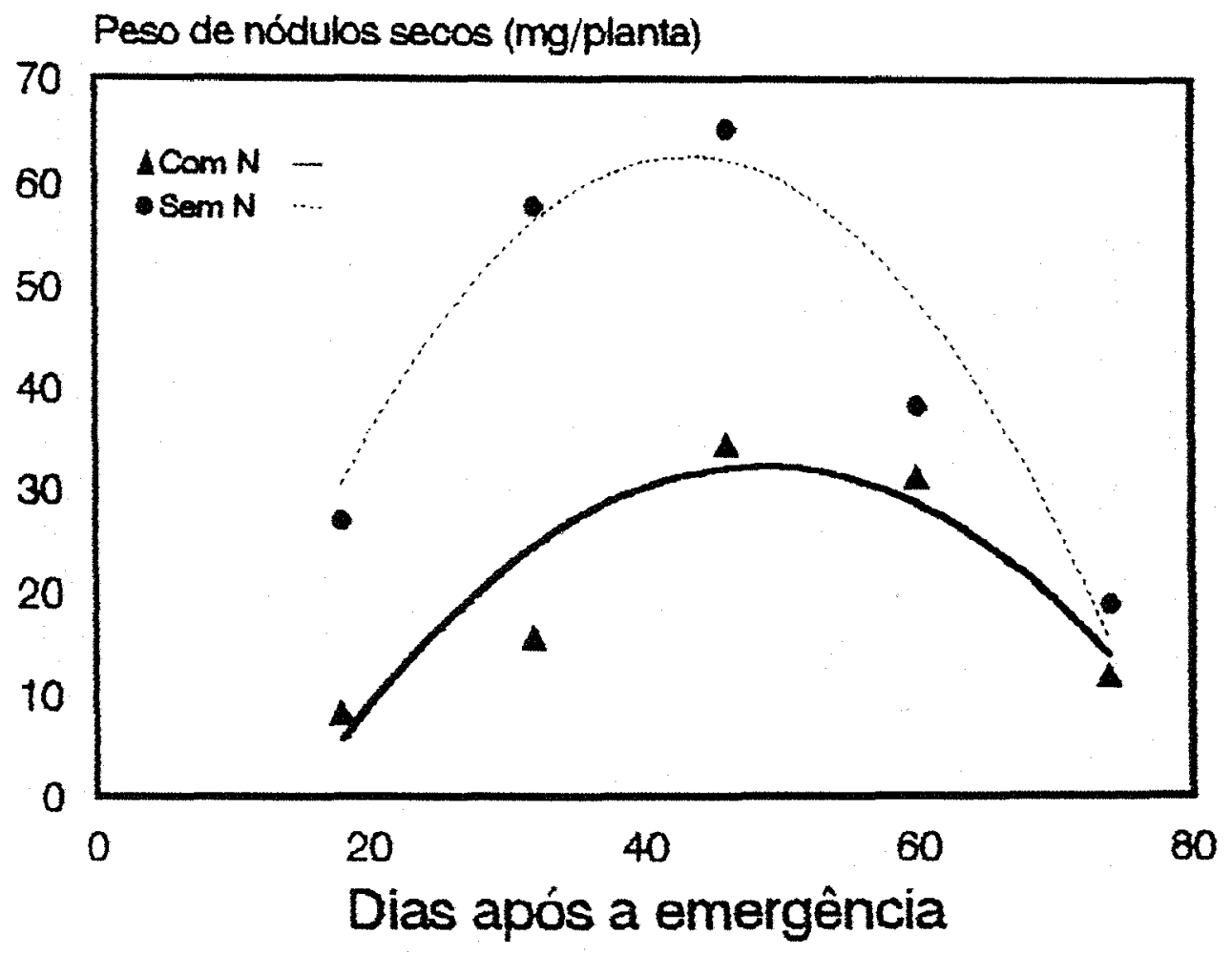

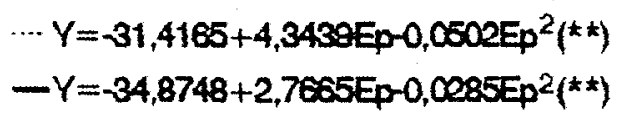

Figura 19 - Efeito da interação $\mathrm{N}$ no plantio x épocas de avaliação no peso dos nódulos secos (mg/planta), em Coimbra, MG (Local I). 
Os dados médios relativos à atividade da redutase do nitrato encontram-se na Tabela 20. A análise de variância mostrou que foram significativos os efeitos de Mo $(\mathrm{P}<0,01)$, épocas de avaliação $(\mathrm{P}<0,01)$ e a interação Mo $\mathrm{x}$ épocas de avaliação ( $\mathrm{P}$ $<0,01)$.

A redutase do nitrato nas plantas que não receberam Mo apresentou um máximo de atividade aos 18 dias de idade; com o decorrer do ciclo do feijoeiro esta atividade caiu linearmente até aos 74 dias (Figura 20). A adição de $40 \mathrm{~g} / \mathrm{ha}$ de $\mathrm{Mo}$ fez com que a atividade da redutase do nitrato apresentasse uma resposta quadrática e aumentasse sobremaneira, atingindo, aos 74 dias, um valor superior ao máximo obtido nas plantas sem Mo, aos 18 dias. Conforme também foi verificado no experimento de Viçosa, a aplicação de Mo fez com que fosse ampliado o período de alta atividade desta enzima. Com a aplicação do micronutriente, a máxima atividade da redutase do nitrato foi obtida aos 50 dias de idade.

A análise de variância dos dados de percentagem de $\mathrm{N}$-amoniacal na parte aérea revelou que foram significativos os efeitos de doses de Mo $(\mathrm{P}<0,01), \mathrm{N}$ em cobertura $(\mathrm{P}<0,01)$, épocas de avaliação $(\mathrm{P}<0,01)$ e as interações Mo $\mathrm{x}$ épocas de avaliação $(\mathrm{P}<0,01), \mathrm{N}$ no plantio $\mathrm{x}$ épocas de avaliação e $\mathrm{N}$ em cobertura $\mathrm{x}$ épocas de avaliação $(P<0,01)$. Os valores médios encontram-se na Tabela 21.

$\mathrm{Na}$ ausência e presença de Mo, a percentagem de $\mathrm{N}$-amoniacal na parte aérea apresentou uma resposta quadrática decrescente. O Mo fez com que a percentagem de $\mathrm{N}$-amoniacal na parte aérea fosse maior ao longo do ciclo do feijoeiro, quando comparado às plantas que não receberam adubação molíbdica (Figura 21). 
Tabela 20 - Atividade da redutase do nitrato $\left(\mu\right.$ moles de $\mathrm{NO}_{2}^{-} \cdot \mathrm{h}^{-1} \cdot$ g. de matéria fresca $^{-1}$ ), em Coimbra, MG (Local I).

\begin{tabular}{|c|c|c|c|c|c|c|c|c|}
\hline \multicolumn{4}{|c|}{ Tratamentos ${ }^{*}$} & \multicolumn{5}{|c|}{ Dias após a emergência } \\
\hline In & Mo & $\mathrm{Np}$ & $\mathrm{Nc}$ & 18 & 32 & 46 & 60 & 74 \\
\hline 0 & 0 & 0 & 0 & 3,77 & 3,01 & 2,85 & 3,77 & 2,69 \\
\hline 0 & 1 & 0 & 0 & 2,46 & 7,99 & 7,44 & 9,65 & 4,31 \\
\hline 0 & 0 & 1 & 0 & 6,20 & 4,83 & 2,32 & 0,30 & 1,07 \\
\hline 0 & 1 & 1 & 0 & 4,25 & 5,54 & 6,81 & 9,31 & 4,43 \\
\hline 0 & 0 & 0 & 1 & 3,31 & 4,14 & 5,18 & 6,52 & 2,39 \\
\hline 0 & 1 & 0 & 1 & 2,82 & 6,47 & 4,79 & 9,61 & 6,96 \\
\hline 0 & 0 & 1 & 1 & 3,81 & 3,93 & 5,10 & 4,38 & 2,85 \\
\hline 0 & 1 & 1 & 1 & 5,24 & 6,83 & 5,75 & 9,74 & 6,21 \\
\hline 1 & 0 & 0 & 0 & 2,45 & 3,80 & 2,64 & 0,63 & 1,23 \\
\hline 1 & 1 & 0 & 0 & 4,27 & 8,10 & 6,06 & 10,99 & 5,04 \\
\hline 1 & 0 & 1 & 0 & 5,30 & 4,46 & 2,47 & 0,47 & 1,30 \\
\hline 1 & 1 & 1 & 0 & 4,31 & 6,04 & 5,44 & 8,03 & 5,00 \\
\hline 1 & 0 & 0 & 1 & 2,35 & 4,37 & 2,40 & 0,83 & 1,01 \\
\hline 1 & 1 & 0 & 1 & 3,70 & 8,40 & 7,36 & 10,20 & 5,16 \\
\hline 1 & 0 & 1 & 1 & 3,31 & 7,43 & 3,99 & 4,19 & 2,23 \\
\hline 1 & 1 & 1 & 1 & 4,06 & 7,12 & 8,27 & 10,71 & 4,77 \\
\hline
\end{tabular}

$\left(^{*}\right) 0$ = ausência

$1=$ presença

In $=$ inoculação

$\mathrm{Np}=$ nitrogênio no plantio

Mo = molibdênio

$\mathrm{Nc}=$ nitrogênio em cobertura 
Atividade da redutase do nitrato ( $\mu$ moles de $\mathrm{NO}_{2}^{-} \cdot h^{-1} \cdot g$ de matéria fresca $\left.{ }^{-1}\right)$

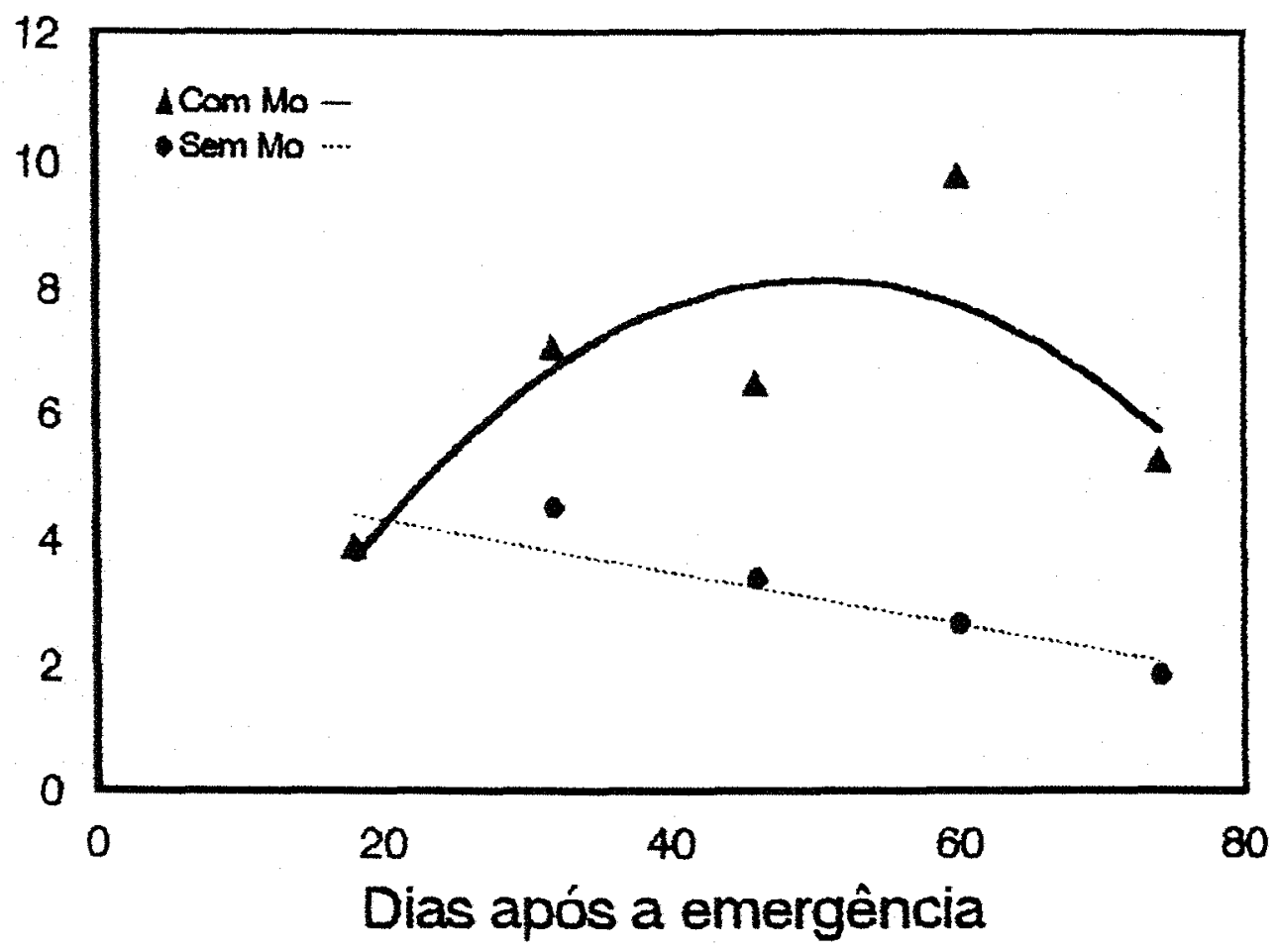

… $Y=5,13890,0414 E p\left({ }^{\star \star}\right)$

$\left.-Y=-2,6835+0,4315 E \mathrm{E}-0,0043 E p^{2}{ }^{\star \star \star}\right)$

Figura 20 - Efeito da interação Mo x épocas de avaliação na atividade da redutase do nitrato ( $\mu$ moles de $\mathrm{NO}_{2} \cdot h^{-1}$. g. de matéria fresca $\left.{ }^{-1}\right)$, em Coimbra, MG (Local I). 
Tabela 21 - Percentagem de N-amoniacal na parte aérea, em Coimbra, MG (Local I).

\begin{tabular}{|c|c|c|c|c|c|c|c|c|}
\hline \multicolumn{4}{|c|}{ Tratamentos ${ }^{*}$} & \multicolumn{5}{|c|}{ Dias após a emergência } \\
\hline In & Mo & $\mathrm{Np}$ & $\mathrm{Nc}$ & 18 & 32 & 46 & 60 & 74 \\
\hline 0 & 0 & 0 & 0 & 3,78 & - & 3,05 & 2,29 & 1,48 \\
\hline 0 & 1 & 0 & 0 & 3,64 & - & 3,55 & 2,71 & 1,76 \\
\hline 0 & 0 & 1 & 0 & 4,70 & - & 2,13 & 1,71 & 1,19 \\
\hline 0 & 1 & 1 & 0 & 4,36 & - & 3,49 & 2,49 & 1,67 \\
\hline 0 & 0 & 0 & 1 & 3,63 & - & 3,24 & 2,87 & 1,56 \\
\hline 0 & 1 & 0 & 1 & 3,08 & - & 4,04 & 3,26 & - \\
\hline 0 & 0 & 1 & 1 & 4,52 & - & 3,66 & 2,78 & - \\
\hline 0 & 1 & 1 & 1 & 4,50 & - & 3,07 & 2,63 & 1,81 \\
\hline 1 & 0 & 0 & 0 & 3,57 & - & 2,97 & 1,87 & 1,28 \\
\hline 1 & 1 & 0 & 0 & 3,67 & - & 3,39 & 2,73 & 1,82 \\
\hline 1 & 0 & 1 & 0 & 4,64 & - & 2,13 & 1,61 & 1,16 \\
\hline 1 & 1 & 1 & 0 & 4,34 & - & 3,07 & 2,73 & 1,84 \\
\hline 1 & 0 & 0 & 1 & 3,71 & - & 3,00 & 2,25 & 1,47 \\
\hline 1 & 1 & 0 & 1 & 3,36 & - & 3,56 & 3,01 & 1,84 \\
\hline 1 & 0 & 1 & 1 & 4,25 & - & 3,05 & 2,95 & 1,75 \\
\hline 1 & 1 & 1 & 1 & 4,51 & - & 3,64 & 2,76 & 1,84 \\
\hline
\end{tabular}

(*) 0 = ausência;

In = inoculação

Mo $=$ molibdênio
$1=$ presença

$\mathrm{Np}=$ nitrogênio no plantio

$\mathrm{Nc}=$ nitrogênio em cobertura 
Percentagem de $\mathrm{N}$-amoniacal na parte aérea.

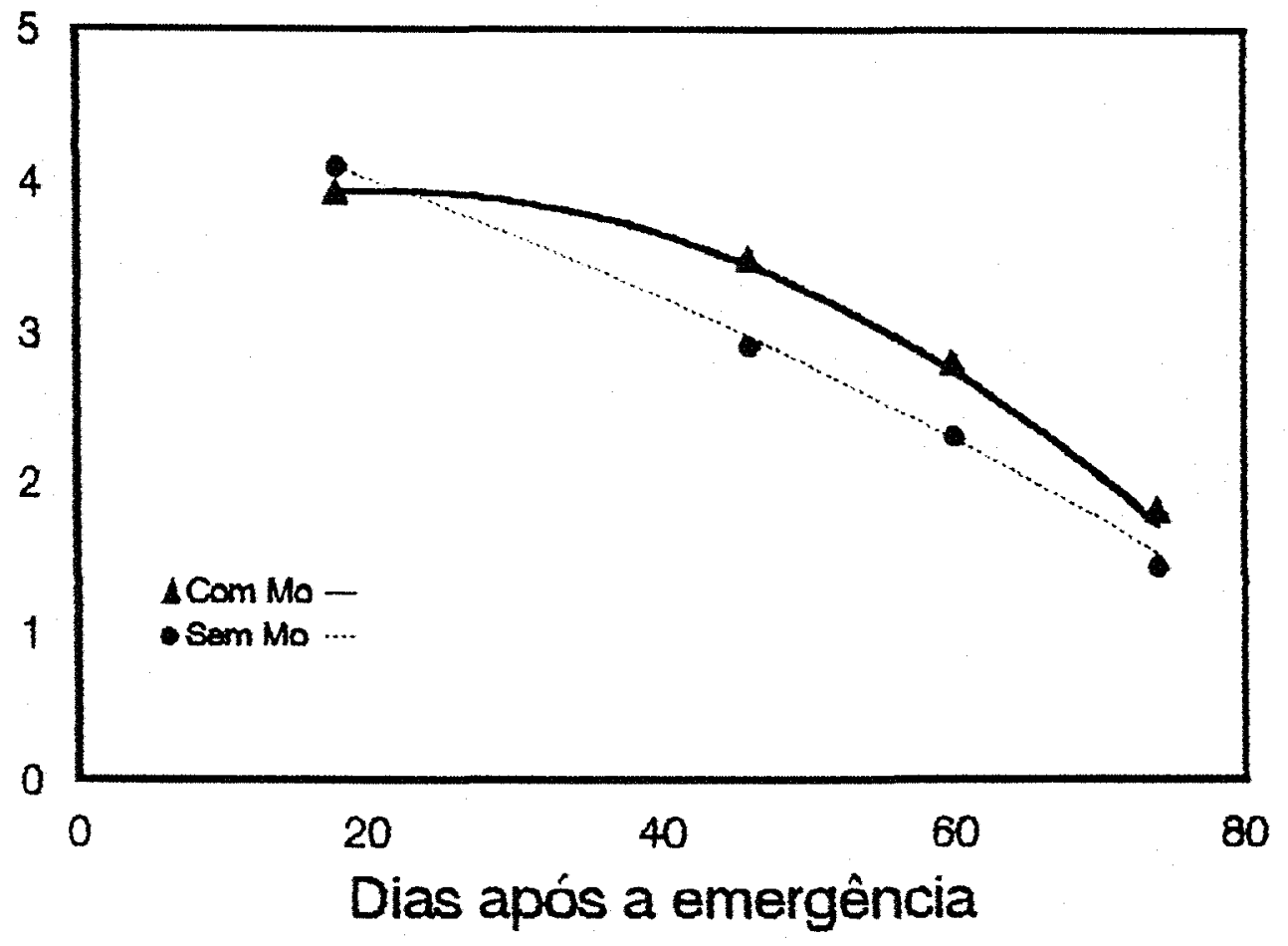

$$
\begin{aligned}
& \cdots Y=4,6656-0,0278 E p-0,0002 E p\left(^{*}\right) \\
& -Y=3,5815+0,0038 E p+0,0008 E p^{2}\left(^{k *}\right)
\end{aligned}
$$

Figura 21 - Efeito da interação Mo x épocas de avaliação na percentagem de $\mathrm{N}$ amoniacal na parte aérea, em Coimbra, MG (Local I). 
$\mathrm{O}$ desdobramento da interação $\mathrm{N}$ no plantio $\mathrm{x}$ épocas de avaliação mostrou que, na ausência da adubação nitrogenada de plantio, a percentagem de $\mathrm{N}$-amoniacal na parte aérea apresentou uma resposta quadrática, com um máximo aos 29 dias, ao passo que na presença de $20 \mathrm{~kg} /$ ha de $\mathrm{N}$ a resposta foi linear (Figura 22). A adição de $\mathrm{N}$ no plantio fez com que a percentagem de $\mathrm{N}$-amoniacal na parte aérea fosse menor ao longo do ciclo do feijoeiro, do que a observada nas plantas não submetidas a essa adubação. Tal efeito pode ser atribuído ao fenômeno de diluição desse elemento, em virtude do maior crescimento das plantas na presença da adubação nitrogenada de plantio (Figura 22).

$\mathrm{Na}$ ausência e presença da adubação nitrogenada de cobertura, a percentagem de $\mathrm{N}$ na parte aérea apresentou resposta quadrática (Figura 23). Na presença de $\mathrm{N}$ em cobertura, as plantas apresentaram uma maior percentagem de $\mathrm{N}$ amoniacal na parte aérea ao longo do ciclo do feijoeiro, em comparação às que não receberam essa adubação.

$\mathrm{Na}$ análise de variância da quantidade total de $\mathrm{N}$-amoniacal na parte aérea, verificou-se que foram significativos os efeitos de Mo $(P<0,01), N$ em cobertura ( $P$ $<0,01)$, épocas de avaliação $(\mathrm{P}<0.01)$ e as interações inoculação $\mathrm{x}$ Mo $(\mathrm{P}<0,05)$, Mo $x$ épocas de avaliação $(\mathrm{P}<0,01)$ e $\mathrm{N}$ em cobertura $\mathrm{x}$ épocas de avaliação $(\mathrm{P}<$ 0,05). Os dados médios se encontram na Tabela 22.

$\mathrm{Na}$ ausência de $\mathrm{Mo}$, a inoculação diminuiu a quantidade total de $\mathrm{N}$ amoniacal na parte aérea, enquanto que, com a adição de $40 \mathrm{~g} / \mathrm{ha}$ de $\mathrm{Mo}$, as plantas inoculadas apresentaram maior quantidade que as não inoculadas (Tabela 23). 
Percentagem de $\mathrm{N}$-amoniacal na parte aérea.

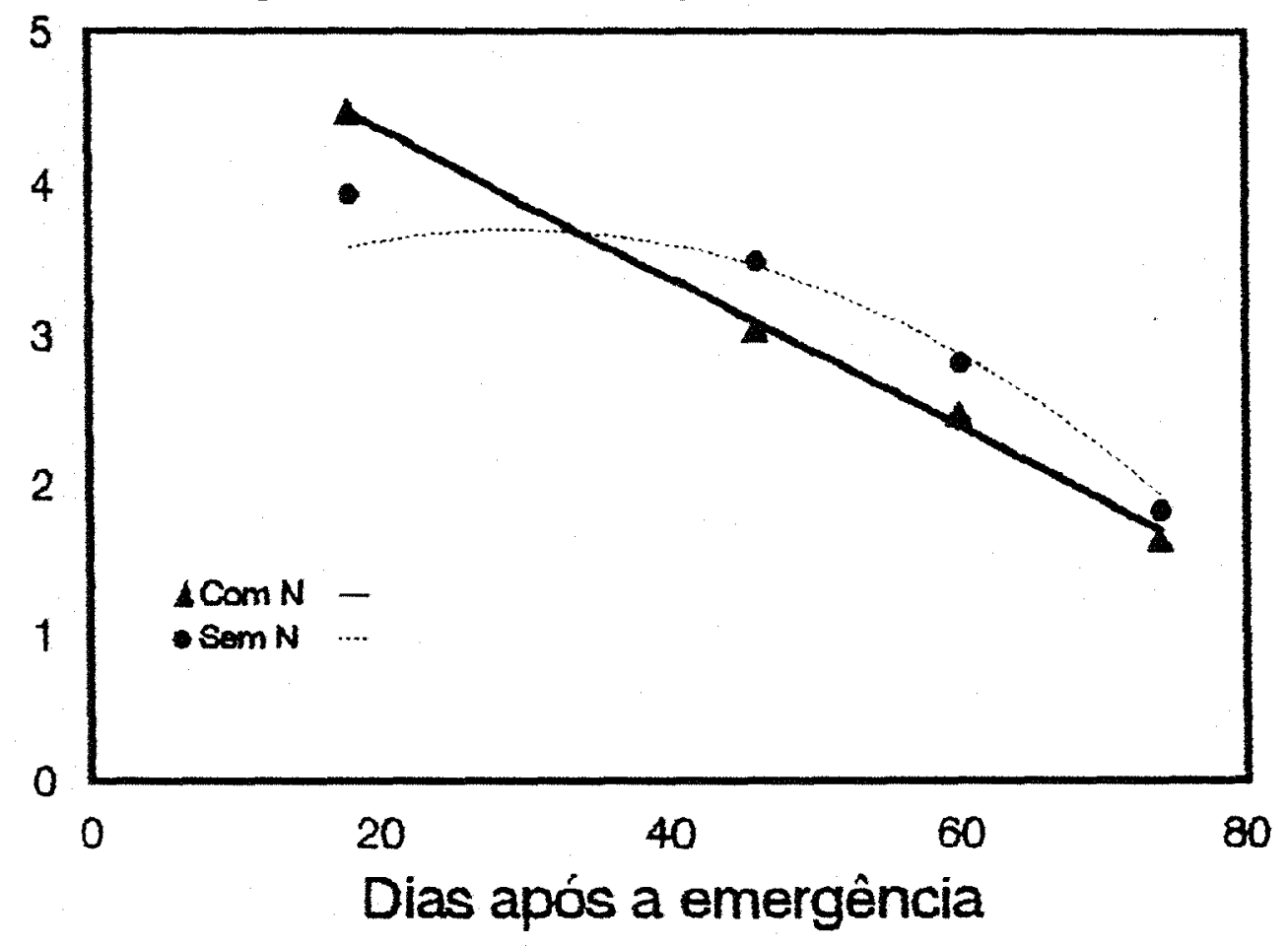

… $Y=2,9165+0,0531 E p-0,0000 E p^{2}(* *)$

$-Y=5,3257-0,0502 E$ ( $\left.^{* \star}\right)$

Figura 22 - Efeito da interação $\mathrm{N}$ no plantio $\mathrm{x}$ épocas de avaliação na percentagem de $\mathrm{N}$-amoniacal na parte aérea, em Coimbra, MG (Local I). 


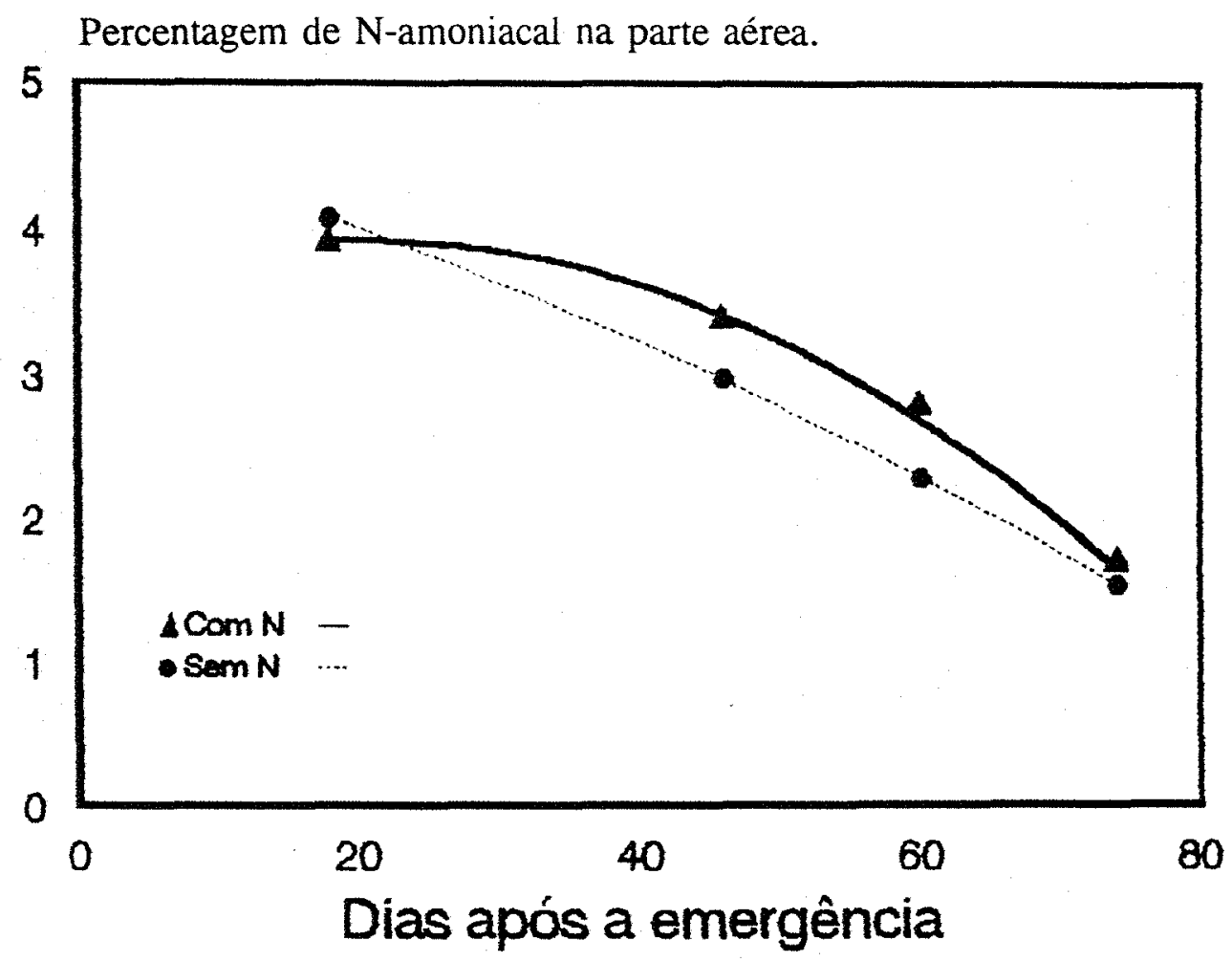

$$
\begin{aligned}
& \cdots . Y=4,05000,0275 E p-0,0002 E p^{2}\left({ }^{\star}\right) \\
& -Y=3,6066+0,0326 E p-0,0008 E p^{2}\left({ }^{\star \star}\right)
\end{aligned}
$$

Figura 23 - Efeito da interação $\mathrm{N}$ em cobertura $\mathrm{x}$ épocas de avaliação na percentagem de N-amoniacal na parte aérea, em Coimbra, MG (Local I). 
Tabela 22 - Quantidade total de $\mathrm{N}$-amoniacal na parte aérea (mg/planta), em Coimbra, MG (Local I).

\begin{tabular}{|c|c|c|c|c|c|c|c|c|}
\hline \multicolumn{4}{|c|}{ Tratamentos ${ }^{*}$} & \multicolumn{5}{|c|}{ Dias após a emergência } \\
\hline In & Mo & $\mathrm{Np}$ & $\mathrm{Nc}$ & 18 & 32 & 46 & 60 & 74 \\
\hline 0 & 0 & 0 & 0 & 20,16 & - & 114,80 & 123,87 & 67,47 \\
\hline 0 & 1 & 0 & 0 & 15,69 & - & 129,79 & 129,35 & 69,10 \\
\hline 0 & 0 & 1 & 0 & 37,55 & - & 149,93 & 117,46 & 53,25 \\
\hline 0 & 1 & 1 & 0 & 27,98 & - & 145,59 & 123,98 & 73,33 \\
\hline 0 & 0 & 0 & 1 & 20,20 & - & 142,24 & 188,80 & 74,94 \\
\hline 0 & 1 & 0 & 1 & 18,43 & - & 178,51 & 212,40 & - \\
\hline 0 & 0 & 1 & 1 & 26,64 & - & 146,48 & 162,26 & 78,97 \\
\hline 0 & 1 & 1 & 1 & 30,57 & - & 166,27 & 182,60 & 139,18 \\
\hline 1 & 0 & 0 & 0 & 13,34 & - & 87,08 & 70,77 & 37,76 \\
\hline 1 & 1 & 0 & 0 & 17,52 & - & 146,08 & 191,59 & 109,41 \\
\hline 1 & 0 & 1 & 0 & 33,12 & - & 105,29 & 81,28 & 39,60 \\
\hline 1 & 1 & 1 & 0 & 31,61 & - & 158,56 & 229,62 & 126,06 \\
\hline 1 & 0 & 0 & 1 & 15,82 & - & 110,13 & 89,20 & 52,66 \\
\hline 1 & 1 & 0 & 1 & 14,96 & - & 162,76 & 173,32 & 127,31 \\
\hline 1 & 0 & 1 & 1 & 26,74 & - & 164,48 & 200,75 & 90,92 \\
\hline 1 & 1 & 1 & 1 & 34,02 & - & 206,61 & 224,16 & 130,61 \\
\hline
\end{tabular}
$\left.{ }^{*}\right) 0$ = ausência;
$1=$ presença
In $=$ inoculação
$\mathrm{Np}=$ nitrogênio no plantio
Mo = molibdênio
$\mathrm{Nc}=$ nitrogênio em cobertura 
Tabela 23 - Efeito de interação inoculação x Mo sobre a quantidade total de Namoniacal na parte aérea (mg/planta), em Coimbra, MG (Local I).

\begin{tabular}{ccc}
\hline \hline & \multicolumn{2}{c}{ Molibdênio } \\
\cline { 2 - 3 } Inoculação & $0 \mathrm{~g} / \mathrm{ha}$ & $40 \mathrm{~g} / \mathrm{ha}$ \\
\hline Sem inoculação & $95,31 \mathrm{aA}$ & $110,62 \mathrm{bA}$ \\
Com inoculação & $76,18 \mathrm{bB}$ & $130,26 \mathrm{aA}$ \\
\hline \hline
\end{tabular}

${ }^{*}$ ) Médias seguidas pela mesma letra minúscula, na vertical, e maiúscula, na horizontal, não diferem siginificativamente pelo teste de Duncan, ao nível de $5 \%$.

Independentemente da inoculação, a adubação foliar com Mo aumentou a quantidade total de $\mathrm{N}$-amoniacal na parte aérea ao longo do ciclo do feijoeiro (Figura 24); aos $32,46,60$ e 74 dias, a quantidade de $\mathrm{N}$-amoniacal na parte aérea das plantas que receberam o micronutriente foi de $21,29,40$ e $61 \%$, respectivamente, maior do que nas plantas que não o receberam.

O ponto de máxima quantidade de $\mathrm{N}$-amoniacal da parte aérea, foi obtido aos 49 dias nas plantas que não receberam Mo e, aos 53 dias, nas plantas submetidas à pulverização com o micronutriente.

Resultados semelhantes aos obtidos com as quantidades totais de $\mathrm{N}$ amoniacal na parte aérea, em decorrência da aplicação de Mo, foram também verificados com a adição de $30 \mathrm{~kg}$ de $\mathrm{N}$ em cobertura (Figura 25); aos 32, 46, 60 e 74 dias 


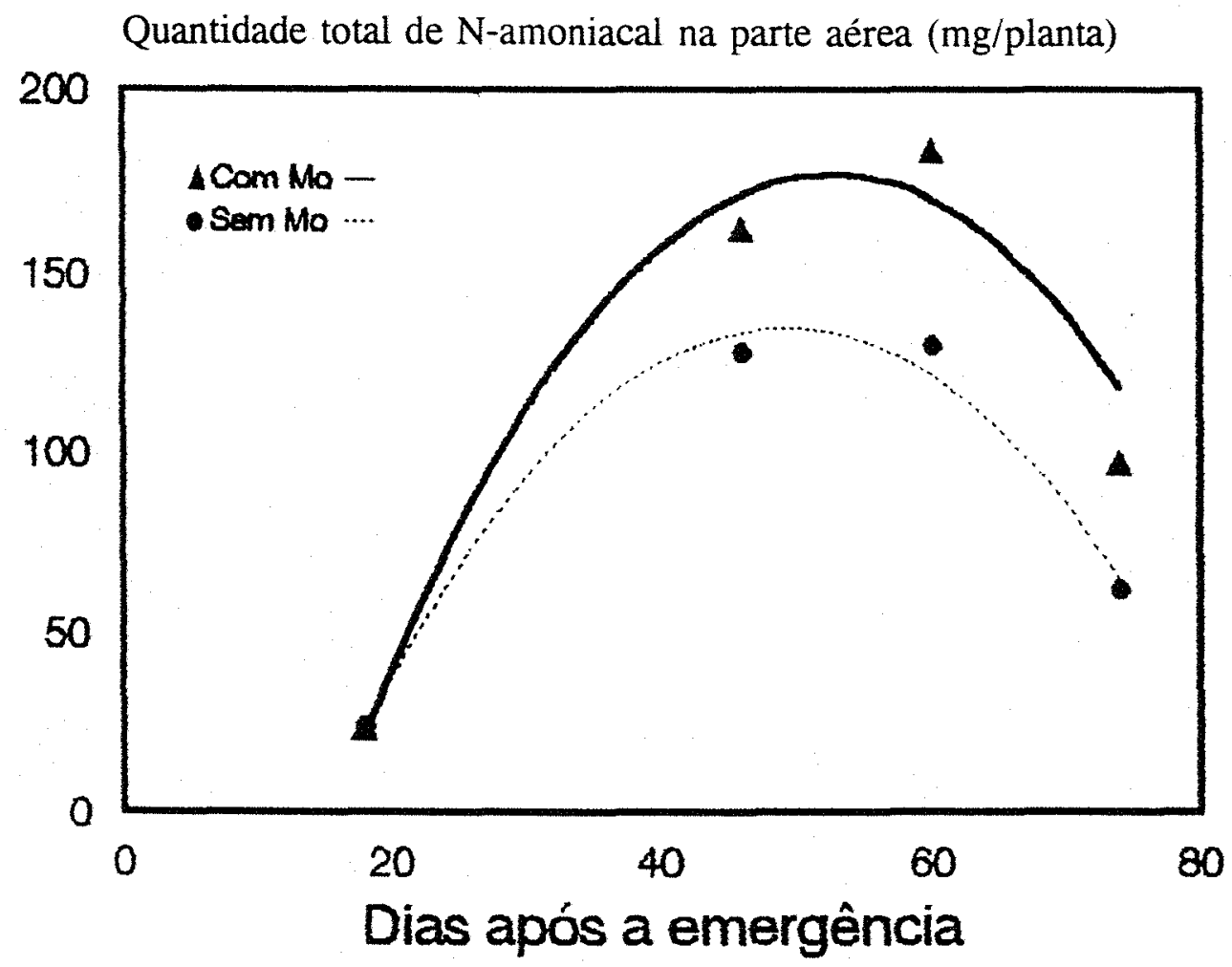

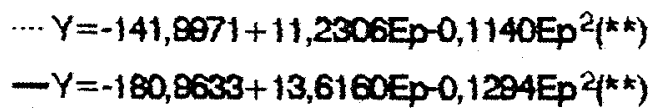

Figura 24 - Efeito da interação Mo x épocas de avaliação na quantidade total de Namoniacal na parte aérea, em Coimbra, MG (Local I). 

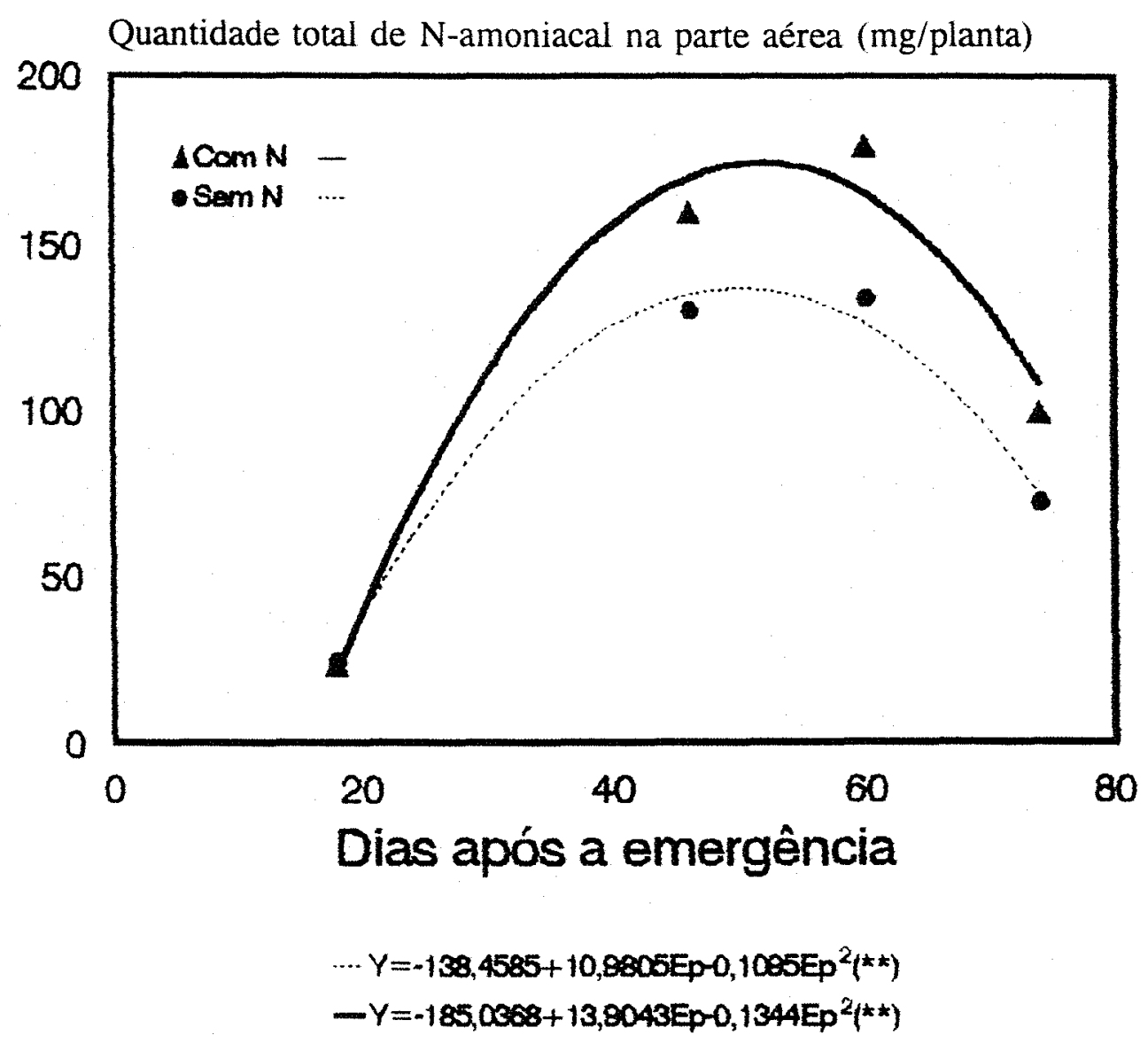

Figura 25 - Efeito da interação $\mathrm{N}$ em cobertura x épocas de avaliação na quantidade total de $\mathrm{N}$-amoniacal na parte aérea, em Coimbra, MG (Local I). 
houve um aumento de $21,26,31$ e $45 \%$ naquele parâmetro, em decorrência da aplicação de $\mathrm{N}$ em cobertura, quando comparado com as plantas que não o receberam. $\mathrm{O}$ ponto de máximo foi obtido aos 51 dias, tanto na presença como na ausência de $\mathrm{N}$ em cobertura.

A análise de variância dos dados de percentagem de $\mathrm{N}-\mathrm{NO}_{3}{ }^{-}$na parte aérea mostrou que foram significativos os efeitos de $\mathrm{N}$ no plantio $(\mathrm{P}<0,01), \mathrm{N}$ em cobertura $(\mathrm{P}<0,01)$, épocas de avaliação $(\mathrm{P}<0,01)$ e as interações Mo x $\mathrm{N}$ no plantio $(\mathrm{P}<$ $0,05)$ e $\mathrm{N}$ no plantio $\mathrm{x}$ épocas de avaliação $(\mathrm{P}<0,01)$. Os dados médios encontram-se na Tabela 24.

A percentagem de $\mathrm{N}-\mathrm{NO}_{3}^{-}$na parte aérea apresentou uma resposta quadrática à aplicação de $\mathrm{N}$ no plantio, em relação à̀s épocas de avaliação (Figura 26). Somente no início do ciclo do feijoeiro, ou seja, aos 18 dias, a aplicação de $\mathrm{N}$ no plantio causou um acentuado aumento dessa percentagem, em relação às plantas nãosubmetidas a essa adubação.

A percentagem de $\mathrm{N}-\mathrm{NO}_{3}$ na parte aérea, como conseqüência da aplicação de $\mathrm{N}$ no plantio, esteve também relacionado à aplicação ou não de molibdênio às plantas (Tabela 25). Na ausência da adubação nitrogenada de plantio, a aplicação de $40 \mathrm{~g} /$ ha de Mo não teve efeito significativo, enquanto que, na presença de $20 \mathrm{~kg} / \mathrm{ha}$ de $\mathrm{N}$ no plantio, a pulverização com o micronutriente causou um decréscimo de $27 \%$ na percentagem de $\mathrm{N}-\mathrm{NO}_{3}^{-}$na parte aérea. 
Tabela 24 - Percentagem de $\mathrm{N}^{-\mathrm{NO}_{3}}{ }^{-}$na parte aérea, em Coimbra, MG (Local I).

\begin{tabular}{|c|c|c|c|c|c|c|c|c|}
\hline \multicolumn{4}{|c|}{ Tratamentos* } & \multicolumn{5}{|c|}{ Dias após a emergência } \\
\hline In & Mo & $\mathrm{Np}$ & $\mathrm{Nc}$ & 18 & 32 & 46 & 60 & 74 \\
\hline 0 & 0 & 0 & 0 & 0,13 & - & 0,06 & 0,04 & 0,01 \\
\hline 0 & 1 & 0 & 0 & 0,10 & - & 0,02 & 0,02 & 0,008 \\
\hline 0 & 0 & 1 & 0 & 0,23 & - & 0,01 & 0,009 & 0,008 \\
\hline 0 & 1 & 1 & 0 & 0,21 & - & 0,03 & 0,01 & 0,01 \\
\hline 0 & 0 & 0 & 1 & 0,15 & - & 0,09 & 0,03 & 0,01 \\
\hline 0 & 1 & 0 & 1 & 0,11 & - & 0,09 & 0,03 & 0,01 \\
\hline 0 & 0 & 1 & 1 & 0,18 & - & 0,05 & 0,03 & 0,01 \\
\hline 0 & 1 & 1 & 1 & 0,32 & - & 0,04 & 0,01 & 0,01 \\
\hline 1 & 0 & 0 & 0 & 0,08 & - & 0,03 & 0,02 & 0,006 \\
\hline 1 & 1 & 0 & 0 & 0,13 & - & 0,04 & 0,03 & 0,007 \\
\hline 1 & 0 & 1 & 0 & 0,33 & - & 0,02 & 0,31 & 0,009 \\
\hline 1 & 1 & 1 & 0 & 0,22 & - & 0,03 & 0,01 & 0,01 \\
\hline 1 & 0 & 0 & 1 & 0,08 & - & 0,06 & 0,01 & 0,007 \\
\hline 1 & 1 & 0 & 1 & 0,11 & - & 0,04 & 0,01 & 0,01 \\
\hline 1 & 0 & 1 & 1 & 0,30 & - & 0,07 & 0,03 & 0,008 \\
\hline 1 & 1 & 1 & 1 & 0,24 & - & 0,03 & 0,02 & 0,01 \\
\hline
\end{tabular}

$\left(^{*}\right) 0$ = ausência

In = inoculação

Mo $=$ molibdênio
$1=$ presença

$\mathrm{Np}=$ nitrogênio no plantio

$\mathrm{Nc}=$ nitrogênio em cobertura 


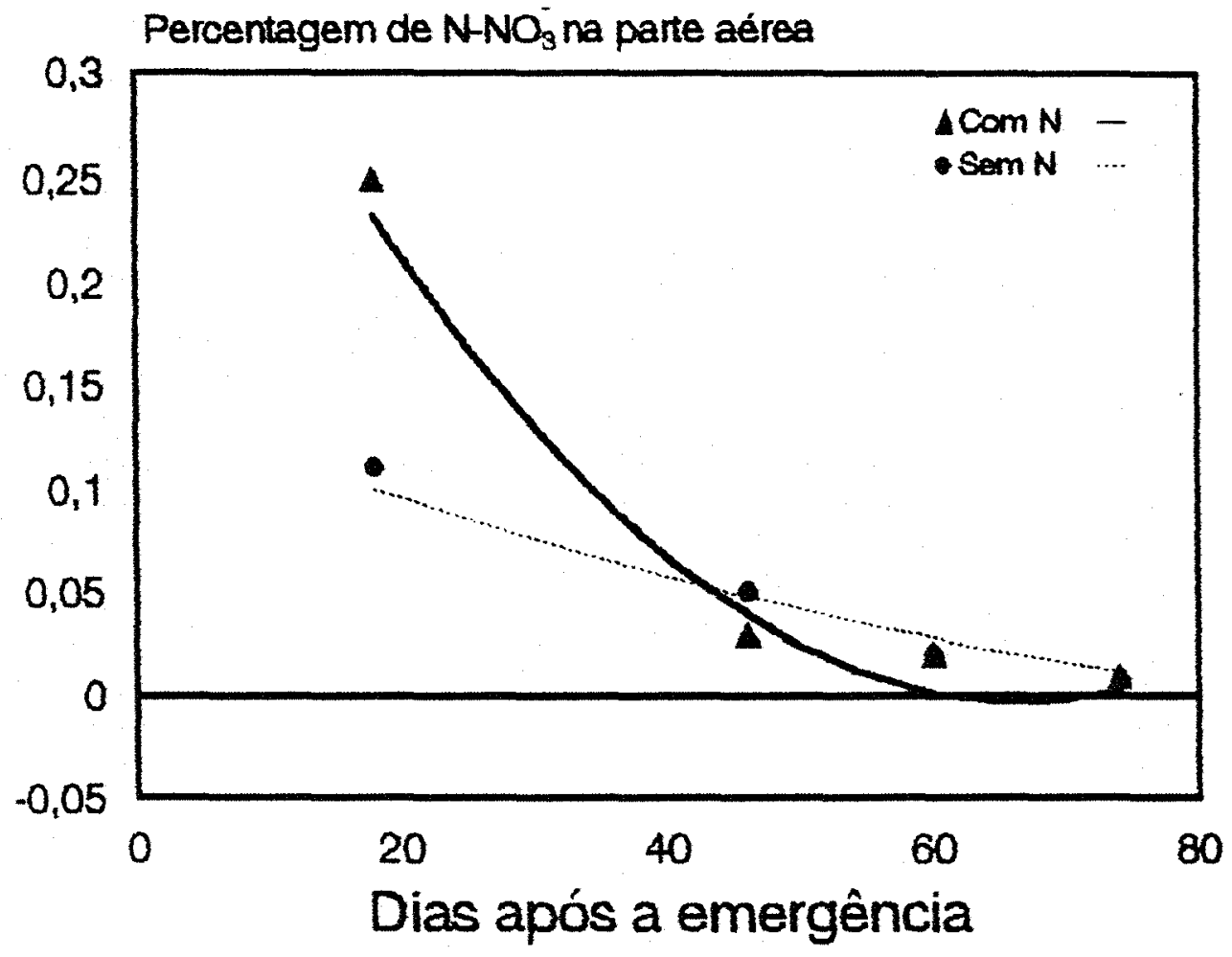

$$
\begin{aligned}
& \cdots Y=0,1416-0,0005 E p+0,00001 E p^{2}(* k) \\
& -Y=0,4395-0,0133 E p+0,0001 E p^{2}\left(^{* k}\right)
\end{aligned}
$$

Figura 26 - Efeito da interação $\mathrm{N}$ no plantio $\mathrm{x}$ épocas de avaliação na percentagem de $\mathrm{N}-\mathrm{NO}_{3}{ }^{-}$na parte aérea, em Coimbra, MG (Local I). 


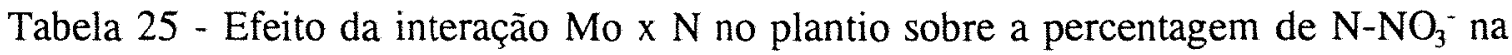
parte aérea, em Coimbra, MG (Local I).

\begin{tabular}{ccc}
\hline & \multicolumn{2}{c}{ Nitrogênio no plantio } \\
\cline { 2 - 3 } Molibdênio & $0 \mathrm{~kg} / \mathrm{ha}$ & $20 \mathrm{~kg} / \mathrm{ha}$ \\
\hline $0 \mathrm{~g} / \mathrm{ha}$ & $0,046 \mathrm{aB}$ & $0,096 \mathrm{aA}$ \\
$40 \mathrm{~g} / \mathrm{ha}$ & $0,052 \mathrm{aB}$ & $0,070 \mathrm{bA}$ \\
\hline
\end{tabular}

* Médias seguidas pela mesma letra minúscula, na vertical, e maiúscula, na horizontal, não diferem siginificativamente pelo teste de Duncan, ao nível de $5 \%$.

Conforme demonstra a análise de variância dos dados de quantidades totais de $\mathrm{N}-\mathrm{NO}_{3} \cdot$ na parte aérea, foram significativos os efeitos de $\mathrm{N}$ no plantio $(\mathrm{P}<0,05), \mathrm{N}$ em cobertura $(\mathrm{P}<0,01)$, épocas de avaliação $(\mathrm{P}<0,01)$ e as interações $\mathrm{N}$ no plantio $x$ épocas de avaliação $(P<0,01)$ e $N$ em cobertura $x$ épocas de avaliação $(P<0,01)$. Os dados médios encontram-se na Tabela 26.

A quantidade total de $\mathrm{N}-\mathrm{NO}_{3}^{-}$na parte área apresentou resposta quadrática, tanto na ausência como na presença de $\mathrm{N}$ no plantio, ou de $\mathrm{N}$ em cobertura, em relação às épocas de avaliação (Figuras 27 e 28).

A aplicação de $\mathrm{N}$ no plantio fez com que a quantidade total de $\mathrm{N}-\mathrm{NO}_{3}^{-}$ aumentasse sobremaneira em relação às plantas isentas desta adubação, mas somente no início do ciclo do feijoeiro; aos 48 dias, a diferença foi de $113 \%$ a favor das plantas adubadas com $\mathrm{N}$ no início do ciclo do feijoeiro (Figura 27). 
Tabela 26 - Quantidade total de $\mathrm{N}_{-} \mathrm{NO}_{3}$ na parte aérea (mg/planta), em Coimbra, MG (Local I).

\begin{tabular}{|c|c|c|c|c|c|c|c|c|}
\hline \multicolumn{4}{|c|}{ Tratamentos ${ }^{*}$} & \multicolumn{5}{|c|}{ Dias após a emergência } \\
\hline In & Mo & $\mathrm{Np}$ & $\mathrm{Nc}$ & 18 & 32 & 46 & 60 & 74 \\
\hline 0 & 0 & 0 & 0 & 0,73 & - & 2,57 & 2,29 & 0,66 \\
\hline 0 & 1 & 0 & 0 & 0,43 & - & 0,96 & 1,32 & 0,33 \\
\hline 0 & 0 & 1 & 0 & 2,48 & - & 1,24 & 0,67 & 0,38 \\
\hline 0 & 1 & 1 & 0 & 1,38 & - & 1,43 & 0,77 & 0,63 \\
\hline 0 & 0 & 0 & 1 & 0,86 & - & 4,80 & 2,50 & 0,83 \\
\hline 0 & 1 & 0 & 1 & 0,71 & - & 3,17 & 2,24 & 0,97 \\
\hline 0 & 0 & 1 & 1 & 1,12 & - & 2,38 & 2,22 & 0,67 \\
\hline 0 & 1 & 1 & 1 & 2,40 & - & 2,24 & 1,39 & 0,83 \\
\hline 1 & 0 & 0 & 0 & 0,29 & - & 0,95 & 0,74 & 0,16 \\
\hline 1 & 1 & 0 & 0 & 0,65 & - & 1,82 & 2,07 & 0,48 \\
\hline 1 & 0 & 1 & 0 & 2,33 & - & 1,11 & 0,85 & 0,31 \\
\hline 1 & 1 & 1 & 0 & 1,57 & - & 1,61 & 1,44 & 0,86 \\
\hline 1 & 0 & 0 & 1 & 0,35 & - & 2,04 & 0,72 & 0,25 \\
\hline 1 & 1 & 0 & 1 & 0,50 & - & 2,07 & 1,06 & 1,05 \\
\hline 1 & 0 & 1 & 1 & 1,93 & - & 4,19 & 2,62 & 0,61 \\
\hline 1 & 1 & 1 & 1 & 1,83 & - & 2,08 & 2,13 & 1,35 \\
\hline
\end{tabular}

(*) 0 = ausência;

In = inoculação

Mo $=$ molibdênio
$1=$ presença

$\mathrm{Np}=$ nitrogênio no plantio

$\mathrm{Nc}=$ nitrogênio em cobertura 


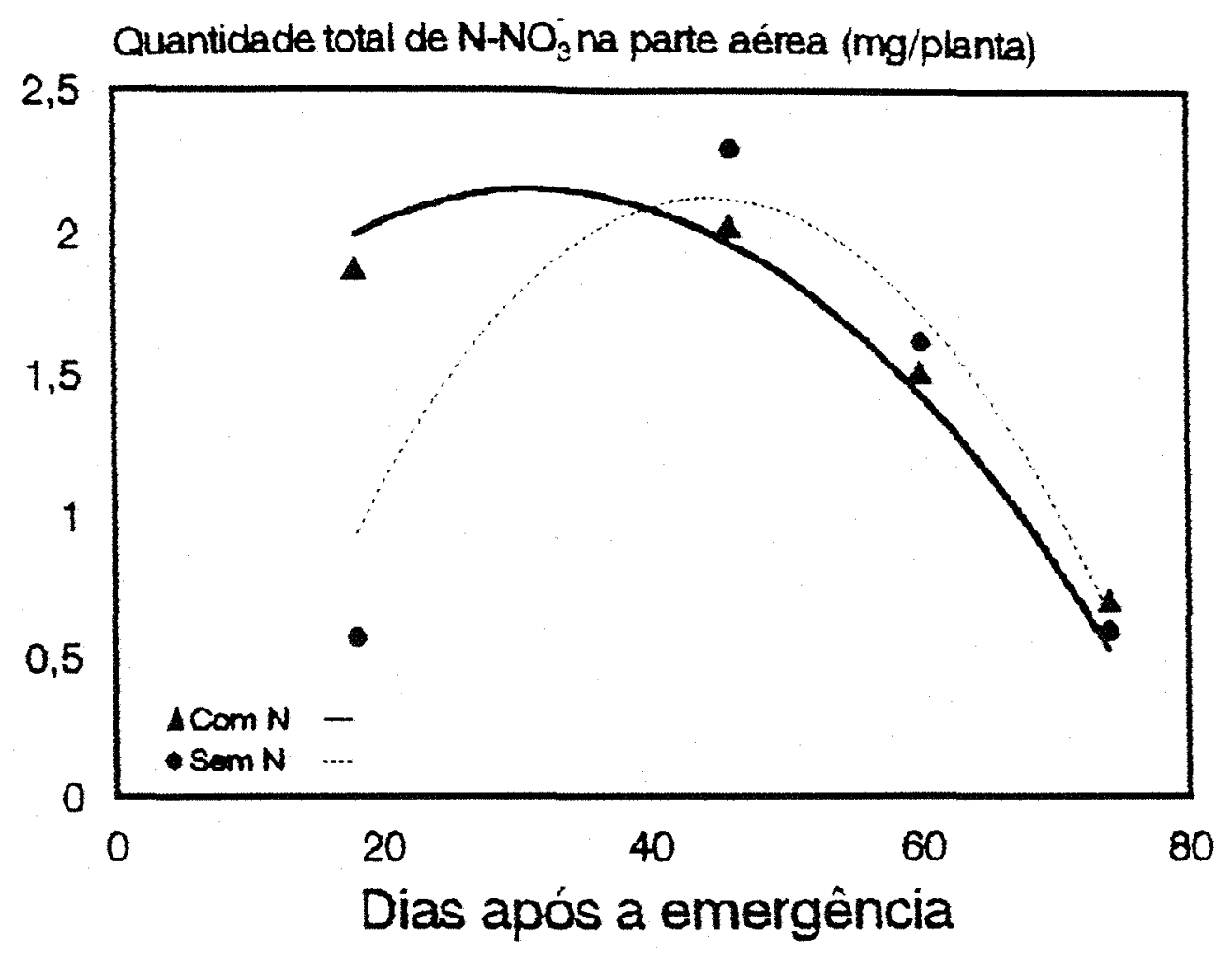

$$
\begin{aligned}
& \cdots . . Y=-1,2334+0,1512 E p-0.0017 \mathrm{Ep}^{2}\left(^{\star \star}\right) \\
& -Y=1,2697+0,0565 \mathrm{Ep}-0,0000 \mathrm{Ep}^{2}\left(^{(\star *}\right)
\end{aligned}
$$

Figura 27 - Efeito da interação $\mathrm{N}$ no plantio x épocas de avaliação na quantidade total de $\mathrm{N}^{-\mathrm{NO}_{3}}{ }_{3}^{-}$na parte aérea (mg/planta), em Coimbra, MG (Local I). 


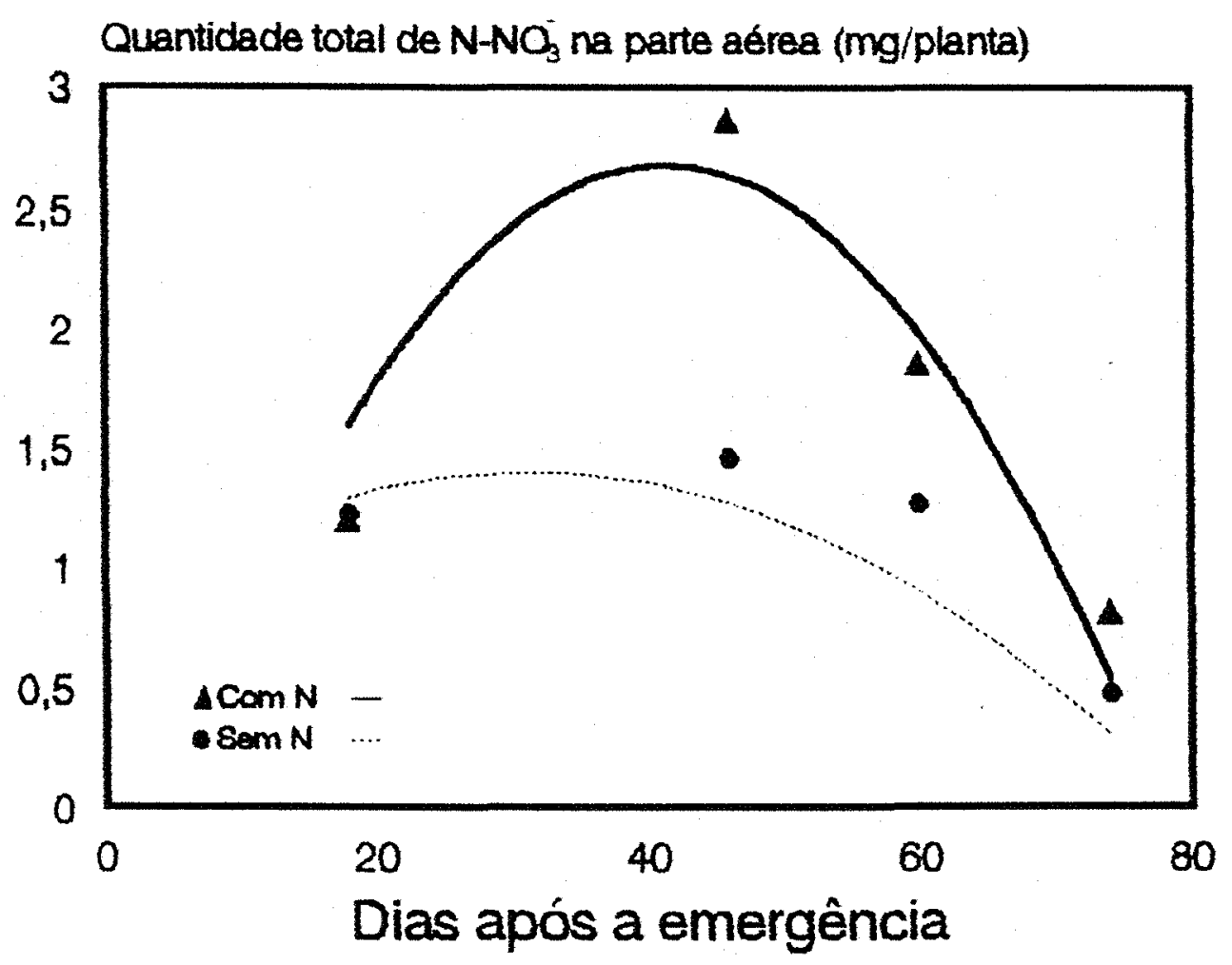

$$
\begin{aligned}
& \text { … } \left.Y=0,8206+0,0075 E p-0,0006 \text { Ep }\left.2\right|^{* k}\right) \\
& -Y=-0,7215+0,1651 \text { Ep-0,00ROEp }{ }^{2} \text { (k) }^{\star k}
\end{aligned}
$$

Figura 28 - Efeito da interação $\mathrm{N}$ em cobertura $\mathrm{x}$ épocas de avaliação na quantidade total de $\mathrm{N}-\mathrm{NO}_{3} \cdot$ na parte aérea (mg/planta), em Coimbra, MG (Local I). 
A máxima quantidade total de $\mathrm{N}-\mathrm{NO}_{3}^{-}$na parte aérea foi obtida aos 44 dias, nas plantas que não receberam $\mathrm{N}$ no plantio, e aos 31 dias, nas plantas submetidas a essa adubação (Figura 27).

A aplicação de $\mathrm{N}$ em cobertura (Figura 28), por outro lado, causou um grande aumento na quantidade total de $\mathrm{N}-\mathrm{NO}_{3}^{-}$na parte aérea, em relação às plantas não sujeitas a essa adubação; foi em média de $94 \%$.

O ponto de máxima quantidade de $\mathrm{N}-\mathrm{NO}_{3}$ na parte aérea ocorreu aos 31 dias, nas plantas isentas de adubação com $\mathrm{N}$ em cobertura, e aos 41 dias, nas plantas que receberam $\mathrm{N}$ em cobertura.

A quantidade total de $\mathrm{N}-\mathrm{NO}_{3}^{-}$na parte aérea, em decorrência da aplicação de $\mathrm{N}$ no plantio, esteve também associado à inoculação com estirpes de Rhizobium selecionadas ou não (Tabela 27). Sem inoculação, a quantidade total de $\mathrm{N}-\mathrm{NO}_{3}^{-}$na parte aérea não diferiu significativamente, tanto na ausência como na presença de 20 $\mathrm{kg} /$ ha de $\mathrm{N}$ no plantio. Com a inoculação, a quantidade total de $\mathrm{N}-\mathrm{NO}_{3}{ }^{-}$na parte aérea foi bem maior na presença da adubação nitrogenada de plantio, do que na sua ausência.

A análise de variância dos pesos de vagens secas mostrou que foram significativos os efeitos de Mo $(\mathrm{P}<0,01), \mathrm{N}$ em cobertura $(\mathrm{P}<0,05)$, épocas de avaliação $(\mathrm{P}<0,01)$ e as interações inoculação $x \mathrm{~N}$ no plantio $(\mathrm{P}<0,05)$ e Mo $\mathrm{x}$ épocas de avaliação $(\mathrm{P}<0,05)$. Os dados médios encontram-se na Tabela 28. 
Tabela 27 - Efeito da interação inoculação $\times \mathrm{N}$ no plantio sobre a quantidade total de $\mathrm{N}^{-} \mathrm{NO}_{3}^{-}$na parte aérea (mg/planta), em Coimbra, MG (Local I).

\begin{tabular}{ccc}
\hline \hline & \multicolumn{2}{c}{ N no plantio } \\
\cline { 2 - 3 } Inoculação & $0 \mathrm{~kg} / \mathrm{ha}$ & $20 \mathrm{~kg} / \mathrm{ha}$ \\
\hline Sem inoculação & $1,49 \mathrm{aA}$ & $1,37 \mathrm{aA}$ \\
Com inoculação & $0,93 \mathrm{aB}$ & $1,68 \mathrm{aA}$ \\
\hline \hline
\end{tabular}

* Médias seguidas pela mesma letra minúscula, na vertical, e maiúscula, na horizontal, não diferem significativamente, pelo teste de Duncan, ao nível de $5 \%$.

A aplicação de $\mathrm{N}$ em cobertura fez com que os pesos das vagens secas aumentassem $17 \%$ em relação às plantas que não receberam essa adubação (Tabela 28).

Apesar de a interação inoculação $\mathrm{x}$ no plantio ter sido significativa $(\mathrm{P}<$ 0,05), o emprego do teste de Duncan não possibilitou detectar diferenças significativas entre as médias (Tabela 29). Observa-se, entretanto, que os maiores pesos de vagens foram obtidos no tratamento sem inoculação e sem adubação de $\mathrm{N}$ no plantio e no inoculado e adubado com $\mathrm{N}$ no plantio, com médias muito próximas (cerca de 4,6 g/planta).

A aplicação foliar de Mo causou um aumento nos pesos de vagens secas na ordem de 41 e $28 \%$, respectivamente, aos 60 e 74 dias após a emergência das plantas (Tabela 30). 
Tabela 28 - Peso (g/planta), percentagem de $\mathrm{N}$ e quantidade total de $\mathrm{N}$-amoniacal (mg/planta) nas vagens secas (mg/planta), em Coimbra, MG (Local I).

\begin{tabular}{|c|c|c|c|c|c|c|c|c|c|}
\hline \multicolumn{4}{|c|}{ Tratamentos ${ }^{*}$} & \multicolumn{6}{|c|}{ Dias após a emergência } \\
\hline \multirow[t]{2}{*}{ In } & Mo & $\mathrm{Np}$ & $\mathrm{Nc}$ & 60 & 74 & 60 & 74 & 60 & 74 \\
\hline & & & & \multicolumn{2}{|c|}{ Pesos } & \multicolumn{2}{|c|}{ Perc. de $\mathrm{N}$} & \multicolumn{2}{|c|}{ Quantidade total } \\
\hline 0 & 0 & 0 & 0 & 1,47 & 8,42 & 2,26 & 2,35 & 42,59 & 164,35 \\
\hline 0 & 1 & 0 & 0 & 1,11 & 5,52 & 2,95 & 2,65 & 32,53 & 146,63 \\
\hline 0 & 0 & 1 & 0 & 1,95 & 5,36 & 1,94 & 1,80 & 38,51 & 100,90 \\
\hline 0 & 1 & 1 & 0 & 1,22 & 5,24 & 2,77 & 2,57 & 34,16 & 136,64 \\
\hline 0 & 0 & 0 & 1 & 2,54 & 7,00 & 2,67 & 2,47 & 68,49 & 176,27 \\
\hline 0 & 1 & 0 & 1 & 2,85 & - & 2,88 & - & 81,62 & - \\
\hline 0 & 0 & 1 & 1 & 1,10 & 5,09 & 3,00 & 2,53 & 33,08 & 128,76 \\
\hline 0 & 1 & 1 & 1 & 3,14 & 8,46 & 2,79 & 2,53 & 63,80 & 213,23 \\
\hline 1 & 0 & 0 & 0 & 0,92 & 3,73 & 2,21 & 2,09 & 20,52 & 78,15 \\
\hline 1 & 1 & 0 & 0 & 2,04 & 8,22 & 2,80 & 2,52 & 57,45 & 209,13 \\
\hline 1 & 0 & 1 & 0 & 1,28 & 4,21 & 1,92 & 1,83 & 24,25 & 77,98 \\
\hline 1 & 1 & 1 & 0 & 2,35 & 8,25 & 2,78 & 2,69 & 63,27 & 216,62 \\
\hline 1 & 0 & 0 & 1 & 0,99 & 4,40 & 2,52 & 2,23 & 24,82 & 97,62 \\
\hline 1 & 1 & 0 & 1 & 2,11 & 8,63 & 2,92 & 2,59 & 61,86 & 221,27 \\
\hline 1 & 0 & 1 & 1 & 1,72 & 8,73 & 2,96 & 2,38 & 50,73 & 153,56 \\
\hline 1 & 1 & 1 & 1 & 2,17 & 8,35 & 2,85 & 2,62 & 52,73 & 224,92 \\
\hline
\end{tabular}

$\left.{ }^{*}\right) 0$ = ausência

In $=$ inoculação

Mo = molibdênio
$1=$ presença

$\mathrm{Np}=$ nitrogênio no plantio

$\mathrm{Nc}=$ nitrogênio em cobertura 
Tabela 29 - Efeito da interação inoculação $\times \mathrm{N}$ no plantio sobre os pesos das vagens secas (g/planta), em Coimbra, MG (Local I).

\begin{tabular}{ccc}
\hline \hline & \multicolumn{2}{c}{ Nitrogênio no plantio } \\
\cline { 2 - 3 } Inoculação & $0 \mathrm{~kg} / \mathrm{ha}$ & $20 \mathrm{~kg} / \mathrm{ha}$ \\
\hline Sem inoculação & $4,57 \mathrm{aA}$ & $3,95 \mathrm{aA}$ \\
Com inoculação & $3,88 \mathrm{aA}$ & $4,64 \mathrm{aA}$ \\
\hline \hline
\end{tabular}

(*) Médias seguidas pela mesma letra minúscula, na vertical, e maiúscula, na horizontal, não diferem significativamente, pelo teste de Duncam, ao nível de $5 \%$.

Tabela 30 - Efeito da interação Mo x épocas de avaliação nos pesos das vagens secas (g/planta), em Coimbra, MG (Local I).

\begin{tabular}{ccc}
\hline \hline Épocas de & \multicolumn{2}{c}{ Molibdênio } \\
\cline { 2 - 3 } avaliação & $0 \mathrm{~g} / \mathrm{ha}$ & $40 \mathrm{~g} / \mathrm{ha}$ \\
\hline Dias após a emergência & & \\
60 & $1,50 \mathrm{aB}$ & $2,12 \mathrm{aA}$ \\
74 & $5,87 \mathrm{bB}$ & $7,52 \mathrm{bA}$ \\
\hline \hline
\end{tabular}

(*) Médias seguidas pela mesma letra minúscula, na vertical, e maiúscula, na horizontal, não diferem significativamente, pelo teste de Duncam, ao nível de $5 \%$. 
$\mathrm{Na}$ análise de variância dos dados de percentagem de $\mathrm{N}$ nas vagens, verificou-se que foram significativos os efeitos de Mo $(\mathrm{P}<0,01), \mathrm{N}$ em cobertura $(\mathrm{P}$ $<0,01)$, épocas de avaliação $(\mathrm{P}<0,01)$ e as interações Mo $x \mathrm{~N}$ em cobertura $(\mathrm{P}<$ $0,01), \mathrm{N}$ no plantio $\mathrm{x} N$ em cobertura $(\mathrm{P}<0,05)$ e $\mathrm{N}$ em cobertura $\mathrm{X}$ épocas de avaliação $(\mathrm{P}<0,05)$. Os dados médios relativos a este parâmetro encontram-se na Tabela 28.

Na presença de $40 \mathrm{~g} /$ ha de Mo, a adubação nitrogenada em cobertura não afetou a percentagem de $\mathrm{N}$ nas vagens (Tabela 31 ); na sua ausência, a aplicação de $30 \mathrm{~kg}$ de $\mathrm{N}$ causou um aumento de $23 \%$. A aplicação de $30 \mathrm{~kg}$ de $\mathrm{N}$ em cobertura apresentou,

Tabela 31 - Efeito da interação Mo x $\mathrm{N}$ em cobertura sobre a percentagem de Namoniacal nas vagens, em Coimbra, MG (Local I)*.

\begin{tabular}{ccc}
\hline \hline Doses de & \multicolumn{2}{c}{ Nitrogênio em cobertura } \\
\cline { 2 - 3 } molibdênio & $0 \mathrm{~kg} / \mathrm{ha}$ & $30 \mathrm{~kg} / \mathrm{ha}$ \\
\hline $0 \mathrm{~g} / \mathrm{ha}$ & $2,11 \mathrm{bB}$ & $2,60 \mathrm{aA}$ \\
$40 \mathrm{~g} / \mathrm{ha}$ & $2,72 \mathrm{aA}$ & $2,72 \mathrm{aA}$ \\
\hline
\end{tabular}

* Médias seguidas pela mesma letra minúscula, na vertical, e maiúscula, na horizontal, não diferem significativamente, pelo teste de Duncan, ao nível de $5 \%$. 
sobre a percentagem de $\mathrm{N}$ nas vagens, o mesmo efeito de $40 \mathrm{~g}$ de Mo. Por outro lado, $20 \mathrm{~kg} / \mathrm{ha}$ de $\mathrm{N}$ no plantio diminuiu a percentagem de $\mathrm{N}$ nas vagens quando associado a $0 \mathrm{~kg}$ de $\mathrm{N}$ em cobertura, e não teve efeito significativo quando associada a $30 \mathrm{~kg}$ de $\mathrm{N}$ em cobertura (Tabela 32). A percentagem de $\mathrm{N}$ nas vagens não apresentou diferença significativa quando se compararam as combinações $0 \mathrm{~kg}$ de $\mathrm{N}$ no plantio - $30 \mathrm{~kg}$ de $\mathrm{N}$ em cobertura e $20 \mathrm{~kg}$ de $\mathrm{N}$ no plantio - $30 \mathrm{~kg}$ de $\mathrm{N}$ em cobertura (Tabela 32).

Tabela 32 - Efeito da interação $\mathrm{N}$ no plantio $\mathrm{x} \mathrm{N}$ em cobertura sobre a percentagem de $\mathrm{N}$-amoniacal nas vagens, em Coimbra, MG (Local I)*.

\begin{tabular}{ccc}
\hline \hline Nitrogênio & \multicolumn{2}{c}{ Nitrogênio em cobertura } \\
\cline { 2 - 3 } no plantio & $0 \mathrm{~kg} / \mathrm{ha}$ & $30 \mathrm{~kg} / \mathrm{ha}$ \\
\hline $0 \mathrm{~kg} / \mathrm{ha}$ & $2,54 \mathrm{aB}$ & $2,60 \mathrm{aA}$ \\
$20 \mathrm{~kg} / \mathrm{ha}$ & $2,29 \mathrm{bB}$ & $2,71 \mathrm{aA}$ \\
\hline \hline
\end{tabular}

(*) Médias seguidas pela mesma letra minúscula, na vertical, e maiúscula, na horizontal, não diferem significativamente, pelo teste de Duncan, ao nível de $5 \%$.

Independentemente das doses de $\mathrm{Mo}$ e dos níveis de $\mathrm{N}$ no plantio, a percentagem de $\mathrm{N}$ nas vagens foi maior aos 60 e 74 dias após a emergência com a adição de $30 \mathrm{~kg}$ de $\mathrm{N}$ em cobertura, comparativamente às plantas que não receberam essa adubação (Tabela 33). 
Quanto à quantidade total de $\mathrm{N}$-amoniacal nas vagens, a análise de variância revelou que foram significativos os efeitos de doses de Mo $(\mathrm{P}<0,01), \mathrm{N}$ em cobertura $(\mathrm{P}<0,05)$, épocas de avaliação $(\mathrm{P}<0,01)$ e as interações inoculação $\mathrm{x}$ Mo $(\mathrm{P}<0,05)$ e Mo x época de avaliação $(\mathrm{P}<0,01)$. Os dados médios encontram-se na Tabela 28.

Tabela 33 - Efeito da interação $\mathrm{N}$ em cobertura $\mathrm{x}$ épocas de avaliação na percentagem de $\mathrm{N}$-amoniacal nas vagens, em Coimbra, MG (Local I)*.

\begin{tabular}{ccc}
\hline \hline Épocas de & \multicolumn{2}{c}{ Nitrogênio em cobertura } \\
\cline { 2 - 3 } avaliação & $0 \mathrm{~kg} / \mathrm{ha}$ & $30 \mathrm{~kg} / \mathrm{ha}$ \\
\hline Dias após a emergência & & \\
60 & $2,45 \mathrm{aB}$ & $2,82 \mathrm{aA}$ \\
74 & $2,31 \mathrm{bB}$ & $2,48 \mathrm{bA}$ \\
\hline
\end{tabular}

(*) Médias seguidas pela mesma letra minúscula, na vertical, e maiúscula, na horizontal, não diferem significativamente, pelo teste de Duncan, ao nível de $5 \%$.

A aplicação de $30 \mathrm{~kg}$ de $\mathrm{N}$ em cobertura causou um aumento de $22 \%$ na quantidade total de $\mathrm{N}$ nas vagens (Tabela 28).

Nas plantas infectadas por estirpes nativas de Rhizobium a aplicação foliar de Mo não afetou significativamente a quantidade total de $\mathrm{N}$-amoniacal nas vagens, ao passo que, nas plantas inoculadas com estirpes selecionadas de Rhizobium, a 
pulverização com o micronutriente produziu um aumento de $110 \%$ nesse parâmetro (Tabela 34). Na ausência da adubação com Mo, as plantas sem inoculação apresentaram uma quantidade total de $\mathrm{N}$-amoniacal nas vagens de $1,43 \mathrm{vez}$ maior que nas plantas inoculadas; na presença de $40 \mathrm{~g} / \mathrm{ha}$ de Mo, ocorreu o inverso, com as plantas inoculadas apresentando uma quantidade total de $\mathrm{N}$-amoniacal 1,21 vez maior que nas plantas nãoinoculadas.

A quantidade total de $\mathrm{N}$ nas vagens foi maior nas plantas que receberam Mo, tanto aos 60 como aos 74 dias de idade (Tabela 35).

$\mathrm{A}$ análise de variância das percentagens de $\mathrm{N}$ nas sementes, das quantidades de $\mathrm{N}$ exportado para os grãos e das produções revelaram que foi significativo o efeito de Mo $(\mathrm{P}<0,01)$ e de $\mathrm{N}$ em cobertura $(\mathrm{P}<0,01)$; para a percentagem de $\mathrm{N}$ nas sementes, o efeito de $\mathrm{N}$ em cobertura foi significatico ao nível de $5 \%(\mathrm{P}<0,05)$. Os dados médios encontram-se na Tabela 36.

Observa-se, na Tabela 36, que o efeito de $\mathrm{N}$ em cobertura e de Mo foram idênticos, no que diz respeito à percentagem de $\mathrm{N}$ nas sementes e à quantidade de $\mathrm{N}$ exportado para os grãos (média dos tratamentos que receberam Mo e $\mathrm{N}$ em cobertura).

A produção média nos tratamentos em que não foram aplicados o Mo nem o $\mathrm{N}$ em cobertura foi de cerca de $853,25 \mathrm{~kg}$ de grãos/hectare. A aplicação de $40 \mathrm{~g} / \mathrm{ha}$ de Mo aos 25 dias após a emergência ou $30 \mathrm{~kg} / \mathrm{ha}$ de $\mathrm{N}$ em cobertura, nesta mesma época, fizeram com que a produção média aumentasse em $578 \mathrm{~kg}$ de grãos (Tabela 36). 
Tabela 34 - Efeito da interação inoculação x Mo sobre a quantidade total de Namoniacal nas vagens (mg/planta), em Coimbra, MG (Local I)*.

\begin{tabular}{ccc}
\hline \hline & \multicolumn{2}{c}{ Molibdênio } \\
\cline { 2 - 3 } Inoculação & $0 \mathrm{~g} / \mathrm{ha}$ & $40 \mathrm{~g} / \mathrm{ha}$ \\
\hline Sem inoculação & $94,12 \mathrm{aA}$ & $113,46 \mathrm{bA}$ \\
Com inoculação & $65,98 \mathrm{bB}$ & $138,53 \mathrm{aA}$ \\
\hline \hline
\end{tabular}

(*) Médias seguidas pela mesma letra minúscula na vertical, e maiúscula, na horizontal, não diferem significativamente, pelo teste de Duncan, ao nível de $5 \%$.

Tabela 35 - Efeito da interação Mo x épocas de avaliação na quantidade total de $\mathrm{N}$-amoniacal nas vagens (mg/planta), em Coimbra, MG (Local I)*.

\begin{tabular}{ccc}
\hline \hline Épocas de & \multicolumn{2}{c}{ Molibdênio } \\
\cline { 2 - 3 } avaliação & $0 \mathrm{~g} / \mathrm{ha}$ & $40 \mathrm{~g} / \mathrm{ha}$ \\
\hline Dias após a emergência & & \\
60 & $37,87 \mathrm{bA}$ & $55,93 \mathrm{bA}$ \\
74 & $122,20 \mathrm{aB}$ & $195,49 \mathrm{aA}$ \\
\hline \hline
\end{tabular}

(*) Médias seguidas pela mesma letra minúscula na vertical, e maiúscula, na horizontal, não diferem significativamente, pelo teste de Duncan, ao nível de $5 \%$. 
Tabela 36 - Percentagem de $\mathrm{N}$ nas sementes, quantidade de $\mathrm{N}$ exportado para os grãos (kg/ha) e produção (kg/ha), em Coimbra, MG (Local I).

\begin{tabular}{|c|c|c|c|c|c|c|}
\hline \multicolumn{4}{|c|}{ Tratamentos ${ }^{*}$} & \multirow{2}{*}{$\begin{array}{c}\mathrm{N} \text { nas } \\
\text { sementes }\end{array}$} & \multirow{2}{*}{$\begin{array}{l}\mathrm{N} \text { exportado } \\
\text { para os grãos }\end{array}$} & \multirow[t]{2}{*}{ Produção } \\
\hline In & Mo & $\mathrm{Np}$ & $\mathrm{Nc}$ & & & \\
\hline 0 & 0 & 0 & 0 & 2,77 & 31,77 & 1117 \\
\hline 0 & 1 & 0 & 0 & 3,32 & 36,61 & 1102 \\
\hline 0 & 0 & 1 & 0 & 2,71 & 24,19 & 892 \\
\hline 0 & 1 & 1 & 0 & 3,21 & 35,41 & 1104 \\
\hline 0 & 0 & 0 & 1 & - & - & 1365 \\
\hline 0 & 1 & 0 & 1 & 3,67 & 76,98 & 2067 \\
\hline 0 & 0 & 1 & 1 & 3,35 & 37,29 & 1105 \\
\hline 0 & 1 & 1 & 1 & 3,25 & 62,26 & 1913 \\
\hline 1 & 0 & 0 & 0 & 2,84 & 13,72 & 483 \\
\hline 1 & 1 & 0 & 0 & 3,39 & 55,06 & 1589 \\
\hline 1 & 0 & 1 & 0 & 2,73 & 25,08 & 921 \\
\hline 1 & 1 & 1 & 0 & 3,36 & 46,28 & 1380 \\
\hline 1. & 0 & 0 & 1 & 3,04 & 31,64 & 1033 \\
\hline 1 & 1 & 0 & 1 & 3,57 & 51,55 & 1442 \\
\hline 1 & 0 & 1 & 1 & 3,41 & 42,55 & 1248 \\
\hline 1 & 1 & 1 & 1 & 3,37 & 61,47 & 1823 \\
\hline
\end{tabular}

$\left(^{*}\right)$ = ausência;

In = inoculação

Mo $=$ molibdênio
$1=$ presença

$\mathrm{Np}=$ nitrogênio no plantio

$\mathrm{Nc}=$ nitrogênio em cobertura 


\subsection{Experimento de Coimbra (Local II)}

A atividade da nitrogenase neste experimento, contrariamente ao que ocorreu em Viçosa e no local I de Coimbra, não foi afetada pela aplicação foliar de molibdênio. A análise de variância mostrou que foram significativos os efeitos de $\mathrm{N}$ no plantio $(\mathrm{P}<0,01)$, épocas de avaliação $(\mathrm{P}<0,01)$ e a interação $\mathrm{N}$ no plantio $\mathrm{x}$ épocas de avaliação $(P<0,01)$. Os dados médios encontram-se na Tabela 37.

Na ausência da adubação nitrogenada de plantio, a atividade da nitrogenase apresentou uma resposta quadrática, enquanto que, na presença de $20 \mathrm{~kg} / \mathrm{ha}$ de $\mathrm{N}$ no plantio, não houve resposta linear nem quadrática (Figura 29).

A atividade da nitrogenase foi baixa tanto na presença como na ausência de $\mathrm{N}$ no plantio. $\mathrm{Na}$ ausência de $\mathrm{N}$ no início do ciclo do feijoeiro, a atividade da nitrogenase foi maior aos 18 dias, decrescendo posteriormente até atingir um mínimo aos 63 dias. A adição de $20 \mathrm{~kg} / \mathrm{ha}$ de $\mathrm{N}$ no plantio fez com que a atividade baixasse ainda mais, não atingindo $1 \mu \mathrm{mol}$ de $\mathrm{C}_{2} \mathrm{H}_{4} \cdot \mathrm{h}^{-1} \cdot$ planta $^{-1}$, em nenhuma das épocas.

A análise de variância dos dados de atividade específica da nitrogenase mostrou que foram siginificativos os efeitos de Mo $(\mathrm{P}<0,01)$, $\mathrm{N}$ no plantio $(\mathrm{P}<$ $0,00)$, épocas de avaliação $(\mathrm{P}<0,01)$ e as interações Mo $\mathrm{x}$ épocas de avalição $(\mathrm{P}<$ $0,05)$ e $\mathrm{N}$ no plantio $\mathrm{x}$ épocas de avaliação $(\mathrm{P}<0,05)$. Os dados médios encontram-se na Tabela 38. 
Tabela 37 - Atividade da nitrogenase $\left(\mu\right.$ moles $\mathrm{C}_{2} \mathrm{H}_{4} \cdot \mathrm{h}^{-1}$. planta $\left.{ }^{-1}\right)$, em Coimbra, MG (Local II).

\begin{tabular}{cccccccccc}
\hline \hline \multicolumn{3}{c}{ Tratamentos } & & \multicolumn{5}{c}{ Dias após a emergência } \\
\cline { 1 - 2 } In & Mo & Np & Nc & & 18 & 32 & 46 & 60 & 74 \\
\hline 0 & 0 & 0 & 0 & & 2,26 & 1,26 & 0,73 & 0,34 & 0,33 \\
0 & 1 & 0 & 0 & & 3,52 & 1,03 & 3,35 & 1,86 & 0,86 \\
0 & 0 & 1 & 0 & & 0,22 & 0,07 & 0,18 & 0,10 & 0,14 \\
0 & 1 & 1 & 0 & & 0,50 & 0,11 & 0,82 & 0,28 & 0,20 \\
0 & 0 & 0 & 1 & & 3,76 & 0,94 & 1,09 & 1,58 & 1,40 \\
0 & 1 & 0 & 1 & & 1,40 & 0,42 & 1,33 & 0,85 & 0,37 \\
0 & 0 & 1 & 1 & & 0,43 & 0,35 & 0,35 & 0,11 & 0,17 \\
0 & 1 & 1 & 1 & & 1,05 & 0,08 & 0,74 & 0,16 & 0,19 \\
1 & 0 & 0 & 0 & & 2,60 & 0,73 & 1,94 & 1,37 & 1,09 \\
1 & 1 & 0 & 0 & & 6,55 & 0,93 & 1,47 & 0,52 & 0,56 \\
1 & 0 & 1 & 0 & 0,47 & 0,22 & 0,19 & 0,16 & 0,22 \\
1 & 1 & 1 & 0 & 0,24 & 0,15 & 0,30 & 0,17 & 0,24 \\
1 & 0 & 0 & 1 & 5,06 & 1,25 & 0,68 & 0,25 & 0,40 \\
1 & 1 & 0 & 1 & 1,89 & 0,45 & 1,16 & 0,64 & 0,27 \\
1 & 0 & 1 & 1 & 0,67 & 0,23 & 0,38 & 0,21 & 0,17 \\
1 & 1 & 1 & 1 & 0,51 & 0,19 & 2,56 & 2,35 & 1,20 \\
\hline \hline
\end{tabular}

(*) 0 = ausência

In = inoculação

Mo = molibdênio
$1=$ presença

$\mathrm{Np}=$ nitrogênio no plantio

$\mathrm{Nc}=$ nitrogênio em cobertura 


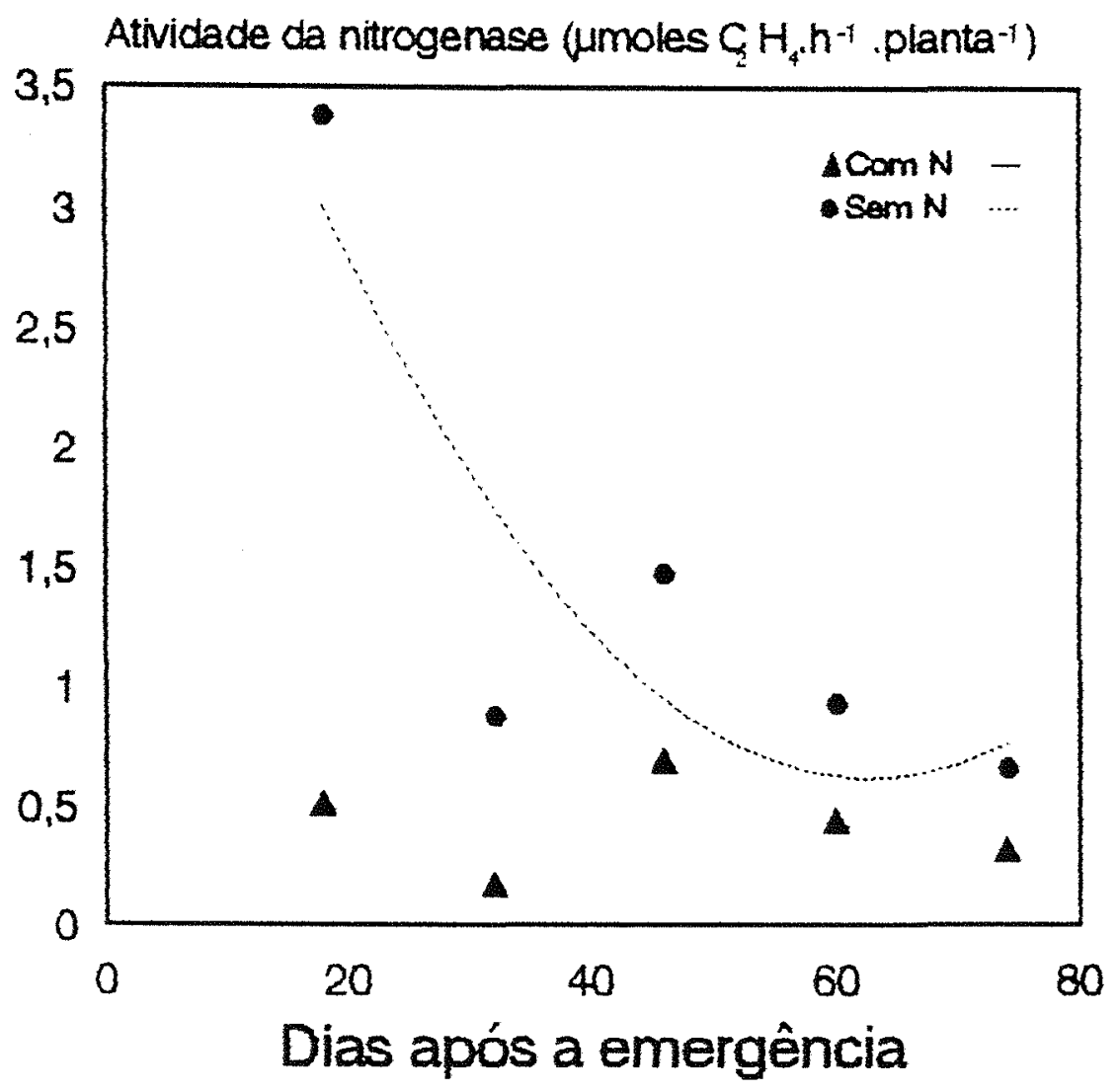

$\cdots=5,3350-0,1505 E p+0,0012 E p{ }^{2}(*)$

Figura 29 - Efeito da interação $\mathrm{N}$ no plantio x épocas de avaliação sobre a atividade da nitrogenase ( $\mu$ moles $\mathrm{C}_{2} \mathrm{H}_{4} \cdot \mathrm{h}^{-1}$. planta ${ }^{-1}$ ), em Coimbra, MG (Local II). 
Tabela 38 - Atividade específica da nitrogenase $\left(\mu\right.$ moles $\mathrm{C}_{2} \mathrm{H}_{4} \cdot \mathrm{h}^{-1} \cdot \mathrm{g}$. de nódulo ${ }^{-1}$ ), em Coimbra, MG (Local II).

\begin{tabular}{|c|c|c|c|c|c|c|c|c|}
\hline \multicolumn{4}{|c|}{ Tratamentos ${ }^{*}$} & \multicolumn{5}{|c|}{ Dias após a emergência } \\
\hline In & Mo & $\mathrm{Np}$ & $\mathrm{Nc}$ & 18 & 32 & 46 & 60 & 74 \\
\hline 0 & 0 & 0 & 0 & 122,91 & 30,18 & 23,53 & 33,04 & 59,04 \\
\hline 0 & 1 & 0 & 0 & 120,13 & 24,83 & 86,88 & 134,68 & 121,13 \\
\hline 0 & 0 & 1 & 0 & 52,81 & 45,70 & 68,31 & 37,58 & 75,77 \\
\hline 0 & 1 & 1 & 0 & 79,87 & 22,63 & 308,60 & 166,44 & 155,99 \\
\hline 0 & 0 & 0 & 1 & 128,42 & 37,95 & 30,17 & 33,73 & 46,77 \\
\hline 0 & 1 & 0 & 1 & 100,36 & 28,60 & 79,42 & 69,97 & 111,36 \\
\hline 0 & 0 & 1 & 1 & 57,78 & 58,65 & 42,54 & 95,32 & 82,56 \\
\hline 0 & 1 & 1 & 1 & 85,66 & 22,25 & 72,65 & 77,30 & 121,04 \\
\hline 1 & 0 & 0 & 0 & 74,02 & 21,92 & 38,53 & 40,26 & 55,88 \\
\hline 1 & 1 & 0 & 0 & 153,53 & 25,17 & 58,90 & 49,15 & 155,63 \\
\hline 1 & 0 & 1 & 0 & 48,91 & 17,77 & 38,40 & 18,63 & 172,21 \\
\hline 1 & 1 & 1 & 0 & 52,42 & 32,04 & 108,02 & 70,40 & 101,82 \\
\hline 1 & 0 & 0 & 1 & 115,82 & 37,67 & 30,54 & 33,13 & 67,25 \\
\hline 1 & 1 & 0 & 1 & 78,56 & 24,05 & 62,75 & 128,35 & 110,43 \\
\hline 1 & 0 & 1 & 1 & 60,44 & 29,48 & 33,57 & 71,04 & 104,43 \\
\hline 1 & 1 & 1 & 1 & 46,50 & 22,90 & 101,01 & 214,41 & 116,55 \\
\hline
\end{tabular}

(*) 0 = ausência;

In = inoculação

Mo $=$ molibdênio
$1=$ presença

$\mathrm{Np}=$ nitrogênio no plantio

$\mathrm{Nc}=$ nitrogênio em cobertura 
A atividade específica da nitrogenase apresentou uma resposta quadrática, na ausência de Mo, e linear, na sua presença, em relação às épocas de avaliação (Figura 30). À exceção da avaliação feita aos 18 dias, a atividade específica da nitrogenase foi maior nas plantas pulverizadas com o Mo; aos 32, 46, 60 e 74 dias, o Mo produziu aumentos de $76 \%, 188 \%, 137 \%$ e $47 \%$, respectivamente, na atividade específica da nitrogenase, em relação às plantas que não o receberam (Figura 30 ).

$\mathrm{Na}$ ausência do micronutriente, a atividade específica da nitrogenase atingiu seu ponto de mínimo aos 45 dias (Figura 30).

A resposta da atividade específica da nitrogenase à aplicação de $\mathrm{N}$ no plantio foi semelhante à obtida com o Mo, ou seja, sem o $\mathrm{N}$ no plantio a resposta foi quadrática, com um ponto de mínimo aos 46 dias, enquanto que, com $\mathrm{N}$, a resposta foi linear (Figura 31).

A aplicação de $\mathrm{N}$ no plantio somente foi prejudicial à atividade específica da nitrogenase no início do ciclo do feijoeiro, ou seja, aos 18 dias. A partir desta época, a adição de $20 \mathrm{~kg} / \mathrm{ha}$ de $\mathrm{N}$ no plantio causou um aumento crescente daquela atividade, cuja magnitude variou com a época de avaliação; entre os 46 e 60 dias este aumento foi, em média, de $87 \%$, em relação aos tratamentos que não receberam o nitrogênio.

Em relação ao número de nódulos, a análise de variância mostrou que foram significativos os efeitos de $\mathrm{N}$ no plantio $(\mathrm{P}<0,01)$, épocas de avaliação $(\mathrm{P}<0,01)$ e a interação $\mathrm{N}$ no plantio $\mathrm{x}$ épocas de avaliação $(\mathrm{P}<0,01)$. Os dados médios encontram-se na Tabela 39. 


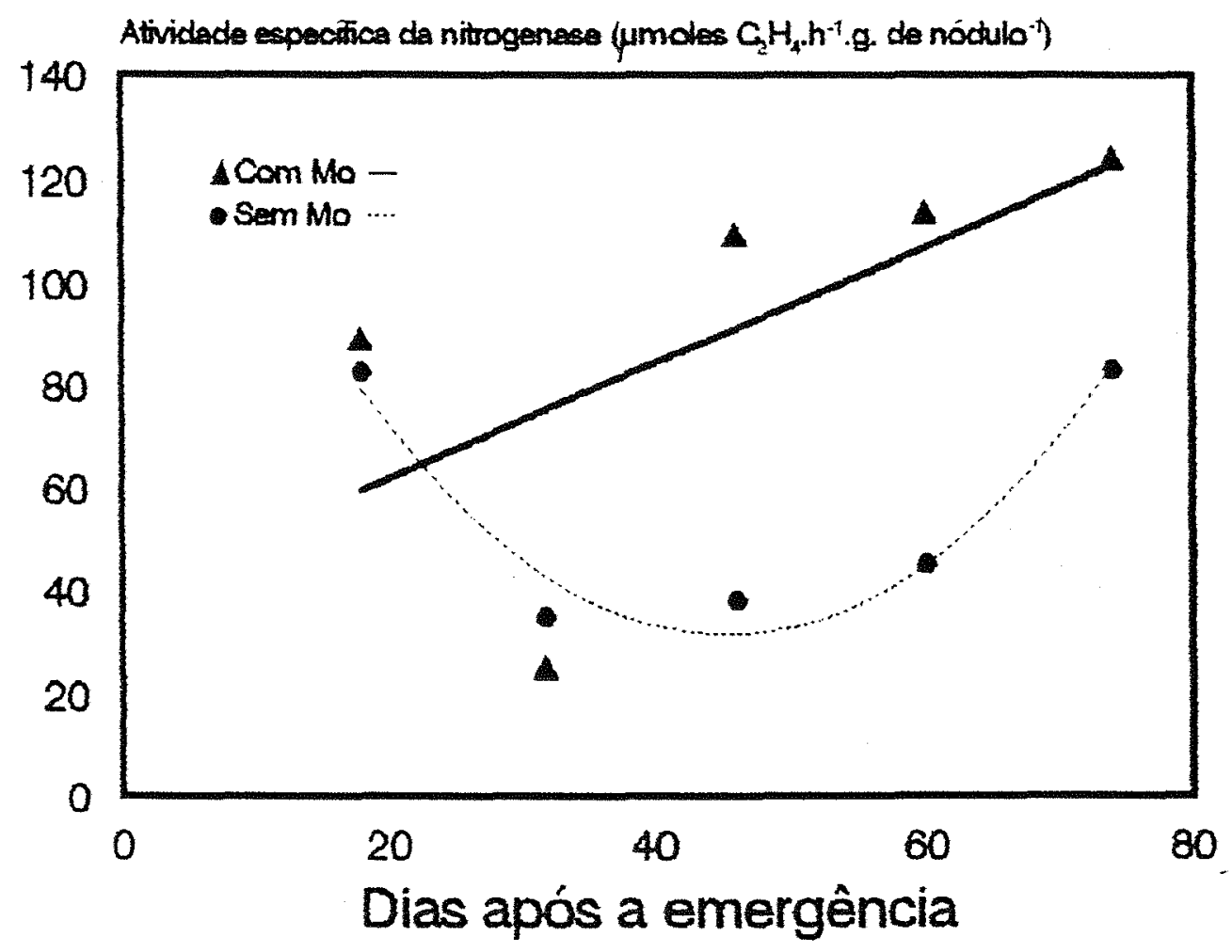

-... $\left.Y=162,90045,7766 \mathrm{Ep}+0,0636 \mathrm{p} \mathrm{q}^{\mathrm{q}} \mathrm{k}\right)$

$-Y=30,7603+1,1269$ Ep $\left.^{(k \star}\right)$

Figura 30 - Efeito da interação Mo x épocas de avaliação na atividade específica da nitrogenase $\left(\mu\right.$ moles de $\mathrm{C}_{2} \mathrm{H}_{4} \cdot \mathrm{h}^{-1} \cdot \mathrm{g}$. de nódulo ${ }^{-1}$ ), em Coimbra, MG (Local II). 


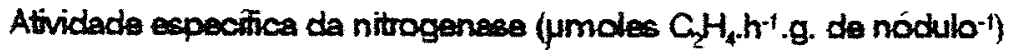

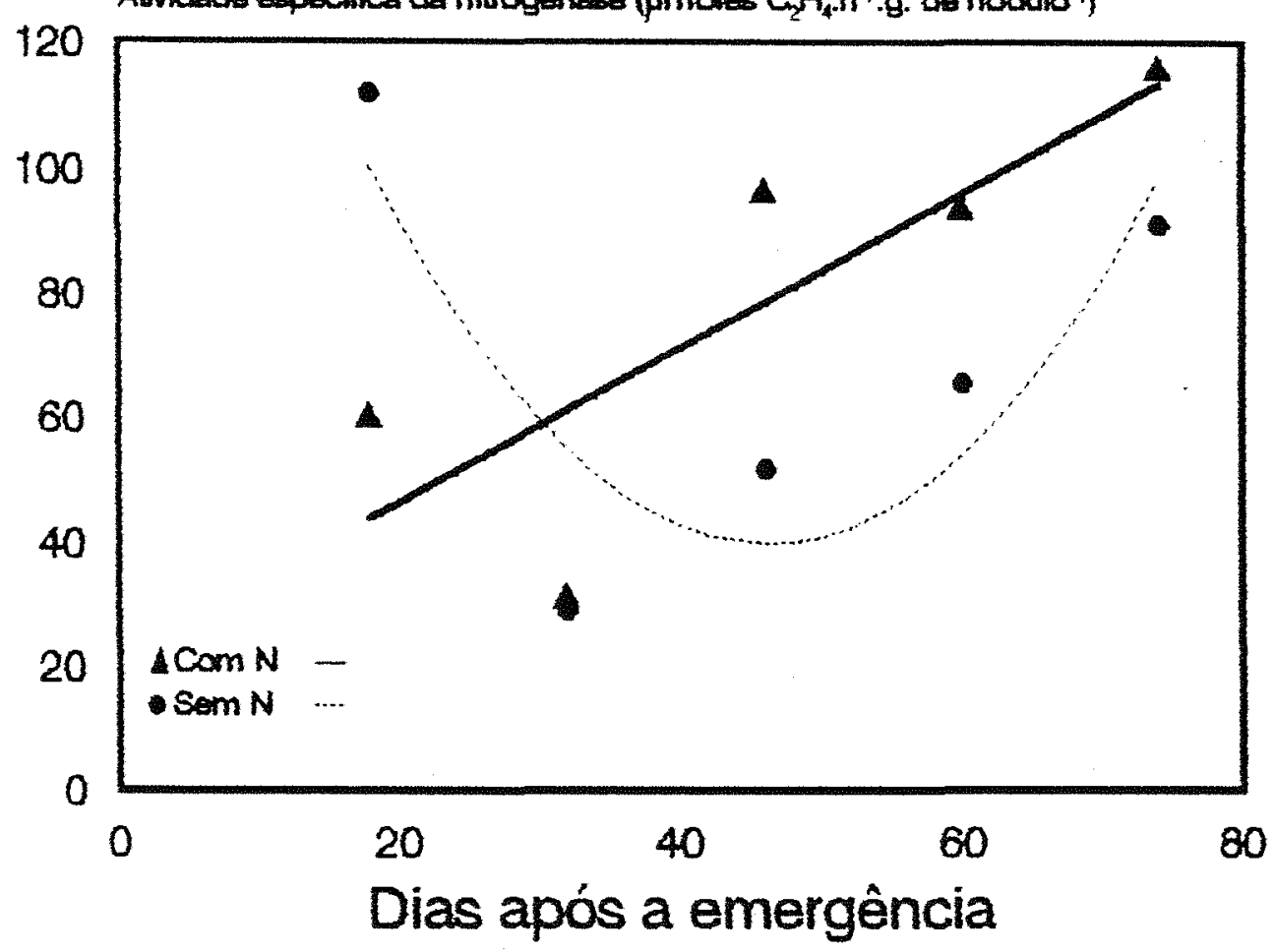

$\left.\cdots Y=200,34737,0000 \mathrm{Ep}+0,0760 \mathrm{Ep} \hat{q}^{\star \star}\right)$
$-Y=21,6392+1,2425 \mathrm{Ep}\left(^{\star \star}\right)$

Figura 31 - Efeito da interação $\mathrm{N}$ no plantio $\mathrm{x}$ épocas de avaliação na atividade específica da nitrogenase ( $\mu$ moles de $\mathrm{C}_{2} \mathrm{H}_{4} \cdot \mathrm{h}^{-1} \cdot \mathrm{g}$. de nódulo ${ }^{-1}$ ), em Coimbra, MG (Local II). 
Tabela 39 - Número de nódulos.planta ${ }^{-1}$, em Coimbra, MG (Local II).

\begin{tabular}{|c|c|c|c|c|c|c|c|c|}
\hline \multicolumn{4}{|c|}{ Tratamentos $^{*}$} & \multicolumn{5}{|c|}{ Dias após a emergência } \\
\hline In & Mo & $\mathrm{Np}$ & $\mathrm{Nc}$ & 18 & 32 & 46 & 60 & 74 \\
\hline 0 & 0 & 0 & 0 & 27,25 & 31,87 & 17,75 & 12,00 & 5,62 \\
\hline 0 & 1 & 0 & 0 & 44,75 & 26,37 & 20,75 & 14,50 & 5,12 \\
\hline 0 & 0 & 1 & 0 & 12,25 & 7,00 & 7,62 & 6,87 & 8,00 \\
\hline 0 & 1 & 1 & 0 & 14,75 & 9,87 & 3,62 & 4,75 & 3,00 \\
\hline 0 & 0 & 0 & 1 & 32,87 & 27,75 & 25,00 & 22,75 & 24,50 \\
\hline 0 & 1 & 0 & 1 & 25,50 & 21,12 & 20,37 & 14,87 & 2,87 \\
\hline 0 & 0 & 1 & 1 & 14,87 & 11,62 & 11,75 & 5,50 & 3,75 \\
\hline 0 & 1 & 1 & 1 & 19,12 & 12,37 & 9,62 & 7,12 & 1,75 \\
\hline 1 & 0 & 0 & 0 & 52,12 & 26,25 & 43,12 & 30,25 & 22,50 \\
\hline 1 & 1 & 0 & 0 & 37,37 & 27,37 & 17,62 & 11,50 & 5,12 \\
\hline 1 & 0 & 1 & 0 & 15,50 & 5,62 & 10,87 & 16,50 & 3,37 \\
\hline 1 & 1 & 1 & 0 & 11,12 & 10,50 & 7,62 & 3,37 & 2,62 \\
\hline 1 & 0 & 0 & 1 & 44,62 & 25,00 & 27,25 & 21,12 & 6,62 \\
\hline 1 & 1 & 0 & 1 & 40,37 & 25,00 & 26,00 & 8,62 & 3,12 \\
\hline 1 & 0 & 1 & 1 & 22,50 & 11,25 & 16,50 & 9,87 & 2,37 \\
\hline 1 & 1 & 1 & 1 & 22,75 & 20,25 & 14,87 & 10,12 & 5,00 \\
\hline
\end{tabular}

(*) 0 = ausência

In $=$ inoculação

Mo = molibdênio
$1=$ presença

$\mathrm{Np}=$ nitrogênio no plantio

$\mathrm{Nc}=$ nitrogênio em cobertura 
A resposta do número de nódulos/planta à aplicação de $\mathrm{N}$ no plantio foi linear, decrescendo com o avanço das épocas de avaliação, tanto na presença do $\mathrm{N}$ como na sua ausência. A aplicação de $20 \mathrm{~kg} / \mathrm{ha}$ de $\mathrm{N}$ causou um decréscimo médio de $57 \%$ no número de nódulos ao longo do ciclo do feijoeiro (Figura 32).

A análise de variância dos pesos de nódulos secos mostrou à semelhança do que ocorreu com o número de nódulos, que foram siginificativos os efeitos de $\mathrm{N}$ no plantio $(\mathrm{P}<0,01)$, épocas de avaliação $(\mathrm{P}<0,01)$ e a interação $\mathrm{N}$ no plantio $\mathrm{x}$ épocas de avaliação $(\mathrm{P}<0,01)$. Os dados médios relativos a este parâmetro encontram-se na Tabela 40.

Os pesos dos nódulos secos apresentaram uma resposta quadrática na ausência de $\mathrm{N}$ no plantio com um ponto de máximos aos 31 dias; com a adição de 20 $\mathrm{kg} / \mathrm{ha}$ de $\mathrm{N}$ no plantio o peso dos nódulos não apresentou resposta linear nem quadrática. Observa-se, na Figura 33, que a adição de $\mathrm{N}$ no plantio causou um grande decréscimo no peso dos nódulos.

A análise de variância dos dados relativos à atividade da redutase do nitrato mostrou que foram significativos os efeitos de Mo ( $\mathrm{P}<0,01), \mathrm{N}$ em cobertura $(\mathrm{P}<$ $0,05)$, épocas de avaliação $(\mathrm{P}<0,01)$ e as interações Mo x $\mathrm{N}$ no plantio $(\mathrm{P}<0,05)$ e Mo x épocas de avaliação $(\mathrm{P}<0,01)$. Os dados relativos a este parâmetro encontramse na Tabela 41.

A atividade da redutase do nitrato nas plantas que receberam $30 \mathrm{~kg} / \mathrm{ha}$ de $\mathrm{N}$ em cobertura foi $15 \%$ maior que nas plantas que não receberam esta adubação (Tabela 41). 


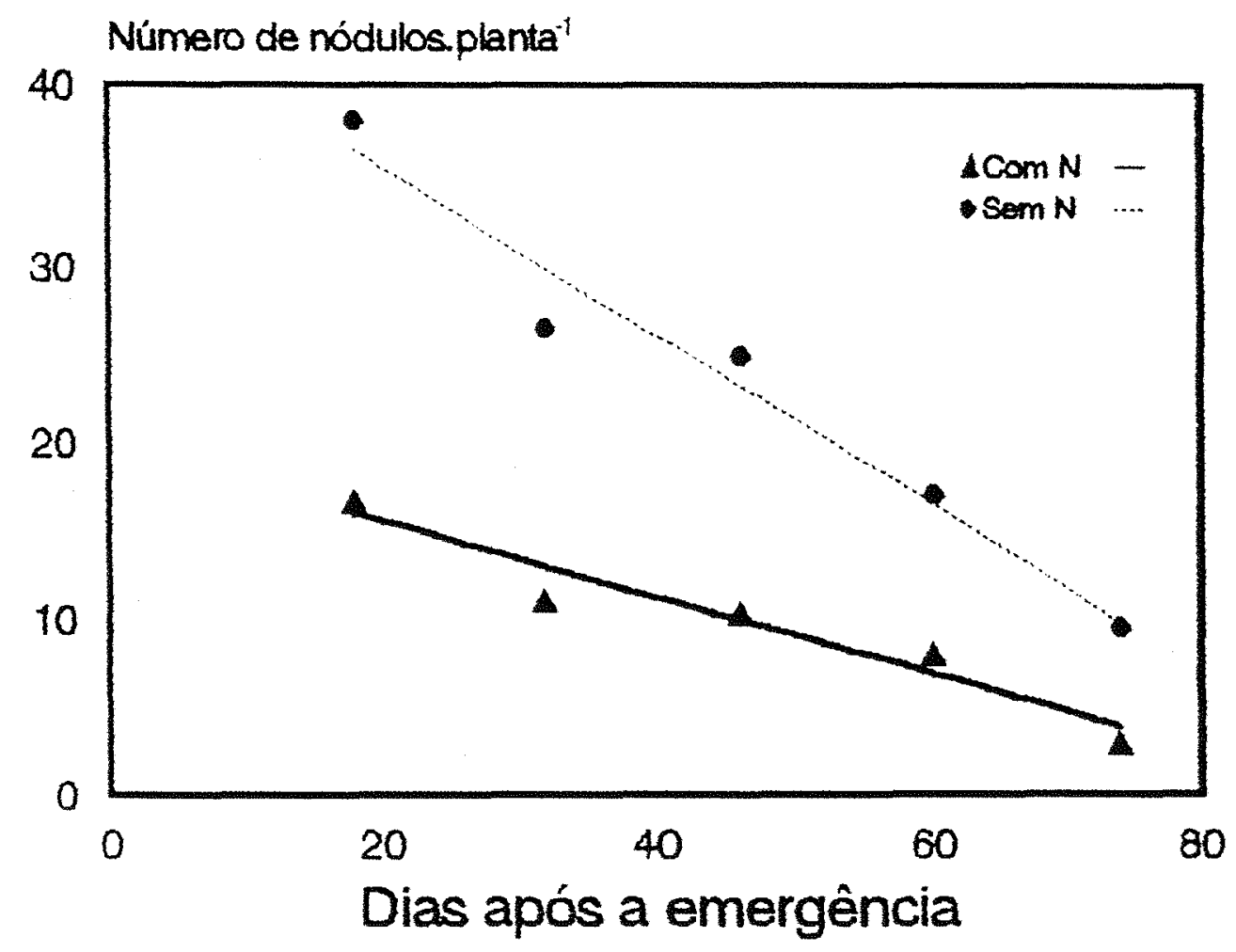

… $Y=45,0428-0,4767 E p$ (*ᄎ) $^{(\star)}$

$-Y=18,8859-0,2164$ Ep $\left(^{\star \star}\right)$

Figura 32 - Efeito de interação $\mathrm{N}$ no plantio $\mathrm{x}$ épocas de avaliação no número de nódulos.planta ${ }^{-1}$, em Coimbra, MG (Local II). 
Tabela 40 - Peso dos nódulos secos (mg/planta), em Coimbra, MG (Local II).

\begin{tabular}{|c|c|c|c|c|c|c|c|c|}
\hline \multicolumn{4}{|c|}{ Tratamentos ${ }^{*}$} & \multicolumn{5}{|c|}{ Dias após a emergência } \\
\hline In & Mo & $\mathrm{Np}$ & $\mathrm{Nc}$ & 18 & 32 & 46 & 60 & 74 \\
\hline 0 & 0 & 0 & 0 & 15,71 & 23,11 & 12,71 & 6,68 & 3,29 \\
\hline 0 & 1 & 0 & 0 & 14,51 & 19,38 & 18,81 & 12,16 & 4,84 \\
\hline 0 & 0 & 1 & 0 & 1,97 & 1,65 & 2,09 & 1,62 & 0,71 \\
\hline 0 & 1 & 1 & 0 & 2,95 & 2,33 & 2,20 & 1,57 & 1,78 \\
\hline 0 & 0 & 0 & 1 & 13,03 & 17,18 & 16,56 & 20,26 & 19,07 \\
\hline 0 & 1 & 0 & 1 & 7,01 & 9,11 & 8,60 & 10,16 & 2,29 \\
\hline 0 & 0 & 1 & 1 & 3,02 & 4,08 & 6,69 & 0,79 & 1,77 \\
\hline 0 & 1 & 1 & 1 & 8,81 & 2,04 & 7,56 & 2,11 & 0,93 \\
\hline 1 & 0 & 0 & 0 & 17,78 & 15,63 & 21,18 & 15,21 & 14,70 \\
\hline 1 & 1 & 0 & 0 & 18,70 & 19,55 & 5,50 & 4,82 & 3,30 \\
\hline 1 & 0 & 1 & 0 & 2,16 & 1,47 & 2,94 & 6,93 & 0,78 \\
\hline 1 & 1 & 1 & 0 & 1,77 & 2,19 & 2,75 & 0,91 & 1,31 \\
\hline 1 & 0 & 0 & 1 & 20,06 & 16,39 & 18,79 & 14,32 & 3,38 \\
\hline 1 & 1 & 0 & 1 & 12,03 & 12,53 & 9,99 & 3,29 & 1,41 \\
\hline 1 & 0 & 1 & 1 & 5,87 & 4,82 & 5,83 & 3,58 & 0,62 \\
\hline 1 & 1 & 1 & 1 & 5,84 & 4,97 & 13,48 & 9,21 & 5,33 \\
\hline
\end{tabular}

$\left.{ }^{*}\right) 0 \quad$ = ausência

In $=$ inoculação

Mo = molibdênio
$1=$ presença

$\mathrm{Np}=$ nitrogênio no plantio

$\mathrm{Nc}=$ nitrogênio em cobertura 


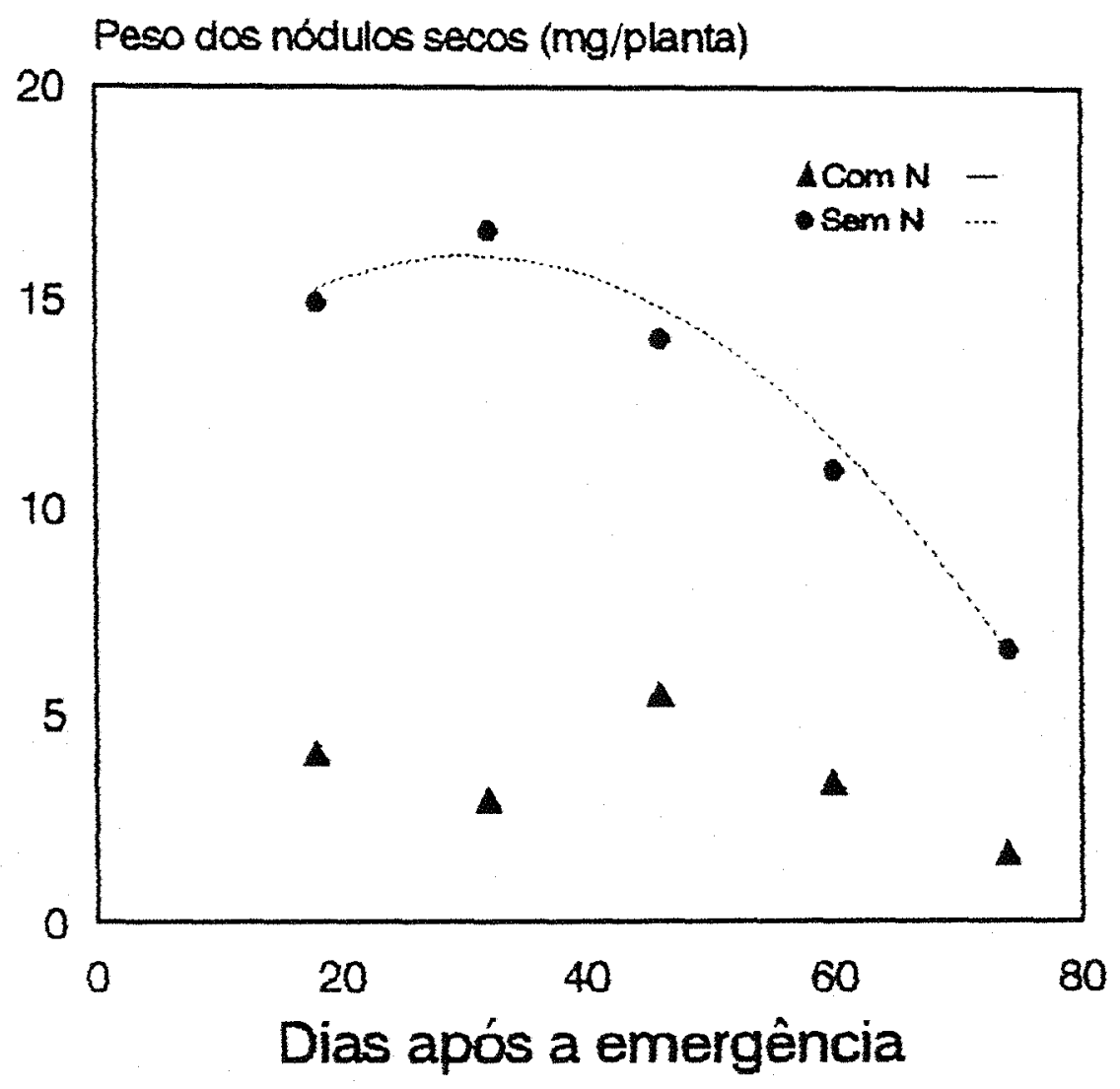

$\cdots . Y=11,2133+0,3127 \mathrm{Ep}-0,0061 \mathrm{Ep}^{2}\left({ }^{2 \star}\right)$

Figura 33 - Efeito da interação $\mathrm{N}$ no plantio x épocas de avaliação no peso dos nódulos secos (mg/planta), em Coimbra, MG (Local II). 
Tabela 41 - $\quad$ Atividade da redutase do nitrato $\left(\mu\right.$ moles de $\mathrm{NO}_{2} \cdot \mathrm{h}^{-1} \cdot \mathrm{g}$. de matéria fresca $^{-1}$ ), em Coimbra, MG (Local II).

\begin{tabular}{|c|c|c|c|c|c|c|c|c|}
\hline \multicolumn{4}{|c|}{ Tratamentos* } & \multicolumn{5}{|c|}{ Dias após a emergência } \\
\hline In & Mo & $\mathrm{Np}$ & $\mathrm{Nc}$ & 18 & 32 & 46 & 60 & 74 \\
\hline 0 & 0 & 0 & 0 & 2,96 & 4,15 & 4,08 & 6,83 & 3,64 \\
\hline 0 & 1 & 0 & 0 & 2,80 & 9,30 & 6,76 & 9,77 & 3,72 \\
\hline 0 & 0 & 1 & 0 & 2,78 & 4,09 & 3,40 & 8,84 & 3,79 \\
\hline 0 & 1 & 1 & 0 & 3,26 & 7,24 & 5,61 & 9,23 & 4,65 \\
\hline 0 & 0 & 0 & 1 & 3,47 & 5,27 & 5,51 & 7,34 & 3,83 \\
\hline 0 & 1 & 0 & 1 & 3,54 & 7,84 & 7,27 & 13,49 & 5,56 \\
\hline 0 & 0 & 1 & 1 & 1,90 & 6,74 & 4,45 & 7,39 & 4,77 \\
\hline 0 & 1 & 1 & 1 & 1,92 & 4,36 & 421 & 10,55 & 4,46 \\
\hline 1 & 0 & 0 & 0 & 2,35 & 3,72 & 3,09 & 7,06 & 2,91 \\
\hline 1 & 1 & 0 & 0 & 1,96 & 6,92 & 5,25 & 9,83 & 2,75 \\
\hline 1 & 0 & 1 & 0 & 1,57 & 4,63 & 4,92 & 7,53 & 3,99 \\
\hline 1 & 1 & 1 & 0 & 1,68 & 4,70 & 4,58 & 7,72 & 3,30 \\
\hline 1 & 0 & 0 & 1 & 1,70 & 7,24 & 3,91 & 7,31 & 3,41 \\
\hline 1 & 1 & 0 & 1 & 2,92 & 9,53 & 8,16 & 11,61 & 4,13 \\
\hline 1 & 0 & 1 & 1 & 2,13 & 4,15 & 3,78 & 8,22 & 6,15 \\
\hline 1 & 1 & 1 & 1 & 1,96 & 6,13 & 6,62 & 9,86 & 3,74 \\
\hline
\end{tabular}

$\left(^{*}\right) 0$ = ausência

In $=$ inoculação

Mo $=$ molibdênio
$1=$ presença

$\mathrm{Np}=$ nitrogênio no plantio

$\mathrm{Nc}=$ nitrogênio em cobertura 
$\mathrm{Na}$ ausência da adubação nitrogenada de plantio, a aplicação de $40 \mathrm{~g} / \mathrm{ha}$ de Mo causou um aumento de $48 \%$ na atividade da redutase do nitrato, enquanto que, na presença de $20 \mathrm{~kg} /$ ha de $\mathrm{N}$ no plantio, não houve efeito significativo da aplicação de Mo sobre a atividade dessa enzima (Tabela 42). Na ausência de Mo, a aplicação ou não de $\mathrm{N}$ no plantio não afetou significativamente a atividade da redutase do nitrato, enquanto que a utilização de $40 \mathrm{~g} /$ ha de Mo diminuiu significativamente a atividade da enzima quando houve associação com $20 \mathrm{~kg}$ de $\mathrm{N}$ no plantio.

As respostas da atividade da redutase do nitrato à presença ou ausência de Mo, em relação às épocas de avaliação, foram quadráticas, com máximos ao redor dos 35 dias (Figura 34). A pulverização com Mo provocou um aumento na atividade da enzima ao longo de todo o ciclo; as avaliações realizadas entre 32 e 60 dias mostraram um aumento médio de $41 \%$, em relação aos tratamentos sem Mo.

No caso das percentagens de $\mathrm{N}$-amoniacal na parte aérea, foram significativos os efeitos de $\mathrm{N}$ no plantio $(\mathrm{P}<0,01)$, épocas de avaliação $(\mathrm{P}<0,01)$ e a interação $\mathrm{N}$ no plantio $\mathrm{x}$ épocas de avaliação $(\mathrm{P}<0,01)$. Os dados médios encontraram-se na Tabela 43.

Ao contrário dos resultados obtidos nos experimentos de Viçosa e de Coimbra (Local I), não houve efeito do Mo e da aplicação de $\mathrm{N}$ em cobertura sobre a percentagem de $\mathrm{N}$-amoniacal na parte aérea. 
Tabela 42 - Efeito da interação Mo x N no plantio sobre a atividade da redutase do nitrato $\left(\mu\right.$ moles de $\mathrm{NO}_{2}^{-} \cdot \mathrm{h}^{-1} \cdot \mathrm{g}$. de matéria fresca $\left.{ }^{-1}\right)$, em Coimbra, MG (Local II)*.

\begin{tabular}{ccc}
\hline \hline Doses de & \multicolumn{2}{c}{ N no plantio } \\
\cline { 2 - 3 } molibdênio & $0 \mathrm{~kg} / \mathrm{ha}$ & $20 \mathrm{~kg} / \mathrm{ha}$ \\
\hline $0 \mathrm{~g} / \mathrm{ha}$ & $4,49 \mathrm{bA}$ & $4,76 \mathrm{aA}$ \\
$40 \mathrm{~g} / \mathrm{ha}$ & $6,66 \mathrm{aA}$ & $5,40 \mathrm{aB}$ \\
\hline
\end{tabular}

$\left.{ }^{*}\right)$ Médias seguidas pela mesma letra minúscula, na vertical, e maiúscula, na horizontal, não diferem significativamente, pelo teste de Duncan, ao nível de $5 \%$.

A percentagem de $\mathrm{N}$-amoniacal na parte aérea apresentou uma resposta quadrática à aplicação ou não de $\mathrm{N}$ no plantio, em relação às épocas de avaliação. Houve um ligeiro aumento nessa percentagem ao longo do ciclo com a aplicação de 20 kg/ha de $\mathrm{N}$ no plantio, em relação à ausência da adubação nitrogenada (Figura 35).

O ponto máximo da percentagem de $\mathrm{N}$-amoniacal ocorreu aos 35 dias, nas plantas sem $\mathrm{N}$ no plantio, e aos 28 dias, nas plantas que receberam essa adubação.

No caso da quantidade total de $\mathrm{N}$-amoniacal na parte aérea, a análise de variância revelou significância somente dos efeitos de $N$ no plantio $(P<0,01)$ e épocas de avaliação $(\mathrm{P}<0,01)$. Os dados médios encontram-se na Tabela 44. 


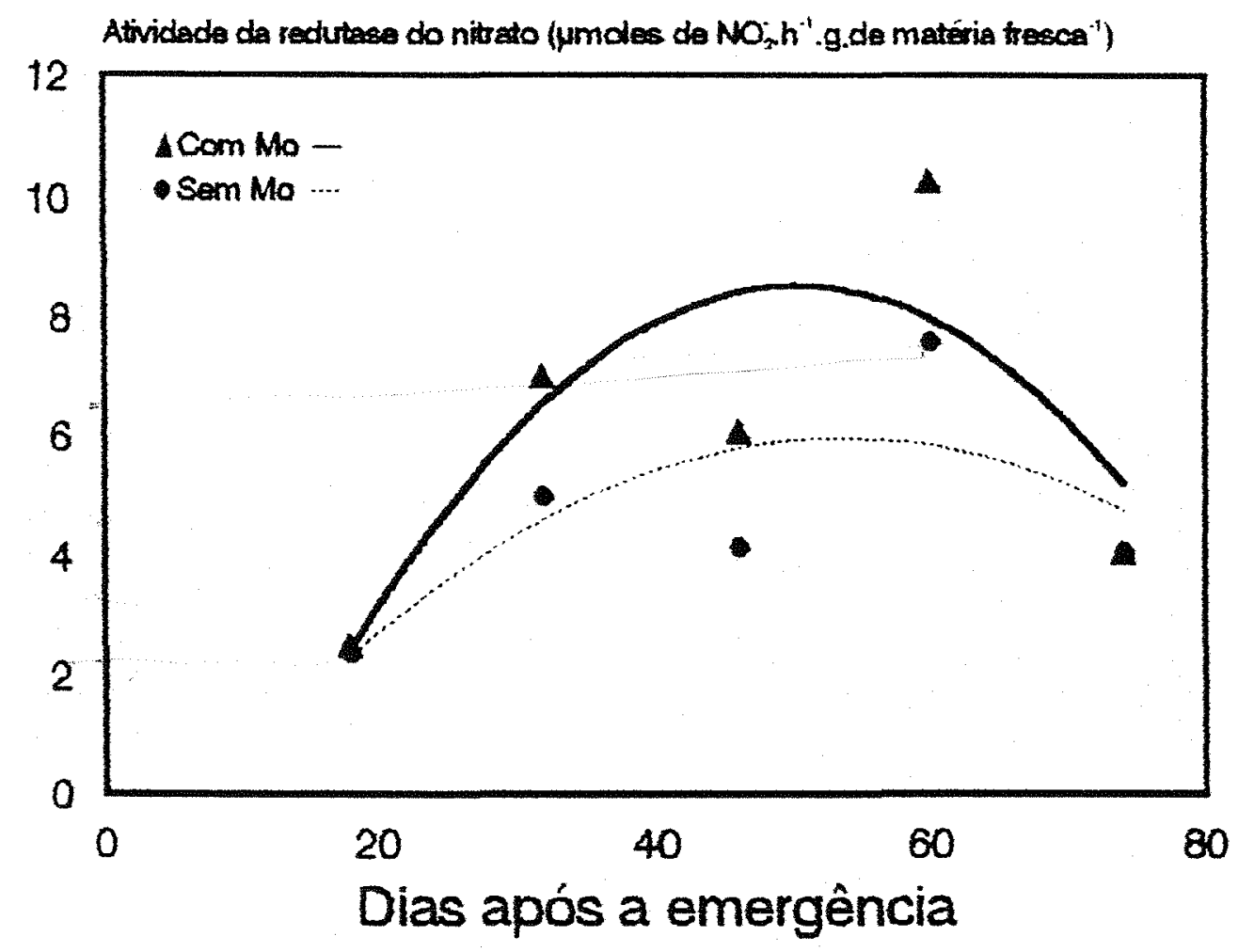

Figura 34 - Efeito da interação Mo x épocas de avaliação na atividade da redutase do nitrato ( $\mu$ moles de $\mathrm{NO}_{2}^{-} \cdot \mathrm{h}^{-1} \cdot \mathrm{g}$. de matéria fresca $\left.{ }^{-1}\right)$, em Coimbra, MG (Local II). 
Tabela 43 - Percentagem de N-amoniacal na parte aérea, em Coimbra, MG (Local II).

\begin{tabular}{|c|c|c|c|c|c|c|c|c|}
\hline \multicolumn{4}{|c|}{ Tratamentos } & \multicolumn{5}{|c|}{ Dias após a emergência } \\
\hline In & Mo & $\mathrm{Np}$ & $\mathrm{Nc}$ & 18 & 32 & 46 & 60 & 74 \\
\hline 0 & 0 & 0 & 0 & 3,87 & - & 4,07 & 2,98 & 1,97 \\
\hline 0 & 1 & 0 & 0 & 3,69 & - & 3,82 & 3,14 & 1,85 \\
\hline 0 & 0 & 1 & 0 & 4,46 & - & 4,29 & 3,52 & 2,43 \\
\hline 0 & 1 & 1 & 0 & 4,49 & - & 4,08 & 3,31 & 1,99 \\
\hline 0 & 0 & 0 & 1 & 3,72 & - & 4,04 & 3,31 & 1,86 \\
\hline 0 & 1 & 0 & 1 & 3,72 & - & 4,08 & 3,35 & 1,96 \\
\hline 0 & 0 & 1 & 1 & 4,55 & - & 4,44 & 3,72 & 2,51 \\
\hline 0 & 1 & 1 & 1 & 4,67 & - & 4,35 & 3,54 & 2,19 \\
\hline 1 & 0 & 0 & 0 & 3,77 & - & 3,99 & 3,98 & 1,80 \\
\hline 1 & 1 & 0 & 0 & 3,73 & - & 4,29 & 3,04 & 1,64 \\
\hline 1 & 0 & 1 & 0 & 4,55 & - & 4,36 & 3,55 & 2,22 \\
\hline 1 & 1 & 1 & 0 & 4,60 & - & 4,34 & 3,50 & 2,27 \\
\hline 1 & 0 & 0 & 1 & 3,91 & - & 4,16 & 3,35 & 2,00 \\
\hline 1 & 1 & 0 & 1 & 3,83 & - & 4,03 & 3,32 & 1,87 \\
\hline 1 & 0 & 1 & 1 & 4,45 & - & 4,29 & 3,18 & 2,44 \\
\hline 1 & 1 & 1 & 1 & 4,21 & - & 4,12 & 3,02 & 2,02 \\
\hline
\end{tabular}

$\left.{ }^{*}\right) 0$ = ausência;

In = inoculação

Mo = molibdênio
$1=$ presença

$\mathrm{Np}=$ nitrogênio no plantio

$\mathrm{Nc}=$ nitrogênio em cobertura 
Percentagem de $\mathrm{N}$-amoniacal na parte aérea.

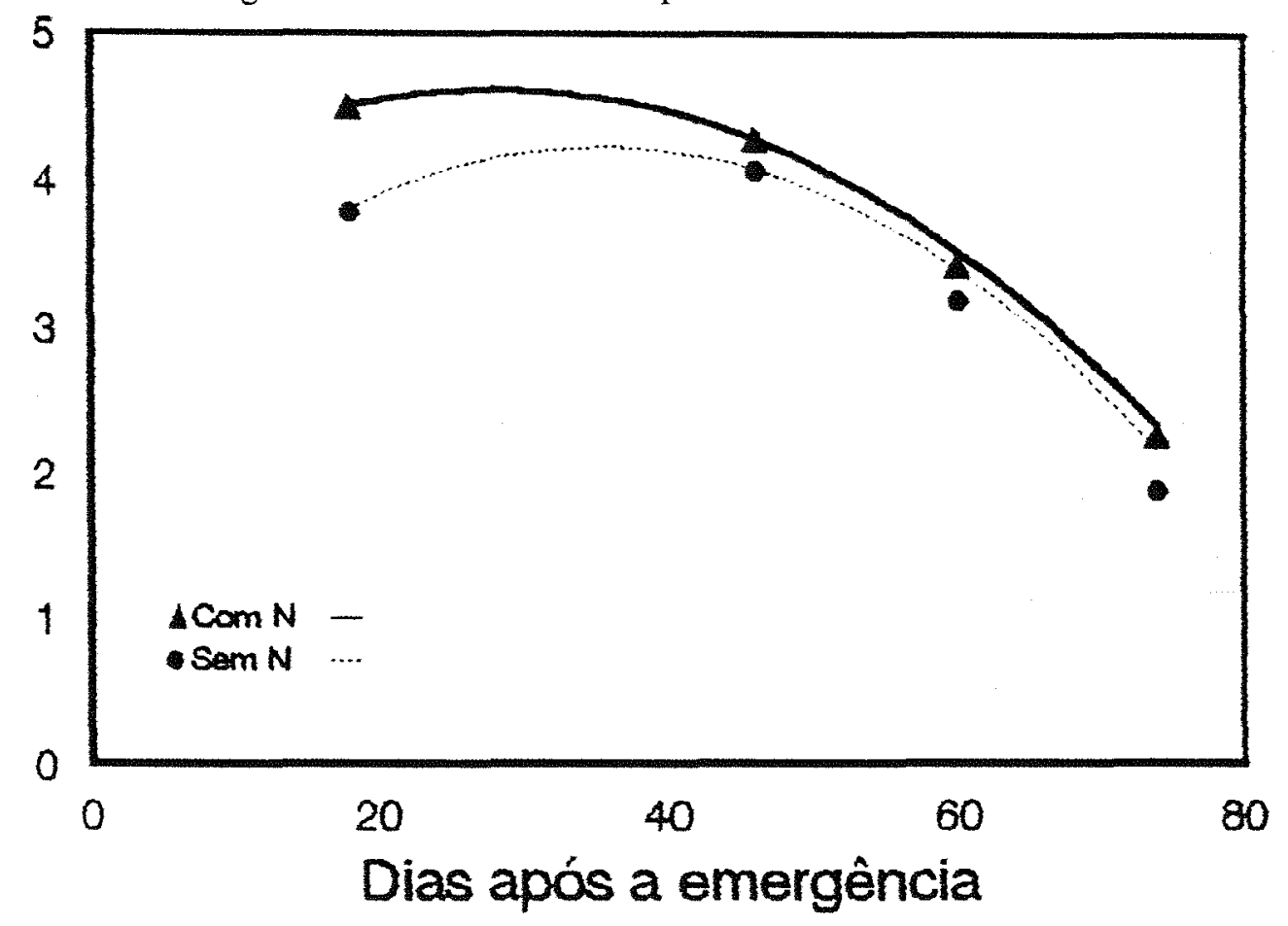

… $\left.Y=2,4678+0,0004 E p-0,0014 E p^{2}{ }^{* \star}\right)$

$-Y=3,7485+0,0622 E p-0,0011 E p^{2}\left(^{\star \star}\right)$

Figura 35 - Efeito da interação $N$ no plantio x épocas de avaliação na percentagem de $\mathrm{N}$-amoniacal na parte aérea, em Coimbra, MG (Local II). 
Tabela 44 - Quantidade total de $\mathrm{N}$-amoniacal na parte aérea (mg/planta), em Coimbra, MG (Local II).

\begin{tabular}{|c|c|c|c|c|c|c|c|c|}
\hline \multicolumn{4}{|c|}{ Tratamentos* } & \multicolumn{5}{|c|}{ Dias após a emergência } \\
\hline In & Mo & $\mathrm{Np}$ & $\mathrm{Nc}$ & 18 & 32 & 46 & 60 & 74 \\
\hline 0 & 0 & 0 & 0 & 22,01 & - & 90,19 & 89,18 & 56,32 \\
\hline 0 & 1 & 0 & 0 & 22,09 & - & 97,75 & 99,92 & 41,87 \\
\hline 0 & 0 & 1 & 0 & 31,46 & - & 107,50 & 126,69 & 81,32 \\
\hline 0 & 1 & 1 & 0 & 30,68 & - & 92,27 & 95,16 & 56,46 \\
\hline 0 & 0 & 0 & 1 & 19,33 & - & 110,81 & 137,67 & 49,01 \\
\hline 0 & 1 & 0 & 1 & 19,89 & - & 80,73 & 116,70 & 45,75 \\
\hline 0 & 0 & 1 & 1 & 27,93 & - & 122,81 & 158,11 & 90,41 \\
\hline 0 & 1 & 1 & 1 & 28,09 & - & 108,91 & 122,19 & 60,90 \\
\hline 1 & 0 & 0 & 0 & 20,79 & - & 134,66 & 158,15 & 84,40 \\
\hline 1 & 1 & 0 & 0 & 20,86 & - & 114,03 & 99,52 & 45,59 \\
\hline 1 & 0 & 1 & 0 & 34,78 & - & 108,84 & 151,24 & 58,78 \\
\hline 1 & 1 & 1 & 0 & 32,98 & - & 102,01 & 135,88 & 46,46 \\
\hline 1 & 0 & 0 & 1 & 19,98 & - & 91,98 & 119,00 & 48,03 \\
\hline 1 & 1 & 0 & 1 & 21,89 & - & 84,05 & 117,49 & 48,73 \\
\hline 1 & 0 & 1 & 1 & 30,14 & - & 169,22 & 169,71 & 108,11 \\
\hline 1 & 1 & 1 & 1 & 30,45 & - & 162,30 & 134,67 & 101,40 \\
\hline
\end{tabular}

(*) 0 = ausência

In = inoculação

Mo = molibdênio
$1=$ presença

$\mathrm{Np}=$ nitrogênio no plantio

$\mathrm{Nc}=$ nitrogênio em cobertura 
A aplicação de $20 \mathrm{~kg} / \mathrm{ha}$ de $\mathrm{N}$ provocou um aumento de $25 \%$ na quantidade total de $\mathrm{N}$-amoniacal na parte aérea (Tabela 44).

As quantidades totais de $\mathrm{N}$-amoniacal foram, indeferentemente de qualquer tratamento, maiores no período situado entre $046^{\circ}$ e $60^{\circ}$ dias após a emergência.

A análise de variância dos dados de percentagem de $\mathrm{N}-\mathrm{NO}_{3}^{-}$na parte aérea revelou que foram significativos os efeitos de $\mathrm{Mo}(\mathrm{P}<0,01)$, $\mathrm{N}$ no plantio $(\mathrm{P}<0,01)$, épocas de avaliação $(\mathrm{P}<0,01)$ e as interações Mo x épocas de avaliação $(\mathrm{P}<0,05)$ e $\mathrm{N}$ no plantio $\mathrm{x}$ épocas de avaliação $(\mathrm{P}<0,01)$. Os dados médios encontram-se na Tabela 45 .

A percentagem de $\mathrm{N}-\mathrm{NO}_{3}{ }^{-}$na parte aérea apresentou uma resposta linear às doses de Mo, em relação às épocas de avaliação (Figura 36). Observa-se ligeira tendência a uma menor percentagem de $\mathrm{N}-\mathrm{NO}_{3}^{-}$na parte aérea nas plantas que receberam o molibênio.

Do mesmo modo, a percentagem de $\mathrm{N}-\mathrm{NO}_{3}{ }^{-}$na parte aérea apresentou uma resposta quadrática às doses de $\mathrm{N}$ no plantio, em relação às épocas de avaliação (Figura 37). A adição de $\mathrm{N}$ no plantio causou acentuado aumento na percentagem de $\mathrm{N}-\mathrm{NO}_{3}^{-}$, em relação às plantas que não receberam essa adubação, somente no início do ciclo do feijoeiro.

Quanto à quantidade total de $\mathrm{N}-\mathrm{NO}_{3}^{-}$na parte aérea, a análise de variância revelou que foram significativos os efeitos da inoculação $(\mathrm{P}<0,05)$, Mo $(\mathrm{P}<0,01)$, $\mathrm{N}$ no plantio $(\mathrm{P}<0,01), \mathrm{N}$ em cobertura $(\mathrm{P}<0,01)$, épocas de avaliação $(\mathrm{P}<0,01)$ 
Tabela 45 - Percentagem de $\mathrm{N}-\mathrm{NO}_{3}{ }^{-}$na parte aérea, em Coimbra, MG (Local II).

\begin{tabular}{|c|c|c|c|c|c|c|c|c|}
\hline \multicolumn{4}{|c|}{ Tratamentos* } & \multicolumn{5}{|c|}{ Dias após a emergência } \\
\hline In & Mo & $\mathrm{Np}$ & $\mathrm{Nc}$ & 18 & 32 & 46 & 60 & 74 \\
\hline 0 & 0 & 0 & 0 & 0,22 & - & 0,11 & 0,08 & 0,04 \\
\hline 0 & 1 & 0 & 0 & 0,24 & - & 0,10 & 0,09 & 0,05 \\
\hline 0 & 0 & 1 & 0 & 0,31 & - & 0,14 & 0,10 & 0,09 \\
\hline 0 & 1 & 1 & 0 & 0,30 & - & 0,09 & 0,07 & 0,05 \\
\hline 0 & 0 & 0 & 1 & 0,23 & - & 0,16 & 0,08 & 0,04 \\
\hline 0 & 1 & 0 & 1 & 0,23 & - & 0,11 & 0,07 & 0,07 \\
\hline 0 & 0 & 1 & 1 & 0,32 & - & 0,16 & 0,14 & 0,10 \\
\hline 0 & 1 & 1 & 1 & 0,29 & - & 0,12 & 0,07 & 0,07 \\
\hline 1 & 0 & 0 & 0 & 0,24 & - & 0,17 & 0,08 & 0,05 \\
\hline 1 & 1 & 0 & 0 & 0,18 & - & 0,11 & 0,07 & 0,04 \\
\hline 1 & 0 & 1 & 0 & 0,30 & - & 0,14 & 0,09 & 0,10 \\
\hline 1 & 1 & 1 & 0 & 0,36 & - & 0,12 & 0,07 & 0,08 \\
\hline 1 & 0 & 0 & 1 & 0,21 & - & 0,14 & 0,09 & 0,06 \\
\hline 1 & 1 & 0 & 1 & 0,27 & - & 0,12 & 0,10 & 0,06 \\
\hline 1 & 0 & 1 & 1 & 0,36 & - & 0,17 & 0,09 & 0,08 \\
\hline 1 & 1 & 1 & 1 & 0,35 & - & 0,11 & 0,08 & 0,04 \\
\hline
\end{tabular}

$\left.{ }^{*}\right) 0$ = ausência

In = inoculação

Mo $=$ molibdênio
$1=$ presença

$\mathrm{Np}=$ nitrogênio no plantio

$\mathrm{Nc}=$ nitrogênio em cobertura 


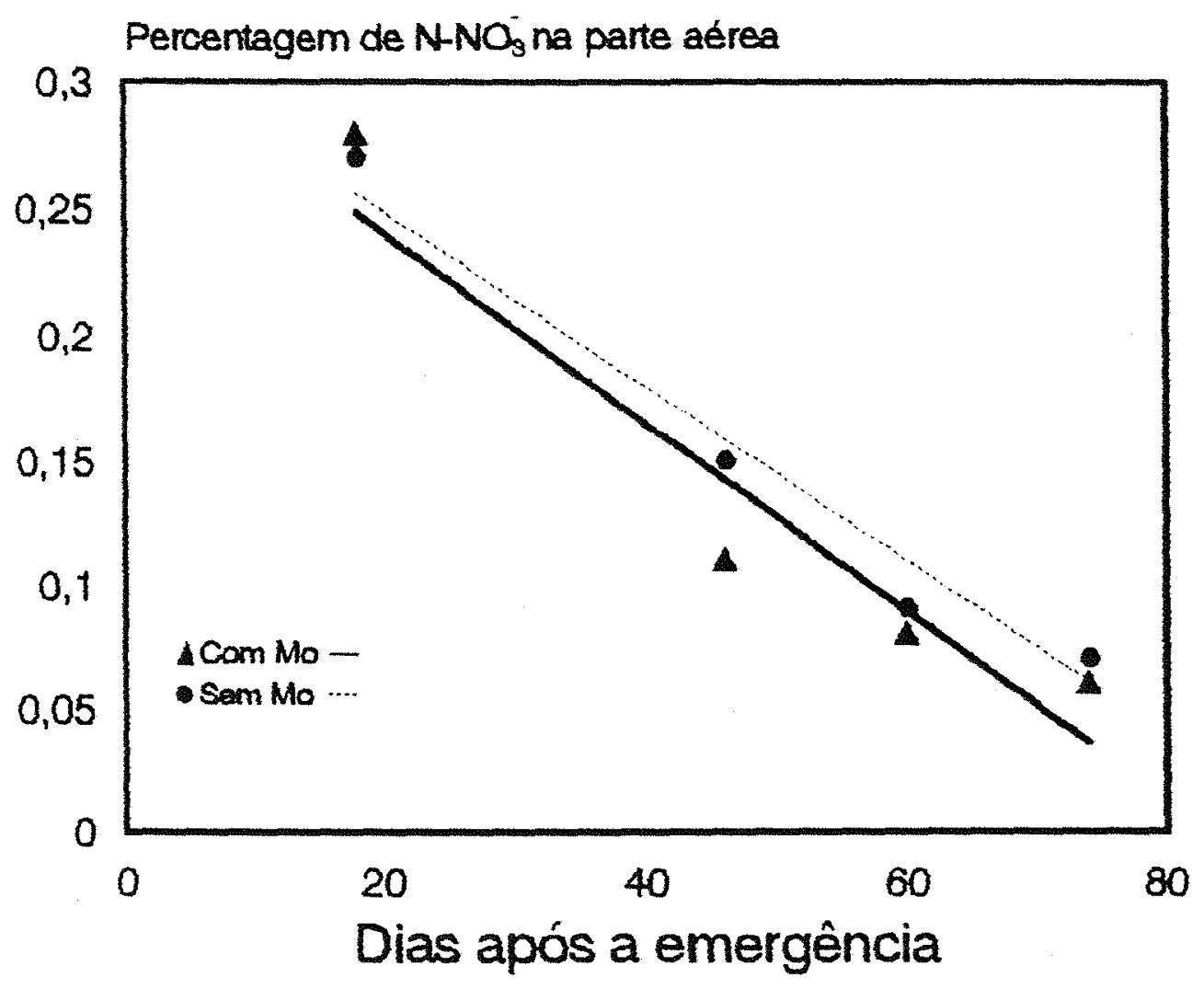

$Y=0,3197-0,00055 \mathrm{E}$
$-Y=0,3172-0,0038 \mathrm{Ep}$

Figura 36 - Efeito da interação Mo x épocas de avaliação na percentagem de $\mathrm{N}_{-} \mathrm{NO}_{3}{ }^{-}$na parte aérea, em Coimbra, MG (Local II). 


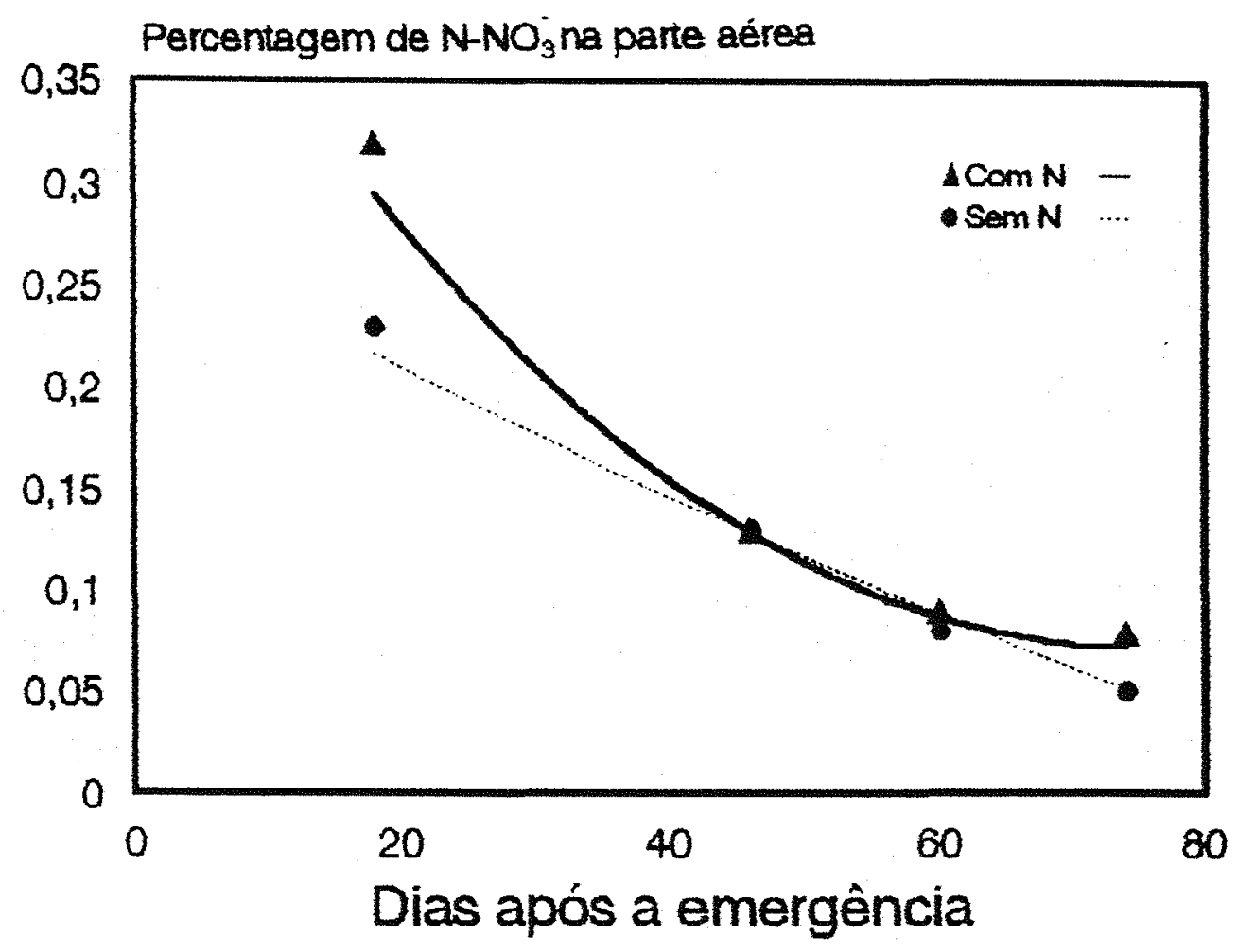

$\cdots Y=0,2799-0,0006 \mathrm{Ep}+0,000007 \mathrm{p}^{2}\left(^{\star \star}\right)$

$-Y=0,45940,0104 E p+0,00007 \mathrm{Ep}^{2}\left({ }^{\star \star}\right)$

Figura 37 - Efeito da interação $\mathrm{N}$ no plantio x épocas de avaliação na percentagem de $\mathrm{N}-\mathrm{NO}_{3}^{-}$na parte aérea, em Coimbra, MG (Local II). 
e as interações Mo x $\mathrm{N}$ no plantio $(\mathrm{P}<0,01)$ e $\mathrm{N}$ no plantio $\times \mathrm{N}$ em cobertura $(\mathrm{P}<$ $0,01)$ e $\mathrm{MO}$ x épocas de avaliação $(\mathrm{P}<0,05)$. Os dados médios encontram-se na Tabela 46.

Tanto na presença como na ausência de $\mathrm{Mo}$, a quantidade total de $\mathrm{N}-\mathrm{NO}_{3}^{-}$na parte aérea apresentaram uma resposta quadrática, em relação às épocas de avaliação (Figura 38). Verifica-se que, na presença de $\mathrm{Mo}$, a quantidade total de $\mathrm{N}-\mathrm{NO}_{3}^{-}$na parte aérea foi, em média, $32 \%$ menor dos 46 aos 74 dias, do que as observadas as plantas que não receberam molibdênio. O ponto de máxima quantidade foi atingido em torno dos 45 dias, tanto nas plantas que receberam Mo como nas que não o receberam.

A adição de $\mathrm{N}$ no plantio aumentou a quantidade total de $\mathrm{N}-\mathrm{NO}_{3}^{-}$na parte aérea em 49\%; a aplicação foliar de Mo fez com que estas quantidades diminuíssem, tanto nas plantas que não receberam $\mathrm{N}$ no plantio, como nas que o receberam, em $14 \%$ e $33 \%$, respectivamente (Tabela 47 ).

A aplicação somente de $30 \mathrm{~kg} / \mathrm{ha}$ de $\mathrm{N}$ em cobertura não afetou a quantidade total de $\mathrm{N}-\mathrm{NO}_{3}^{-}$na parte aérea em relação às plantas que não receberam essa adubação. A maior quantidade de $\mathrm{N}-\mathrm{NO}_{3}{ }^{-}$na parte aérea foi obtida com a adição de $20 \mathrm{~kg} / \mathrm{ha}$ de $\mathrm{N}$ no plantio $+30 \mathrm{~kg} / \mathrm{ha}$ de $\mathrm{N}$ em cobertura.

A inoculação do feijoeiro com estirpes selecionadas de rizóbio fez com que a quantidade total de $\mathrm{N}-\mathrm{NO}_{3}^{-}$na parte aérea aumentasse em $16 \%$, em relação às nãoinoculadas. 
Tabela 46 - Quantidade total de $\mathrm{N}-\mathrm{NO}_{3}^{-}$na parte aérea (mg/planta), em Coimbra, MG (Local II).

\begin{tabular}{|c|c|c|c|c|c|c|c|c|}
\hline \multicolumn{4}{|c|}{ Tratamentos* } & \multicolumn{5}{|c|}{ Dias após a emergência } \\
\hline In & Mo & $\mathrm{Np}$ & $\mathrm{Nc}$ & 18 & 32 & 46 & 60 & 74 \\
\hline 0 & 0 & 0 & 0 & 1,23 & - & 2,93 & 2,66 & 1,19 \\
\hline 0 & 1 & 0 & 0 & 1,44 & - & 2,45 & 2,89 & 1,32 \\
\hline 0 & 0 & 1 & 0 & 2,24 & - & 3,63 & 3,96 & 3,21 \\
\hline 0 & 1 & 1 & 0 & 2,10 & - & 2,09 & 2,25 & 1,47 \\
\hline 0 & 0 & 0 & 1 & 1,24 & - & 4,47 & 3,46 & 1,01 \\
\hline 0 & 1 & 0 & 1 & 1,24 & - & 2,19 & 2,70 & 1,88 \\
\hline 0 & 0 & 1 & 1 & 1,98 & - & 4,53 & 6,26 & 3,80 \\
\hline 0 & 1 & 1 & 1 & 1,79 & - & 3,12 & 2,56 & 2,16 \\
\hline 1 & 0 & 0 & 0 & 1,36 & - & 5,92 & 4,65 & 2,17 \\
\hline 1 & 1 & 0 & 0 & 1,07 & - & 3,02 & 2,20 & 1,16 \\
\hline 1 & 0 & 1 & 0 & 2,32 & - & 3,67 & 3,90 & 2,58 \\
\hline 1 & 1 & 1 & 0 & 2,65 & - & 2,77 & 3,00 & 1,66 \\
\hline 1 & 0 & 0 & 1 & 1,10 & - & 3,10 & 3,19 & 1,66 \\
\hline 1 & 1 & 0 & 1 & 1,54 & - & 2,94 & 3,68 & 1,64 \\
\hline 1 & 0 & 1 & 1 & 2,44 & - & 6,65 & 5,35 & 3,72 \\
\hline 1 & 1 & 1 & 1 & 2,54 & - & 4,25 & 3,71 & 2,08 \\
\hline
\end{tabular}

$\left(^{*}\right)$ = ausência

In = inoculação

Mo = molibdênio
$1=$ presença

$\mathrm{Np}=$ nitrogênio no plantio

$\mathrm{Nc}=$ nitrogênio em cobertura 


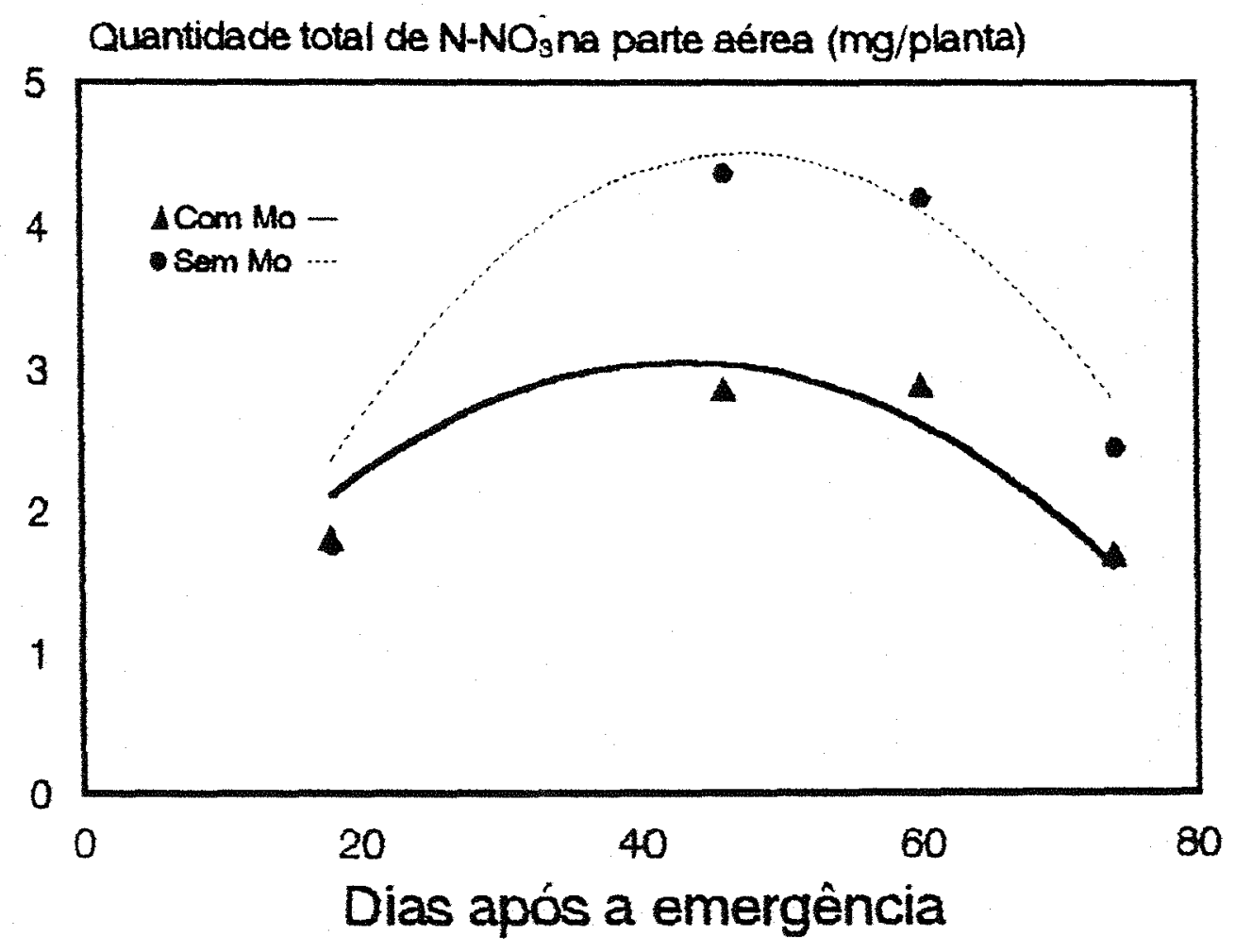

$$
\begin{aligned}
& \text { … } \left.Y=-1,0004+0,2360 \text { Ep-0,0025Ep }{ }^{2} f^{\star \star}\right) \\
& -Y=0,2818+0,1286 E p-0,0015 E p^{2} \text { (*k) }^{*}
\end{aligned}
$$

Figura 38 - Efeito da interação Mo x épocas de avaliação na quantidade total de $\mathrm{N}^{-\mathrm{NO}_{3}}$ na parte aérea (mg/planta), em Coimbra, MG (Local II). 
Tabela 47 - Efeito da interação Mo x $\mathrm{N}$ no plantio sobre a quantidade total de $\mathrm{N}-\mathrm{NO}_{3}{ }^{-}$ na parte aérea (mg/planta), em Coimbra, MG (Local II)*.

\begin{tabular}{ccc}
\hline \hline & \multicolumn{2}{c}{ N no plantio } \\
\cline { 2 - 3 } Molibdênio & $0 \mathrm{~kg} / \mathrm{ha}$ & $20 \mathrm{~kg} / \mathrm{ha}$ \\
\hline $0 \mathrm{~g} / \mathrm{ha}$ & $2,53 \mathrm{aB}$ & $3,77 \mathrm{aA}$ \\
$40 \mathrm{~g} / \mathrm{ha}$ & $2,18 \mathrm{aA}$ & $2,51 \mathrm{bA}$ \\
\hline
\end{tabular}

(*) Médias seguidas pela mesma letra minúscula, na vertical, e maiúscula, na horizontal, não diferem significativamente, pelo teste de Duncan, ao nível de 5\%.

Tabela 48 - Efeito da interação $\mathrm{N}$ no plantio $\mathrm{x} \mathrm{N}$ em cobertura sobre a quantidade total de $\mathrm{N}-\mathrm{NO}_{3}{ }^{-}$na parte aérea $(\mathrm{mg} /$ planta), em Coimbra, MG (Local II)*.

\begin{tabular}{ccc}
\hline \hline Nitrogênio & \multicolumn{2}{c}{ Nitrogênio em cobertura } \\
\cline { 2 - 3 } no plantio & $0 \mathrm{~kg} / \mathrm{ha}$ & $30 \mathrm{~kg} / \mathrm{ha}$ \\
\hline $0 \mathrm{~kg} / \mathrm{ha}$ & $2,40 \mathrm{aA}$ & $2,32 \mathrm{bA}$ \\
$20 \mathrm{~kg} / \mathrm{ha}$ & $2,72 \mathrm{aB}$ & $3,56 \mathrm{aA}$ \\
\hline \hline
\end{tabular}

(*) Médias seguidas pela mesma letra minúscula, na vertical, e maiúscula, na horizontal, não diferem significativamente, pelo teste de Duncan, ao nível de $5 \%$. 
As análises de variância dos dados relacionados às vagens mostraram que foram significativos, para peso de vagens secas, os efeitos das épocas de avaliação $(\mathrm{P}<0,01)$ e da interação $\mathrm{N}$ no plantio $x \mathrm{~N}$ em cobertura $(\mathrm{P}<0,05)$; para percentagem de $\mathrm{N}$ nas vagens, das doses de Mo $(\mathrm{P}<0,05)$ do $\mathrm{N}$ no plantio $(\mathrm{P}<0,01)$ e das épocas de avaliação $(\mathrm{P}<0,05)$; e para o teor total de $\mathrm{N}$ nas vagens, do $\mathrm{N}$ em cobertura $(\mathrm{P}<$ $0,05)$ e das épocas de avaliação $(\mathrm{P}<0,01)$. Os dados médios encontram-se na Tabela 49.

$\mathrm{Na}$ ausência de $\mathrm{N}$ no plantio, a aplicação ou não do $\mathrm{N}$ em cobertura não afetou significativamente o peso das vagens. Porém, quando se aplicaram $20 \mathrm{~kg} / \mathrm{ha}$ de $\mathrm{N}$ no plantio, o fornecimento adicional de $\mathrm{N}$ em cobertura trouxe um aumento significativo de $45 \%$ no peso das vagens (Tabela 50 ).

A aplicação foliar de Mo provocou uma queda de $6 \%$ na percentagem de $\mathrm{N}$ nas vagens, enquanto que a aplicação de $20 \mathrm{~kg} /$ ha de $\mathrm{N}$ no plantio provocou-lhe um aumento de $9 \%$.

A quantidade total de $\mathrm{N}$ nas vagens não foi afetado significativamente pelo Mo nem pelo $\mathrm{N}$ no plantio. Mas, com a aplicação de $30 \mathrm{~kg} / \mathrm{ha}$ de $\mathrm{N}$ em cobertura houve um aumento de cerca de $28 \%$. 
Tabela 49 - Peso (g/planta), percentagem de $\mathrm{N}$ e quantidade total de $\mathrm{N}$-amoniacal nas vagens secas (mg/planta), em Coimbra, MG (Local II)*.

\begin{tabular}{|c|c|c|c|c|c|c|c|c|c|}
\hline \multicolumn{4}{|c|}{ Tratamentos ${ }^{*}$} & \multicolumn{6}{|c|}{ Dias após a emergència } \\
\hline \multirow[t]{2}{*}{ In } & Mo & $N p$ & $\mathrm{Nc}$ & 60 & 74 & 60 & 74 & 60 & 74 \\
\hline & & & & \multicolumn{2}{|c|}{ Peso } & \multicolumn{2}{|c|}{ Perc. de $\mathrm{N}$} & \multicolumn{2}{|c|}{ Quantidade total } \\
\hline 0 & 0 & 0 & 0 & 1,24 & 3,83 & 2,74 & 2,91 & 34,03 & 110,06 \\
\hline 0 & 1 & 0 & 0 & 1,41 & 4,01 & 3.05 & 2,85 & 43,13 & 115,81 \\
\hline 0 & 0 & 1 & 0 & 1,05 & 3,81 & 3,18 & 3,72 & 33,48 & 139,15 \\
\hline 0 & 1 & 1 & 0 & 0,98 & 4,28 & 3,06 & 3,11 & 29,81 & 134,87 \\
\hline 0 & 0 & 0 & 1 & 1,72 & 3,56 & 2,98 & 3,05 & 52,10 & 109,26 \\
\hline 0 & 1 & 0 & 1 & 1,73 & 4,52 & 3,07 & 3,20 & 53,28 & 144,84 \\
\hline 0 & 0 & 1 & 1 & 1,57 & 4,83 & 3,51 & 3,42 & 54,49 & 162,62 \\
\hline 0 & 1 & 1 & 1 & 1,40 & 4,15 & 3,05 & 3,20 & 42,45 & 131,65 \\
\hline 1 & 0 & 0 & 0 & 1,97 & 6,47 & 2,77 & - & 53,79 & - \\
\hline 1 & 1 & 0 & 0 & 1,40 & 4,78 & 2,84 & 2,73 & 40,13 & 132,16 \\
\hline 1 & 0 & 1 & 0 & 1,22 & 4,23 & 3,16 & 3,25 & 38,51 & 136,94 \\
\hline 1 & 1 & 1 & 0 & 1,52 & 3,13 & 3,13 & 3,30 & 48,00 & 102,87 \\
\hline 1 & 0 & 0 & 1 & 1,13 & 4,10 & 3,25 & 3,12 & 35,18 & 126,77 \\
\hline 1 & 1 & 0 & 1 & 1,31 & 4,82 & 2,81 & 2,98 & 37,01 & 143,86 \\
\hline 1 & 0 & 1 & 1 & 1,91 & 5,34 & 3,26 & 3,48 & 60,57 & 178,18 \\
\hline 1 & 1 & 1 & 1 & - & 6,94 & 2,82 & 2,92 & - & 198,08 \\
\hline
\end{tabular}

$\left(^{*}\right)$ = ausência

In $=$ inoculação

Mo $=$ molibdênio
$1=$ presença

$\mathrm{Np}=$ nitrogênio no plantio

$\mathrm{Nc}=$ nitrogênio em cobertura 
Tabela 50 - Efeito da interação $\mathrm{N}$ no plantio $\mathrm{x} \mathrm{N}$ em cobertura sobre o peso das vagens secas (g/planta), em Coimbra, MG (Local II)*

\begin{tabular}{ccc}
\hline \hline Nitrogênio & \multicolumn{2}{c}{ Nitrogênio em cobertura } \\
\cline { 2 - 3 } no plantio & $0 \mathrm{~kg} / \mathrm{ha}$ & $30 \mathrm{~kg} / \mathrm{ha}$ \\
\hline $0 \mathrm{~kg} / \mathrm{ha}$ & $3,14 \mathrm{aA}$ & $2,86 \mathrm{aA}$ \\
$20 \mathrm{~kg} / \mathrm{ha}$ & $2,51 \mathrm{aB}$ & $3,65 \mathrm{aA}$ \\
\hline
\end{tabular}

$\left(^{*}\right)$ Médias seguidas pela mesma letra minúscula, na vertical, e maiúscula, na horizontal, não diferem significativamente, pelo teste de Duncan, ao nível de $5 \%$.

A análise de variância dos dados de percentagem de $\mathrm{N}$ nas sementes mostrou que foi significativo somente o efeito de $\mathrm{N}$ no plantio, tendo a adição de 20 $\mathrm{kg} /$ ha de $\mathrm{N}$ causado um aumento de $15 \%$. Quanto à quantidade de $\mathrm{N}$ exportado para os grãos foi significativo somente o efeito do $\mathrm{N}$ em cobertura, que provocou um aumento de $52 \%$. Quanto à produção, nenhum fator teve efeito significativo (Tabela 51). A produção média, neste experimento, considerando todos os tratamentos, foi de $773 \mathrm{~kg}$ de grãos/ha. 
Tabela 51 - Percentagem de $\mathrm{N}$ nas sementes, quantidades de $\mathrm{N}$ exportado para os grãos ( $\mathrm{kg} / \mathrm{ha})$ e produção ( $\mathrm{kg} / \mathrm{ha})$, em Coimbra, MG (Local II).

\begin{tabular}{|c|c|c|c|c|c|c|}
\hline \multicolumn{4}{|c|}{ Tratamentos ${ }^{*}$} & \multirow{2}{*}{$\begin{array}{c}\mathrm{N} \text { nas } \\
\text { sementes }\end{array}$} & \multirow{2}{*}{$\begin{array}{l}\mathrm{N} \text { exportado } \\
\text { para os grãos }\end{array}$} & \multirow[t]{2}{*}{ Produção } \\
\hline In & Mo & $\mathrm{Np}$ & $\mathrm{Nc}$ & & & \\
\hline 0 & 0 & 0 & 0 & 3,67 & 26,29 & 720 \\
\hline 0 & 1 & 0 & 0 & - & - & 674 \\
\hline 0 & 0 & 1 & 0 & 4,28 & 28,74 & 667 \\
\hline 0 & 1 & 1 & 0 & 4,06 & 29,52 & 727 \\
\hline 0 & 0 & 0 & 1 & 3,53 & 36,83 & 1070 \\
\hline 0 & 1 & 0 & 1 & 3,97 & 23,48 & 591 \\
\hline 0 & 0 & 1 & 1 & 5,68 & 53,89 & 902 \\
\hline 0 & 1 & 1 & 1 & 3,99 & 27,39 & 686 \\
\hline 1 & 0 & 0 & 0 & 3,57 & 33,79 & 1026 \\
\hline 1 & 1 & 0 & 0 & 3,90 & 18,31 & 469 \\
\hline 1 & 0 & 1 & 0 & 4,36 & 24,80 & 578 \\
\hline 1 & 1 & 1 & 0 & 4,32 & 16,74 & 394 \\
\hline 1 & 0 & 0 & 1 & - & - & 775 \\
\hline 1 & 1 & 0 & 1 & - & - & 584 \\
\hline 1 & 0 & 1 & 1 & 3,91 & 46,23 & 1200 \\
\hline 1 & 1 & 1 & 1 & 3,62 & 45,12 & 1305 \\
\hline
\end{tabular}

$\left(^{*}\right)$ = ausência

In $=$ inoculação

Mo = molibdênio
$1=$ presença

$\mathrm{Np}=$ nitrogênio no plantio

$\mathrm{Nc}=$ nitrogênio em cobertura 


\section{DISCUSSÃO}

Neste trabalho, verificou-se que o efeito do Mo sobre a atividade da nitrogenase não dependeu da estirpe de rizóbio utilizada, uma vez que a população nativa do solo e a introduzida pela inoculação, não produziram resultados diferentes.

Sabe-se, hoje, conforme já discutido no capítulo de revisão de literatura, que a ausência de sincronização entre o início da fixação do $\mathrm{N}_{2}$ atmosférico e a depleção de $\mathrm{N}$ nos cotilédones pode ser altamente prejudicial para o feijoeiro, em decorrência do seu ciclo curto.

A aplicação de Mo aos 25 dias não elimina o problema de depleção de $\mathrm{N}$ no início do ciclo do feijoeiro, mas faz com que a atividade da nitrogenase aumente sobremaneira após a aplicação do micronutriente, persistindo em alto nível em alguns casos, até os 60 dias (Figuras 1 e 11). Deste modo, a aplicação foliar de Mo amplia o período de alta atividade da nitrogenase, com conseqüente aumento na quantidade total de N-orgânico na parte aérea (Figuras 9 e 24).

Segundo PEREIRA et alii (1989), o estabelecimento de uma simbiose eficiente não se restringe somente a uma maior atividade da nitrogenase ou a uma maior quantidade de $\mathrm{N}$ na parte aérea, mas também a uma adequada translocação dos 
compostos nitrogenados para as partes reprodutivas da planta. Em Coimbra (local I), no caso das plantas inoculadas com bactérias selecionadas, o efeito benéfico do Mo sobre a simbiose chegou a aumentar a quantidade total de $\mathrm{N}$ nas vagens (Tabela 34 ), sem se refletir sobre a percentagem de $\mathrm{N}$ nas sementes ou sobre a produção; neste caso, somente houve efeito do Mo, independentemente da estirpe de rizóbio. Estes resultados demonstram, portanto, existir uma tendência à resposta diferenciada ao Mo entre as estirpes de rizóbio. Diante disso, não deve ser descartada a possibilidade de que outras estirpes possam responder mais eficientemente à adubação foliar com Mo, beneficiando o feijoeiro em termos de produção. Ademais, as épocas e quantidades de Mo a serem aplicadas devem também ser mais minuciosamente estudadas.

Embora a atividade da nitrogenase possa, em alguns casos, não ser um parâmetro adequado para se medir a eficiência da simbiose, LARA et alii (1983) mostraram que um rápido aumento na atividade da nitrogenase e do conteúdo de leghemoglobina nos nódulos são acompanhados por um aumento na atividade das enzimas de assimilação de $\mathrm{N}$ (glutamina sintetase e glutamato sintase) no citossol dos nódulos. No caso dos experimentos conduzidos em Viçosa e Coimbra (local I), se a aplicação de Mo causou um aumento tão acentuado na atividade da nitrogenase, de acordo com LARA et alii (1983) isso estaria também ocasionando um aumento na assimilação de $\mathrm{N}$ pela planta.

Um dos problemas que tem sido associado à baixa eficiência da simbiose rizóbio-feijão é a queda abrupta da atividade da nitrogenase após o florescimento das 
plantas. HUNGRIA (1985) verificou que o suprimento de fotossintatos para os nódulos, após o florescimento das plantas não era o principal fator limitante da fixação biológica do nitrogênio. Por outro lado, sabe-se que em condições de baixa disponibilidade de Mo, tanto o feijoeiro (FRANCO \& MUNNS, 1981) como a soja (ISHIZUKA, 1982) apresentam teores mais altos de Mo nos nódulos do que nas demais partes da planta. Considerando os resultados de FRANCO \& MUNNS (1981), de que ocorre uma diminuição na concentração de Mo nos nódulos com a idade da planta, uma das hipóteses para explicar a queda da atividade da nitrogenase no período de pós-floração do feijoeiro seria a queda na concentração de Mo nos nódulos. Segundo JACOB-NETO et alii (1988), porém, a queda da atividade da nitrogenase logo após a floração ocorreu mesmo com um suprimento adequado de Mo nos nódulos, ou seja, ocorreu mesmo com a concentração de Mo nos nódulos estando acima do nível crítico estabelecido por JACOB-NETO (1985).

Nos experimentos conduzidos em Viçosa e Coimbra (local I), não foi avaliado o teor de Mo nos nódulos ou em outras partes da planta. Verificou-se, porém, que a aplicação foliar de Mo não impediu uma queda da atividade da nitrogenase após a floração, como ocorreu em Viçosa já aos 41 dias (Figura 1), ou em Coimbra (local I), aos 47 dias (Figura 11). É interessante que se observe que, embora tenha ocorrido esse decréscimo na atividade da nitrogenase, os valores obtidos foram próximos aos verificados no início do ciclo nas plantas que não receberam adubação molíbdica.

A aplicação de $\mathrm{N}$ no plantio deve ser considerada quando se pretende obter aumento na atividade da nitrogenase em decorrência da aplicação foliar de molibdênio. 
No solo de Viçosa, por exemplo, a aplicação de $20 \mathrm{~kg} / \mathrm{ha}$ de $\mathrm{N}$ no plantio não permitiu que o micronutriente expressasse todo o seu efeito benéfico sobre a nitrogenase (Tabela 2), enquanto que, na ausência daquela adubação nitrogenada, o efeito do Mo sobre a nitrogenase foi acentuadamente maior. No experimento de Coimbra (local I), o efeito benéfico do Mo sobre a atividade da nitrogenase não foi afetado pela aplicação de 20 $\mathrm{kg} / \mathrm{ha}$ de $\mathrm{N}$ no plantio. Tais resultados permitem levantar a hipótese de que o efeito benéfico do Mo sobre a atividade da nitrogenase no feijoeiro está condicionado ao teor de $\mathrm{N}$ no solo. Possivelmente, o teor de $\mathrm{N}$ no solo de Viçosa era maior, e a adição de mais $20 \mathrm{~kg} / \mathrm{ha}$ de $\mathrm{N}$ no plantio prejudicou a resposta do feijoeiro ao Mo, enquanto que, em Coimbra (local I), tal fato não ocorreu.

Segundo alguns autores, a aplicação de uma baixa dose de $\mathrm{N}$ no início do ciclo do feijoeiro estimula a fixação biológica do nitrogênio (VAKHANIYA, 1989) ou não afeta a atividade da nitrogenase e o peso da matéria fresca dos nódulos (FRANCO et alii, 1979). Conforme foi visto nos experimentos de Viçosa e de Coimbra (local I), a simbiose entre os rizóbios e o feijoeiro se manifestou diferentemente em relação à aplicação de $20 \mathrm{~kg} /$ ha de $\mathrm{N}$ no plantio.

Em Viçosa, a aplicação da adubação nitrogenada de plantio pode não ter afetado a atividade da nitrogenase, porque o solo já apresentava um teor relativamente alto de $\mathrm{N}$, o que prejudicaria a enzima de qualquer forma, ao contrário de Coimbra (local I). Isto pode ser melhor visualizado pela Tabela 2 e pela Figura 12. Em Viçosa, a atividade foi baixa com ou sem a aplicação de $\mathrm{N}$ no plantio (Tabela 2), enquanto que 
em Coimbra ela foi $84 \%$ e $34 \%$ maior aos 18 e 32 dias, respectivamente, quando não se aplicou $\mathrm{N}$ no plantio. Verifica-se que o valor médio da atividade da nitrogenase no início do ciclo do feijoeiro, aos 18 e 32 dias, em Coimbra (local I) $\left(2,23 \mu\right.$ moles $\mathrm{C}_{2} \mathrm{H}_{4}$ . $h^{-1} \cdot$ planta $\left.^{-1}\right)$, nos tratamentos que receberam adubação nitrogenada no plantio (Figura 12), foi semelhante à média obtida em Viçosa com os tratamentos com e sem aplicação de $\mathrm{N}$ no plantio, ou seja, $2,43 \mu$ moles $\mathrm{C}_{2} \mathrm{H}_{4} \cdot \mathrm{h}^{-1}$. planta ${ }^{-1}$ (Tabela 2). Portanto, pelos resultados obtidos nesses experimentos, não se observou em nenhum dos dois solos, um estímulo da fixação biológica do nitrogênio, em decorrência da aplicação de uma pequena dose de $\mathrm{N}$ no plantio. Ademais, a aplicação dessa adubação, tanto em Viçosa como em Coimbra (local I), provocou um decréscimo no número e peso dos nódulos secos (Figuras 4, 16 e 19).

A aplicação de $\mathrm{N}$ no plantio pode causar ainda um atraso na obtenção dos máximos pesos dos nódulos secos (Figura 4) e do número de nódulos (Figura 16), durante o ciclo do feijoeiro.

A obtenção do número máximo de nódulos, durante a fase inicial de crescimento vegetativo do feijoeiro, parece ser extremamente importante para uma maior atividade nitrogenase. Tanto no experimento de Viçosa como no de Coimbra (local I), o efeito benéfico do Mo na atividade da nitrogenase (Figuras 1 e 11) esteve associado a uma obtenção mais precoce do número máximo de nódulos na planta (Figuras 3 e 15).

Essa ligação entre maior atividade da nitrogenase com a obtenção precoce do número máximo de nódulos, pode também ser observado nos tratamentos que 
receberam ou não $\mathrm{N}$ no plantio. $\mathrm{A}$ atividade da nitrogenase em Coimbra (local I) foi maior no início do ciclo do feijoeiro, quando não se adicionou $\mathrm{N}$ no plantio, e atingiu seu ponto de máxima atividade aos 29 dias; com a adição de $20 \mathrm{~kg} / \mathrm{ha}$ de $\mathrm{N}$ no plantio, o ponto de máxima atividade da nitrogenase foi obtido aos 48 dias (Figura 12). Do mesmo modo, o número de nódulos nos tratamentos sem adubação nitrogenada no plantio atingiu seu ponto máximo aos 24 dias, enquanto que na presença daquela adubação, além do número de nódulos ter sido menor durante todo o ciclo, o máximo somente foi obtido aos 43 dias (Figura 16).

Em todos os três experimentos, ficou claro que a aplicação de $30 \mathrm{~kg} / \mathrm{ha}$ de $\mathrm{N}$ em cobertura e a inoculação com rizóbio não afetaram a atividade da nitrogenase. $\mathrm{O}$ aumento da atividade dessa enzima, em decorrência da aplicação foliar do Mo, mostra que as estirpes nativas do solo podem ter a sua eficiência simbiótica aumentada, desde que adequadamente manejadas.

A atividade específica da nitrogenase mede a atividade desta enzima por grama de nódulos. Por este parâmetro, pode-se saber se a atividade da nitrogenase é maior ou menor em determinada situação, em decorrência do maior ou menor número ou peso de nódulos, ou em função da maior ou menor atividade de cada nódulo em si.

Tanto no experimento de Viçosa como no de Coimbra (local I), a atividade específica foi marcadamente aumentada pela adubação com molibdênio (Figuras 2 e 13). Em Viçosa, o aumento na atividade específica da nitrogenase esteve relacionada com o 
aumento na atividade da nitrogenase e com a queda no número de nódulos, em decorrência da aplicação foliar com molibdênio (Figura 3). Como não houve efeito do micronutriente sobre o peso dos nódulos, concluiu-se que, em Viçosa, o aparecimento de um menor número de nódulos, em conseqüência da adubação com Mo, esteve associado ao aparecimento de nódulos grandes.

Em Coimbra (local I), o aumento na atividade específica da nitrogenase, em consequência da aplicação foliar com Mo (Figura 13), esteve também relacionado a um aumento na atividade da nitrogenase, associado a uma tendência à diminuição do número de nódulos (Figura 15) e a um grande aumento no seu peso (Figura 18); portanto, semelhantemente ao que ocorreu em Viçosa, a pulverização dos feijoeiros com Mo, em Coimbra (local I), também induziu o aparecimento de nódulos grandes.

Como a atividade específica da nitrogenase mede a atividade da enzima por grama de nódulos, é de se esperar que, desde que a atividade seja mantida constante, um declínio no peso dos nódulos secos, aumente a sua atividade específica. Conforme mencionado anteriormente, em Viçosa a aplicação foliar de Mo não afetou o peso dos nódulos, mas aumentou a atividade da nitrogenase, o que produziu uma maior atividade específica dessa enzima. Em Coimbra (local I), por outro lado, o micronutriente aumentou o peso dos nódulos ao longo de todo o ciclo (Figura 18). A atividade específica da nitrogenase em Coimbra, apesar disso, foi bem maior na presença de Mo, porque a relação de aumento na atividade da nitrogenase, em decorrência da adubação molíbdica, foi de 2,89 vezes, enquanto que, para o peso de nódulos secos, foi de 1,27 
vez $\left(A N=X_{\mathrm{s} / \mathrm{Mo}}=1,85 \mu\right.$ moles $\mathrm{C}_{2} \mathrm{H}_{4} \cdot \mathrm{h}^{-1} \cdot$ planta $^{-1}, \mathrm{X}_{\mathrm{c} / \mathrm{Mo}}=5,34 \mu$ moles $\mathrm{C}_{2} \mathrm{H}_{4} \cdot \mathrm{h}^{\mathrm{r}}$ ${ }^{1} \cdot$ planta $\left.^{-1} ; \mathrm{PN}=\mathrm{X}_{\mathrm{s} / \mathrm{Mo}}=27,93 \mathrm{~g}, \mathrm{X}_{\mathrm{c} / \mathrm{Mo}}=35,48 \mathrm{~g}\right)^{1}$.

Em Coimbra (local I), contrariamente ao ocorrido em Viçosa, o efeito do Mo na atividade específica da nitrogenase foi aumentado pela presença de $20 \mathrm{~kg} / \mathrm{ha}$ de $\mathrm{N}$ no plantio (Tabela 15): este aumento esteve associado ao menor peso dos nódulos nos tratamentos sujeitos à adubação nitrogenada (Figura 19).

Conforme citado anteriormente, no capítulo de resultados, a atividade da redutase do nitrato, tanto no experimento de Viçosa como no de Coimbra (local I), foi aumentada pela aplicação foliar de molibdênio. A proporção deste aumento foi bem maior nas plantas cultivadas em Coimbra (local I) (Figura 20) do que em Viçosa (Figura 5). Considerando que as plantas cultivadas em Viçosa apresentaram um crescimento maior que as plantas cultivadas em Coimbra (local I), e por ser a redutase do nitrato uma enzima cuja atividade é induzida pelo substrato (CAMPBELL, 1988), pode-se considerar ter havido, em Viçosa, uma diluição da quantidade total de $\mathrm{N}^{-\mathrm{NO}_{3}^{-}}$nas folhas, o que levou a uma menor atividade da enzima.

Verifica-se também que a aplicação de $\mathrm{N}$ no plantio ou em cobertura não afetou a atividade da redutase do nitrato, tanto em Viçosa como em Coimbra (local I), embora tenha sido verificado que, em Coimbra, a aplicação de $\mathrm{N}$ no plantio aumentou a quantidade total de $\mathrm{N}^{-\mathrm{NO}_{3}}$ no início do ciclo e a aplicação em cobertura aumentou a

\footnotetext{
AN = Atividade da nitrogenase

$\mathrm{X}_{\mathrm{s} / \mathrm{MO}}=$ média sem molibdênio

$\mathrm{X}_{\mathrm{c} / \mathrm{Mo}}=$ média com molibdenio
} 
quantidade total de $\mathrm{N}^{-\mathrm{NO}_{3}}$ na parte aérea logo após a sua realização (Figuras 27 e 28). A aplicação foliar ou não de Mo não afetou a percentagem ou a quantidade total de $\mathrm{N}$ $\mathrm{NO}_{3}^{-}$na parte aérea, o que permite concluir que este micronutriente, por meio de sua ação benéfica sobre a redutase do nitrato, promoveu uma maior redução desse íon na planta para $\mathrm{N}$-orgânico.

Segundo PILBEAM \& KIRBY (1990), quando as plantas são transferidas para um meio de maior concentração de nitrato, as taxas de absorção e translocação do nitrato das raízes para a parte aérea aumentam e a atividade da redutase do nitrato também aumenta. Após algum tempo, a atividade da enzima alcança uma condição de estabilidade e se a taxa de absorção excede a taxa de redução, o nitrato se acumula nos "pools" de armazenamento. No caso dos dois experimentos, aqui mencionados, o solo talvez tenha um nível de $\mathrm{N}$ ou uma taxa de mineralização tal que supra as plantas com uma quantidade de $\mathrm{NO}_{3}^{-}$suficiente para a máxima atividade da enzima, embora não apresentem também o teor de Mo suficiente para este fim. Também, no trabalho de HERVAS et alii (1991) foi observado que a atividade da redutase do nitrato nas folhas aumentou com um maior teor de $\mathrm{NO}_{3}^{-}$no meio de cultivo, mas somente até uma certa concentração. Por outro lado FRANCO et alii (1979) mostraram que uma maior redução do nitrato está associada à aplicação de $\mathrm{N}$ no solo. Segundo estes autores, a adubação nitrogenada realizada na floração pode ser benéfica para a formação e enchimento das vagens no feijoeiro, pois induz a atividade da redutase do nitrato nas folhas, promovendo maior disponibilidade de $\mathrm{N}$-protéico nessa fase. De acordo com os 
resultados obtidos em Viçosa e Coimbra (local I), tal sugestão não seria apropriada; nesses dois locais, $40 \mathrm{~g} / \mathrm{ha}$ de Mo sem adubação nitrogenada teria o mesmo efeito do descrito por FRANCO et alii (1979).

A relação entre concentração de nitrato no meio e a taxa de redução de nitrato não é tão direta como parece devido à possibilidade de ocorrência de uma forma constitutiva da enzima. TIMPO \& NEYRA (1983) mostraram que é possível medir a atividade da redutase do nitrato em folhas retiradas de feijoeiros crescendo em solução nutritiva, usando apenas amônio ou uréia como fontes de nitrogênio.

É interessante observar que, nos experimentos de Viçosa e de Coimbra (local I), a aplicação de Mo ampliou o período de alta atividade da redutase do nitrato, no decorrer do ciclo do feijoeiro. A máxima atividade, que ocorreu aos 18 dias nas plantas que não receberam Mo, passou a se situar próximo aos 60 dias, em Viçosa (Figura 5), e aos 50 dias, em Coimbra (Figura 20), com a pulverização do micronutriente, sem ser menor no início do ciclo, em relação às plantas que não receberam adubação molíbdica.

Diante do exposto, fica evidente a necessidade do estabelecimento dos teores de $\mathrm{N}$ e Mo no solo para máxima atividade da redutase do nitrato. Em Coimbra (local I), apesar dos valores da atividade da redutase do nitrato (Figura 20) terem sido bem maiores que em Viçosa (Figura 5), as plantas apresentaram quantidades totais de $\mathrm{N}^{-\mathrm{NH}_{4}}$ mais baixas, com conseqüente menor transporte para os grãos e menor produção. Isto se deve ao fato de que o eficiente metabolismo do $\mathrm{N}$ na planta depende também de 
outros elementos, como P, $\mathrm{Zn}$ etc, que, em Coimbra, estavam em concentrações bem menores no solo. Produções maiores que as obtidas neste experimento, em Coimbra (local I), poderiam ser conseguidas possivelmente por meio de adubações mais pesadas com todos os nutrientes, exceto o $\mathrm{N}$, associadas a $40 \mathrm{~g} / \mathrm{ha}$ de molibdênio, em pulverização foliar.

Segundo FRANCO et alii (1979) e NEVES \& FERNANDES (1982), a assimilação de $\mathrm{NO}_{3}^{-}$e a fixação de $\mathrm{N}_{2}$ contribuem maximamente para o desenvolvimento do feijoeiro em estádios diferentes. Outros autores têm demonstrado que, também na soja, o processo de assimilação de $\mathrm{NO}_{3}{ }^{*}$ e a fixxação de $\mathrm{N}_{2}$ são eventos sucessivos, cada um contribuindo com o $\mathrm{N}$ em estádios definidos do desenvolvimento da planta (THIBODEAU \& JAWORSKY, 1975). No experimento de Coimbra (local I), tanto a nitrogenase como a redutase do nitrato tiveram os seus períodos de máxima atividade no início do ciclo do feijoeiro, quando não foi aplicado Mo, ou em torno dos 48 dias, quando as plantas receberam $40 \mathrm{~g} /$ ha de Mo (Figuras 11 e 20). Já em Viçosa, observouse, principalmente quando se adubou com Mo, que a máxima atividade da redutase do nitrato tendeu a ocorrer quando a atividade da nitrogenase estava baixa, mas com valores bem superiores aos obtidos na ausência de molibdênio (Figuras 1 e 5).

Tanto no experimento de Viçosa como no de Coimbra (local I), a inoculação não afetou a atividade da redutase no nitrato, embora se observasse em Coimbra que a introdução de estirpes selecionadas diminuiu a quantidade total de $\mathrm{N}-\mathrm{NO}_{3}^{-}$na parte aérea das plantas que não receberam $\mathrm{N}$ no plantio, quando comparadas às plantas não 
inoculadas (Tabela 27). Em algumas culturas, como a soja, alguns autores têm mostrado que a nodulação pode afetar marcadamente a expressão da atividade dessa enzima (CONEJERO et alii, 1986), enquanto que, em outras, como ervilha, os resultados têm sido contraditórios (HERVAS et alii, 1991; LIGERO et alii, 1987). As possíveis causas dessas diferenças na ervilha pode, segundo HERVAS et alii (1991), estar relacionada a diferenças intervarietais, idade da planta e estirpes de Rhizobium utilizadas na inoculação.

Em Viçosa, a quantidade máxima de $\mathrm{N}$-amoniacal na parte aérea, na presença de Mo, foi obtido provavelmente no período de enchimento de grãos (Figura 9), enquanto que, na ausência do micronutriente, esse máximo foi obtido mais cedo. Isto implica em maior taxa de absorção de $\mathrm{N}$ por um período mais prolongado do ciclo do feijoeiro, quando na presença de molibdênio. Como esse micronutriente aumentou sobremaneira a atividade da nitrogenase e da redutase do nitrato, a maior taxa de absorção de $\mathrm{N}$ pode tanto ser devida ao elemento proveniente do solo, como também da fixação biológica do nitrogênio. Por outro lado, verifica-se que, na presença de $\mathrm{N}$ no plantio, a taxa máxima de absorção de $\mathrm{N}$ pelo feijoeiro ocorreu mais tardiamente, do que na sua ausência (Figura 10). Apesar da quantidade total de $\mathrm{N}$-amoniacal na parte aérea das plantas que receberam $\mathrm{N}$ no plantio ter sido também tão alta como os obtidos nas plantas que receberam Mo (Figuras 9 e 10), ou mesmo nas que receberam $\mathrm{N} \mathrm{em}$ cobertura (média tirada da Tabela 8), não houve efeito da adubação nitrogenada de plantio sobre a produção do feijoeiro. Isto leva a crer que o efeito benéfico do Mo ou 
da aplicação de $\mathrm{N}$ em cobertura, estão associados a uma maior translocação do $\mathrm{N}$ para as partes reprodutivas da planta. Em Viçosa, não foram avaliadas as quantidades de $\mathrm{N}$ nas vagens como em Coimbra (local I), mas verificou-se que a aplicação de Mo e de $\mathrm{N}$ em cobertura aumentou a quantidade de $\mathrm{N}$ exportado para os grãos em 13,4\% e 10\%, respectivamente, em relação aos tratamentos sem essas adubações (Tabela 9).

Deve-se considerar, porém, que no experimento em Viçosa, por causa do crescimento excessivo das plantas e por ser o Ouro Negro 1992 uma variedade de crescimento indeterminado com hastes longas, houve grande dificuldade na recuperação das partes aéreas totais na terceira e quarta avaliações, ou seja, aos 60 e 74 dias, o que pode ter influenciado a avaliação das quantidades totais de $\mathrm{N}$-amoniacal dos vários tratamentos.

Quando se avaliam os dados de percentagem de $\mathrm{N}$ nas sementes (Tabelas 10 e 11), verifica-se que as estirpes de rizóbio podem afetar a quantidade de $\mathrm{N}$ exportada para os grãos de modo diferente, de acordo com o tipo de adubação nitrogenada a que foi submetido o feijoeiro. Apesar das interações mostradas pelas Tabelas 10 e 11 , não se observou nenhum efeito da inoculação sobre as quantidades totais de $\mathrm{N}$-orgânico na parte aérea ou sobre a produção.

Em Viçosa, as maiores produçōes foram obtidas com a aplicação de $40 \mathrm{~g} / \mathrm{ha}$ de Mo ou de $30 \mathrm{~kg} / \mathrm{ha}$ de $\mathrm{N}$, aos 25 dias após a emergência (Tabela 12).

Estes resultados confirmam os obtidos por VIEIRA (1992) de que a adubação com Mo, nas doses e épocas aqui descritas, podem substituir os efeitos da 
adubação nitrogenada de cobertura, na cultura do feijão, variedade Ouro Negro 1992. É interessante também que se observe, pela Tabela 12, que os efeitos de Mo e de $\mathrm{N}$ em cobertura não se somam, de modo que a aplicação conjunta dos dois não traria benefícios adicionais para a produção do feijoeiro.

Em Coimbra (local I), o valor máximo de $\mathrm{N}$-total acumulado na parte aérea ocorreu no período de floração plena do feijoeiro, ou seja, aos 50 dias, tanto nas plantas que receberam Mo (Figura 24) como nas plantas que receberam adubação nitrogenada de cobertura (Figura 25). As plantas não-submetidas à aplicação foliar de Mo também apresentaram um ponto de máxima quantidade de $\mathrm{N}$-amoniacal na parte aérea em torno dos 50 dias (Figura 24), contrariamente ao ocorrido em Viçosa. Neste caso, a pulverização com o micronutriente pode não ter prolongado a taxa de absorção de $\mathrm{N}$, possivelmente devido à menor disponibilidade de outros elementos envolvidos no processo; a quantidade total de $\mathrm{N}$-amoniacal na parte aérea, foi, porém, maior na presença de Mo, em todas as épocas.

Nesse experimento de Coimbra (local I), conforme já discutido para o experimento de Viçosa, verifica-se também a necessidade de um estudo mais detalhado das possíveis interações entre estirpes de rizóbio e o efeito do Mo na cultura do feijoeiro. A Tabela 23 demonstra claramente que a quantidade total de $\mathrm{N}$-amoniacal na parte aérea, em decorrência da aplicação foliar de Mo, foi maior nas plantas sujeitas à inoculação com bactérias selecionadas, causando, nessas plantas, conseqüentemente, uma maior remobilização do $\mathrm{N}$ para as partes reprodutivas (Tabela 34). 
Em Coimbra (local I), aos 60 e 74 dias, em média 23\% e 64\%, respectivamente, da quantidade de $\mathrm{N}$ acumulada na parte aérea, foram aparentemente translocados para as partes reprodutivas da planta, independentemente do tratamento a que foram sujeitas (Figura 39).

Observa-se ainda na Figura 39, que a aplicação de 40 g/ha de Mo ou de 30 $\mathrm{kg} / \mathrm{ha}$ de $\mathrm{N}$ em cobertura fez com que fossem remobilizados para as partes reprodutivas aos 74 dias, $75 \%$ a mais de $\mathrm{N}$ em relação às plantas que não receberam tais tratamentos. Essa maior remobilização de $\mathrm{N}$ para as partes reprodutivas, nos tratamentos com Mo e $\mathrm{N}$ em cobertura fez com que a quantidade de $\mathrm{N}$ exportada para os grãos apresentasse um valor médio de $48,83 \% \mathrm{~kg} / \mathrm{ha}$, com uma conseqüente produção de $1431 \mathrm{~kg} / \mathrm{ha}$ de grãos (Tabela 36). Nos tratamentos sem Mo ou $\mathrm{N}$ em cobertura, a quantidade média de $\mathrm{N}$ exportada para os grãos foi de $23,69 \mathrm{~kg} / \mathrm{ha}$, resultando numa produção média de $853,25 \mathrm{~kg} / \mathrm{ha}$ de grãos (Tabela 36). Esses dados demonstram que, na área de Coimbra (local I) e para a cultivar Ouro Negro 1992, são necessários, aproximadamente, a remobilização para os grãos de $31 \mathrm{~kg} / \mathrm{ha}$ de $\mathrm{N}$ para a produção de $1000 \mathrm{~kg} / \mathrm{ha}$ de grãos. 

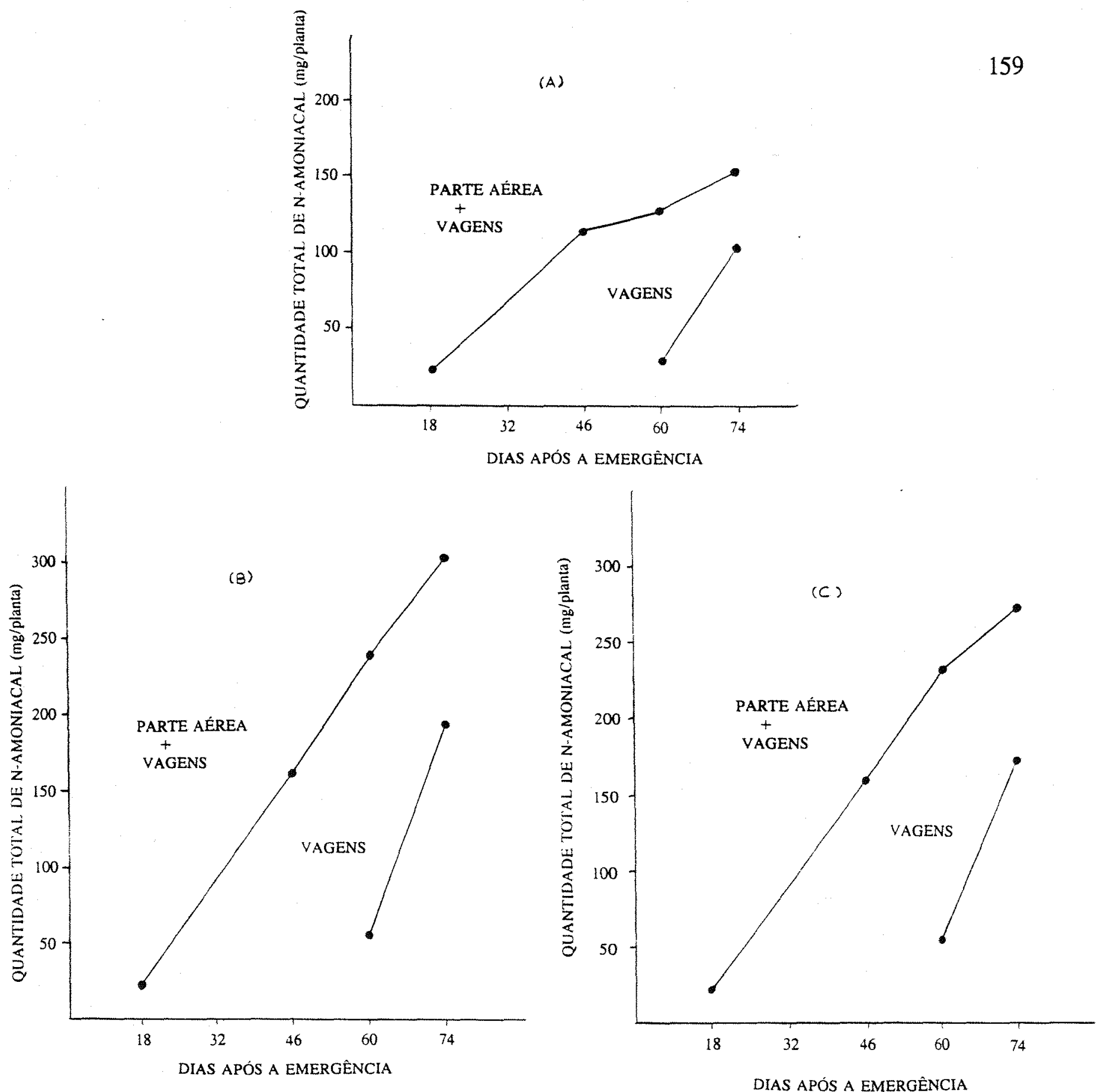

Figura 39 - Distribuição de $N$-amoniacal na parte aérea e nas vagens, aos 60 e 74 dias após a emergência das plantas.

$\mathrm{A}=$ sem molibdênio e sem $\mathrm{N}$ em cobertura; $\mathrm{B}=$ com molibdênio e sem $\mathrm{N}$ em cobertura; $\mathrm{C}=$ sem molibdênio e com $\mathrm{N}$ em cobertura. 
Toda essa discussão mostra que, apesar dessa necessidade de $\mathrm{N}$ para a produção de grãos, o efeito de $30 \mathrm{~kg} / \mathrm{ha}$ de $\mathrm{N}$ em cobertura sobre a produção do feijoeiro pode ser conseguido pela aplicação foliar de $40 \mathrm{~g} / \mathrm{ha}$ de Mo, conforme verificado em Viçosa. Em ambos os locais, não se verificou a necessidade de adubação nitrogenada no plantio.

Tanto no experimento de Viçosa como no de Coimbra (local I), a resposta do feijoeiro à aplicação foliar de Mo está relacionada, igualmente à aplicação de $\mathrm{N}$ em cobertura, a um metabolismo assimilatório do $\mathrm{N}$ mais eficiente, associado a um adequado transporte deste nutriente para as partes reprodutivas da planta (verificar efeito sobre produção de vagens nas Tabelas 30 e 35); pelas médias exibidas na Tabela 28 verifica-se que a aplicação de $30 \mathrm{~kg} / \mathrm{ha}$ de $\mathrm{N}$, aos 25 dias, ocasionou um aumento de $17 \%$ no peso das vagens secas e de $22 \%$ na sua quantidade total de $\mathrm{N}$-amoniacal.

O aumento na atividade das enzimas nitrogenase e redutase do nitrato, aos 60 e 74 dias, após a emergência das plantas, em decorrência da adubação foliar com Mo, pode ter favorecido a nutrição nitrogenada do feijoeiro, numa época de grande demanda desse nutriente, ou seja, no período de enchimento de grãos.

Ademais, sabe-se hoje que o amônio proveniente da redução de $\mathrm{N}_{2}$ atmosférico pela nitrogenase é convertido em composto orgânico ainda no citossol das células contendo os bacteróides. No caso do feijão e de outras leguminosas, o amônio é convertido em compostos ricos em $\mathrm{N}$ denominados ureídeos (SALISBURY \& ROSS, 1992). A enzima xantina desidrogenase desempenha importante papel na biossíntese de ureídeos nos nódulos de raízes de várias plantas fixadoras de $\mathrm{N}_{2}$ atmosférico, inclusive 
o feijão (WINKLER et alii, 1988) e, segundo CAMPBELL (1988), essa enzima também requer Mo para sua atividade. Dessa forma, a adubação molíbdica do feijoeiro parece fazer também com que haja uma translocação mais eficiente para a parte aérea do produto da fixação biológica do $\mathrm{N}_{2}$ atmosférico.

Contrariamente ao ocorrido no experimento de Viçosa e de Coimbra (local I), a aplicação foliar de Mo não afetou a atividade da nitrogenase, no experimento de Coimbra (local II). Ademais, verifica-se pelas Tabelas 13 e 37 que, independentemente de qualquer tratamento, a atividade da nitrogenase em Coimbra (local II) foi, em geral, bem menor que no local I. Por outro lado, verifica-se nesse experimento, como nos outros dois, o efeito maléfico da aplicação de $20 \mathrm{~kg} / \mathrm{ha}$ de $\mathrm{N}$ no plantio, tanto na atividade da nitrogenase (Figura 29), como no número e peso dos nódulos secos (Figuras 32 e 33).

A ausência do efeito da aplicação foliar de Mo, na atividade da nitrogenase, no local II de Coimbra, pode estar relacionado à deficiência de micronutriente nesse solo; sabe-se, por exemplo, que a deficiência de Zn está associada a uma diminuição no metabolismo de carboidratos e síntese de proteínas na planta, o que pode ter afetado o processo simbiótico (MARSCHNER, 1986).

Observa-se na Figura 30 que, apesar de não ter havido efeito significativo do Mo sobre a atividade da nitrogenase e sobre o peso de nódulos, a atividade específica da nitrogenase foi aumentada sobremaneira com a aplicação do micronutriente. Tirandose a média da atividade da nitrogenase aos 18, 32, 46, 60 e 74 dias (Tabela 37), com e sem aplicação de Mo, verifica-se que ela se mantém constante frente à aplicação do 
micronutriente ou apresenta um ligeiro aumento: $\left[\mathrm{AN}_{18 \mathrm{~d}}=\left(\mathrm{Mo}_{0}=1,93 ; \mathrm{Mo}_{1}=1,96\right)\right.$, $\mathrm{AN}_{32 \mathrm{~d}}=\left(\mathrm{Mo}_{0}=0,63 ; \mathrm{Mo}_{1}=0,42\right), \mathrm{AN}_{46 \mathrm{~d}}=\left(\mathrm{Mo}_{0}=0,69 ; \mathrm{Mo}_{1}=1,47\right), \mathrm{AN}_{60 \mathrm{~d}}=$ $\left.\left(\mathrm{Mo}_{0}=0,51 ; \mathrm{Mo}_{1}=0,85\right), \mathrm{AN}_{744}=\left(\mathrm{Mo}_{0}=0,49 ; \mathrm{Mo}_{1}=0,49\right)\right]^{2}$. No caso do peso dos nódulos secos, observa-se, pelas médias obtidas na Tabela 40, que a pulverização com o Mo tende a causar um pequeno decréscimo nesse parâmetro: $\mathrm{PN}_{18 d}=\left(\mathrm{Mo}_{0}=\right.$ 9,$\left.95 ; \mathrm{Mo}_{1}=8,95\right), \mathrm{PN}_{32 \mathrm{~d}}=\left(\mathrm{Mo}_{0}=10,54 ; \mathrm{Mo}_{1}=9,01\right), \mathrm{PN}_{46 \mathrm{~d}}=\left(\mathrm{Mo}_{0}=10,85 ;\right.$ $\left.\mathrm{Mo}_{1}=8,61\right), \mathrm{PN}_{60 \mathrm{~d}}=\left(\mathrm{Mo}_{0}=8,67 ; \mathrm{Mo}_{1}=5,53\right), \mathrm{PN}_{74 \mathrm{~d}}=\left(\mathrm{Mo}_{0}=5,54 ; \mathrm{Mo}_{1}=\right.$ $2,65)^{3}$. Essas diferenças na atividade da nitrogenase e no peso dos nódulos secos, na presença ou ausência de Mo, embora não fossem significativas, foram suficientes para causar um grande aumento na atividade específica daquela enzima, nas plantas submetidas à aplicação foliar com molibdênio.

$\mathrm{O}$ grande efeito maléfico da aplicação de $\mathrm{N}$ no plantio sobre o peso dos nódulos secos (Figura 33) fez também com que a atividade específica da nitrogenase aumentasse sobremaneira com a realização dessa adubação (Figura 31).

Nos experimentos de Viçosa e de Coimbra (local I), a pulverização do feijoeiro com Mo induziu o aparecimento de nódulos grandes; em Coimbra (local II) tal fato não ocorreu, uma vez que a aplicação foliar de Mo não teve efeito sobre o número e sobre o peso dos nódulos.

\footnotetext{
$2 \cdot 3 \mathrm{AN}=$ Atividade da nitrogenase

$\mathrm{X}_{\mathrm{s} / \mathrm{MO}}=$ média sem molibdênio

$X_{c / M O}=$ média com molibdênio

$\mathrm{PN}=$ Peso dos nódulos secos
} 
Ao contrário do ocorrido com a atividade da nitrogenase, a redutase do nitrato teve a sua atividade aumentada em decorrência da aplicação foliar com Mo (Figura 34); estes dados estão de acordo com os obtidos nos dois experimentos anteriores.

$\mathrm{Na}$ ausência da pulverização com o Mo, a atividade da redutase do nitrato, no local II, foi maior do que a observada em Viçosa ou no experimento de Coimbra (local I) (Figuras 5, 20 e 34). Isto pode estar associado a um acúmulo de nitrato nas plantas, devido ao seu pequeno crescimento em Coimbra (local II). Tal fato pode ser visualizado pelas médias das quantidades de nitrato (Tabela 26) na ausência de Mo, no local I $\left(18\right.$ dias $=1,26 ; 46$ dias $=2,41 ; 60$ dias $=1,58 ; 74$ dias $=0,48 \mathrm{mg} \mathrm{N-N^{- }}$ ${ }_{3}$ /planta) e as quantidades bem mais elevadas obtidas na ausência do micronutriente no local II, em Coimbra (Figura 38). Com a adubação molíbdica, a atividade da redutase do nitrato aumentou, em média, $39 \%$ no período situado entre o $32^{\circ}$ e o $60^{\circ}$ dia do ciclo do feijoeiro (Figura 34), com conseqüente decréscimo da quantidade total de N$\mathrm{NO}_{3}$ na parte aérea (Figura 38).

Conforme observado em Viçosa e em Coimbra (local I), a adubação nitrogenada de plantio não ocasionou um aumento na atividade da redutase do nitrato, no local II (Tabela 42). A aplicação de $30 \mathrm{~kg} / \mathrm{ha}$ de $\mathrm{N}$ em cobertura, por outro lado, causou um aumento de $15 \%$ na atividade desta enzima, conforme mostram as médias retiradas da Tabela 41. De acordo com as discussões anteriores, os solos utilizados nestes experimentos já teriam um teor de $\mathrm{N}$ suficientemente alto para provocar uma maior atividade da enzima redutase do nitrato, o que não ocorreria também com o 
molibdênio. No local II, uma possível deficiência de algum micronutriente pode ter afetado a absorção de nitrogênio $\left(\mathrm{NO}_{3}^{-}\right)$do solo, fazendo com que a atividade da redutase do nitrato e beneficiasse da aplicação de $\mathrm{N}$ em cobertura.

Verifica-se, na Tabela 42, que a aplicação de $\mathrm{N}$ no plantio pode até afetar o efeito benéfico do Mo sobre a atividade da redutase do nitrato, em situações como a do local II de Coimbra; o pequeno aumento na atividade da redutase do nitrato nos tratamentos com $\mathrm{Mo}+20 \mathrm{~kg} / \mathrm{ha}$ de $\mathrm{N}$ no plantio, embora não significativo em relação ao tratamento sem Mo, foi suficiente para diminuir em $34 \%$, a quantidade total de $\mathrm{N}$ $\mathrm{NO}_{3}^{-}$na parte aérea (Tabela 47 ).

Apesar do efeito benéfico da aplicação foliar de Mo sobre a redutase do nitrato, não houve efeito deste micronutriente na percentagem e quantidade total de $\mathrm{N}$ amoniacal na parte aérea, conforme ocorreu em Viçosa e no local I, de Coimbra.

Apesar da alta atividade da redutase do nitrato obtida em decorrência da aplicação foliar de Mo, a produção foi a mesma em todas as combinações de tratamentos no local II (Tabela 51). Tal fato leva à suposição de que a atividade dessa enzima não é um bom parâmetro para se medir a eficiência da adubação nitrogenada do feijoeiro ou para ser relacionado à sua maior ou menor produção. Em trabalho recente conduzido por PURCINO et alii (1994), os autores também verificaram que a atividade da redutase do nitrato não se correlacionou significativamente com a produtividade do milho.

O efeito benéfico da aplicação foliar de Mo sobre a produção do feijoeiro, parece portanto, estar mais relacionado a um sistema nitrogenase mais atuante. 


\section{6 - CONCLUSÕES}

- A nitrogenase e a redutase do nitrato têm as suas atividades aumentadas, em decorrência da aplicação foliar de molibdênio;

- A aplicação foliar de Mo não impede que haja uma queda na atividade da nitrogenase após o florescimento do feijoeiro, mas a mantém em um patamar superior àquele obtido na ausência do micronutriente;

- A pulverização com Mo induz o aparecimento de nódulos grandes e em menor número;

- As estirpes nativas de Rhizobium do feijoeiro podem ter a sua eficiência aumentada, desde que adequadamente manejadas;

- A aplicação de uma pequena dose de $\mathrm{N}$ no início do ciclo do feijoeiro afetou negativamente o processo simbiótico;

- A aplicação foliar de Mo pode, nas condições de solo da região de Viçosa e de Coimbra (local I), substituiu completamente a adubação nitrogenada do feijoeiro, variedade Ouro Negro 1992. 


\section{LITERATURA CITADA}

AMANE, M.I.V. Resposta da cultura do feijão (Phaseolus vulgaris L.) às adubações nitrogenadas e molíbdica. Universidade Federal de Viçosa, 1994. 70 p. Tese de Mestrado.

AMARA, D.S. \& MILLER, R.H. Effect of moisture and salt stress on selected Rhizobium phaseoli strains. Mircen Journal of Applied Microbiology and Biotechnology, Oxford, 2:373-382, 1986.

ANDREW, C.S. \& NORRIS, D.O. Comparative responses to calcium of five tropical and four temperature pasture legume species. Australian Journal Agricultural Research, Csỉro, 12:40-55, 1961.

ARAÚJO, G.A. de A.; FONTES, L.A.N.; AMARAL, F. de. A.L. do \& CONDÉ, A.R. Influência do molibdênio e do nitrogênio sobre duas variedades de feijão (Phaseolus vulgaris L.). Revista Ceres, Viçosa, 34:333-339, 1987. 
ARAYA, V.R.; VIEIRA, C.; MONTEIRO, A.A.T.; CARDOSO, A.A. \& BRUNE, W. Adubação nitrogenada da cultura do feijoeiro (Phaseolus vulgaris L.) na Zona da Mata de Minas Gerais. Revista Ceres, Viçosa, 28(156):134-149, 1981.

BARRADAS, C.A.; BODDEY, L.H. \& HUNGRIA, M. Seleção de cultivares de feijão e estirpes de Rhizobium para nodulação precoce e senescência tardia dos nódulos. Revista Brasileira de Ciência do Solo, Campinas, 13:169-179, 1989.

BARRADAS, C.A. \& HUNGRIA, M. Seleção de estirpes de Rhizobium para o feijoeiro. I. Precocidade para nodulação e fixação de nitrogênio. Turrialba, Coronado, 39(2):236-242, 1989.

BERGER, P.G.; VIEIRA, C.; CHAGAS, J.M.; BRAGA, J.M. \& CARDOSO, A.A. Resposta da cultura do feijão (Phaseolus vulgaris L.) à adubação nitrogenada e fosfatada. Revista Ceres, Viçosa, 30(169): 221-223, 1983.

BERGER, P.G.; VIEIRA, C. \& ARAÚJO, G.A.A. Adubação molíbdica por via foliar na cultura do feijão: efeito de doses. In: Reunião Nacional de Pesquisa do Feijão, 4 , Londrina, 1993. Resumos, n 159. 
BERGER, P.G.; VIEIRA, C.; ARAÚJO, G.A.A: \& MIRANDA, G.V. Adubação molíbdica por via foliar na cultura do feijão: efeito de épocas de aplicação. In: Reunião Nacional de Pesquisa do Feijão, 4º Londrina, 1993. Resumos, $\mathrm{n}^{\circ} 160$.

BONETTI, R.; MONTANHEIRO, M.N.S. \& SAITO, S.M.T. The effects of phosphate and soil moisture on the nodulation and growth of Phaseolus vulgaris. Journal of Agricultural Science, Cambridge, 103:95-102, 1984.

BRAGA, J.M. Resposta do feijoeiro "Rico 23" à aplicação de enxofre, boro e molibdênio. Revista Ceres, Viçosa, 19(103):222-226, 1972.

BRODRICK, S.J. \& GILLER, K.E. Root nodules of Phaseolus: Efficient scavengers of molybdenum for $\mathrm{N}_{2}$ fixation. Journal of Experimental Botany, Oxford, 42(238):679-686, 1991a.

BRODRICK, S.J. \& GILLER, K.E. Genotypic difference in molybdenum accumulation affects $\mathrm{N}_{2}$ fixation in tropical Phaseolus vulgaris L. Journal of Experimental Botany, Oxford, 43(243):1339-1343, 1991 b. 
CABALLERO, S.V; LIBARDI, P.L.; REICHARDT, K.; MATSU, E. \& VICTORIA, R.L. Utilização do fertilizante nitrogenado aplicado a uma cultura de feijão. Pesquisa Agropecuária Brasileira, Brasília, 20(9):1031-1040, 1985.

CAMPBELL, W.H. Nitrate reductase and its role in nitrate assimilation in plants. Physiologia Plantarum, Musksgaard, 74:214-219, 1988.

CARDOSO, A.A.; FONTES, L.A.N. \& VIEIRA, C. Efeitos de fontes e doses de adubo nitrogenado sobre a cultura do feijão (Phaseolus vulgaris L.). Revista Ceres, Viçosa, 25(139): 292-295, 1978.

CARROL, B.R. \& DUNIGAN, E.P. Effects of pH and pre-plant flooding on survival of soybean nodulating bacteria and yields. Agronomy Abstracts, Madison, 1977, p.147.

CARTER, K.R. JENNINGS, N.T.; HANNUS, J. \& EVANS, H.J. Hydrogen evolution and uptake by nodules of soybeans inoculated with different strains of Rhizobium japonicum. Canadian Journal of Microbiology, Ottawa, 24:304-311, 1978. 
CATALDO, D.A.; HAROON, M.; SCHRADER, L.E. \& YOUNGS, V.L. Rapid colorimetric determination of nitrate in plant tissue by nitration of salicylic acid. Communication in Soil Science and Plant Analysis, New York, 6(1):71-80, 1975.

CENTRO INTERNACIONAL DE AGRICUltura TropiCAL. Cali, Colômbia, Annual Report, Cali, 1976. p. 30-31.

COBRA NETO, A. Absorção e deficiência dos macronutrientes pelo feijoeiro (Phaseolus vulgaris L. var. roxinho). Escola Superior de Agricultura "Luiz de Queiroz", Piracicaba, 1967. 69 p. (Tese de Doutorado).

CONEJERO, G.; TIRADO, J.C. \& ROBIN, P. Effect of nodulating on the nitrate assimilation in vegetative soybean plants. Plant and Soil, The Hague, 91:385-389, 1986.

DANSO, S.K.A. \& ALEXANDER, M. Regulation of predation by prey density: the protozoan - Rhizobium relationship. Applied Microbiology, Baltimore, 29:515-521, 1975 . 
DE POLLI, H.; FRANCO, A.A. \& DOBEREINER, J. Survival of Rhizobium in flooded soils. Pesquisa Agropecuária Brasileira, Série Agronomia, Brasília, 8:133-138, 1973.

DUQUE, F.F.; NEVES, M.C.P.; FRANCO, A.A.; VICTORIA, R.L. \& BODDEY, R.M. The response of field grown Phaseolus vulgaris to Rhizobium inoculation and the quantification of $\mathrm{N}_{2}$ fixation using ${ }^{15} \mathrm{~N}$. Plant and Soil, The Hague, 88:333-343, 1985 .

FANCELLI, A.L. Tecnologia para produção do feijoeiro. Escola Superior de Agricultura "Luiz de Queiroz", Depto. de Agricultura, Piracicaba, 154p, 1994.

FERRAZ, S.M.G. \& CARDOSO, E.J.B.N. Fixação biológica de nitrogênio no feijoeiro em monocultivo e consorciado com milho. In: XXIV Congresso Brasileiro de Ciência do Solo. Goiânia, p.307-308, 1993.

FRANCO, A.A. \& MUNNS, D.N. Response of Phaseolus vulgaris L. to molybdenum under acid conditions. Soil Science Society of American Journal, Madison, 45:1144-1148, 1981. 
FRANCO, A.A. \& MUNNS, D.N. Acidity and aluminum restraints on nodulation, nitrogen fixation and growth of Phaseolus vulgaris L. in solution culture. Soil Science Society of American Journal, Madison, 46:296-301, 1982.

FRANCO, A.A. \& DAY, J.M. Effects of lime and molybdenum on nodulation and nitrogen fixation of Phaseolus vulgaris L. in acid soils of Brazil. Turrialba, Coronado, 30(1):99-105, 1980.

FRANCO, A.A. \& DÖBEREINER, J. Especificidade hospedeira na simbiose com Rhizobium - feijão e influência de diferentes nutrientes. Pesquisa Agropecuária Brasileira, Brasília, 2:467-474, 1967.

FRANCO, A.A. \& DÖBEREINER, J. Interferência do cálcio e nitrogênio na fixxação simbiótica do nitrogênio por duas variedades de Phaseolus vulgaris L. Pesquisa Agropecuária Brasileira, Brasília, 3:223-227, 1968.

FRANCO, A.A.; PEREIRA, J.C. \& NEYRA, C.A. Seasonal patterns of nitrate reductase and nitrogenase activities in Phaseolus vulgaris L. Plant Physiology, Bethesda, 63:421-424, 1979. 
GALLO, J.R. \& MIYASAKA, S. Composição química do feijoeiro e absorção de elementos nutritivos do florescimento à maturação. Bragantia, Campinas, 20(40):867-884, 1961 .

GIBSON, A.H.; DREYFUS, B.L.; LAWM, R.L.; SPRENT, J.I. \& TURNER, G.L. Host and environmental factors affecting hydrogen evolution and uptake. In: GIBSON, A.H. \& NEWTON, W.E., eds. Current perspectives in nitrogen fixation; proceedings of the Fourth International Symposium on Nitrogen Fixation, Canberra, Australian Academic Science, 1981. p.373.

GRAHAM, P.H. \& ROSAS, J.C. Growth and development of indeterminate bush and climbing cultivars of Phaseolus vulgaris L. inoculated with Rhizobium. Journal of Agricultural Science, Cambridge, 88:503-508, 1977.

GRAHAM, P.H. \& ROSAS, J.C. Phosphorus fertilization and symbiotic fixation in common bean. Agronomy Journal, Madison, 71:925-926, 1979.

GRAHAM, P.H. Influence of temperature on growth and nitrogen fixation in cultivars of Phaseolus vulgaris L. inoculated with Rhizobium. Journal Agricultural Science, Cambridge, 93:365-370, 1979. 
GRAHAM, P.H. Some problems of nodulation and symbiotic nitrogen fixation in Phaseolus vulgaris L.; a review. Field Crops Research, Amsterdam, 4:93-112, 1981.

HAAG, H.P.; MALAVOLTA, E.; GARGANTINI, H. \& BLANCO, H.G. Absorção de nutrientes pela cultura do feijoeiro. Bragantia, Campinas, 26(30):381-391, 1967.

HABTE, M. \& ALEXANDER, M. Further evidence for the regulation of bacterial populations in soil by protozoa. Archives of Microbiology, New York, 113:181-183, 1977.

HAGEMAN, R.H. \& REED, A.J. Nitrate reductase from higher plants. In: Methods in Enzymology, San Diego, 69:270-280, 1980.

HERVAS, A.; LIGERO, F. \& LLUCH, C. Nitrate reduction in pea plants: effects of nitrate application and Rhizobium strains. Soil Biology Biochemistry, Oxford, 23(7):695-699, 1991,

HEWITT, E.J. Some aspects of mineral nutrition in legumes. In: Hallsworth, E.G. (ed.) Nutrition of legumes. Academic Press, New York, 1958. p.15-43. 
HUNGRIA, M. \& FRANCO, A.A. Effects of high temperature on nodulation and $\mathrm{N}_{2}$ fixation by Phaseolus vulgaris L. Turrialba, Coronado, 25:101-109, 1990a.

HUNGRIA, M. \& FRANCO, A.A. New sources of high temperature tolerant rhizobia for Phaseolus vulgaris. Turrialba, Coronado, 25:110-115, $1990 \mathrm{~b}$.

HUNGRIA, M. \& NEVES, M.C.P. Ontogenia da fixação biológica do nitrogênio em Phaseolus vulgaris. Pesquisa Agropecuária Brasileira, Brasília, 21(7):715-730, 1986a.

HUNGRIA, M. \& NEVES, M.C.P. Partitioning of nitrogen from biological fixation and fertilizer in Phaseolus vulgaris. Physiologia Plantarum, Munksgaard, 69:55-63, 1986b.

HUNGRIA, M. \& RUSCHEL, A.P. Atividade da nitrogenase e evolução do hidrogênio pelos nódulos de Phaseolus vulgaris . Revista Brasileira de Ciência do Solo, Campinas, 11:269-274, 1987.

HUNGRIA, M. \& RUSCHEL, A.P. Eficiência da fixação biológica do nitrogênio em Phaseolus vulgaris . II. Efeito da aplicação de $\mathrm{N}$ mineral. In: Reunião Latinoamericana de Rhizobium. XI, Lima, 1982. Memórias Lima, ALAR, 1982, p.80. 
HUNGRIA, M. Fisiologia da fixação biológica do nitrogênio em Phaseolus vulgaris L. Universidade Federal Rural do Rio de Janeiro, 1985, 292p. Tese de Doutorado.

HUNGRIA, M.; BARRADAS, C.A.A. \& WALLSGROVE, R.M. Nitrogen fixation, assimilation and transport during the inicial growth state of Phaseolus vulgaris L. Journal of Experimental Botany, Oxford, 42(240):839-844, 1991.

HUNGRIA, M.; NEVES, M.C.P. \& VICTORIA, R.L. Assimilação do nitrogênio pelo feijoeiro. II. Absorção e translocação do $\mathrm{N}$ mineral e do $\mathrm{N}_{2}$ fixado. Revista Brasileira de Ciência do Solo, Campinas, 9:201-209, 1985a.

HUNGRIA, M.; THOMAS, R.J. \& DÖBEREINER, J. Efeito do sombreamento na fixação biológica de nitrogênio em feijoeiro. Pesquisa Agropecuária Brasileira, Brasília, 20(20):1143-1156, 1985 b.

ISHIZUKA, J. Characteristics of molybdenum absorption and translocation in soybean plants. Soil Science and Plant Nutrition, Tokyo, 28:63-71, 1982.

JACKSON, C.M. Soil Chemical Analysis. Englewood Clifss, Prentice-Hall, 1965. p.195-196. 
JACOB-NETO, J. Variação estacional, concentração nas sementes e níveis críticos de Mo nos nódulos do feijoeiro (Phaseolus vulgaris L.). Universidade Federal Rural do Rio de Janeiro, 1985. 141 p. Tese de Mestrado.

JACOB-NETO, J.; THOMAS, R.J. \& FRANCO, A.A. Variação estacional da concentração de molibdênio nos nódulos e demais partes da planta do feijoeiro (Phaseolus vulgaris L.). Turrialba, Coronado, 38(1):51-58, 1988.

JUNQUEIRA NETTO, A.; SANTOS, O.S. dos; AIDAR, H. \& VIEIRA, C. Ensaios preliminares sobre a aplicação de molibdênio e de cobalto na cultura do feijão (Phaseolus vulgaris L.), Revista Ceres, Viçosa, 24(36):628-633, 1977.

KEYA, S.O. Ecological aspects of feeding of protozoa and Bdellovibrio on cowpea Rhizobium. East African Agriculture Forestry Journal, Nairobi, 42(4):397-407, 1977.

KEYSER, H.H. \& MUNNS, D.N. Tolerance of rhizobia to acidity, aluminum and phosphate. Soil Science Society of American Journal, Madison, 43:519-523, 1979. 
KORNELIUS, E.; SOBRAL, L.F.; GOMES: J.C. \& RODRIGUES, E.M. Efeitos de doses e épocas de aplicação de nitrogênio na produção de feijão. In: Congresso Brasileiro de Ciência do Solo, 15․, Campinas, 1975. Resumo dos trabalhos Científicos... Campinas, SBCS-IAC, 1975. p.36.

KUCEY, R.M.N. Responses of field bean to levels of Rhizobium leguminosarum biovar phaseoli inoculation in soils containing effective R.leguminosarum biovar phaseoli. Canadian Journal of Plant Science, Ottawa, 69:419-426, 1989.

LA FAVRE, A.K. \& EAGLESHAM, A.R.J. The effects of high temperatures on soybean nodulation and growth with different strains of bradyrhizobia. Canadian Journal of Microbiology, Ottawa, 32:22-27, 1986.

LARA, M.; CULlimORE, J.V.; LEA, P.J.; MIFLINO, B.J.; JOHNSTON, A.W.B. \& LAMB, J.W. Appearance of a novel form of plant glutamine synthetase during nodule development in Phaseolus vulgaris L. Ibid, 157:254-258, 1983.

LENNOX, L.B. \& ALEXANDER, M. Fungicide enhancement of nitrogen fixation and colonization of P.vulgaris by R.phaseoli. Applied Environmental Microbiology, Baltimore, 41(2):404-411, 1981. 
LIGERO, F.; LLUCH, C.; OLIVARES, J. \& BEDMAR, E. Nitrate reductase activity in nodules of pea inoculated with hydrogenase positive and hydrogenase negative strains of Rhizobium leguminosarum. Physiologia Plantarum, Munksgaard, 69:313-316, 1987.

LOVATO, P.E.; PEREIRA, J.C. \& VIDOR, C. Flutuação populacional de estirpes de Rhizobium phaseoli em solos com e sem calagem. Revista Brasileira de Ciência do Solo, Campinas, 9:9-12, 1985a.

LOVATO, P.E.; PEREIRA, J.C. \& VIDOR, C. Flutuação populacional de estirpes de Rhizobium phaseoli na rizosfera de feijão. Revista Brasileira de Ciência do Solo, Campinas, 9:211-218, 1985b.

MACHADO, J. dos S.; JUNQUEIRA NETTO, A.; GUEDES, G.A. de A. \& REZENDE, P.M. de. Efeito do fósforo, molidnênio e cobalto sobre o feijoeiro comum (Phaseolus vulgaris) cultivados em oxissolos. Ciência e Prática, Lavras, 3(2): 101-106, 1979.

MAFRA, R.C.; VIEIRA, C.; BRAGA, J.M.; SIQUEIRA, C. \& BRANDES, D. Efeitos da população de platas e da época de plantio no crescimento do feijoeiro (Phaseolus vulgaris L.). Absorção de nutrientes. Experientiae, Viçosa, 17:217-239, 1974 . 
MALAVOLTA, E. Nutrição e adubação. In: Simpósio Brasileiro de Feijão, 1., Campinas, 1971. Anais, Viçosa, Universidade Federal de Viçosa, 1972. pp. 209-42.

MARSCHNER, $H$. Functions of mineral nutrients: micronutrients. In: MARSCHNER, H., ed. Mineral Nutrition of Higher Plants. Academic Press, London, 1986. p. 269-340.

MARTINEZ-ROMERO, E.; SEGOVIA, L.; MERCANTE, F.M.; FRANCO, A.A.; GRAHAN, P. \& PARDO, M.A. Rhizobium tropici, a novel species nodulating Phaseolus vulgaris L. beans abd Leucaena sp. tress. International Journal of Sistematic Bacteriology, Iowa, 41:417-426, 1991.

MASCARENHAS, H.A.A.; MIYASAKA, S.; IGUE, T; VEIGA, A.A. \& ALVES, S. Influência das formas de fertilizantes nitrogenadas e suas épocas de aplicação na cultura do feijoeiro. Bragantia, Campinas, 25: XLI-XLIII, 1966.

MASEFIELD, G.B. The effect of irrigation on nodulation of some leguminous crops. Empire Journal of Experimental Agriculture, Oxford, 29(113): 51-59, 1961. 
MEIRELLES, N.M.F.; LIBARDI, P.L. \& REICHARDT, K. Absorção e lixiviação de nitrogênio em cultura do feijão (Phaseolus vulgaris L.). Revista Brasileira de Ciência do Solo, Campinas, 4:83-88, 1980.

MIYASAKA, S.; FREIRE, E.S. \& MASCARENHAS, H.A.A. Modo e época de aplicação de nitrogênio na cultura do feijoeiro. Bragantia, Campinas, 22:511-519, 1963.

MORAES, J.F.V. Calagem e adubação. In: ZIMMERMANN, M.J. de O.; ROCHA, M. \& YAMADA, T., eds. Cultura do feijoeiro: Fatores que afetam a produtividade. Piracicaba, Associação Brasileira para Pesquisa de Potassa e do Fosfato. p.261-301, 1988.

MULDER, E.G. Importance of molibdenum in the nitrogen metabolism of microrganisms and higher plants. Plant and Soil, The Hague, n.1, 1984.

NEPTUNE, A.M.L. \& MURAOKA, T. Aplicaçção da ureia, ${ }^{15} \mathrm{~N}$ em feijoeiro (Phaseolus vulgaris L.) cultivar Carioca. Revista Brasileira de Ciência do Solo, Campinas, 2(1):51-55, 1978 . 
NEVES, M.C.P.; FERNANDES, M.S. \& SÁ, M.F.M. Assimilação de nitrogênio em plantas noduladas de Phaseolus vulgaris L. e Vigna unguiculata (L.) Walp. Pesquisa Agropecuária Brasileira, Brasília, 17(5):689-695, 1982.

OLIVEIRA, L.C.B. de; FRANCO, A.A. \& DÖBEREINER, J. Estabilidade da efetividade e eficiência de estirpes de Rhizobium phaseoli submetidas a altas temperaturas. In: Congresso Brasileiro de Ciência do Solo, Curitiba, 1983. Resumos, $n^{\circ} 36$.

PACOVSKY, R.S.; BAYNE, H.G. \& BETHLENFALVAY, G.J. Symbiotic interactions between strains of Rhizobium phaseoli and cultivars of Phaseolus vulgaris L. Crop Science, Madison, 24:101-105, 1984.

PEREIRA, P.A.A \& BLISS, F.A. Nitrogen fixation and plant growth of common bean (Phaseolus vulgaris L.) at different levels of phosphorus availability. Plant and Soil, Dordrecht, 104:79-84, 1987.

PEREIRA, P.A.A; ROCHA, R.E.M. da \& ARAÚJO, R.S. Nodulação do feijoeiro em monocultivo e associado com fileiras de milho maduro. Pesquisa Agropecuária Brasileira, Brasília, 19(8):951-954, 1984a. 
PEREIRA, P.A.A; ARAÚJO, R.S.; ROCHA, R.E.M. da \& STEINMETZ, S. Capacidade de genótipos de feijoeiro de fixar $\mathrm{N}_{2}$ atmosférico. Pesquisa Agropecuária Brasileira, Brasília, 19(7):811-815, 1984b.

PEREIRA, P.A.A; BURRIS, R.H. \& BLISS, F.A. ${ }^{15} \mathrm{~N}$ - determined dinitrogen fixation potencial of genetically diverse bean lines (Phaseolus vulgaris L.). Plant and Soil, Dordrecht, 120:171-179, 1989.

PIHA, M.I. \& MUNNS, D.N. Sensibility of the common bean (Phaseolus vulgaris L.) symbiosis to high soil temperature. Plant and Soil, Dordrecht, 98: 183-194, 1987.

PILBEAM, D.J. \& KIRKLY, E.A. The physiology of nitrate uptake. ABROE, Y.P., ed. Nitrogen in Higher Plants. p.39-61, 1990.

PURCINO, A.A.C.; MAGNAVACA, R.; MACHADO, A.T. \& MARRIEL, I.E. Atividade da redutase do nitrato em genótipos antigos e modernos de milho, cultivados sob dois níveis de nitrogênio. Revista Brasileira de Fisiologia Vegetal, Londrina, 6(1):41-46, 1994.

RAMOS, M.L.G. \& BODDEY, R.M. Yield and nodulation of Phaseolus vulgaris and the competitivity of an introduced Rhizobium strain: effects of lime, mulch and repeated cropping. Soil Biology and Biochemistry, Oxford, 19(2):171-177, 1987. 
REIS, M.S.; VIEIRA, C. \& BRAGA, J.M. Efeitos de fontes, doses e épocas de aplicação de adubos nitrogenados sobre a cultura do feijão. Revista Ceres, Viçosa, 19(101):25-42, 1972.

RENNIE, R.J. \& KEMP, G.A. $\mathrm{N}_{2}$ fixation in field beans quantified by ${ }^{15} \mathrm{~N}$ isotope dilution. I. Effect of strains of Rhizobium phaseoli. Agronomy Journal, Madison, 75:640-644, 1983a.

RENNIE, R.J. \& KEMP, G.A. $\mathrm{N}_{2}$ fixation in field beans quantified by ${ }^{15} \mathrm{~N}$ isotope dilution. II. Effect of cultivars of beans. Agronomy Journal, Madison, 75:645-649, $1983 b$.

ROBITAILLE, H.A. Effect of foliar molybdenum sprays on nitrogen fixation in Phaseolus vulgaris L. Annual Report Bean Improvement Cooperative, 18:65, 1975.

RUSCHEL, A.P. \& SAITO, S.M.T. Efeito da inoculação de Rhizobium, nitrogênio e matéria orgânica na fixação simbiótica de nitrogênio em feijão (Phaseolus vulgaris L.). Revista Brasileira de Ciência do Solo, Campinas, 1:21-24, 1977. 
RUSCHEL, A.P.; SAITO, S.M.T. \& TULMAN NETO, A. Eficiência da inoculação de Rhizobium em Phaseolus vulgaris L. I. Efeito de fontes de nitrogênio e cultivares. Revista Brasileira de Ciência do Solo, Campinas, 3:13-17, 1979.

RUSCHEL, A.P.; VOSE, P.B.; MATSUI, E.; VICTORIA, R.L. \& SAITO, S.M.T. Field evaluation of $\mathrm{N}_{2}$ - fixation and nitrogen utilization by Phaseolus bean varieties determined by ${ }^{15} \mathrm{~N}$ isotope dilution. Plant and Soil, The Hague, 65:397-407, 1982.

SAITO, S.M.T. Avaliação em campo da capacidade de fixação simbiótica de Rhizobium phaseoli. Pesquisa Agropecuária Brasileira, Brasilia, 17(7):999-1006, 1982.

SAITO, S.M.T. \& RUSCHEL, A.P. Influência da calagem, adubação fosfatada e micronutrientes na nodulação natural do feijoeiro (Phaseolus vulgaris L.). Anais da E.S.A. "Luiz de Queiroz". Vol XXXV, 1978.

SALISBURY, F.B. \& ROSS, C.W. Assimilation of nitrogen and sulfur. In: SAlisbUeY, F.B. \& ROSS, C.W. eds., Plant Physiology. 1992. p.289-307.

SANTA CECILIA, F.C. Resposta de treze variedades de feijão (Phaseolus vulgaris L.) à adubação nitrogenada e fosfatada. Universidade Federal de Viçosa, 1972. 38p. Tese de Mestrado. 
SANTOS, A.B. dos; VIEIRA, C.; LOURES, E.G.; BRAGA, J.M. \& THIEBAUT, J.T.L. Resposta do feijoeiro (Phaseolus vulgaris L.) ao molibdênio e ao cobalto em solos de Viçosa e Paula Cândido, Minas Gerais, Revista Ceres, Viçosa, 26(143):92-101, 1979.

SCHUBERT, K.R. \& EVANS, H.J. Hydrogen evolution: A major factor affeting the efficiency of nitrogen fixation in nodutated symbionts. Proceedings of National Academy of Science, Washington, 73(4):1207-1211, 1976.

SHAH, V.K.; UGALDE, R.A.; IMPERIAL, J. \& BRILL, W.J. Molybdenum in nitrogenase. Annual Review of Biochemistry, Palo Alto, 53:231-257, 1984.

SILVA, M.T.; DARIVA, T.; MAMINSKI, J. \& XAVIER, T.M. Efeito de níveis e épocas de aplicação de N na produção do feijão (Phaseolus vulgaris L.). Revista do Centro de Ciências Rurais, Santa Maria, 7(4):395-401, 1977.

SMITH, D.L. \& HUME, D.J. Effects of irrigation and fertilizer $\mathrm{N}$ on $\mathrm{N}_{2}\left(\mathrm{C}_{2} \mathrm{H}_{2}\right)$ fixation and yield of white bean and soybean. Canadian Journal of Plant Science, Ottawa, 65:307-316, 1985. 
SSALI, H. \& KEYA, S.O. Effect of nitrogen fertilizer on yield of beans inoculated with Rhizobium phaseoli. Kenya Journal of Science and Technology, Nairobi, 3:87-89, 1982.

TAYLOR, J.D.; DAY, J.M. \& DUDLEY, C.L. The effect of Rhizobium inoculation and nitrogen fertilizer on nitrogen fixation and seed yield of dry beans (Phaseolus vulgaris). Annual Applied Biology, 103:419-429, 1983.

THIBODEAU, P.S. \& JAWORSKY, E.G. Patterns of nitrogen utilization in the soybean. Planta, New York, 127:133-147, 1975.

TIMPO, E.E. \& NEYRA, C.A. Expression of nitrate and nitrite reductase activities under various forms of nitrogen nutrition in Phaseolus vulgaris L. Plant Physiology, Rockville, 75:71-75, 1983.

URBEN FILHO, G.; CARDOSO, A.A.; VIEIRA, C.; FONTES, L.A.N. \& THIÉBAUT, J.T.L. Doses e modos de aplicação do adubo nitrogenada na cultura do feijão (Phaseolus vulgaris L.). Revista Ceres, Viçosa, 27:302-312, 1980.

VIEIRA, C.; NOGUEIRA, A.O. \& ARAÚJO de A. Adubação nitrogenada e molíbdica na cultura do feijão. Revista de Agricultura, Piracicaba, 67:117-124, 1992. 
WEISER, G.C.; GRAFTON, K.F. \& BERRYHILL, D.L. Nodulation of dry beans by commercial and indigenous strains of Rhizobium phaseoli. Agronomy Journal, Madison, 77:856-859, 1985.

WESTERMANN, D.T.; KLEINFORPFT, G.E.; PORTER, L.K. \& LEGGETT, G.E. Nitrogen sources for bean production. Agronomy Journal, Madison, 73:660-664, 1981.

WeStermanN, D.T.; KOLAR, J.J. Symbiotic $\mathrm{N}_{2}\left(\mathrm{C}_{2} \mathrm{H}_{2}\right)$ fixation by Phaseolus vulgaris L. Crop Science, Madison, 18:986-990, 1978.

WINKLER, R.G.; BLEVINS, D.G.; POLACCO, J.C. \& RANDALL, D.D. Ureide catabolism in nitrogen fïxing legumes. Trends in Biochemistry Science, New York, 13:97-100, 1988.

WOLYN, D.J.; ATTEWELL, J.; LUDDEN, P.W. \& BLISS, F.A. Indirect measures of $\mathrm{N}_{2}$ fixation in common bean (Phaseolus vulgaris L.). under field conditions: The role of lateral root nodules. Plant and Soil, Dordrecht, 113:181-187, 1989. 